\author{
UNIVERSIDADE DE SÃO PAULO \\ ESCOLA DE ENGENHARIA DE SÃO CARLOS \\ DEPARTAMENTO DE ENGENHARIA DE ESTRUTURAS
}

ENIO CARLOS MESACASA JÚNIOR

COMPORTAMENTO ESTRUTURAL E DIMENSIONAMENTO DE CANTONEIRAS DE AÇO FORMADAS A FRIO SUBMETIDAS À COMPRESSÃO 

ENIO CARLOS MESACASA JÚNIOR

\title{
COMPORTAMENTO ESTRUTURAL E DIMENSIONAMENTO DE CANTONEIRAS DE AÇO FORMADAS A FRIO SUBMETIDAS À COMPRESSÃO
}

\begin{abstract}
Dissertação apresentada à Escola de Engenharia de São Carlos da Universidade de São Paulo, como parte dos requisitos para obtenção do Título de Mestre em Engenharia de Estruturas.
\end{abstract}

Área de concentração: Engenharia de Estruturas

Orientador: Prof. Dr. Maximiliano Malite

\section{Versão Corrigida}

A versão original encontra-se na Escola de Engenharia de São Carlos

SÃO CARLOS

2012 


\section{AUTORIZO A REPRODUÇÃO E DIVULGAÇÃO TOTAL OU PARCIAL DESTE TRABALHO, POR QUALQUER MEIO CONVENCIONAL OU ELETRÔNICO, PARA FINS DE ESTUDO E PESQUISA, DESDE QUE CITADA A FONTE.}

Ficha catalográfica preparada pela Seção de Atendimento ao Usuário do Serviço de Biblioteca - EESC/USP

Mesacasa Júnior, Enio Carlos.

M578c Comportamento estrutural e dimensionamento de cantoneiras de aço formadas a frio submetidas à compressão. / Enio Carlos Mesacasa Júnior; orientador Maximiliano Malite. São Carlos, 2012.

Dissertação - Mestrado (Programa de Pós-Graduação em Engenharia de Estruturas e Área de concentração em Estruturas Metálicas)-- Escola de Engenharia de São Carlos da Universidade de São Paulo, 2012. 


\section{FOLHA DE IULGAMENTO}

Candidato: Engenheiro ENIO CARLOS MESACASA JÚNIOR.

Título da dissertação: "Comportamento estrutural e dimensionamento de cantoneiras de aço formadas a frio submetidas à compressão".

Data da defesa: $27 / 04 / 2012$

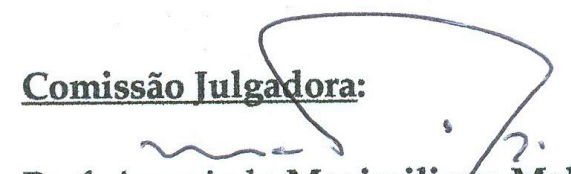

Prof. Associado Maximiliano Malite (Orientador)

(Escola de Engenharia de São Carlos/EESC)

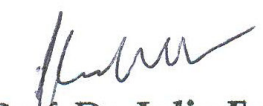

Prof. Dr. Julio Fruchtengarten

(Escola de Politécnica/USP)

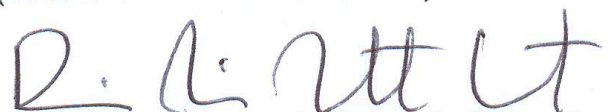

Prof. Dr. Dinar Reis Zamith Camotim

(Instituto Superior Técnico/IST-Lisboa)
Resultado:

APROVADO

Aprocado

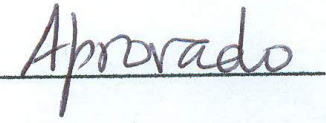

Coordenador do Programa de Pós-Graduação em Engenharia Civil (Engenharia de Estruturas):

Profa. Associada Ana Lucia Homce de Cresce E1 Debs

Presidente da Comissão de Pós-Graduação:

Prof. Associado Paulo Cesar Lima Segantine 

"NenHUM hOMEM REALMENTE PROdUtivo PENSA COMO SE ESTIVESSE ESCREVENDO UMA DISSERTAÇÃO."

ALBERT EINSTEIN, IN: O PROFESSOR CÓSMICO - UMA HISTÓRIA SOBRE ALBERT EINSTEIN. ANDREW DONKIN. ED. MODERNA, 1996. 

Aos meus pais, Enio e Maisa, e as minhas irmãs, Franciele e Heloísa, fontes intermináveis de inspiração e incentivo. 



\section{AGRADECIMENTOS}

A Deus, pelas condições as quais foge o controle humano, e que são indispensáveis ao sucesso.

À minha família, fonte inesgotável de incentivo, e junto da qual sempre tenho o repouso necessário para revigorar as energias.

Ao Prof. Maximiliano Malite, pelo compromisso (que iniciou antes mesmo do mestrado) e incentivo durante todas as fases deste trabalho. Como orientador, demonstrou excelência, especialmente pela acessibilidade, presteza, amizade e magnífica visão, sempre prática e coerente.

Ao Prof. Dinar Camotim, do Instituto Superior Técnico (Lisboa - PT), pela magnífica recepção em Lisboa, auxílio prestado no período de minha estadia em Portugal e principalmente por todo conhecimento compartilhado, indispensável não somente na elaboração deste trabalho mas também para minha vida acadêmica. Sempre lembrarei de que nenhum dia será perdido enquanto se tiver ao menos uma "novidade".

Ao Prof. Pedro Borges Dinis, do Instituto Superior Técnico (Lisboa - PT), pelas ótimas idéias e enriquecedores momentos de discussão sobre os trabalhos conduzidos em conjunto durante o período de trabalho em Lisboa.

Ao Prof. André Teófilo Beck, pela disposição e presteza quando busquei conhecimentos específicos de sua área.

Aos funcionários do Departamento de Engenharia de Estruturas (SET) pela constante e eficiente assessoria prestada.

Ao Prof. Zacarias Chamberlain, pela excelente iniciação científica, e ao Prof. Gilnei Drehmer, pelo incentivo constante desde as bases do aprendizado na engenharia.

Aos colegas de departamento pela amizade, momentos de descontração e constante aprendizado que tive ao acompanhar tantas pesquisas, momentos de dúvidas e suas superações, e também por toda confiança transmitida ao longo dos últimos dois anos.

Aos velhos e antigos amigos que hoje, apesar de distantes por suas escolhas profissionais, mantém todo respeito e confiança desenvolvidos ao longo de anos. Sempre foram e sempre serão irmãos de vida, e cada rara reunião me abastece de bons sentimentos para mais um longo período de trabalho.

Ao CNPq (Conselho Nacional de Desenvolvimento Científico e Tecnológico) pelo financiamento através da bolsa concedida, e também à FIPAI (Fundação para o Incremento da Pesquisa e do Aperfeiçoamento Industrial) pelo auxílio para o desenvolvimento e divulgação da pesquisa.

Enfim, a todos que contribuíram para que este trabalho iniciasse e terminasse, os meus mais sinceros agradecimentos. 



\section{RESUMO}

Mesacasa Jr., E. C. (2012). Comportamento Estrutural e Dimensionamento de Cantoneiras de Aço Formadas a Frio Submetidas à Compressão. 123f. Dissertação (Mestrado) - Escola de Engenharia de São Carlos, Universidade de São Paulo, São Carlos, 2012.

Envolto ao já conhecido comportamento de cantoneiras esbeltas de abas iguais, questões aparentemente contraditórias tem sido reportadas em estudos experimentais de diversos autores, entre elas a ocorrência de modos de instabilidade em desacordo com aqueles obtidos via análise de estabilidade elástica, e forças axiais resistentes muito diferentes dos resultados teóricos (em geral, conservadoramente). Nestas condições, este trabalho procura analisar a fundo o comportamento das cantoneiras esbeltas de abas iguais, de modo a contribuir com o entendimento dos fenômenos que dificultam a interpretação dos resultados experimentais, dentre os quais, o afastamento longitudinal entre a rótula e a extremidade das barras (no caso de barras com extremidades rotuladas), e o sentido da imperfeição global de flexão em torno do eixo de menor inércia, o qual mostrou-se um fator chave na determinação do comportamento das cantoneiras, especialmente para comprimentos próximos da transição entre os dois modos globais de instabilidade elástica. Para esta faixa de comprimentos, diferentes níveis de interação entre os dois modos globais podem ser obtidos. Ademais, estudos experimentais realizados por diversos autores, aqui complementados por uma série de ensaios realizados em cantoneiras com extremidades engastadas, formam um vasto banco de resultados, que é utilizado para (além de comparações nos estudos teóricos) avaliar diversos procedimentos de previsão teórica sugeridos por diferentes autores, ou advindos de interpretações a partir do procedimento normativo, à luz do comportamento teórico estudado na primeira etapa do trabalho. Assim, destes procedimentos, apenas um baseado no Método da Resistência Direta, e dois baseados no Método das Larguras Efetivas demonstraram bons resultados, sendo que todos eles, desconsiderando o modo de flexo-torção como um modo global de instabilidade. Ao fim, comenta-se da necessidade de se expandir alguns estudos específicos, pois ao adotar-se um procedimento baseado somente no modo global de flexão, apesar de se mostrar estatisticamente mais eficiente, verifica-se a possível ocorrência de resultados demasiadamente contra a segurança.

Palavras-chave: Estruturas de aço, Perfis formados a frio, Cantoneiras, Instabilidade. 

Mesacasa Jr., E. C. (2012). Structural Behavior and Design of Cold-Formed Steel Angle Columns. 123p. (Master's thesis) - School of Engineering of São Carlos, University of São Paulo, São Carlos, 2012.

On the well known behavior of equal-leg angle columns, some questions apparently paradoxical have been reported in experimental results from several authors, including the occurrence of different instability modes from the expected by the elastic stability analysis, and maximum axial compressive load expressly different (generally conservative) from theoretical previsions. Therefore, the aim of this work is to improve the knowledge about the equal-leg angle columns behavior, contributing to the understanding of the features that complicate the interpretation of experimental results, among which, the longitudinal distance between the end sections and the center of hinges (pin-ended columns), and also the direction of the minor-axis flexural initial imperfection, which proved to play a key role in the post-critical column behavior, specially for column lengths near of the transition between global buckling modes (major-axis flexural-torsional and minor-axis flexural modes). On this range of lengths, different modal interaction amplitudes can be obtained, only with the direction of the minor-axis flexural initial imperfection (i.e., the amplitude of this imperfection plays a negligible influence on the column behavior). Furthermore, putting together a fairly large column ultimate strength data bank comprising experimental test results performed by several authors, collected from the available literature, and new experimental results on fixed-ended angle columns performed in this work, important comparisons with theoretical studies can be showed as well as evaluation of several ultimate strength theoretical prevision procedures, either those suggested by another authors as those arising from interpretations of normative procedures in the light of theoretical behavior verified in the first stage of labor. In conclusion, only one procedure based on Direct Strength Method and two procedures based on Effective Width Method exhibited accurate results, all of which neglecting the flexural-torsional mode as a global mode. Thus, it is important to mention that some additional studies are needed, because if adopted a procedure based only in the minor-axis flexural mode, despite being statistically advantageous, it is verified the possibility to occurs quite unconservative results.

Keywords: Steel Structures, Cold-formed members, Angles, Buckling. 

1 Introdução ...............................................................................................16

2 Comportamento de Cantoneiras Simples de Abas Iguais ............................20

2.1 Influência do Afastamento Longitudinal entre a Rótula e a Barra ................................36

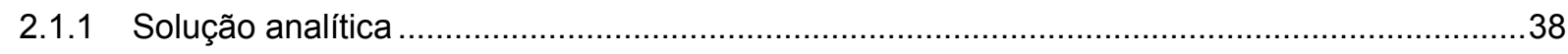

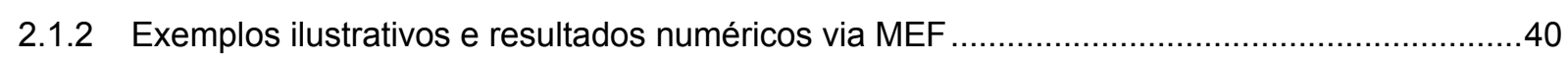

2.1.3 Implicações ao comportamento de flambagem de cantoneiras.............................................42

2.1.4 Interpretação de resultados experimentais relacionados ......................................................43

2.1.5 Comportamento elástico não linear de cantoneiras com elementos rígidos de extremidade ...46

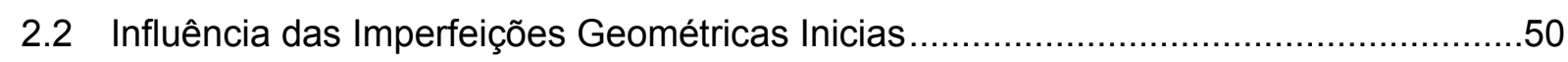

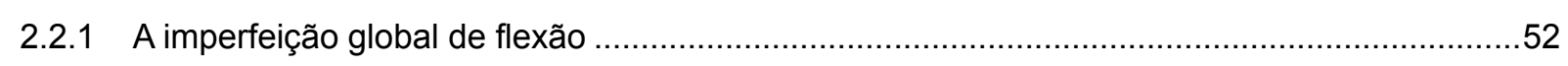

2.2.2 Comportamento elasto-plástico de cantoneiras sob diferentes condições de imperfeição

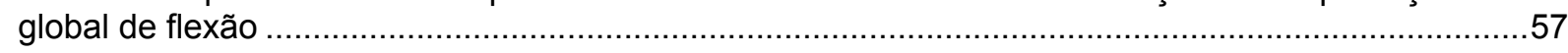

2.2.3 Efeito da amplitude da imperfeição global de torção com diferentes imperfeições de flexão ...67

2.2.4 Interpretação de resultados experimentais considerando os efeitos da imperfeição

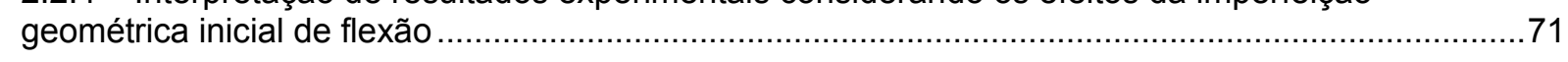

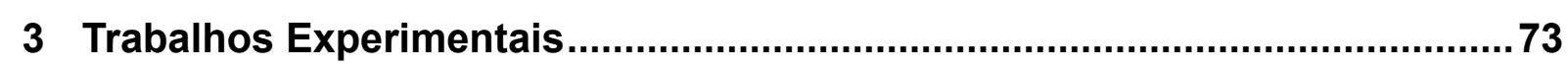

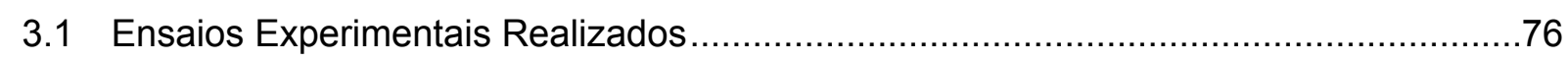

4 Procedimentos de Dimensionamento ....................................................81

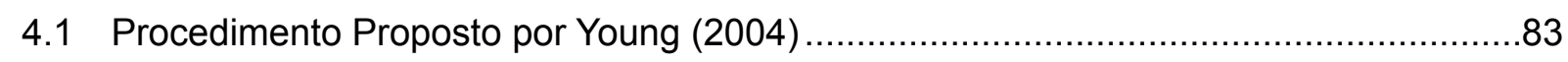

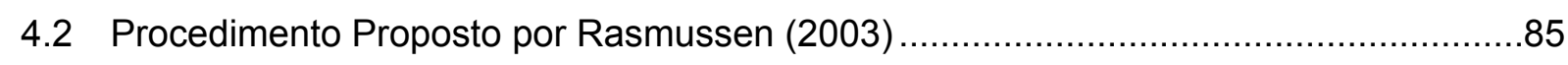

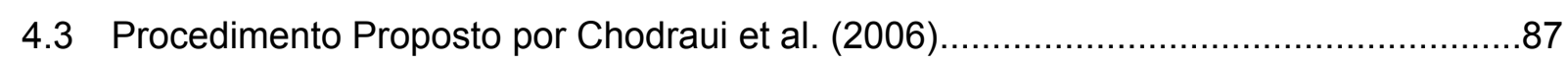

4.4 Procedimento Proposto por Silvestre et al. (2012) .................................................

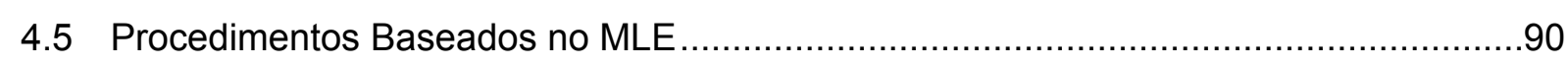

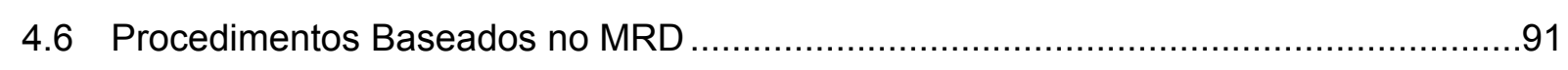

5 Avaliação dos Resultados Teóricos e Experimentais ..................................93

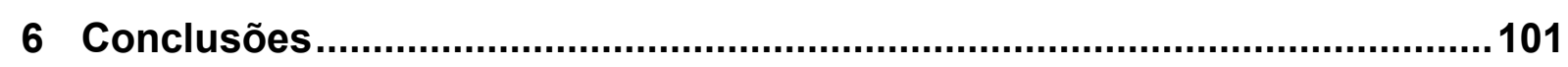

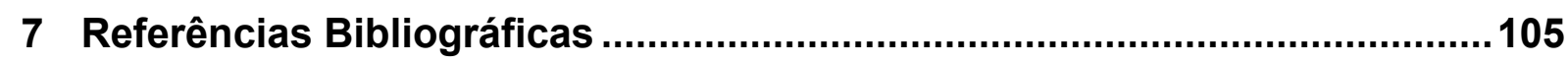

APÊNDICE A - Erros de Modelo .............................................................. 110

APÊNDICE B - Ensaios Experimentais .................................................... 117 


\section{INTRODUÇÃO}

Dentre a imensa variedade de perfis de aço formados a frio, as cantoneiras correspondem à forma mais simples, e são largamente utilizadas em todo tipo de construção metálica. Contudo, alguns pesquisadores têm demonstrado que o comportamento destes perfis possui particularidades interessantes que devem ser mais bem estudadas para a completa compreensão dos fenômenos de instabilidade envolvidos.

Segundo Young (2004), as regras de dimensionamento, nas quais se enquadram as cantoneiras sob compressão centrada, (carregamento atuando sobre o centróide da seção efetiva do perfil) ainda contidas nas atuais especificações normativas (e.g., ANSI AISI-S10007 e AS/NZS 4600:2005) são baseadas em um trabalho desenvolvido por Teoman Peköz na década de 80 (Peköz, 1987), o qual faz referência à necessidade de um estudo mais detalhado para cantoneiras esbeltas.

Em particular, trabalhos como o de Rasmussen (2003), Young (2004), Chodraui et al. (2006), e Maia et al. (2008), demonstram claramente um mau desempenho dos procedimentos normativos frente a resultados experimentais para cantoneiras simples de abas iguais, evidenciando a necessidade de se buscar um procedimento teórico mais eficiente na previsão da força de compressão resistente.

Primeiramente, vale lembrar que seções transversais em que a linha média de cada elemento cruza com as demais em um determinado ponto (e.g., cantoneiras simples, seções T e seções cruciformes) apresentam empenamento primário nulo, havendo assim, apenas a contribuição do empenamento secundário, derivado basicamente da espessura dos elementos. Com isto, em se tratando de seções abertas de paredes finas, a constante de empenamento torna-se desprezível, o que muito contribui com uma baixa rigidez à torção para estes casos.

Segundo Chodraui et al. (2006), as cantoneiras simples apresentam dois modos típicos de flambagem, o modo local/global por torção, (teoricamente modo global de flexo-torção, que inclui flexão em torno do eixo de maior inércia e torção), e o modo global por flexão em 
torno do eixo de menor inércia, ambos mostrados pela linha cheia do gráfico da Figura 1.1, que representa a força axial de flambagem elástica (primeiro modo de instabilidade da seção transversal também indicada) em função do comprimento de semi-onda.

Neste ponto, é importante mencionar que será apresentado oportunamente neste trabalho um estudo mais completo sobre o comportamento de cantoneiras simples, onde se busca detalhar melhor a ocorrência dos diferentes modos de instabilidade.

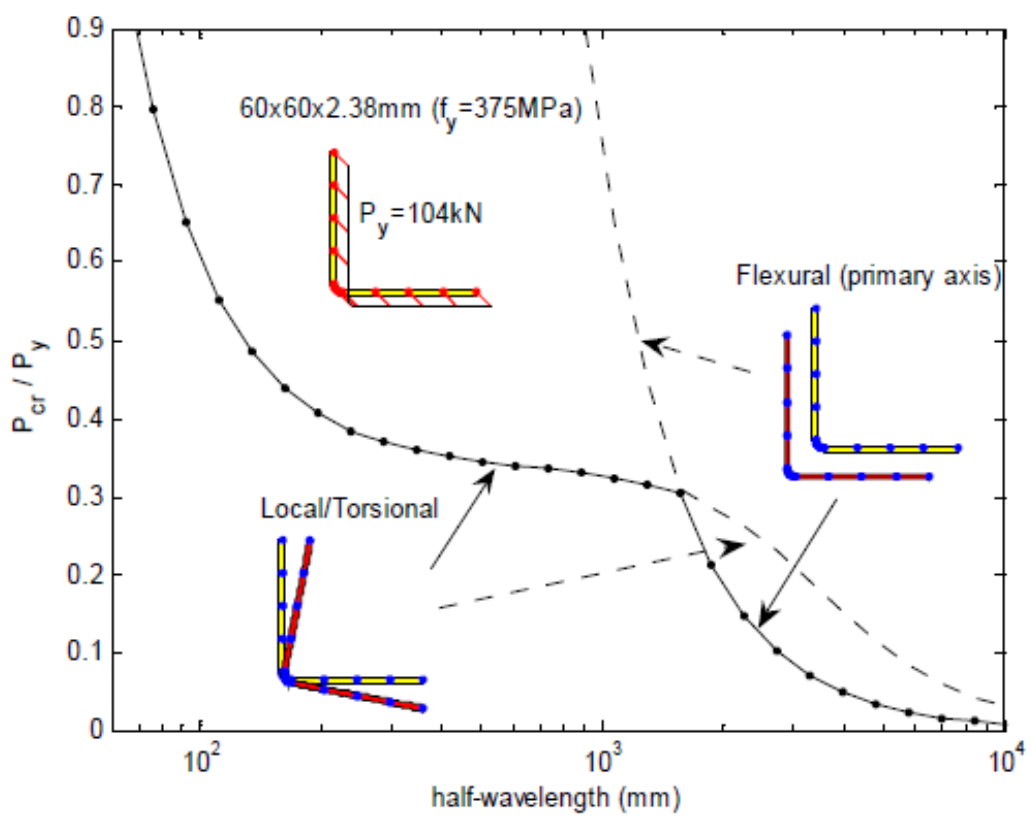

Figura 1.1. Análise de estabilidade elástica via método das faixas finitas - programa computacional CUFSM (Schafer e Adany, 2006). Fonte: Chodraui et al. (2006)

Referindo-se ainda a Fig. 1.1, há uma particularidade interessante, que tem merecido a atenção de pesquisadores, que se trata da coincidência entre os modos local de chapa e global por torção, que é representado pelo primeiro trecho descendente da curva (indicada pela seta como "Local/torsional"), o qual termina na transição com o modo de flexão em torno do eixo de menor inércia (segundo trecho descendente). De fato, esta peculiaridade levou alguns autores a apresentarem interpretações distintas com o intuito de propor um procedimento eficaz na previsão da força de compressão resistente. Rasmussen (2003), por exemplo, após demonstrar algebricamente a referida coincidência entre os modos de instabilidade, sugere que o modo global por torção (a rigor, modo de flexo-torção) seja totalmente desconsiderado nos procedimentos teóricos, pois, sendo este idêntico ao modo local, entende-se que estaria sendo 
duplamente considerado nos procedimentos vigentes, e por isso da ocorrência de resultados conservadores já então citados em trabalhos de outros autores (e.g., Popovic et al., 1999).

Entretanto, Chodraui et al. (2006) obtiveram resultados experimentais de força de compressão resistente que, comparativamente aos valores obtidos pelos procedimentos normativos vigentes e também pelo procedimento proposto por Rasmussen (2003), evidenciaram tendências de resultados contra a segurança, sugerindo melhores resultados caso não seja desprezado o modo de flexo-torção. Além disso, todos os ensaios realizados por Chodraui et al. (2006) apresentaram modo de falha relatado pelos autores como "local/global por torção, com predominância de torção".

Tal confusão com relação aos modos de instabilidade típicos em cantoneiras de abas iguais foi foco de um estudo mais recente, conduzido por Dinis et al. (2011-a), que, aproveitandose de conveniências relacionadas à Teoria Generalizada de Vigas (GBT - Generalized Beam Theory), apresentaram uma explicação detalhada para a manifestação dos diferentes modos de instabilidade que ocorrem em cantoneiras simples de abas iguais, abrindo caminho para novos estudos relacionados ao dimensionamento destes perfis.

Contudo, ainda permanecem inúmeros resultados experimentais curiosos (apresentados oportunamente ao longo deste trabalho) que não se enquadram completamente às teorias apresentadas, sugerindo a influência de fatores não relacionados nos estudos conduzidos até então. Entre tais fatores, já é conhecida a influência das condições de extremidade, apresentada no trabalho de Silvestre, et al. (2011), entretanto, tal influência também é revista neste trabalho, complementando o exposto pelos referidos autores.

Além disso, com a melhor caracterização do comportamento teórico e experimental das cantoneiras de abas iguais, torna-se mais conveniente prover uma reanálise ${ }^{1}$ dos principais procedimentos de dimensionamento existentes, tanto aqueles baseados em normas ${ }^{2}$ como outros sugeridos por pesquisadores ao longo da última década.

Dentre os procedimentos sugeridos por pesquisadores, podem ser citados de antemão o de Young (2004) e o de Rasmussen (2003), baseados no clássico Método das Larguras Efetivas (MLE), e também o de Chodraui et al. (2006) e o de Silvestre et al. (2012), ambos

\footnotetext{
${ }^{1}$ Um estudo prévio já foi apresentado por Mesacasa Jr. e Malite (2011), os quais destacam a influência das condições de extremidade e da esbeltez local das abas no comportamento global do perfil, sugerindo que uma correção estatística possa conduzir aos melhores resultados em um procedimento de previsão teórica.

2 Entende-se aqui que, não havendo um procedimento específico para dimensionamento de cantoneiras, diferentes procedimentos baseados em norma podem ser interpretados, conforme exposto no decorrer desta dissertação.
} 
baseados no método da Resistência Direta (MRD). Outros três procedimentos baseados no MLE são detalhados e testados neste trabalho, bem como outros dois procedimentos baseados no MRD, todos apresentados mais adiante em um capítulo específico.

Desta forma, pretende-se ao fim deste trabalho contribuir com o completo entendimento dos fenômenos envolvidos no comportamento de cantoneiras de abas esbeltas submetidas à compressão, mostrando bons procedimentos para um dimensionamento efetivo e seguro destas, e justificando com base teórica, numérica e experimental as recomendações propostas. 


\section{COMPORTAMENTO DE CANTONEIRAS SIMPLES DE ABAS}

\section{IGUAIS}

Cantoneiras simples de abas iguais apresentam uma série de peculiaridades em termos de comportamento. Uma em particular, se refere à coincidência (melhor comentada mais adiante neste trabalho) entre o modo local de chapa e o modo global por torção, conforme já comentado na introdução deste trabalho.

Sobre esta linha, um desenvolvimento algébrico interessante é apresentado por Rasmussen (2003), partindo da teoria de estabilidade elástica para um perfil monossimétrico e simplesmente apoiado (Timoshenko (1945); e Chajes e Winter (1965)). Assim, assumindo os eixos $x$ e $y$ como sendo os eixos de maior e menor inércia, respectivamente, a força axial de flambagem elástica relativa ao modo de flexo-torção é dada por:

$$
N_{e x z}=\frac{N_{e x}+N_{e x} \pm \sqrt{\left(N_{e x}+N_{e z}\right)^{2}-4 N_{e x} N_{e z}\left(1-\frac{x_{0}^{2}}{r_{0}^{2}+x_{0}^{2}}\right)}}{2\left(1-\frac{x_{0}^{2}}{r_{0}^{2}+x_{0}^{2}}\right)}
$$

onde $N_{e x}, N_{e z}$ e $r_{0}^{2}$ são dados por,

$$
\begin{gathered}
N_{e x}=\frac{\pi^{2} E I_{x}}{\left(K_{x} L_{x}\right)^{2}} \\
N_{e z}=\frac{1}{\left(r_{0}^{2}+x_{0}^{2}\right)}\left[\frac{\pi^{2} E C_{w}}{\left(K_{z} L_{z}\right)^{2}}+G J\right] \\
r_{0}^{2}=\frac{I_{P}}{A}=\frac{I_{x}+I_{y}}{A}
\end{gathered}
$$

sendo, $I_{x}$ e $I_{y}$ os momentos de inércia da seção bruta em relação ao eixo $x$ e $y$, respectivamente, $A$ a área da seção bruta, $x_{0}$ a distância do centro de torção ao centróide, na direção do eixo $x$, e as demais variáveis são o módulo de elasticidade $(E)$, a constante de torção da seção ( $)$, o módulo de 
elasticidade transversal $(G)$, a constante de empenamento de seção $\left(C_{w}\right)$, e o comprimento efetivo de flambagem global por flexão em relação ao eixo x $\left(K_{x} L_{x}\right)$, e por torção - eixo z $\left(K_{z} L_{z}\right)$.

Assumindo-se então que para o caso de cantoneiras a constante de empenamento seja nula (o empenamento primário é nulo, havendo somente contribuição do empenamento secundário, sendo $C_{w} \approx 0$ ), e chamando de $b$ a largura da aba (medida na linha central da espessura dos elementos, i.e., linha de eixo) e $t$ a espessura, é possível simplificar os parâmetros de forma que,

$$
N_{e z}=\frac{G J}{\left(r_{0}{ }^{2}+x_{0}^{2}\right)} \quad r_{0}^{2}=\frac{5}{24} b^{2} \quad x_{0}^{2}=\frac{1}{8} b^{2} \quad J=\frac{2}{3} b t^{3} \quad G=\frac{E}{2(1+v)}
$$

e permitindo assim obter que,

$$
N_{e z}=\frac{E}{(1+v)} \frac{t^{3}}{b}
$$

Segundo Rasmussen (2003), a força axial de flambagem local de uma cantoneira simples é exatamente a mesma de uma chapa retangular com três bordas simplesmente apoiadas e uma completamente livre. Segundo Bulson (1969) apud Rasmussen (2003), a equação característica para este caso é dada por:

$$
q r^{4} \operatorname{senh}(p) \cos (q)-p s^{4} \cosh (p) \operatorname{sen}(q)=0
$$

onde

$$
\begin{array}{cc}
p=\left[\frac{\pi^{2}}{\varphi}\left(\sqrt{k}+\frac{1}{\varphi}\right)\right]^{1 / 2} \quad q=\left[\frac{\pi^{2}}{\varphi}\left(\sqrt{k}-\frac{1}{\varphi}\right)\right]^{1 / 2} \\
r^{4}=\left[p^{2}-\frac{v \pi^{2}}{\varphi^{2}}\right]^{2} & s^{4}=\left[p^{2}+\frac{v \pi^{2}}{\varphi^{2}}\right]^{2}
\end{array}
$$

No grupo de Equações 2.8, $k$ é o coeficiente de flambagem de chapa e $\varphi$ é o fator de forma, dado por $l / b$, onde $l$ é o comprimento e $b$ a largura da chapa.

Desta forma a Eq. 2.7 não possui uma solução geral fechada, mas se $l \rightarrow \infty$, tem-se que,

$$
k=\frac{6(1-v)}{\pi^{2}}
$$

Assim, substituindo-se a Eq. 2.9 na expressão para o cálculo de força crítica de flambagem de chapa, tem-se que,

$$
N_{c r}=\frac{k \pi^{2} E}{6\left(1-v^{2}\right)} \frac{t^{3}}{b}
$$


sendo que, para o valor de $k$ onde $l \rightarrow \infty$, se reproduz exatamente a expressão (2.6), o que permite apontar que o valor da força crítica de flambagem local tende assintoticamente ao valor da força axial de flambagem elástica global por torção.

Segundo Rasmussen (2003), adotando-se uma expressão aproximada para $k$ (Eq. 2.11), apresentada por Bulson (1969), percebe-se que há uma rápida convergência para o valor assintótico definido pela expressão 2.9, conforme apresentado graficamente na Fig. 2.1, para a qual se adotou $\nu=0,3$. Assim, segundo o autor, é possível assumir que a força crítica de flambagem local e a força axial de flambagem global por torção são iguais para comprimentos típicos de perfis de cantoneiras simples.

$$
k=\frac{6(1-v)}{\pi^{2}}+\frac{1}{\varphi^{2}}
$$

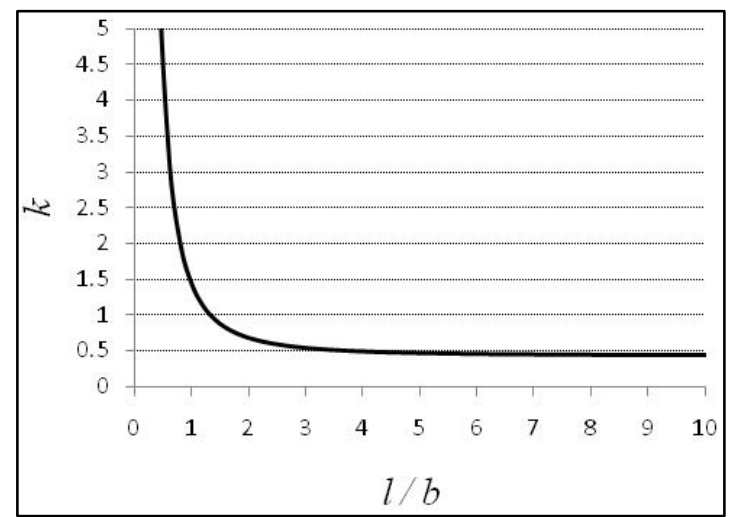

Figura 2.1 - Variação do coeficiente de flambagem de chapa $(k)$ em função do fator de forma $(\varphi=l / b)$

Esta demonstração algébrica feita por Rasmussen (2003), contudo, pouco ajuda na definição da atuação modal das cantoneiras, pois além de não ser possível separar o modo global por torção do modo local, sugere que, do ponto de vista de previsão teórica da força resistente à compressão, considerar ambos os modos seria redundante, e, portanto, conservador.

Para melhor estudar tais considerações, Dinis et al. (2010-b) apresentam um interessante estudo delineado por diferentes abordagens com a Teoria Generalizada de Vigas (GBT), onde se procura fornecer um adequado embasamento teórico para explicar a mecânica do comportamento das cantoneiras, especialmente com relação aos modos de instabilidade ainda pouco compreendidos.

Tirando certo proveito de algumas propriedades da GBT, especialmente o fato de se ter, na discretização da linha média da seção transversal, funções de aproximação que correspondem a modos de deformação da mesma seção, os quais traduzem 
comportamentos mecânicos/estruturais bem definidos (Camotim et al., 2006), Dinis et al. (2010-b) demonstram que somente quatro modos de deformação são necessários para descrever o comportamento típico das cantoneiras, sendo eles, a flexão em torno dos eixos de (i) maior e (ii) menor inércia, (iii) torção pura, e (iv) um modo local não simétrico (modos 2, 3, 4 e 6 apresentados na Fig. 2.4.c).

Além disso, segundo Dinis et al. (2010-b), na GBT, a flambagem local está associada à ocorrência de um ponto de mínimo valor característico na curva $N_{c r} v s$. $L$ ( $N_{c r}$ é a força axial de flambagem elástica, e $L$ o comprimento da barra), e à formação de múltiplas semi-ondas. No entanto, isto somente é possível se a chapa (ou seção transversal) apresentar flexão transversal, do contrário, a simples rotação (movimento de corpo rígido) da seção transversal caracteriza um modo puramente de torção.

Para demonstrar mais claramente o trabalho da flexão transversal em um elemento de chapa retangular (caso associado à aba de uma cantoneira), Dinis et al. (2010-b) exemplificam analiticamente o que ocorre em uma análise via GBT para uma chapa simplesmente apoiada em três bordas e livre na outra (Figura 2.2), uniformemente comprimida através das bordas $x=0$ e $x=L$, e considerando ainda, ao longo da borda $s=0$ uma mola de rigidez (S), de modo que o elemento tenha seu giro elasticamente restringido segundo a rigidez (S) da mola.

Além disso, apenas dois modos de deformação são incluídos na análise: (i) modo 1, que consiste em uma "rotação de corpo rígido" da chapa em torno da borda elasticamente restringida $(s=0)$ e; (ii) modo 2 , que apresenta rotação nula na borda $s=0$, mas com flexão transversal. Ambos os modos são ilustrados juntamente de suas funções de deslocamento também na Figura 2.2.
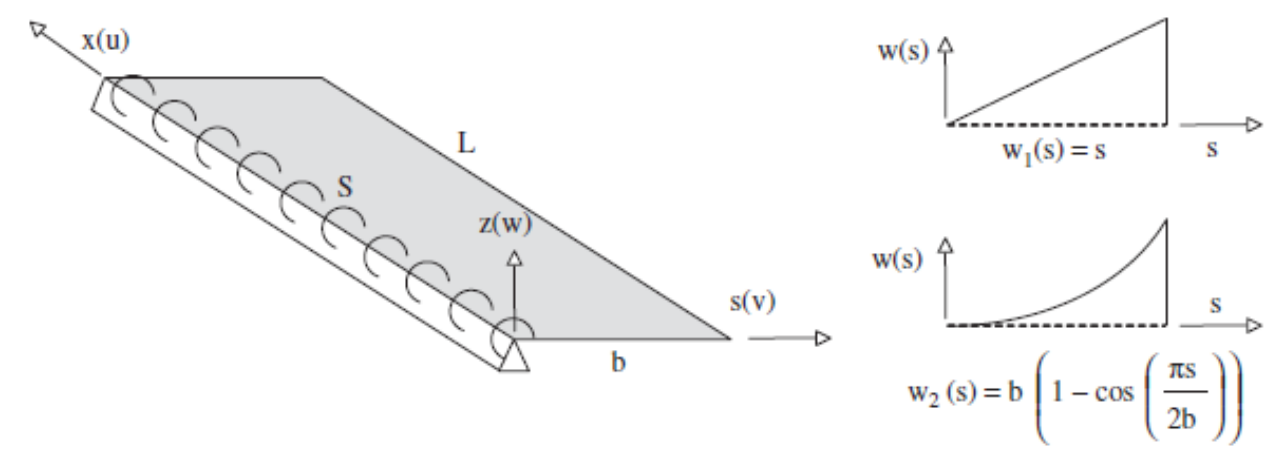

Figura 2.2 - Chapa simplesmente apoiada em três bordas e livra na outra, com restrição elástica distribuída na borda simplesmente apoiada $s=0$, juntamente com modos de deformação incluídos na análise. Fonte: Dinis et al. (2010-b). 
Os resultados da referida análise conduzida por Dinis et al. (2010-b), podem ser analisados na da Figura 2.3, a qual ilustra a variação do coeficiente de flambagem de chapa $\left(k_{c r}\right)$ em função do fator de forma $(\varphi)$, para diferentes curvas que representam determinados valores de rigidez $\mathrm{S}$, representada pelo parâmetro adimensional $\alpha=\left(1-v^{2}\right)\left(12 S b / E t^{3}\right)$.

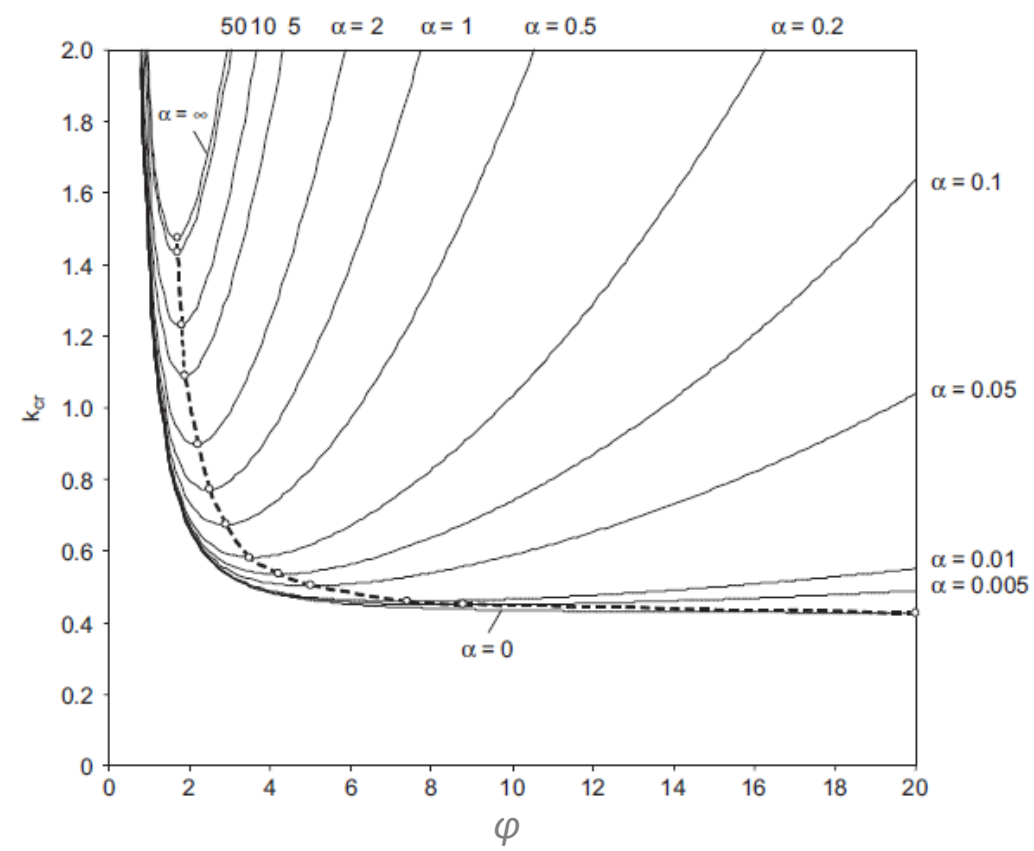

Figura 2.3 - Variação do coeficiente de flambagem de chapa em função do fator de forma e da rigidez da mola. Adaptado de: Dinis et al. (2010-b).

Com relação à Figura 2.3, Dinis et al. (2010-b) destacam que:

i. Para $\alpha=0$, a curva $k_{c r}(\varphi)$ é continuamente decrescente, e não apresenta ponto de mínimo característico, tendendo ao valor de $k_{c r}=0,425$ (vale acrescentar aqui aos comentários de Dinis et al. (2010-b), que esta curva reproduz exatamente a curva representada na Fig. 2.1). Além disso, o modo de flambagem do elemento apresenta uma única semi-onda, independentemente do comprimento da chapa (ou $\varphi$ ), assim, com o aumento de $\varphi$, tem-se também o aumento na participação do modo 1, enquanto a participação do modo 2 reduz rapidamente. Desta forma, pode-se concluir que para $\varphi>4$ (ver platô horizontal da curva $\alpha=0$ ) o modo 1 corresponde à solução exata do problema. Segundo os autores, isto denota que uma chapa simplesmente apoiada conforme as condições descritas, com comprimento maior do que quatro vezes a largura $(L>4 b)$ sempre apresenta um modo de flambagem com uma única semi-onda, sem flexão transversal. Por 
outro lado, para $\alpha=\infty$ apenas se tem a atuação do modo 2 na solução, e o coeficiente de flambagem da chapa $\left(k_{\mathrm{cr}}\right)$ apresenta um valor de mínimo característico em função do comprimento de semi-onda, sendo o comprimento de cada semi-onda aproximadamente igual a 1,6 vezes a largura $b$;

ii. Também, todas as curvas $k_{c r}(\varphi)$ apresentam um valor mínimo característico desde que $\alpha>0$, ou seja, qualquer pequena rigidez ao giro implica em um modo de flambagem com múltiplas semi-ondas. Para valores crescentes de $\alpha$, o valor de $k_{c r}$ aumenta enquanto $\varphi$ diminui. Conforme Dinis et al. (2010-b), isto se deve à participação relativa aos modos 1 e 2: conforme a contribuição do modo 1 diminui, a respectiva atuação do modo 2 aumenta, assim, conforme aumenta a rigidez ao giro $\alpha$, a tensão mínima de flambagem local também aumenta, conforme ilustra a linha tracejada que une os pontos de mínimo valor de $k_{c r}$ para as diferentes curvas de $\alpha$ na figura 2.3.

Com isto, Dinis et al. (2010-b) demonstram a diferença entre a atuação do modo global por torção e do modo local em uma chapa simplesmente apoiada com uma borda completamente livre. Segundo os autores, este caso de chapa apresenta um comportamento muito particular, não partilhado por chapas em quaisquer outras condições de apoio. Além disso, sobre a confusão causada pela associação do modo global por torção e um modo local com uma única semi-onda, deve-se salientar que a ausência de flexão transversal, que está ligada a ausência de um mínimo valor característico na curva $N_{c r} v s . L$, é verdadeiramente atípica no sentido em que nenhuma outra configuração em chapas partilha dos mesmos resultados.

Logo, os referidos autores são claros em afirmar que, do ponto de vista mecânico, os deslocamentos típicos do primeiro ramo descendente da curva $N_{c r} v s$. L (a exceção dos deslocamentos de flexão em torno dos eixos principais de inércia, que serão comentados mais adiante) devem mesmo ser vistos como de um modo global por torção em vez de um modo local. 
○ Comportamento elástico linear para diferentes condições de extremidade

Analogamente, Dinis et al. (2010-a) mostram um estudo sobre cantoneiras com diferentes condições de extremidade, o qual foi conduzido com ajuda do código computacional GBTUL (Bebiano et al. - 2008) e do programa comercial ABAQUS (Simulia Inc. - 2008). Neste, foram simuladas barras com extremidades totalmente engastadas $(\mathrm{F})$, barras somente com rotação em torno do eixo de menor inércia livre, simulando uma rótula cilíndrica (PC), e barras com as rotações em torno de ambos os eixos livres, mas mantendo o empenamento secundário restringido, caracterizando uma rótula esférica (PS) (em todas as barras foram desprezados os cantos arredondados, portanto a seção transversal não possui empenamento primário).

Apresenta-se na Figura 2.4.a, portanto, três diferentes curvas que mostram a variação da força axial de flambagem elástica $\left(N_{c r}\right)$ de uma cantoneira de aço (neste caso, com $E=210 \mathrm{GPa}$ e $v=0,3)$ de abas iguais com dimensões $70 \times 1,20 \mathrm{~mm}$ em função do comprimento $(L)$ em escala logarítmica, onde cada curva representa uma diferente condição de apoio nas extremidades, conforme citado no parágrafo anterior. Além disso, repara-se que as análises feitas via GBT (GBTUL) e MEF (ABAQUS) se mostram virtualmente coincidentes.

Da mesma forma, a Figura 2.4.b, apresenta, para as três condições de extremidade, os diagramas de participação modal obtidos pela GBT, e a Figura 2.4.c apresenta a seção transversal na metade do comprimento $(L / 2)$ de duas barras com extremidades com rótulas cilíndricas e comprimentos 100 e $364 \mathrm{~cm}$, bem como os 5 primeiros modos de deformação obtidos via GBT.

Logo, Dinis et al. (2012) destacam alguns comentários sobre a Fig. 2.4, assim citados:

i. Todas as barras com comprimentos curtos a intermediários estão associadas ao modo de flambagem por flexo-torção, com contínua participação dos modos de deformação 2 e 4, sendo que para barras curtas o modo 2 é praticamente imperceptível (porém não nulo), mas torna-se mais visível conforme aumenta-se o comprimento da barra. Assim, devido à simetria da seção transversal em relação ao eixo de maior inércia, as barras curtas a intermediárias apresentam flambagem em um modo que combina torção (4) com flexão em torno do eixo de maior inércia (2), e correspondem a um platô praticamente horizontal na curva $N_{c r}$ vs. L;

ii. As três diferentes condições de extremidade analisadas possuem comportamentos semelhantes, apresentando o típico platô horizontal na curva $N_{c r} v s$. L, que culmina em 
último trecho descendente característico do modo de flexão em torno do eixo de menor inércia (apenas modo de deformação 3);

iii. Comparativamente à barra com extremidades engastadas $(F)$, especificamente no trecho de comprimentos curtos a intermediários, as barras com extremidades rotuladas (PC e PS) apenas diferem por apresentarem o fim do platô em um comprimento menor (no caso, $P C=P S=420 \mathrm{~cm}$ e $F=890 \mathrm{~cm}$ ). Assim, se for considerado um comprimento menor que $420 \mathrm{~cm}$, as barras rotuladas apresentam as mesmas forças axiais de flambagem e mesmos modos de deformação atuantes da barra com extremidades engastadas;

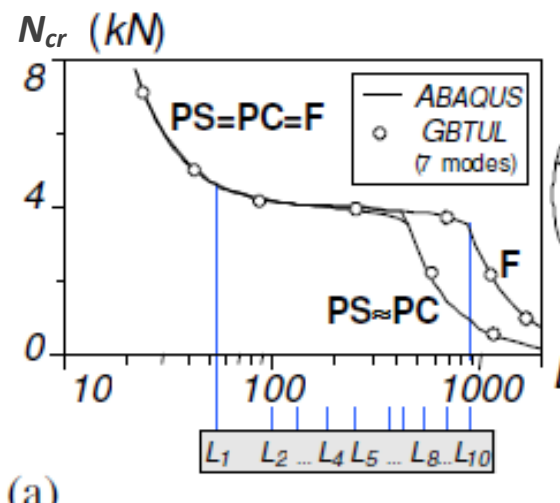

(a)

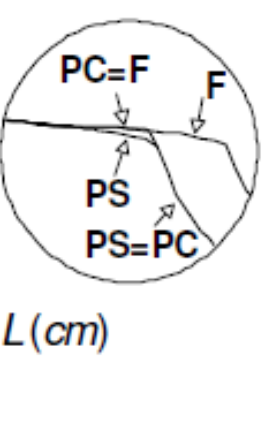

Barras (PC)

\begin{tabular}{|c|c|c|}
\hline \multicolumn{3}{|c|}{ Barras (PC) } \\
\hline$L(\mathrm{~cm})$ & 100 & 364 \\
\hline 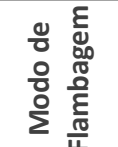 & $\leftarrow$ & \\
\hline
\end{tabular}

(c)

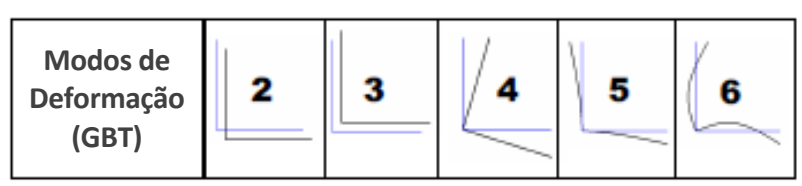

Figura 2.4 - (a) Curvas $N_{c r}$ vs. L, (b) diagramas de participação modal obtidos via GBT, e (c) seção transversal na metade do comprimento de duas barras com rótulas cilíndricas com os primeiros 5 modos de deformação (GBT). Adaptado de: Dinis et al. (2012).

iv. Com relação às barras rotuladas (PC e PS), estas apenas se diferenciam ao trecho final do platô, devido a uma maior participação da flexão em torno do eixo de maior inércia (participação do modo 2) para a barra PS, o que provoca uma sensível queda na força axial de flambagem da barra na transição entre o modo de flexo-torção e o modo de flexão em torno do eixo de menor inércia (neste caso, para o comprimento $420 \mathrm{~cm}$ a força axial de flambagem elástica da barra PS é 7,4\% menor que a respectiva força da barra PC). 


\section{○ Comportamento não linear elástico}

Adicionalmente às análises elásticas de estabilidade, tem-se também o estudo do comportamento não linear elástico das barras com imperfeições geométricas ${ }^{1}$, que segundo Dinis et al. (2012), apresentam diferentes níveis de reserva de resistência segundo seu comprimento. Apresentar tal comportamento também é importante ao início deste trabalho, mas vale lembrar que uma descrição mais detalhada pode ser encontrada diretamente no trabalho de Dinis et al. (2012).

Foram marcados na Figura 2.4 (a) e (b) uma série de comprimentos denominados $L_{1}, L_{2}, \ldots, L_{10}$. Com ajuda do programa AbAQus (Simulia Inc. - 2008), Dinis et al. (2012) analisaram a trajetória de equilíbrio elástico não-linear destas barras (no caso das barras rotuladas não foram analisadas aquelas com comprimento $L_{8}, L_{9}$ e $L_{10}$, dando enfoque apenas ao platô de flexo-torção) para as três condições de extremidade descritas anteriormente (PC, PS e F) e com imperfeições geométricas iniciais de torção com amplitude de $10 \%$ da espessura do perfil (equivalente a um giro relativo $\left(\beta_{0}\right)$ na metade do comprimento de aproximadamente $0,098 \mathrm{rad}$ ).

Os resultados são apresentados separadamente para os três diferentes casos de condições de extremidade.

Assim, dando enfoque primeiramente as barras com extremidades engastadas, é mostrado na Fig. 2.5 um trecho superior da trajetória de equilíbrio para os dez comprimentos de barras $\left(L_{1}\right.$ a $L_{10}$ ) selecionados na Figura 2.4 (a) e (b), em função do giro na metade do comprimento da barra $(\beta)$. Além disso, a mesma figura exibe ainda a seção transversal na metade do comprimento da barra para pontos definidos da trajetória das barras $F_{3}$ (curta) e $F_{9}$ (longa).

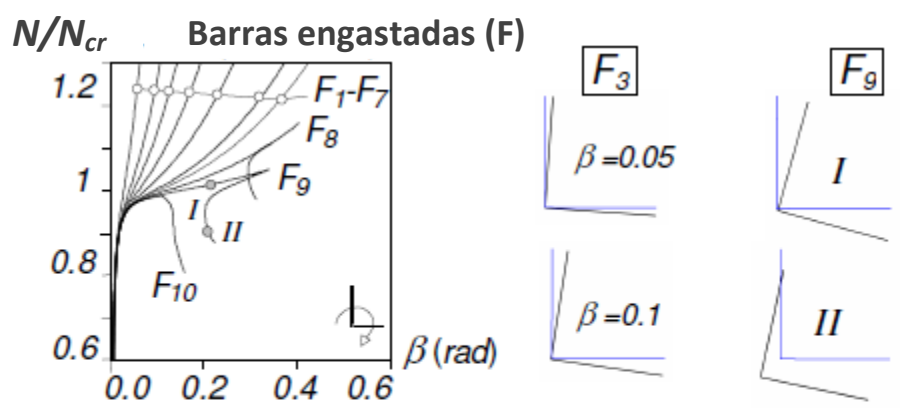

Figura 2.5 - Trajetória de equilíbrio normalizada $\left(N / N_{c r} v s . \beta\right)$ das barras $F_{1}$ a $F_{10}$ e seção transversal deformada na metade do comprimento para $\beta=0,05 \mathrm{rad}$ e $\beta=0,1 \mathrm{rad}$ (barra $F_{3}$ ) e $\beta \approx 0,2 \mathrm{rad}$ (barra $F_{9}$ ). Adaptado de Dinis et al. (2012).

\footnotetext{
${ }^{1}$ No trabalho de Dinis et al. (2012) é utilizado o termo "post-buckling", referindo-se à trajetória de equilíbrio elástico não linear.
} 
Com relação aos resultados obtidos para as barras engastadas, Dinis et al. (2012) tecem, entre outros, os seguintes comentários:

i. As trajetórias de equilíbrio se mostram progressivamente mais flexíveis com o incremento do comprimento $L$, sendo que todas apresentam comportamentos qualitativamente distintos. Enquanto as barras $F_{1}$ a $F_{7}$ apresentam-se estáveis, as barras $F_{8}$ a $F_{10}$ apresentam instabilidades por ponto limite, com a ocorrência de rotações reversas abruptas $\left(F_{8}\right.$ e $\left.F_{9}\right)$ ou rotação contínua sem reversão $\left(F_{10}\right)$;

ii. Nas barras $F_{8}$ e $F_{9}$, a deformação típica do modo de flexo-torção muda abruptamente de uma semi-onda para três semi-ondas logo após atingir a força máxima ("peak load"). Esta mudança abrupta no número de semi-ondas da configuração deformada ocorre para valores menores de $\beta$ conforme maior o comprimento $L$, sendo que a barra $F_{10}$ demarca a transição entre a flambagem por flexo-torção (torção com flexão em torno do eixo de maior inércia) e a flambagem por flexão em torno do eixo de menor inércia.

Não menos importante, também são apresentadas as análises de Dinis et al. (2012) com relação às tensões normais atuantes nas barras com extremidades engastadas (obtidas nas linhas de eixo da seção transversal), conforme ilustra a Fig. 2.6, que reproduz as trajetórias de equilíbrio de duas barras $\left(F_{3}\right.$ e $\left.F_{9}\right)$, e mostra, para três níveis de carregamento, a distribuição das tensões normais ao longo da seção transversal.
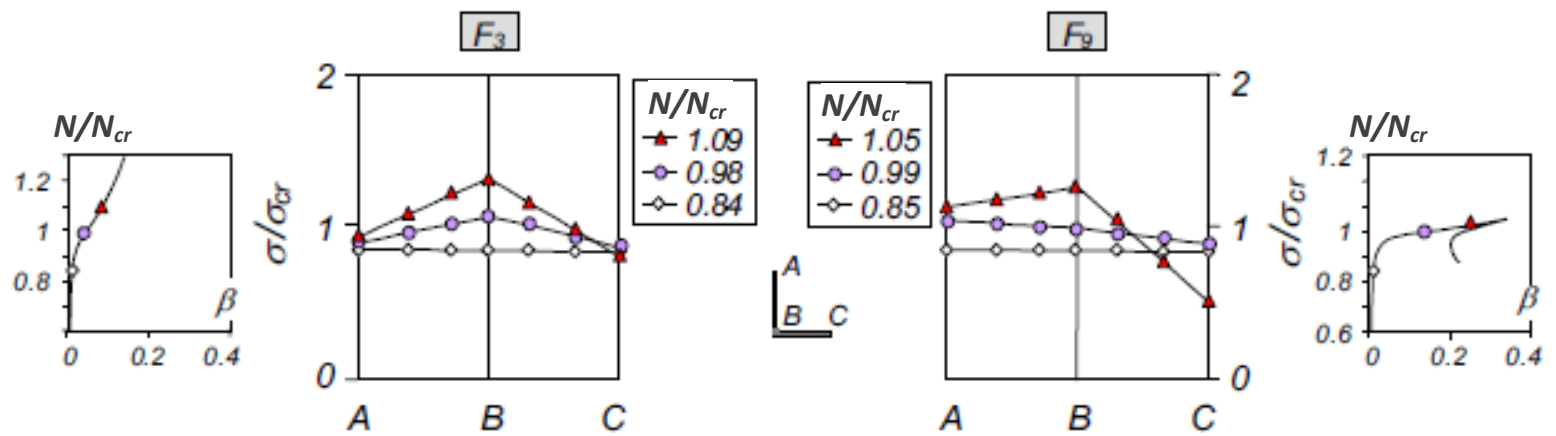

Figura 2.6 - Evolução da distribuição de tensões normais na metade do comprimento das barras F3 e F9 para três níveis de carregamento. Adaptado de Dinis et al. (2012).

Segundo Dinis et al. (2012), com esta análise é possível verificar que enquanto $N / N_{c r} \approx 0,8$, as tensões são praticamente constantes em toda seção transversal, no entanto, conforme aumenta o carregamento, as tensões passam a se distribuir não uniformemente, sendo 
aproximadamente lineares ao longo de cada uma das abas, e crescentes no sentido das bordas livres para a dobra. Além disso, a distribuição das tensões é diferente entre a barra curta $\left(F_{3}\right)$ e a longa $\left(F_{9}\right)$, pois é praticamente simétrica entre cada uma das abas no caso de $F_{3}$, e nitidamente assimétrica no caso de $F_{9}$.

Digno de comentário, tal como os próprios autores fazem em seu trabalho, é que esta distribuição de tensões apresentada se difere consideravelmente daquela teoricamente esperada, conforme apresentado por Rasmussen (2003) - vide Fig. 2.7 - onde a distribuição das tensões em cada aba se assemelharia a de uma chapa retangular simplesmente apoiada em três bordas e livre na outra. Conforme Dinis et al. (2012), tal discrepância se deve a ocorrência de deslocamentos na região da dobra devidos a flexão (no eixo de maior e menor inércia), que são particularmente maiores nas barras mais longas.

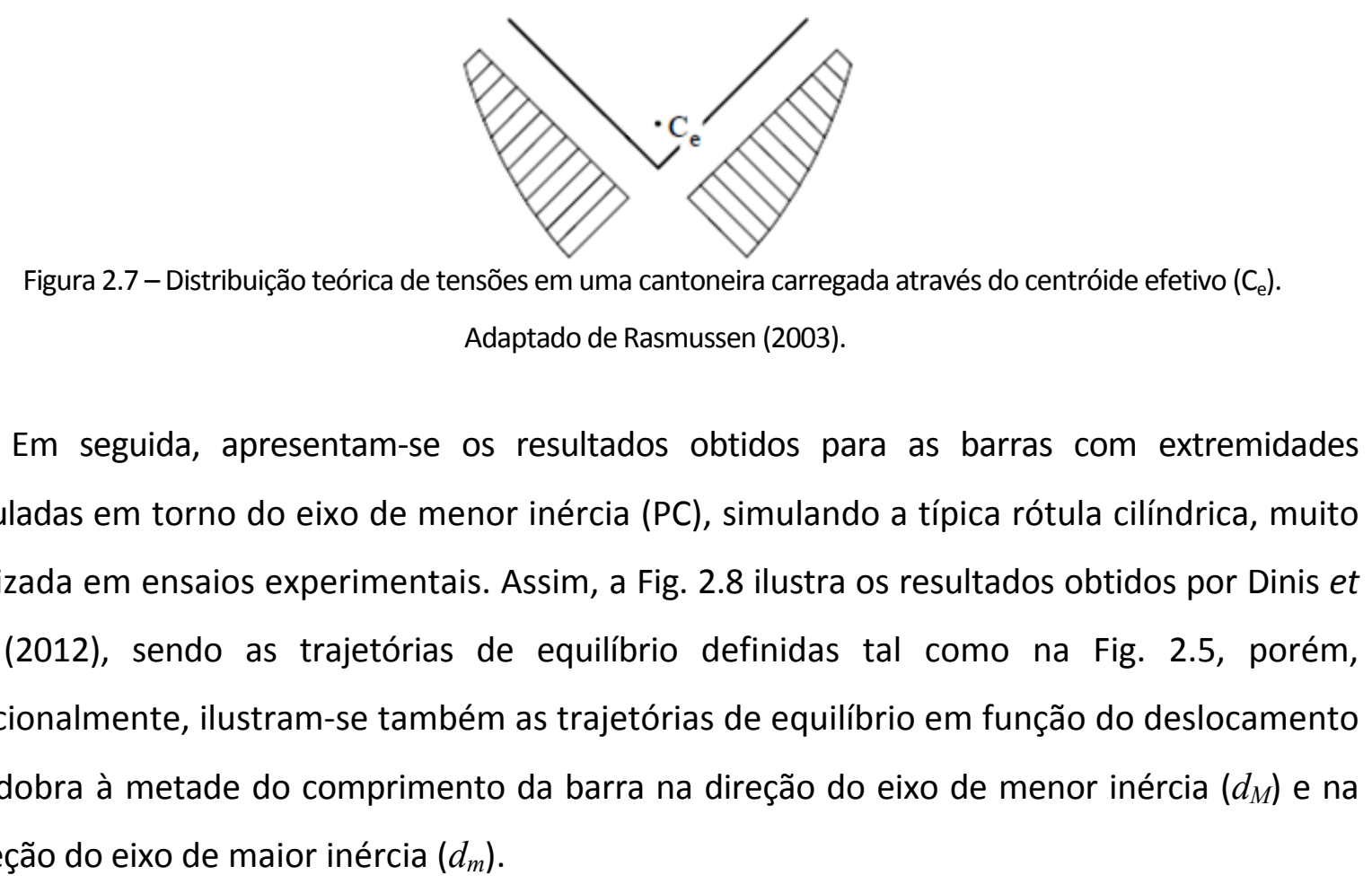




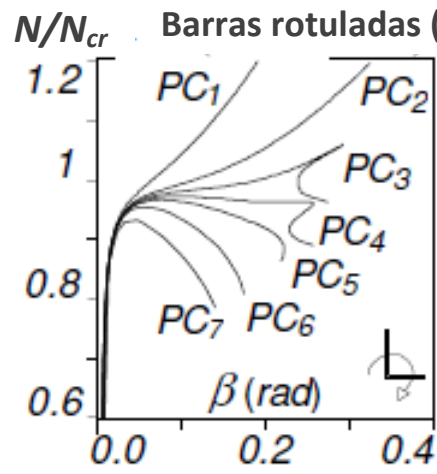

(a)

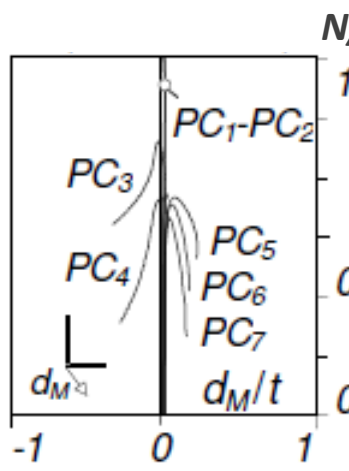

(b)

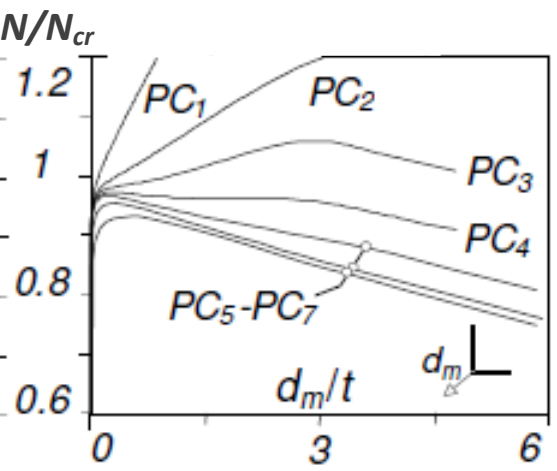

(c)

Figura 2.8 - Trajetórias de equilíbrio normalizadas $\left(N / N_{c r}\right)$ em função do giro $(\beta)$ - (a), do deslocamento na direção do eixo de menor inércia $\left(d_{M}\right)$ - (b) e do eixo de maior inércia $\left(d_{m}\right)-(\mathrm{c})$ à metade do comprimento das barras $P C_{1}$ a $P C_{10}$. Adaptado de Dinis et al. (2012).

Com relação a estes resultados, Dinis et al. (2012) apresentam os seguintes comentários:

i. Tal como no caso das barras engastadas, as barras com rótulas cilíndricas apresentam uma reserva de resistência decrescente em função do aumento do comprimento $L$, mostrando dois típicos comportamentos em trajetória de equilíbrio distintos. Enquanto as barras $\mathrm{PC}_{1}$ e $\mathrm{PC}_{2}$ mostram-se estáveis (com grande reserva de resistência) e exibem mínimos valores de $d_{M}$ e relativamente pequenos deslocamentos $d_{m}$, as barras $\mathrm{PC}_{3}$ a $\mathrm{PC}_{7}$ mostram-se menos estáveis, envolvem deslocamentos consideravelmente maiores de $d_{m}$ ao centro do comprimento, e instabilidade por ponto-limite, com uma abrupta inversão da rotação $\left(\mathrm{PC}_{3}\right.$ e $\left.\mathrm{PC}_{4}\right)$, ou suave com rotação contínua $\left(\mathrm{PC}_{5}\right.$ a $\left.\mathrm{PC}_{7}\right)$;

ii. Algumas outras verificações são as mesmas já associadas ao comportamento obtido para as barras engastadas, tais como as rotações reversas estarem relacionadas à mudança de uma para três semi-ondas no modo de instabilidade $\left(\mathrm{PC}_{3}\right.$ e $\mathrm{PC}_{4}$ ), e pequenos valores de $d_{M}$ (independentemente da magnitude do carregamento), que aumentam somente em função do comprimento $L$.

Adicionalmente, apresenta-se na Fig. 2.9 a distribuição das tensões normais atuantes no centro de duas das barras $\left(\mathrm{PC}_{3}\right.$ e $\mathrm{PC}_{6}$ ) para três diferentes níveis de carregamento. 


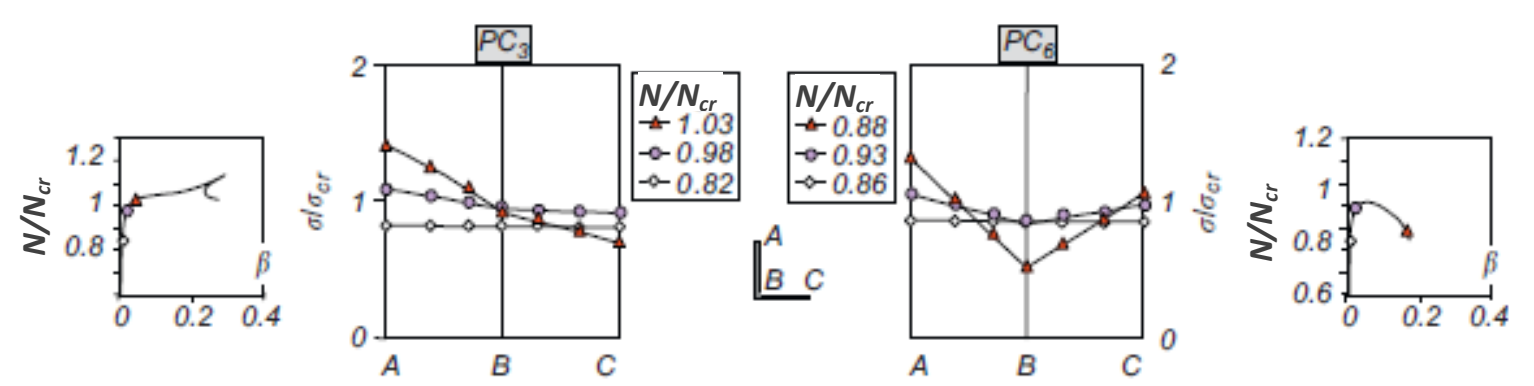

Figura 2.9 - Evolução da distribuição de tensões normais na metade do comprimento das barras PC3 e PC6 para três níveis de carregamento. Adaptado de Dinis et al. (2012).

Com isso, Dinis et al. (2012) acrescentam que as distribuições de tensões ao longo da seção transversal na metade do comprimento das barras rotuladas PC são ainda mais diferentes da distribuição teórica esperada (Fig. 2.7) do que aquelas verificadas nas barras engastadas. Enquanto a barra mais longa (PC6) apresenta uma distribuição de tensões com razoável simetria, a barra mais curta (PC3) apresenta-se claramente assimétrica.

Ademais, algumas das diferenças mais significantes citadas em termos de trajetória de equilíbrio elástico não linear entre as barras rotuladas $(P C)$ e as engastadas $(F)$, além das configurações de deformação longitudinal (esperadamente distintas, e comentadas com mais detalhes no trabalho de Dinis et al. (2012)), são os valores de $d_{m}$ e $d_{M}$, os quais possuem ordem de grandeza cerca de dez vezes maior para o caso das barras rotuladas (PC), independentemente da magnitude do carregamento aplicado, e também, o limite elástico da força de compressão das barras rotuladas (PC), que é menor e decresce mais rapidamente com $L$ do que para as respectivas com vínculos engastados.

Com relação as barras com extremidades com rótulas esféricas (PS), Dinis et al. (2012) comentam uma grande semelhança com as barras com rótulas cilíndricas (PC). Segundo os autores, foi notável apenas uma pequena diferença no fato de que as barras PS exibem trajetórias sensivelmente mais flexíveis, sem apresentar rotações reversas, além da configuração deformada de flexão em torno do eixo de maior inércia também apresentar uma única semi-onda (conforme esperado), fato que não é verificado nas barras PC e $F$, em função do engaste nesta direção.

Por fim, é importante mencionar também, que os deslocamentos típicos de flexão em torno do eixo de menor inércia $\left(d_{m}\right)$ foram vistos como uma variável muito influente sobre a reserva de resistência das cantoneiras nas análises não lineares elásticas, muito embora a 
imperfeição geométrica inicial inserida tenha contido apenas deslocamentos típicos do modo de flexo-torção (torção e flexão em torno do eixo de maior inércia).

Segundo Dinis et al. (2012), os motivos mecânicos para o surgimento de tais deslocamentos podem ser encontrados no Anexo A do trabalho de Stowell (1951). Eles resultam das rotações de torção, as quais originam distribuições de tensões normais (sobre a linha média da seção transversal) variáveis ao longo do eixo da barra seguindo um padrão com três semi-ondas, sendo os valores máximos verificados próximos de $1 / 4$ e $3 / 4$ do comprimento da barra, e os valores mínimos próximos às extremidades e ao centro. Estes deslocamentos, acabam por originar uma mudança na posição do centróide efetivo da barra, que se dá no sentido das bordas livres para a dobra, e também seguindo um padrão com três semi-ondas (não ilustrados graficamente nesta dissertação).

Assim, conforme Dinis et al. (2012), é este deslocamento do centróide efetivo, responsável pelos deslocamentos (positivos) de $d_{m}$, os quais apresentam sua maior influência sobre as barras de comprimentos maiores, chegando em alguns casos a provocar o surgimento do modo de instabilidade por flexão em torno do eixo de menor inércia (apresentando os deslocamentos $d_{m}$ em uma única semi-onda, ao invés de três como no caso de instabilidade por flexo-torção).

Além disso, cabe acrescentar que, em função desta forte sensibilidade aos deslocamentos de flexão, a flambagem local não pode ser equiparada à flambagem global por torção (corroborando com o que foi apresentado por Dinis et al. (2010-b)), já que o comportamento da cantoneira não pode ser visto como a "soma" de duas chapas com três bordas simplesmente apoiadas e a outra livre. Nestas condições, a componente de flexão (que também diferencia o modo "local" do modo global de flexo-torção) não deve ser omitida, mesmo que sua contribuição não altere significativamente a previsão teórica da força axial resistente da barra.

\section{○ Comportamento elasto-plástico não linear}

$\mathrm{Na}$ análise do comportamento considerando a não linearidade física, conforme verificado por Dinis et al. (2010-a), é possível obter respostas bem características segundo o comprimento das cantoneiras.

Esta relação entre o comportamento elasto-plástico e o comprimento está ligada à reserva de resistência verificada nas análises não lineares elásticas, logo, as barras mais 
curtas, que apresentam comportamento mais estável (maior reserva de resistência) apresentam um tipo de resposta em função do escoamento do material, enquanto as barras mais longas, que são mais flexíveis (menor reserva de resistência) apresentam outro tipo de comportamento. Além disso, dada a influência do comportamento não linear elástico, também entende-se que há uma considerável diferença em função das condições de extremidade das barras, conforme comentado a seguir.

Tomando primeiramente uma barra com extremidades engastadas da mesma série de barras analisadas anteriormente (F1 a F10), com comprimento L5, e fazendo variar a tensão de escoamento $\left(f_{y}\right)$ de modo a se obter relações $f_{y} / \sigma_{c r} \approx 1,3 ; 2,5$ e 5,0 ( $f_{y}=30,60$ e $\left.120 \mathrm{MPa}\right)$, é possível visualizar a influência do aumento da tensão de escoamento sobre o comportamento das barras. A Figura 2.10 ilustra esta análise, juntamente com a trajetória de equilíbrio elástico não linear $\left(f_{y} / \sigma_{c r} \approx \infty\right)$, e para a relação $f_{y} / \sigma_{c r} \approx 2,5$, em três pontos da trajetória indicados (Fig. 2.10.a), o diagrama de deformação plástica, ilustrando o mecanismo de falha típico.

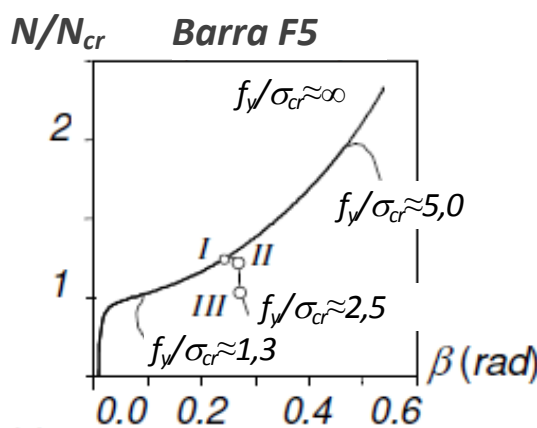

(a)

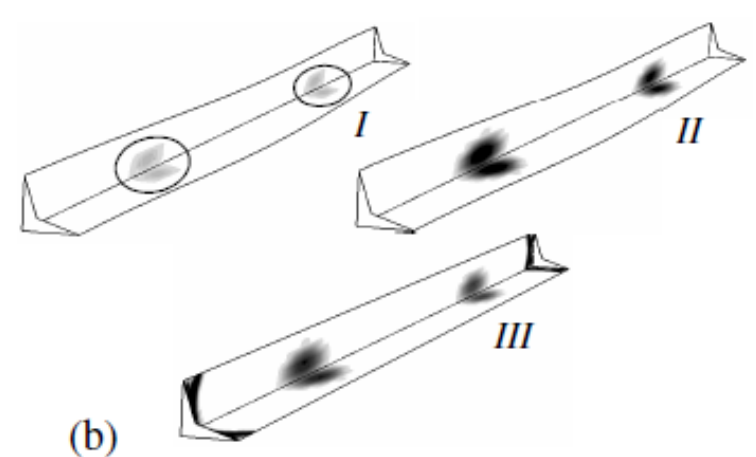

Figura 2.10 - Comportamento elasto-plástico da barra F5: (a) Trajetória de equilíbrio normalizada $\left(N / N_{c r} v s . \beta\right)$ para $f_{y} / \sigma_{c r} \approx 1,3 ; 2,5$ e 5,0, e diagramas de deformação plástica e formação de mecanismo associada com $f_{y} / \sigma_{c r} \approx 2,5$. Adaptado de Silvestre et al. (2012).

Segundo Silvestre et al. (2012), é notável o aumento da capacidade resistente da cantoneira com o aumento de $f_{y}$, da mesma forma que também se nota a diminuta capacidade de deformação plástica antecedendo a falha da mesma. Além disso, o diagrama $I$ de deformação plástica (Fig. 2.10.b) demonstra que o escoamento inicia nas regiões a $1 \frac{1}{4}$ e $3 / 4$ do comprimento da barra, próximos da dobra, onde as tensões normais e de cisalhamento são maiores devido à variação da rotação em torno do eixo longitudinal (Stowell (1951) e Dinis et al. (2011-a)).

Por outro lado, tomando como referência uma barra com extremidades rotuladas (no caso PC3), tem-se os resultados ilustrados na Figura 2.11 demonstrando uma marcante 
diferença no comportamento em relação à barra com extremidades engastadas analisada anteriormente.

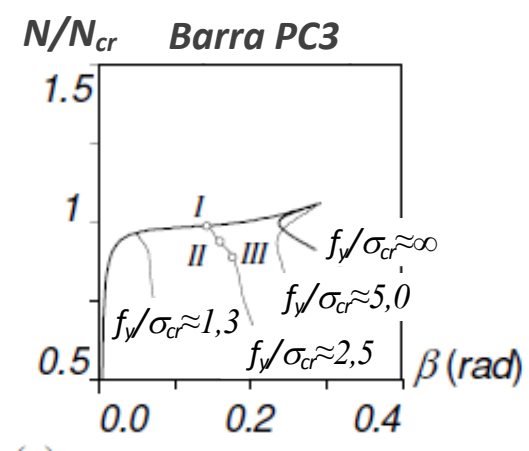

(a)

Figura 2.11 - Comportamento elasto-plástico da barra PC3: (a) Trajetória de equilíbrio normalizada ( $N / N_{c r}$ vs. $\beta$ ) para

Adaptado de Silvestre et al. (2012).

Neste caso, não se verifica nenhuma ductilidade antecedendo o mecanismo de falha, ou seja, nenhuma reserva de resistência adicional em regime elasto-plástico. Além disso, o escoamento inicia na região central da aba, também próximo de $1 / 4 \mathrm{e}$ 3/4 do comprimento da barra.

Segundo Silvestre et al. (2012), no caso da barra PC3 analisada, o escoamento precipita o mecanismo de colapso da barra, no entanto, pouco acréscimo na força resistente é obtido pelo aumento na tensão de escoamento.

Desta maneira, percebe-se que o comportamento elástico da cantoneira possui uma forte influência, determinando a sensibilidade da barra à variação da tensão de escoamento.

Neste ponto, vale mencionar, como fazem Silvestre et al. (2012) em seu trabalho, que com estes diferentes comportamentos elásticos e elasto-plásticos entre as barras com extremidades rotuladas e engastadas, e de diferentes comprimentos (diferentes reservas de resistência), pode haver uma significativa dispersão nos resultados associados a uma determinada tensão de escoamento. Isto é, em um grupo de cantoneiras possuindo a mesma força axial de flambagem elástica (e.g., comprimentos ao longo do platô característico de flexo-torção), compartilhando assim o mesmo índice de esbeltez reduzido $\left(\lambda_{0}=\left(A \cdot f_{y} / N_{c r}\right)^{0,5}\right)$, os valores de força resistente podem exibir uma alta dispersão vertical com relação a $\lambda_{0}$ (i.e., um único valor de $\lambda_{0}$, e vários valores de força resistente).

Não obstante, ao se iniciar o trabalho com foco no comportamento experimental das cantoneiras sob compressão centrada (Mesacasa Jr. e Malite, 2011), comparativamente aos 
procedimentos de dimensionamento baseados no MLE (citados ao final da introdução desta dissertação), verificou-se ainda uma série de comportamentos peculiares, dentre os quais a ocorrência de modos de falha por flexo-torção em barras com comprimentos tais que o modo de instabilidade relacionado seria de flexão em torno do eixo de menor inércia, bem como o contrário, ocorrência de flexão em torno do eixo de menor inércia onde se esperava flexo-torção (e.g., Maia et al. (2008) e Popovic et al. (1999)).

Ademais, houveram casos de ensaios repetidos (mais de um caso), com a ocorrência de distintos modos de falha, um por flexo-torção e outro por flexão em torno do eixo de menor inércia, sendo uma curiosa constatação de que neste último a força de compressão resistente resultou muito maior que a correspondente com falha por flexo-torção.

Tais ocorrências, aparentemente paradoxais por não se apresentarem de acordo com o comportamento esperado, sugerem a influência de fatores não abordados até então. Desta forma, buscou-se estudar neste trabalho as seguintes variáveis: (i) o afastamento longitudinal entre o centro das rótulas e a extremidade do perfil (item 2.1), que é aplicado somente aos casos de barras com rótulas cilíndricas, e (ii) a influência das imperfeições geométricas iniciais (item 2.2), aplicado a todos os casos, mas limitado neste trabalho às cantoneiras com rótulas cilíndricas.

Vale comentar, no entanto, que também foi alvo de estudo neste trabalho a influência das tensões residuais, não apresentando estas uma influência significativa nos resultados numéricos, o que vai de acordo com o encontrado por outros autores como Chodraui et al. (2006), Ellobody e Young, (2005), e mais recentemente, Shi et al. (2009).

\subsection{Influência do afastamento longitudinal entre a rótula e a barra}

O afastamento longitudinal entre o centro das rótulas e a barra no caso de ensaios à compressão (apoios com rótulas cilíndricas) é um fator importante no comportamento das cantoneiras, mas pode ter seus efeitos aplicados sobre barras com qualquer seção transversal monossimétrica.

Em uma primeira análise, estes afastamentos longitudinais se comportam como barras rígidas, pois em geral, tratam-se dos aparelhos de apoio de máquinas, os quais são 
constituídos por chapas de elevada inércia, tal que não afete de nenhuma forma o comportamento do experimento (e.g., Fig. 2.12).

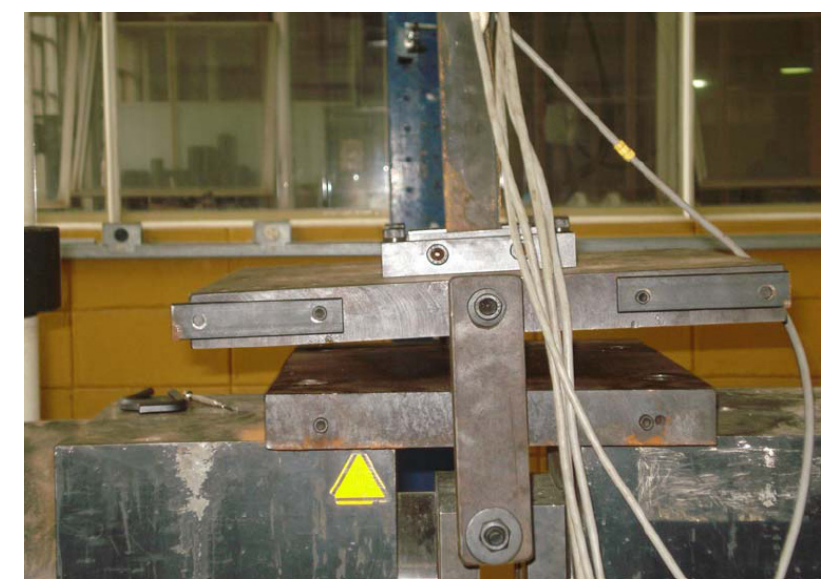

Figura 2.12 - Típico aparelho de apoio - afastamento longitudinal entre a barra e a rótula cilíndrica.

De fato, tais elementos rígidos estão para o conjunto, devido à grande diferença entre a inércia destes com a inércia da barra flexível central, praticamente como barras rotuladas em balanço (sistema hipostático). Em outras palavras, tais elementos possuem rigidez a flexão nula, e contribuem somente com a rigidez geométrica global - i.e., apresentam um efeito desestabilizante na flambagem por flexão.

Assim, tem-se um quadro geral equiparável ao de colunas pendulares ("leaning columns") em pórticos não contraventados (Peng, 2004), o que significa que a força axial de flambagem elástica por flexão do conjunto torna-se menor quanto maior for o comprimento destes elementos rígidos.

A influência dos elementos rígidos na flambagem por flexão pode ser determinada com uma análise bidimensional de estabilidade elástica do sistema estrutural ilustrado na Fig. 2.13.a, que consiste em dois elementos rígidos $\left((E I)_{r} \rightarrow \infty\right)$ de extremidade (aparelhos de apoio) com comprimento $L_{r}$, e uma barra central de comprimento $L_{c}$ e rigidez $E I$.

A análise de estabilidade pode ser realizada analiticamente por meio da aplicação de elementos finitos com matriz de rigidez total "exata" baseada nas funções de estabilidade desenvolvidas por Livesley e Chandler (1956) apud Reis e Camotim (2001), e também numericamente por meio de análises conduzidas com ajuda do programa comercial ANsYs (SAS, 2009), com a utilização de elementos finitos de viga, conforme comentado a seguir. 


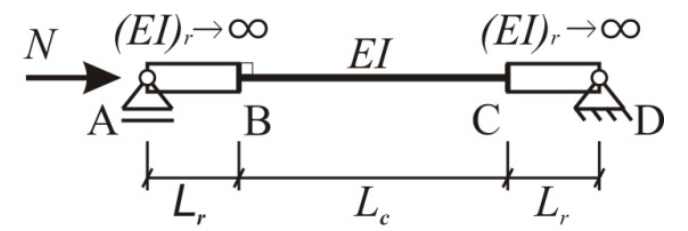

(a)

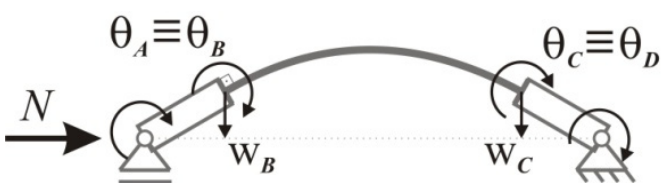

(b)

Figura 2.13 - Barra comprimida: (a) geometria e carregamento e (b) configuração deformada e graus de liberdade adotados na formulação analítica

\subsubsection{Solução Analítica}

De modo a estabelecer as equações de equilíbrio num ponto adjacente à trajetória fundamental (equilíbrio adjacente), é necessário considerar a matriz de rigidez "exata" para um elemento flexível uniformemente comprimido com extremidades engastadas e para um elemento rígido com extremidades rotuladas.

A matriz associada aos elementos rígidos ("leaning columns"), segundo Gonçalves (2000), pode ser deduzida considerando-se o equilíbrio na posição deslocada (Fig. 2.14).
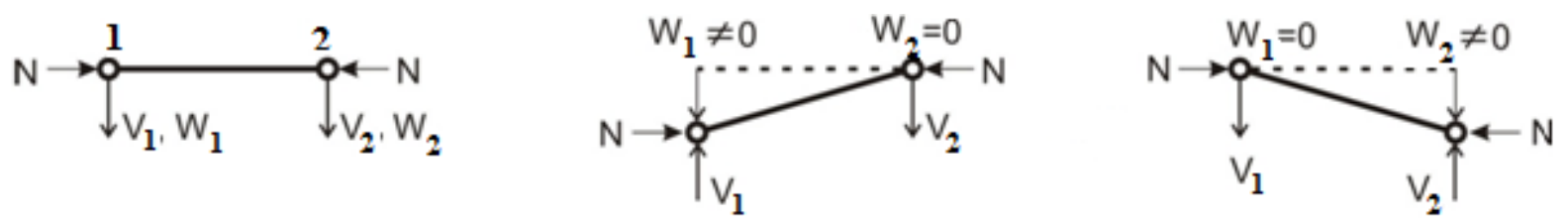

Figura 2.14 - Graus de liberdade nodais e equilíbrio da barra na posição deslocada

Assim, admitindo a hipótese de pequenos deslocamentos, o equilíbrio é dado por:

$$
\begin{gathered}
{\left[\begin{array}{ll}
\mathrm{V}_{1} & \mathrm{~V}_{2}
\end{array}\right]^{\top}=\mathrm{K} \cdot\left[\begin{array}{ll}
\mathrm{W}_{1} & \mathrm{~W}_{2}
\end{array}\right]^{\top}} \\
\mathrm{K}=\frac{N}{L}\left[\begin{array}{cc}
-1 & 1 \\
1 & -1
\end{array}\right]
\end{gathered}
$$

Nota-se em 2.13 que a rigidez da barra é afetada somente pela força axial $(N)$ e pelo comprimento $(L)$, ou seja, não depende de sua rigidez a flexão. Além disso, a matriz K possui determinante nulo, o que, segundo Gonçalves (2000), indica obviamente que a barra isolada não possui qualquer rigidez. Isto faz com que a coluna pendular (comprimida) num pórtico constitua um "fator desestabilizante". 
Ainda com relação aos elementos rígidos, vale comentar também que, neste caso, apenas os termos negativos (associados ao movimento "pendular") são envolvidos no sistema.

A matriz de rigidez associada ao elemento flexível com extremidades engastadas adotada neste trabalho, que é baseada nas funções de estabilidade $\phi_{i}(i=1, \ldots, 4)$ propostas por Livesley e Chandler (1956), é apresentada na Fig. 2.15, juntamente com os correspondentes graus de liberdade nodais. As funções de estabilidade (Chen et al., 1996 apud Reis e Camotim, 2001) são expressas pelas equações 2.14 .

$$
\begin{array}{ll}
\phi_{1}=\xi \phi_{2} \cot \xi & \phi_{2}=\frac{\xi^{2}}{3(1-\beta \cot \beta)} \\
\phi_{3}=\frac{3}{4} \phi_{2}+\frac{1}{4} \xi \cot \xi & \phi_{4}=\frac{3}{2} \phi_{2}-\frac{1}{2} \xi \cot \xi
\end{array}
$$

Conforme Reis e Camotim (2001), as funções de estabilidade dependem do esforço axial $(N)$, que está concentrado no parâmetro $\xi=(\pi / 2) \cdot\left(N / N_{E}\right)^{0,5}$, onde $N_{E}$ é a força axial de flambagem elástica por flexão (Euler $\left.-N_{E}=\pi^{2} E I / L^{2}\right)$.

$$
\left[K_{i j}^{c}\right]=\frac{E I}{L}\left[\begin{array}{cccc}
4 \phi_{3} & \frac{6 \phi_{2}}{L} & 2 \phi_{4} & \frac{-6 \phi_{2}}{L} \\
\frac{6 \phi_{2}}{L} & \frac{12 \phi_{1}}{L^{2}} & \frac{6 \phi_{2}}{L} & \frac{-12 \phi_{1}}{L^{2}} \\
2 \phi_{4} & \frac{6 \phi_{2}}{L} & 4 \phi_{3} & \frac{-6 \phi_{2}}{L} \\
\frac{-6 \phi_{2}}{L} & \frac{-12 \phi_{1}}{L^{2}} & \frac{-6 \phi_{2}}{L} & \frac{12 \phi_{1}}{L^{2}}
\end{array}\right]
$$

Figura 2.15 - Matriz de rigidez exata e graus de liberdade nodais associados a barra biengastada sob compressão uniforme.

Com isso, levando-se em consideração que os graus de liberdade são restringidos de forma que $w_{B}=L_{r} \theta_{A}$, e também $w_{C}=-L_{r} \theta_{D}$ (conforme Fig. 2.13.b), tem-se equilíbrio na posição adjacente somente se o sistema 2.15 for satisfeito.

$$
\left[\begin{array}{l}
M_{A} \\
M_{D}
\end{array}\right]=\left[\begin{array}{cc}
L_{r}{ }^{2}(-A+B)+2 L_{r} C+D & L_{r}{ }^{2} B+2 L_{r} C+E \\
L_{r}{ }^{2} B+2 L_{r} C+E & L_{r}{ }^{2}(-A+B)+2 L_{r} C+D
\end{array}\right] \cdot\left[\begin{array}{c}
\theta_{A} \\
\theta_{D}
\end{array}\right]=0
$$

onde, 


$$
\begin{array}{lll}
A=\frac{N}{L_{r}} & B=\frac{12 \phi_{1} E I}{L_{c}{ }^{3}} & C=\frac{6 \phi_{2} E I}{L_{c}{ }^{2}} \\
D=\frac{4 \phi_{3} E I}{L_{c}} & E=\frac{2 \phi_{4} E I}{L_{c}}
\end{array}
$$

e as duas equações representam o equilíbrio de momentos nos elementos rígidos $A B$ e $C D$.

A força axial de flambagem (bifurcação do equilíbrio) é dada pela solução não trivial do problema de autovalores dado por 2.15. Desta forma, substituindo 2.16 em 2.15, é possível extrair a equação direta associada às raízes do problema, obtendo-se,

$$
\left(A L_{r}^{2}-D+E\right)\left(A L_{r}^{2}-2 B L_{r}^{2}-4 C L_{r}-D-E\right)=0
$$

onde a menor raiz é a força axial de flambagem elástica do conjunto ilustrado na Fig. 2.13 (a).

Para demonstrar, então, a influência dos elementos rígidos (afastamentos longitudinais) sobre o comportamento de flambagem por flexão das cantoneiras de abas iguais com extremidades rotuladas, é apresentada uma série de análises, iniciando-se por uma validação da solução analítica (2.17) por meio de análises numéricas via MEF com a utilização de elementos finitos de viga no programa comercial ANSYS (SAS, 2009).

\subsubsection{Exemplos Ilustrativos e Resultados Numéricos via MEF}

Foram obtidos resultados numéricos para uma série de barras com $E=20000 \mathrm{kN} / \mathrm{cm}^{2}$, $I=1 \mathrm{~cm}^{4}, L_{c}=100 \mathrm{~cm}$ e $L_{r}$ variando de 0 a $300 \mathrm{~cm}$, o que corresponde a $0 \leq L_{r} / L_{c} \leq 3,0-$ obviamente, $L_{r}=0$ corresponde à "coluna de Euler", e então $N_{c r}=N_{E}=19,739 \mathrm{kN}$.

Assim, as curvas apresentadas nas Figuras 2.16 e 2.17 mostram a variação da força axial de flambagem elástica $\left(N_{c r}\right)$ normalizada com relação a $N_{E}$, em função da relação $L_{r} / L_{c}$, para duas situações: (i) $L_{c}$ permanece constante enquanto $L_{r}$ aumenta, correspondendo a uma barra com comprimento total $L_{\text {tot }}=2 \times L_{r}+L_{c}$ (Fig. 2.16), e (ii) $L_{c}$ diminui enquanto $L_{r}$ aumenta, de modo que o comprimento total do conjunto permanece inalterado (Fig. 2.17). 


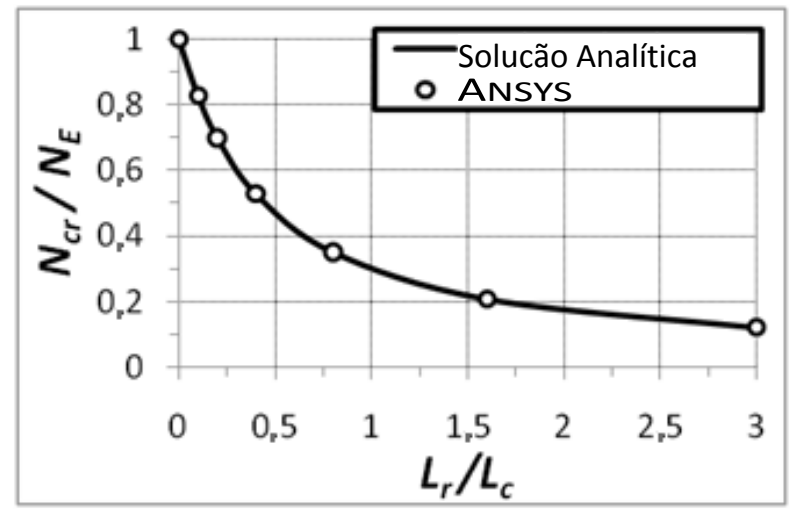

Figura 2.16 - Exemplo ilustrativo - variação de $N_{c r} / N_{E}$ com $L_{r} / L_{c}$ (para $L_{c}$ constante)

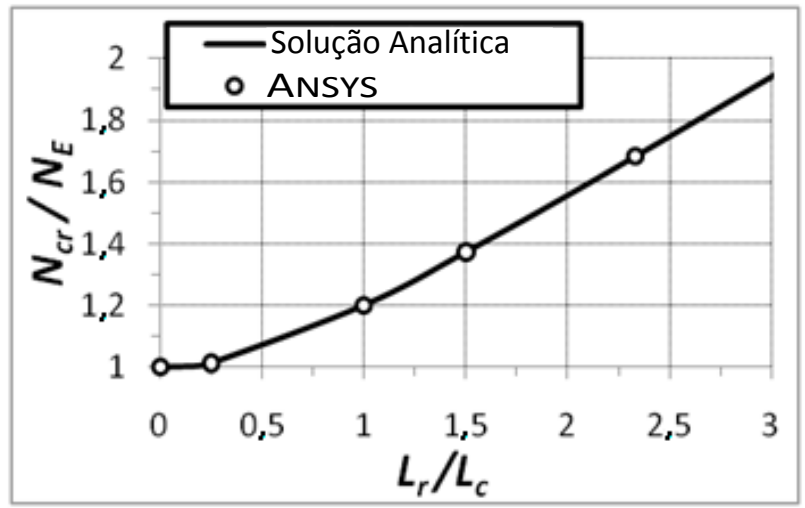

Figura 2.17 - Exemplo ilustrativo - variação de $N_{c r} / N_{E} \operatorname{com} L_{r} / L_{c}$ (para $L_{t o t}=2 x L_{r}+L_{c}$ constante)

A observação dos resultados ilustrados nas Figuras 2.16 e 2.17 permite os seguintes comentários:

(i) Primeiramente, os resultados numéricos coincidem perfeitamente com a solução analítica proposta, validando as equações 2.15 e 2.17;

(ii) Ao manter $L_{c}$ constante, o que implica no aumento de dois elementos "instabilizantes" conforme aumenta $L_{r}$, a força axial de flambagem do conjunto decresce continuamente, sendo esta redução particularmente alta para pequenos valores de $L_{r}$. Por exemplo, quando $L_{r}$ aumenta de 0 para $5 \mathrm{~cm}\left(L_{r} / L_{c}=0,05\right)$, o valor de $N_{c r}$ reduz de $19,739 \mathrm{kN}$ para $16,333 \mathrm{kN}(17 \%)$, por outro lado, quando $L_{r}$ aumenta de 15 para $20 \mathrm{~cm}$, o valor de $N_{c r}$ não reduz mais do que $8 \%$;

(iii) Esta alta redução inicial na força axial de flambagem é devido à combinação de dois fatores, $\left(\mathrm{iii}_{1}\right)$ o incremento do comprimento total do conjunto, e ( $\mathrm{ii}_{2}$ ) a contribuição negativa da rigidez dos elementos rígidos, que, sendo função do comprimento $L_{r}$, e considerando este em termos de percentagem, apresentam 
um incremento gradualmente menos relevante conforme aumenta $L_{r} / L_{c}$, fazendo com que a redução de $N_{c r}$ seja progressivamente menor;

(iv) Por outro lado, ao se manter inalterado o comprimento total $L_{\text {tot, }}$, põe-se uma situação em que se diminui o elemento flexível em troca do aumento de elemento rígido, o que é logicamente dedutível que ocasione um aumento na força axial de flambagem elástica $\left(N_{c r}\right)$ conforme aumenta o comprimento $L_{r}$. Contudo, neste caso o aumento de $N_{c r}$ é imperceptível para pequenos valores de $L_{r}$ (valores de $L_{r} / L_{c}$ até cerca de 0,25$)$, sendo seguido de um segundo trecho distinto aproximadamente constante $\left(N_{c r} / N_{E}\right.$ aproximadamente proporcional a $\left.L_{r} / L_{c}\right)$;

(v) Este pequeno aumento inicial de $N_{c r}$ está ligado ao fato de que o segmento "flexível" que é "substituído" por elemento rígido representa muito pouco da curvatura do conjunto. Conforme o comprimento $L_{r}$ aumenta, esta substituição "retifica" um trecho progressivamente maior do conjunto, contribuindo com o aumento de $N_{c r}$.

\subsubsection{Implicações ao Comportamento de Flambagem de Cantoneiras}

Dando um enfoque neste momento às cantoneiras de comprimentos pequenos a intermediários (comportamento elástico sobre o platô característico de flexo-torção), lembra-se que, conforme mostrado no início do capítulo 2 deste trabalho, as cantoneiras sobre este trecho são caracterizadas por (i) um modo crítico de flambagem por flexo-torção, contudo, possuem também (ii) um modo "não crítico" correspondente à flambagem por flexão em torno do eixo de menor inércia.

Além disso, é sabido que estes dois modos de instabilidade tornam-se progressivamente próximos com o incremento do comprimento da barra, até o ponto em que o modo (ii) torna-se crítico (Fig. 2.4.a).

Nas cantoneiras com rótulas cilíndricas, a presença dos elementos rígidos implica diretamente sobre o comprimento relacionado ao modo de flexão (em torno do eixo menor inércia), contudo, o comprimento relacionado ao modo de flexão em torno do eixo de maior inércia, e também torção (modo de flexo-torção), não é afetado, i.e., os comprimentos para os diferentes modos de instabilidade são diferentes. Mais especificamente, o modo de flexo- 
torção é governado pelo comprimento da barra $L_{c}$, enquanto o modo de flexão em torno do eixo de menor inércia é governado pelo comprimento total $L_{t o t}=L_{c}+2 L_{r}$.

Em termos práticos, a existência dos afastamentos longitudinais devidos aos aparelhos de apoio (elementos rígidos) nos conjuntos experimentais acaba por provocar uma "aproximação" entre os dois modos de instabilidade. Em outras palavras, se na análise de uma barra cujo comprimento nominal conduza teoricamente à ocorrência de flexo-torção, a depender do comprimento $L_{r}$ (se este for grande o suficiente), a força axial de flambagem elástica por flexão pode vir a se tornar mais baixa que aquela referente ao modo de flexotorção, conduzindo a um inesperado (ou "paradoxal") resultado experimental, e ainda a uma má interpretação do mesmo.

\subsubsection{Interpretação de Resultados Experimentais Relacionados}

Para mostrar os efeitos dos elementos rígidos aplicados a alguns resultados experimentais, foram selecionadas séries de ensaios conduzidas por Popovic et al. (1999), Chodraui et al. (2006) e Maia et al. (2008). As propriedades materiais e geométricas das seções transversais das cantoneiras testadas por estes (e outros) autores se encontram na Tabela 3.1, (no Capítulo 3 deste trabalho), enquanto a Tabela 3.2 apresenta dados como (i) o comprimento nominal da barra $\left(L_{c}\right)$, (ii) o afastamento longitudinal entre a rótula e a barra $\left(L_{r}\right)$, (iii) a força de compressão resistente $\left(N_{u, \text { exp }}\right)$, e (iv) o modo de falha observado no ensaio.

Assim, para prover uma melhor visualização das características de flambagem para cada ensaio, as Figuras 2.18 a 2.22 ilustram as localizações dos comprimentos correspondentes a cada barra analisada, e três correspondentes curvas de flambagem $\left(N_{b} v s\right.$. $L$ ), associadas (i) ao modo de flexo-torção (que inclui o platô característico), (ii) ao modo de flexão em torno do eixo de menor inércia baseado no comprimento nominal da coluna $L_{c}$, i.e., negligenciando o afastamento longitudinal das rótulas, e (iii) ao modo de flexão em torno do eixo de menor inércia baseado no comprimento total $L_{\text {tot }}$, i.e., levando em consideração os afastamentos longitudinais, mas lembrando que estes não afetam a flambagem por flexo-torção. 


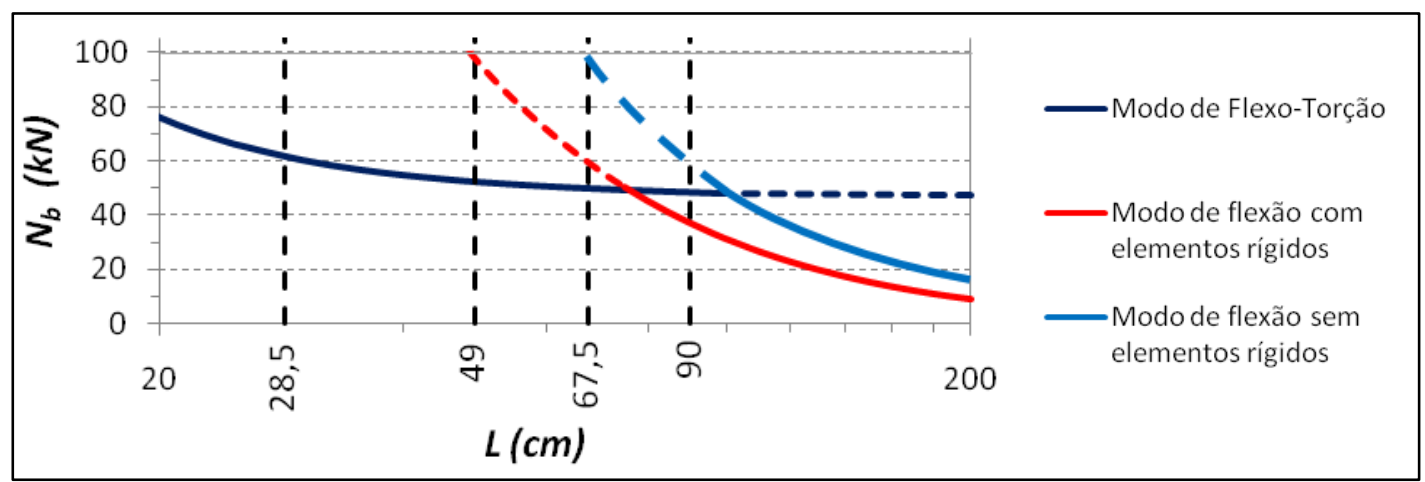

Figura 2.18 - Curvas de flambagem $N_{b}$ vs $L$ e comprimentos de barras ensaiadas por Popovic et al. (1999) - L50x2,50

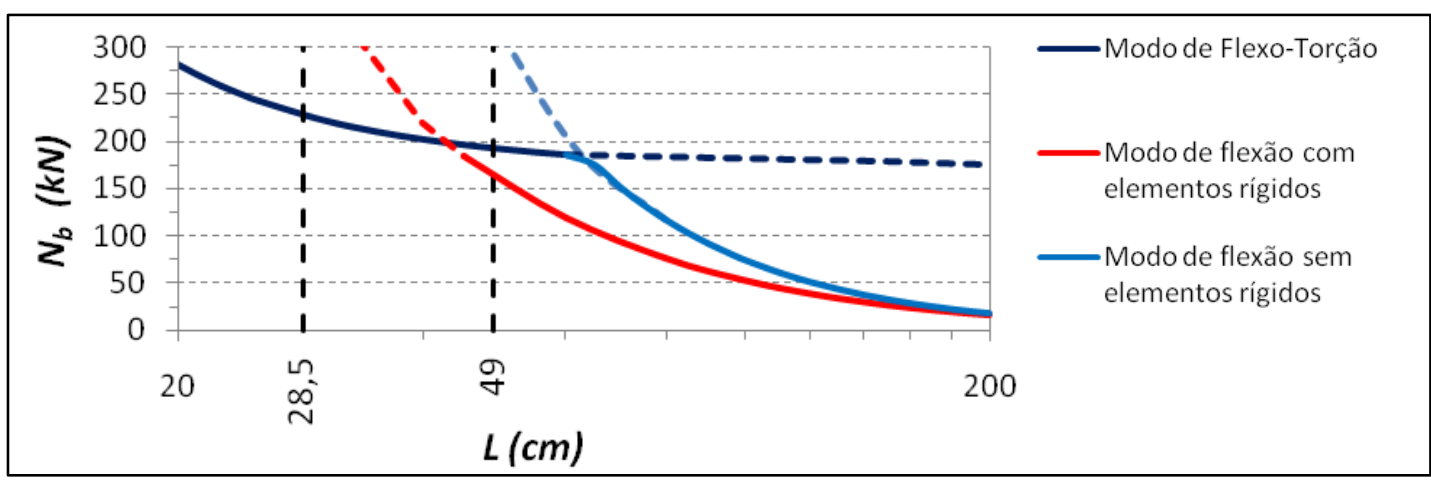

Figura 2.19 - Curvas de flambagem $N_{b}$ vs $L$ e comprimentos de barras ensaiadas por Popovic et al. (1999) - L50x4,00

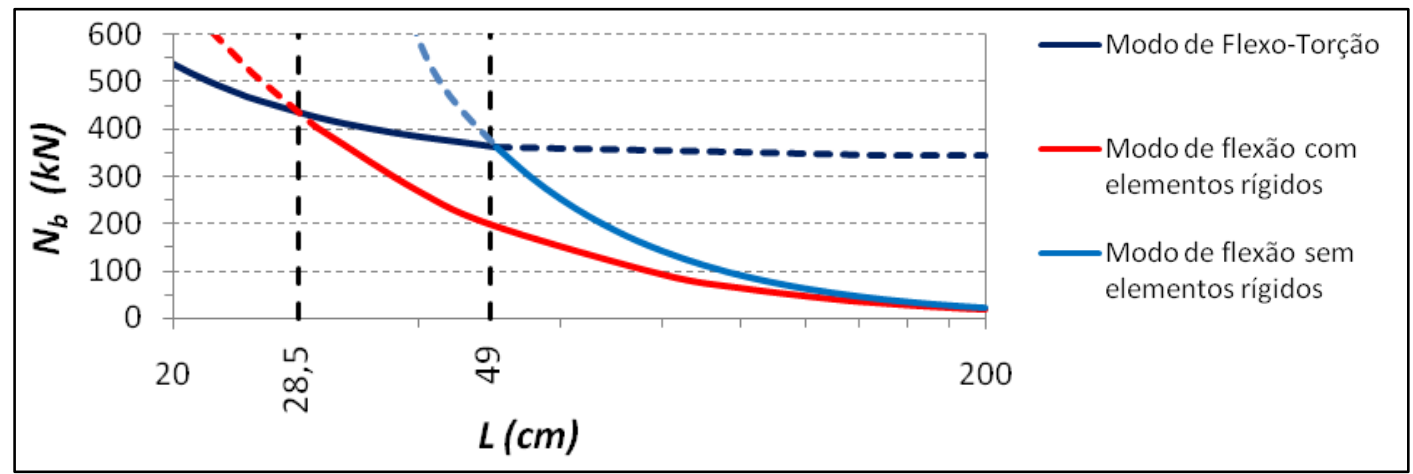

Figura 2.20 - Curvas de flambagem $N_{b}$ vs $L$ e comprimentos de barras ensaiadas por Popovic et al. (1999) - L50x5,00

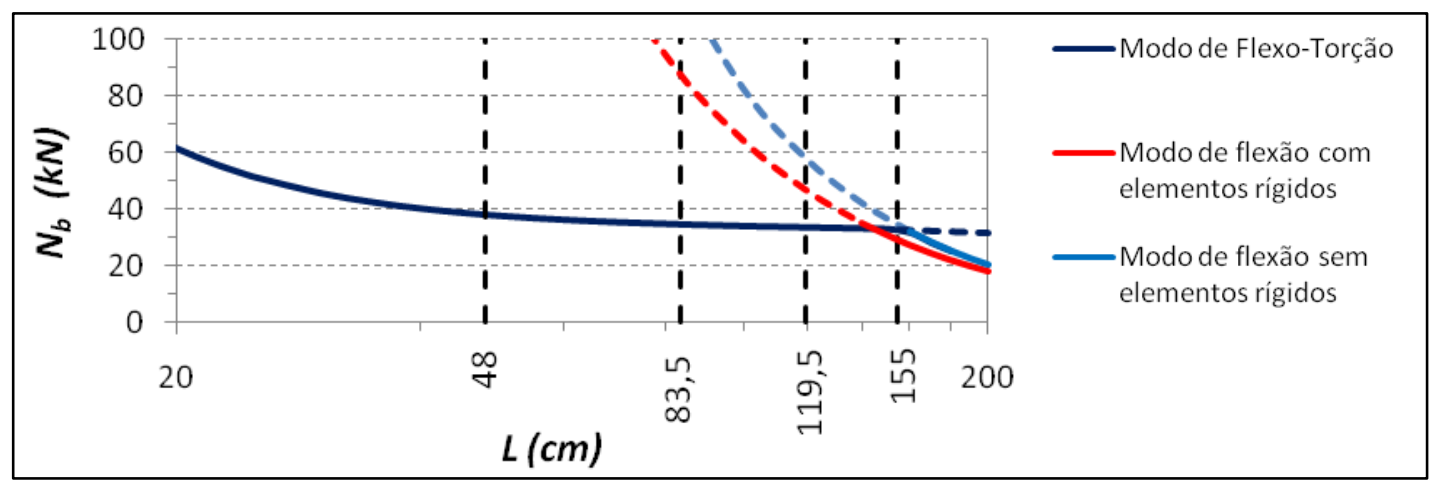

Figura 2.21 - Curvas de flambagem $N_{b}$ vs L e comprimentos de barras ensaiadas por Chodraui et al. (2006) - L60x2,38 


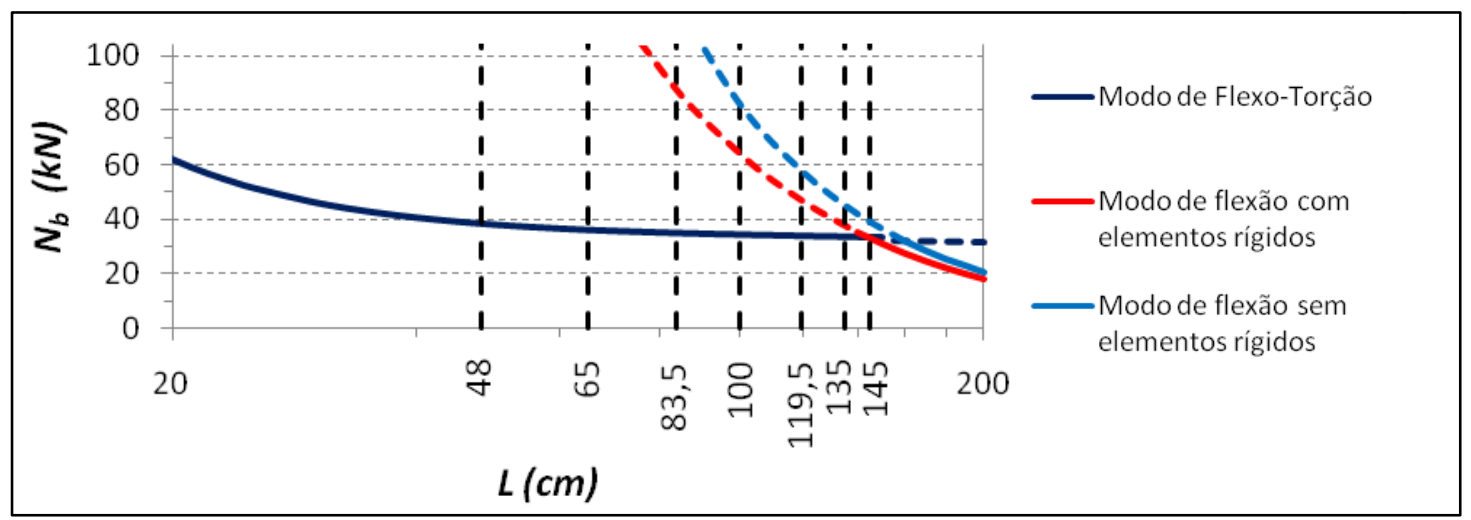

Figura 2.22 - Curvas de flambagem $N_{b}$ vs $L$ e comprimentos de barras ensaiadas por Maia et al. (2008) - L60x2,38

A análise dos resultados apresentados na Tabela 3.2, juntamente com os gráficos exibidos nas figuras acima, permitem citar as seguintes considerações:

i. Para cada série experimental existe ao menos uma barra para a qual a consideração dos afastamentos longitudinais das rótulas reduz a força axial de flambagem por flexão em torno do eixo de menor inércia para um valor abaixo da curva característica de flambagem por flexo-torção. Além disso, os afastamentos tornam os dois modos de instabilidade muito próximos para várias outras barras ensaiadas;

ii. Com exceção de uma, todas as barras para as quais a força axial de flambagem por flexão em torno do eixo de menor inércia ficou abaixo da força axial de flambagem por flexo-torção (ou muito próxima), apresentaram (segundo os autores de cada experimento) falha com evidências de flexão em torno do eixo de menor inércia. A exceção se refere a uma barra ensaiada por Maia et al. (2008) com $L_{c}=145 \mathrm{~cm}$, para a qual foi observado modo de falha por flexo-torção (FT) mas apresenta modo crítico de flambagem por flexão em torno do eixo de menor inércia;

iii. A influência dos afastamentos longitudinais das rotulas é claramente mais relevante para os ensaios de Popovic et al. (1999), mostrados nas Figs. 2.18 a 2.20, do que para os de Chodraui et al. (2006) e Maia et al. (2008), mostrados nas Figs. 2.21 e 2.22. Isto se deve ao fato de que a relação $L_{r} / L_{c}$ correspondente possui valores muito maiores nos ensaios de Popovic et al. (1999) , i.e., variam entre 0,35 e 0,11 para os ensaios de Popovic et al. (1999), entre 0,14 e 0,04 para os de Chodraui et al. (2006), e entre 0,14 e 0,05 para os de Maia et al. (2008); 
iv. Por fim, muitas barras também tiveram relatados modos de falha em que apresentaram ao mesmo tempo flexão em torno do eixo de menor inércia, flexão em torno do eixo de maior inércia e torção $(F+F T)$. Assim, antes de supor as causas, no próximo item é apresentado um estudo de comportamento elástico não-linear dos afastamentos longitudinais das rótulas, de modo a expandir o entendimento desta variável.

\subsubsection{Comportamento Elástico Não Linear de Cantoneiras com Elementos Rígidos de}

\section{Extremidade}

Para avaliar o comportamento elástico não linear das cantoneiras com rótulas cilíndricas foram feitas análises geometricamente não lineares de duas barras testadas por Popovic et al. (1999), ambas de seção transversal L50×2,50 mm, sendo uma com comprimento $L_{c}=67,5 \mathrm{~cm}$ e a outra $L_{c}=90 \mathrm{~cm}$.

Para cada uma das barras, analisou-se diferentes comprimentos para os elementos rígidos (afastamentos longitudinais das rótulas), fixando-se os valores de $L_{r}$ entre 0 e $30 \mathrm{~cm}$. Além disso, foram inseridas imperfeições geométricas iniciais de flexo-torção com amplitude igual a $10 \%$ da espessura das abas ${ }^{1}$.

As análises foram feitas com ajuda do programa comercial ANSYS (SAS 2009), utilizandose, para os perfis, elementos de casca (Shell181) definidos por 4 nós com três graus de liberdade por nó, e para os elementos rígidos, os mesmos elementos com módulo de elasticidade majorado $\left(E=2 \times 10^{14} \mathrm{kN} / \mathrm{cm}^{2}\right)$.

Para simular as condições de extremidade como cilindricamente rotuladas da melhor maneira possível, as extremidades da barra flexível foram totalmente engastadas no elemento rígido de cada extremidade, restringindo completamente o giro em torno do eixo axial da barra e o empenamento. No elemento rígido, ao longo de uma linha modelada exatamente sobre o eixo de menor inércia da cantoneira, foram aplicadas as restrições de deslocamento axial. Além disso, foram restringidos os deslocamentos em todos os nós na direção do eixo de menor inércia em ambas as extremidades do elemento rígido, eliminando com isso a possibilidade de qualquer tipo de giro ou translação neste sentido, conforme ilustra a Fig. 2.23.

\footnotetext{
${ }^{1}$ Não foram inseridas imperfeições geométricas iniciais de flexão em torno do eixo de menor inércia, pois, sabendo de sua grande influência sobre o comportamento das barras, optou-se por inserir somente imperfeições de flexo-torção, para avaliar melhor a influência dos elementos rígidos. As imperfeições de flexão são estudadas separadamente neste trabalho.
} 
São apresentadas nas Figuras 2.24.a - 2.24.b $\left(L_{c}=67,5 \mathrm{~cm}\right)$, e 2.25.a - 2.25.b $\left(L_{c}=90 \mathrm{~cm}\right)$, as curvas de força aplicada normalizada $\left(N / N_{c r}\right)$, sendo que $N_{c r}$ é a força axial de flambagem elástica da barra "desconsiderando" os elementos rígidos (i.e., corresponde a flambagem por flexo-torção), em função de $\beta$ e $d_{m}$, sendo $\beta$ o giro da região da dobra da seção na metade do comprimento da barra e $d_{m}$ o deslocamento da região da dobra da seção na metade do comprimento da barra na direção do eixo de maior inércia.

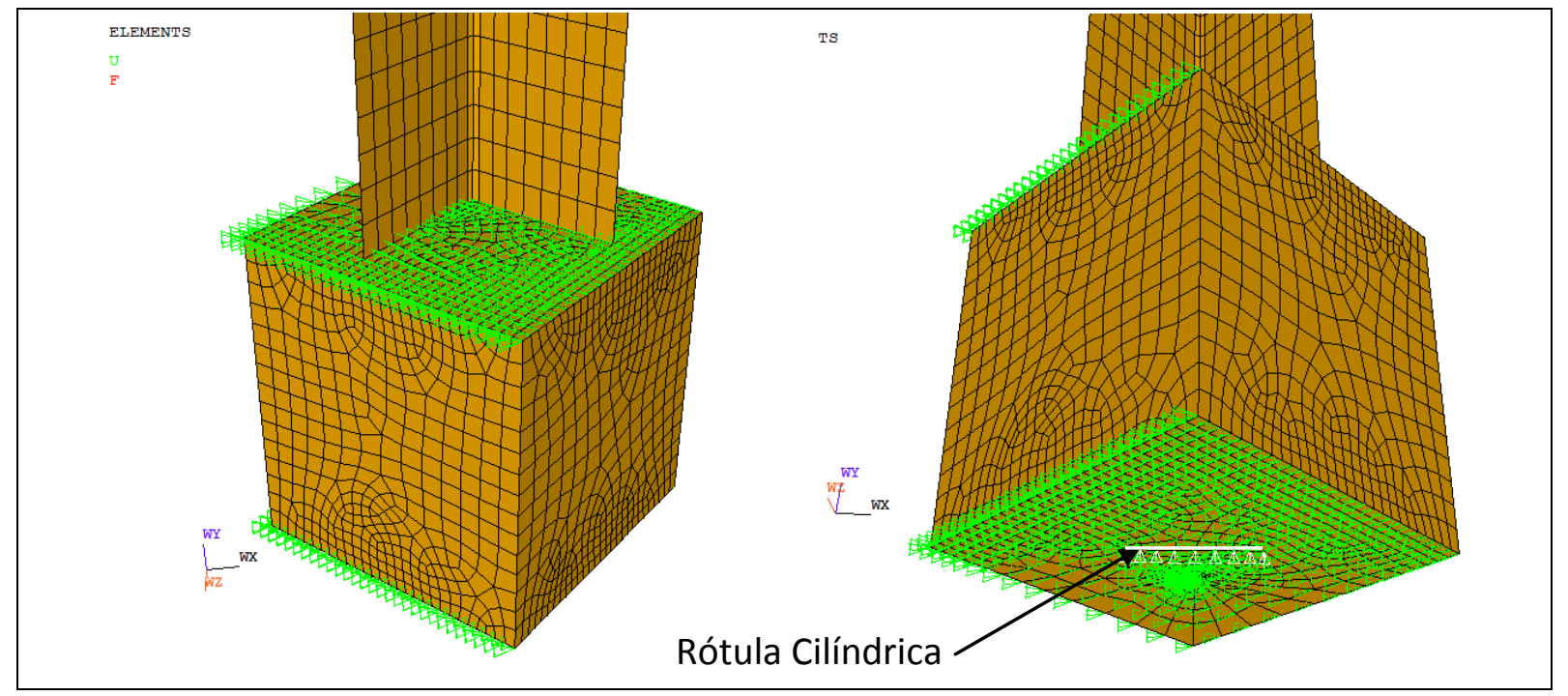

Figura 2.23 - Condições de contorno na extremidade inferior do conjunto

Para cada barra foram simulados cinco comprimentos de $L_{r}(0 ; 5 ; 10 ; 20 ;$ e $30 \mathrm{~cm})$ lembrando que $L_{r}=10 \mathrm{~cm}$ é exatamente a configuração de ensaio característica para os testes realizados por Popovic et al.(1999).

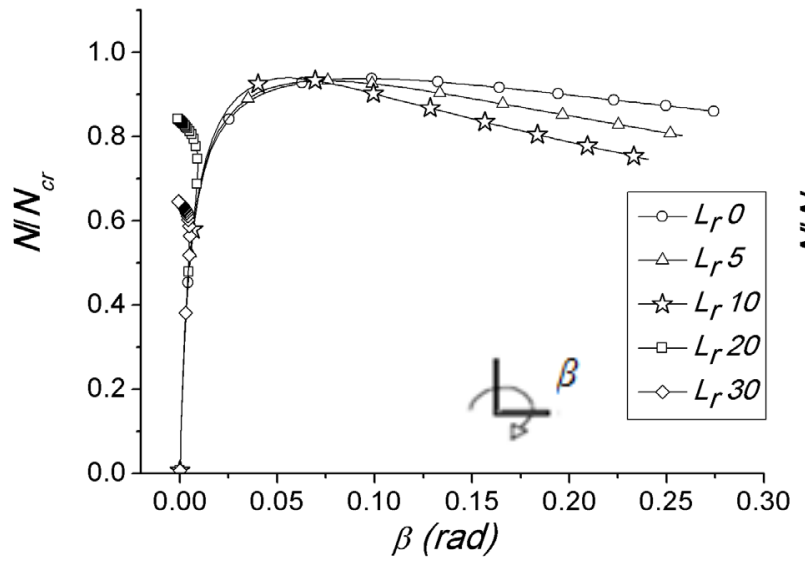

(a)

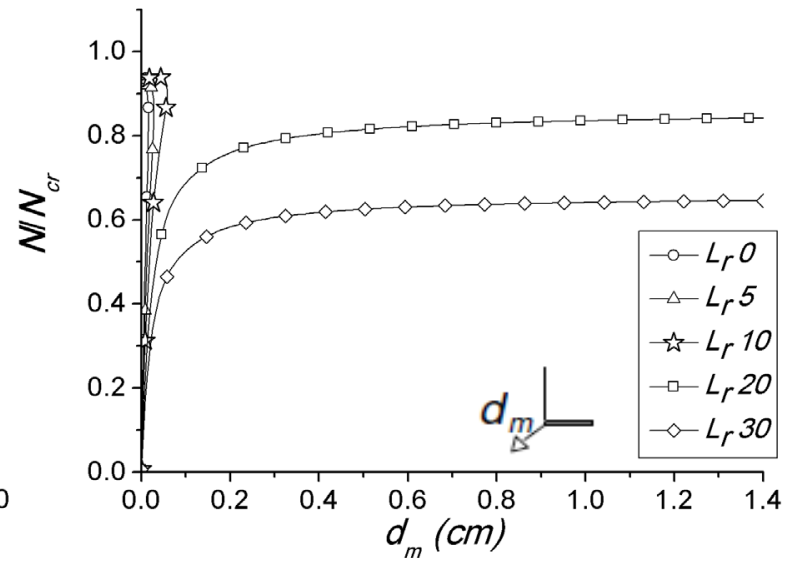

(b)

Figura 2.24 - Trajetórias de equilíbrio elástico não linear (a) $N / N_{c r} v s \beta$ e (b) $N / N_{c r} v s d_{m}-L 50 \times 2,50, L_{c}=67,5 \mathrm{~cm}$ e cinco valores de $L_{r}$. 


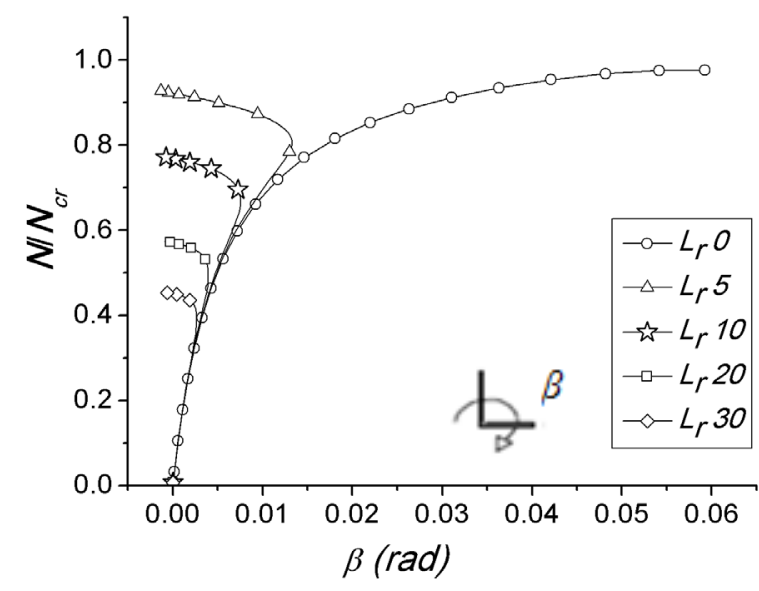

(a)

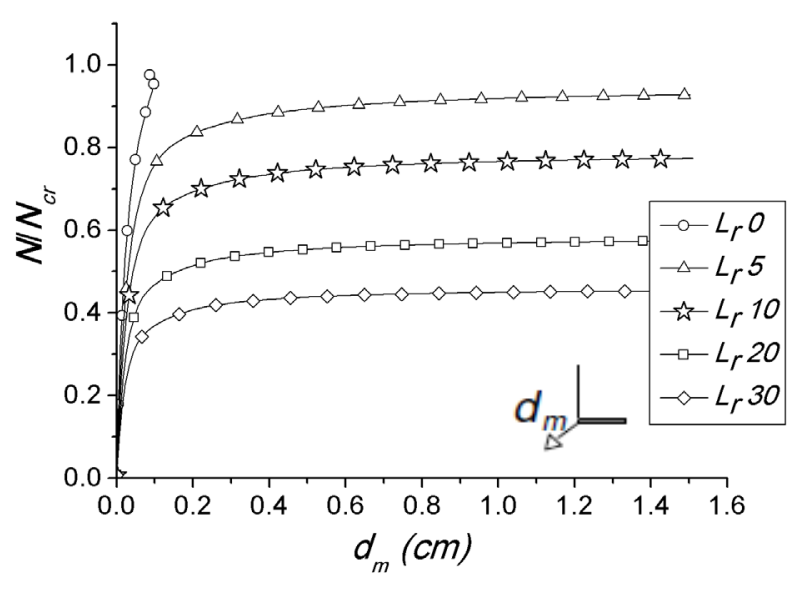

(b)

Figura 2.25 - Trajetórias de equilíbrio elástico não linear (a) $N / N_{c r} v s \beta$ e (b) $N / N_{c r} v s d_{m}-L 50 \times 2,50, L_{c}=90 \mathrm{~cm}$ e cinco valores de $L_{r}$.

A observação das trajetórias de equilíbrio elástico não linear obtidas permitem fazer os seguintes comentários:

i. Primeiramente, é importante mencionar que todas as barras apresentaram um padrão de deformações claro, caracterizando o modo de flexo-torção (valores grandes para $\beta$ e muito pequenos para $d_{m}$ ) ou modo de flexão em torno do eixo de menor inércia (valores grandes para $d_{m}$ e muito pequenos para $\beta$ ). Neste último caso, no entanto, pode ser vista também uma mudança no padrão das deformações ao longo da aplicação do carregamento, dado que apenas imperfeições de flexo-torção foram inseridas;

ii. Nas barras de comprimento $L_{c}=67,5 \mathrm{~cm}$, as deformações de flexo-torção são dominantes para os valores de $L_{r}=0 ; 5 ;$ e $10 \mathrm{~cm}$, enquanto as deformações de flexão em torno do eixo de menor inércia são dominantes para $L_{r}>20 \mathrm{~cm}$. Tais comportamentos, logicamente, vão de acordo com o esperado em função do comprimento $L_{r}$, pois para os primeiros comprimentos $\left(L_{r}=0 ; 5 ;\right.$ e $\left.10 \mathrm{~cm}\right) 0$ conjunto apresenta modo crítico de flambagem por flexo-torção, enquanto para os últimos dois comprimentos o conjunto corresponde ao modo crítico de flambagem por flexão em torno do eixo de menor inércia;

iii. As barras de comprimento $L_{c}=67,5 \mathrm{~cm}$ com elementos rígidos $L_{r}$ menores que $10 \mathrm{~cm}$ são caracterizadas por pontos limite (elásticos) bem definidos, que são atingidos para valores pequenos a intermediários de $\beta$, resultando em forças 
máximas muito parecidas. Com isso, entende-se que a falha ocorre exclusivamente devido a efeitos de não linearidade geométrica, e a força de compressão resistente não é influenciada pelo comprimento $L_{r}$;

iv. Para as mesmas barras, com comprimentos $L_{r}$ acima de $10 \mathrm{~cm}$, não é verificada a ocorrência de ponto limite, e forças máximas resistentes consideravelmente diferentes são observadas por meio dos platôs na curva $N / N_{c r} v s d_{m}$. Desta forma, é necessária a ocorrência de plastificação do material para desencadear o processo de falha, mas já fica clara a redução da força de compressão resistente com o aumento de $L_{r}$;

v. Para as barras com $L_{c}=90 \mathrm{~cm}$, as deformações de flexo-torção apenas ocorrem para $L_{r}=0$, justamente o único caso para o qual o modo de flexo-torção é crítico. Aos demais, a presença dos elementos rígidos faz com que seja dominante o modo de flambagem por flexão em torno do eixo de menor inércia, sendo estes casos semelhantes aos da barra $L_{c}=67,5 \mathrm{~cm}$, pois há uma forte redução na resistência com o aumento de $L_{r}$, conforme se nota nas curvas $N / N_{c r} v s d_{m}$.

Ademais, a observação conjunta das trajetórias de equilíbrio para $L_{r}=10 \mathrm{~cm}$, a Figura 2.18, e a Tabela 3.2, revela que existe uma boa concordância entre os resultados numéricos e o modo de falha observado experimentalmente ${ }^{1}$.

Todavia, tanto para as colunas $L_{c}=67,5 \mathrm{~cm}$ quanto para $L_{c}=90 \mathrm{~cm}$, verifica-se ensaios experimentais repetidos, para os quais há a ocorrência de modos de falha por flexão em torno do eixo de menor inércia e também por flexo-torção, para o mesmo comprimento $L_{c}$.

Investigando tal fato, verifica-se que cada barra ensaiada por Popovic et al. (1999) foi submetida a compressão, não centrada, mas sim excêntrica, com uma distância de aproximadamente $L / 1000$ entre o ponto de aplicação do carregamento e o centróide da seção bruta, de modo a comprimir as extremidades das abas.

Esta excentricidade, segundo o autor, tem a finalidade compatibilizar os ensaios realizados com as normas então em vigor (e.g., AISI 1996 e AS/NZS 4600-1996), que exigiam uma excentricidade mínima de $L / 1000$ na aplicação da força, fazendo com que o dimensionamento de cantoneiras recaísse num procedimento para flexo-compressão.

\footnotetext{
${ }^{1}$ Um estudo comparativo também foi feito para todas as barras com extremidades engastadas (lembrando que nestas o comprimento $L_{r}$ é nulo), mostrando que absolutamente todos os ensaios apresentaram modo de falha condizente com aquele apresentado na análise de estabilidade elástica.
} 
Desta forma, segundo o autor, todos os ensaios repetidos tiveram a excentricidade trocada para o sentido oposto, resultando num ensaio com a excentricidade induzindo tensões de compressão sobre as extremidades das abas e tração na região da dobra, e outro com a excentricidade induzindo tensões de compressão nas extremidades das abas e tração na região da dobra.

Sendo evidente, portanto, a grande influência da excentricidade na aplicação do carregamento verificada por Popovic et al. (1999), parte-se para uma investigação em torno das imperfeições geométricas iniciais, conforme explicado no próximo item.

\subsection{Influência das Imperfeições Geométricas Inicias}

Maia et al. (2008), constataram numericamente que ao serem introduzidas imperfeições globais de flexão em torno do eixo de menor inércia de modo a comprimir as bordas livres da cantoneira, a força resistente é menor que no caso desta imperfeição no sentido contrário, e corresponde à pior situação para a introdução deste tipo de imperfeição do ponto de vista de força resistente.

Este estudo feito por Maia et el. (2008) corrobora com o que foi verificado experimentalmente por Popovic et al. (1999), porém, os objetivos deste último autor eram de apenas reproduzir uma exigência normativa da época, enquanto o primeiro limitou-se a trabalhar com a pior condição da imperfeição de flexão, não estudando o comportamento das cantoneiras para ambos os sentidos desta imperfeição.

Maia et al. (2008) verificaram ainda que ao serem introduzidas imperfeições de torção, independentemente da sua amplitude, o modo de instabilidade dominante é de flexo-torção. Em outras palavras, segundo os autores, a presença de qualquer imperfeição de torção o modo de instabilidade deve ser de flexo-torção, independentemente da imperfeição de flexão (desde que o comprimento da cantoneira esteja, segundo análise de estabilidade elástica da mesma barra sem imperfeições, sobre o platô característico de flexo-torção).

Contudo, é possível encontrar, tanto no trabalho de Popovic et al. (1999) como de Maia et al. (2008), resultados experimentais caracterizados por deformações de flexão em torno do eixo de menor inércia com força resistente maior que de barras de mesmo comprimento 
onde o modo de falha relatado é caracterizado por flexo-torção (e.g., resultados de força resistente para os ensaios de Popovic et al. (1999), mostrados na Tabela 3.2).

As Figuras 2.26 e 2.27 mostram as curvas de flambagem ( $\left.N_{b} v s . L\right)$ associadas aos dois modos de instabilidade típicos (flexão em torno do eixo de menor inércia e flexo-torção), considerando os elementos rígidos de extremidade, para o perfil $L 60 \times 2,38 \mathrm{~mm}$ ensaiado por Maia et al (2008) e L50x2,50mm ensaiado por Popovic et al. (1999), respectivamente. Juntamente, são mostrados também os comprimentos das barras ensaiadas experimentalmente e os respectivos modos de falha relatados pelos autores.

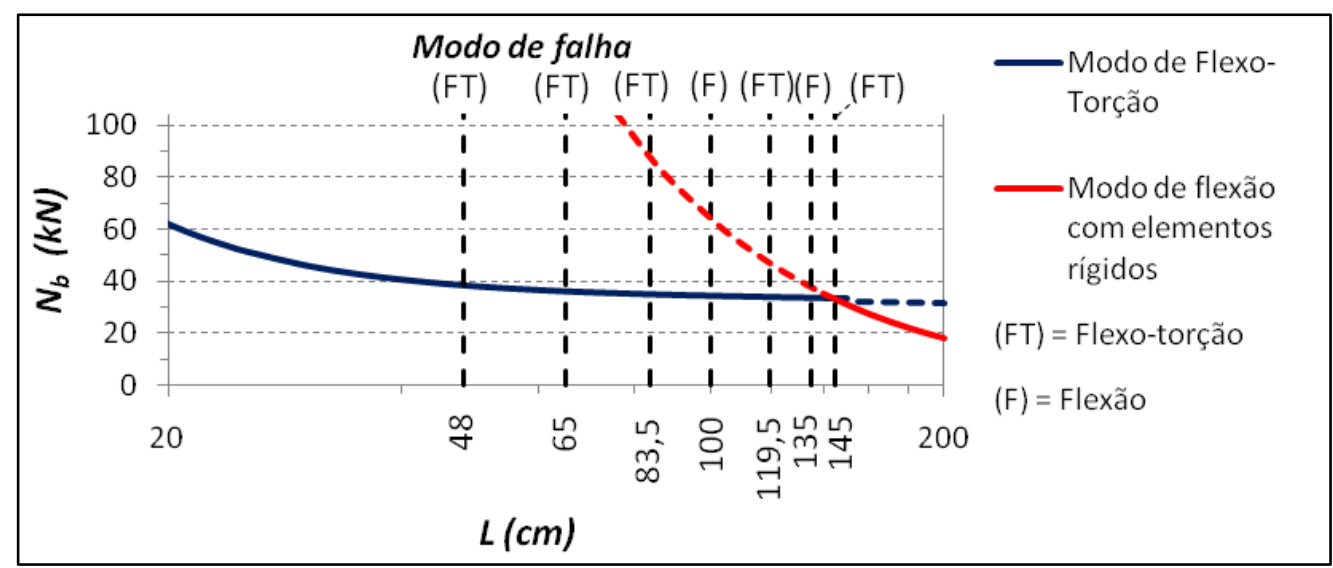

Figura 2.26 - Curvas de flambagem $N_{b} v s L$ e comprimentos de barras ensaiadas por Maia et al. (2008) - L60x2,38-com seus respectivos modos de falha

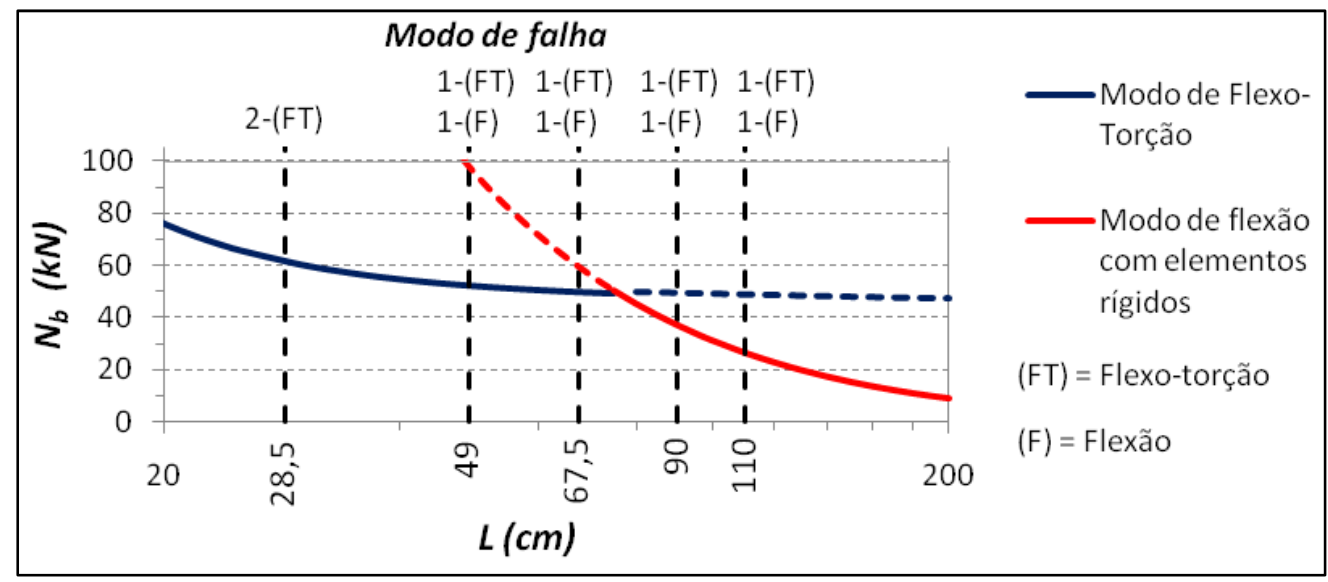

Figura 2.27 - Curvas de flambagem $N_{b}$ vs $L$ e comprimentos de barras ensaiadas por Popovic et al. (1999) - L50x2,50 com seus respectivos modos de falha (dois ensaios para cada comprimento) 
Portanto, analisando-se as figuras 2.26 e 2.27 , nota-se que:

i. Para os ensaios de Maia et al. (2008), duas barras que apresentam modo crítico de flambagem por flexo-torção (cujo comprimento situa-se sobre o platô de flexo-torção, mesmo se considerando os elementos rígidos) possuem deslocamentos característicos de flexão em torno do eixo de menor inércia. Em outras palavras, o efeito do afastamento longitudinal das rótulas não é suficiente para explicar a manifestação do modo "não crítico" de flambagem por flexão, especialmente para o comprimento $L_{c}=100 \mathrm{~cm}$, para o qual a força axial de flambagem elástica do modo de flexão em torno do eixo de menor inércia é cerca de $60 \%$ maior que a respectiva força do modo de flexo-torção;

ii. Nos ensaios de Popovic et al. (1999), têm-se duas barras semelhantes ao caso anterior, no entanto, contrariando as expectativas, têm-se também duas barras com modo crítico de flambagem de flexão em torno do eixo de menor inércia que apresentam deslocamentos característicos do modo de flexo-torção juntamente com alguma flexão em torno do eixo de menor inércia.

Lembrando mais uma vez que o afastamento longitudinal das rótulas pode influenciar o comportamento das barras somente no sentido de se apresentar um modo de flexão quando se espera flexo-torção, contrariamente ao que ocorre com barras ensaiadas por Popovic et al. (1999).

Não obstante, tendo em vista o efeito da excentricidade na aplicação da força (comentado ao final do item 2.1.5) mostrado por Popovic et al. (1999), entende-se que esteja sobre a imperfeição global de flexão uma variável fundamental no comportamento das cantoneiras. Adicionalmente, no item 2.2.3 os efeitos devidos a imperfeição global por torção também são verificados.

\subsubsection{A imperfeição Global de Flexão}

Inicialmente, consideram-se duas distintas situações, (i) a aplicação de uma força com excentricidade (e) sobre uma barra perfeitamente reta (Fig. 2.28.a), e (ii) a barra deslocada segundo seu comprimento na forma senoidal, conforme a Figura 2.28.b, mantendo a aplicação da força sobre o centróide da seção bruta. 


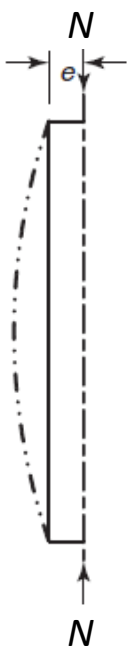

(a)

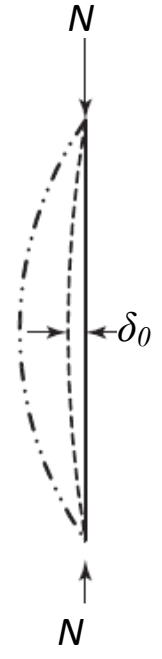

(b)

Figura 2.28 - Diferentes formas de considerar a imperfeição geométrica inicial (global de flexão)

(a) excentricidade na aplicação da força e (b) barra imperfeita (no caso, forma senoidal).

Adaptado de: Galambos e Surovek (2008).

Segundo Galambos e Surovek (2008), já é historicamente aceita e aplicada a idéia de que ambos os casos supracitados conduzem a resultados muito parecidos, e em termos de deslocamentos, duas curvas praticamente sobrepostas são obtidas.

Apenas para ilustrar o fato, optou-se por mostrar a curva da força atuante $(N)$ em função do deslocamento $\left(d_{m}\right)$ para os dois casos de imperfeição relacionados considerando uma cantoneira $L 70 \times 1,50 \mathrm{~mm}$, com comprimento $L_{c}=300 \mathrm{~cm}, L_{r}=0$, e uma excentricidade $(e)$ ou uma imperfeição de flexão $\left(\delta_{0}\right)$ de $0,5 \mathrm{~cm}$ (ambos no mesmo sentido). Com isso, foi realizada uma análise elástica não linear utilizando os mesmos parâmetros e metodologia apresentados no item 2.1.5 deste trabalho.

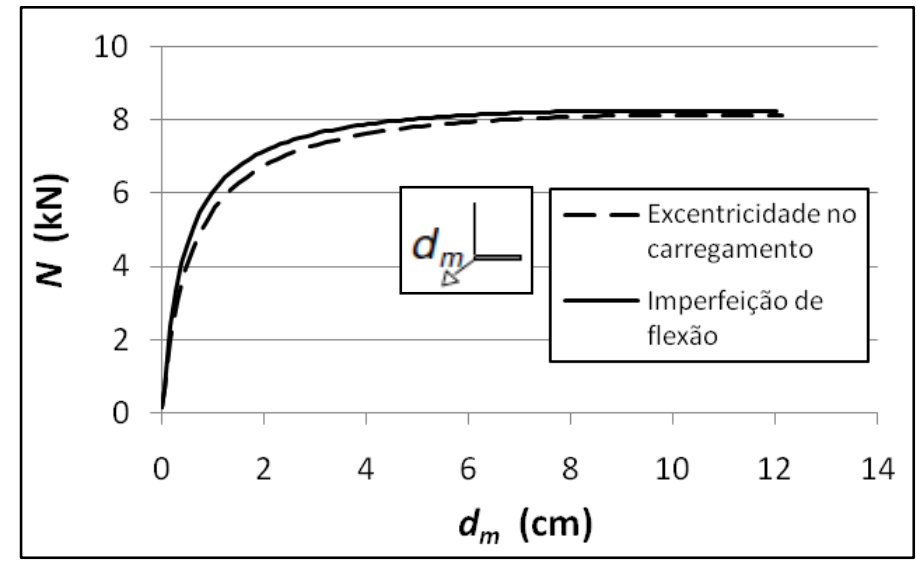

Figura 2.29 - Curvas $N$ vs. $d_{m}$ para cantoneira com excentricidade no carregamento e imperfeição geométrica de flexão 
Como esperado, vê-se na Fig. 2.29 que ambos os casos apresentaram respostas muito parecidas, o que justifica assumir a partir deste ponto, nos estudos numéricos deste trabalho, somente o caso de imperfeição geométrica de flexão, tendo em vista a ocorrência de eventuais dificuldades de convergência em análises não lineares para o caso de excentricidades na aplicação da força.

Assim, mais uma vez com a ajuda do programa comercial ANSYS (SAS 2009), foi elaborada uma série de análises elásticas e geometricamente não lineares, a fim de se determinar as trajetórias de equilíbrio características em cantoneiras sob diferentes condições de imperfeição geométrica de flexão. Para tal, foram modeladas as cantoneiras com elementos finitos de casca (Shell181), ignorando-se os elementos rígidos das extremidades $\left(L_{r}=0\right)$, mas mantendo, ainda, a restrição ao empenamento (secundário) por meio de uma chapa rígida, pela qual foram aplicadas as restrições nodais, de modo a simular a rótula cilíndrica e também a força axial de compressão.

Para o controle da imperfeição de flexão inserida no modelo utilizou-se um fator de amplificação (correção), permitindo corrigir a amplitude dos deslocamentos nodais que são obtidos em uma análise de estabilidade elástica prévia. Este fator de amplificação, além do ajuste da amplitude, permite também, pela simples mudança no sinal, a correção do sentido destes deslocamentos, de modo a se controlar a deformada da barra, ora tendendo a comprimir as bordas livres, ora tendendo a tracioná-las.

A Figura 2.30 ilustra as duas condições de sentido na imperfeição, bem como o ponto de máxima amplitude dos deslocamentos, tomado como parâmetro no controle das análises não lineares.

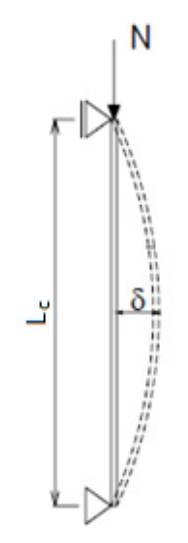

(a)

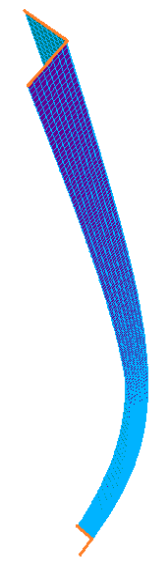

(b)

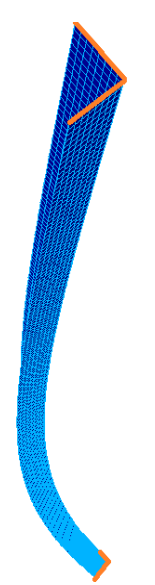

(c)

Figura 2.30 - (a) Esquema de imperfeição global de flexão (em torno do eixo de menor inércia no caso das cantoneiras)

(b) comprimindo, ou (c) tracionando as bordas livres. 
A partir disso, foram definidos os seguintes parâmetros:

(i) Com base em uma análise linear de estabilidade elástica via GBT, conduzida com ajuda do código computacional GBTUL (Bebiano et al. - 2008), para uma cantoneira $L 70 \times 1,50 \mathrm{~mm}$, foram selecionados seis comprimentos $\left(L_{1}, \ldots, L_{6}\right)$, conforme mostra a Fig. 2.31, de modo a se estudar comprimentos ao longo de todo platô característico de flexo-torção, bem como o trecho inicial do ramo descendente, característico do modo de flexão;

(ii) Além disso, Maia et al. (2008) verificaram em seu trabalho que existe uma considerável diferença no comportamento das cantoneiras com ou sem imperfeições de flexão, entretanto, pouca diferença resulta da variação da amplitude desta imperfeição. Assim, baseado nestes resultados, somente uma amplitude (L/1000) foi adotada neste estudo, porém, são analisados ambos os sentidos da mesma (ora tracionando a região da dobra (TD) (Fig. 2.30.b), ora comprimindo-a (CD) (Fig. 2.30.c). Lembrando ainda que nenhuma imperfeição de torção ou flexão em torno do eixo de maior inércia foi inserida nestes modelos.

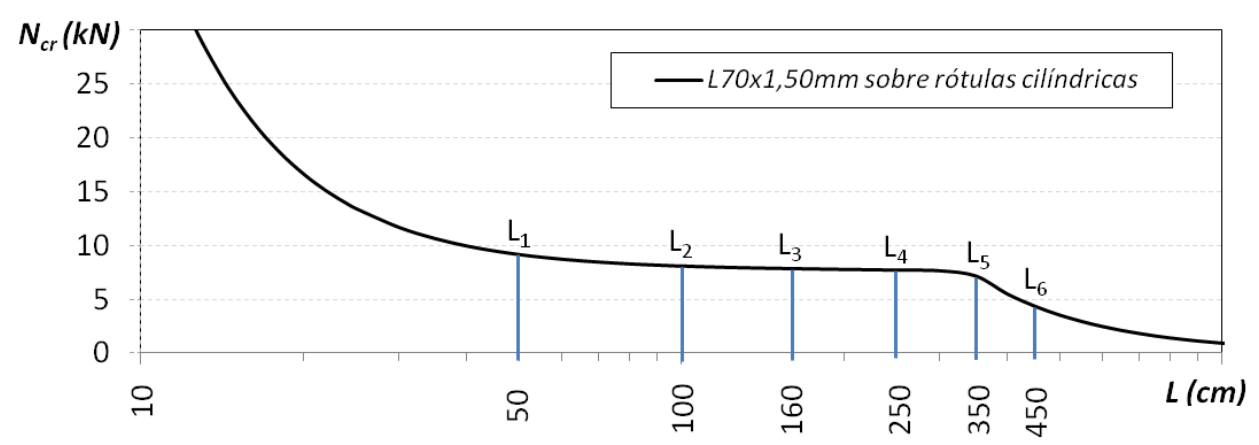

Figura 2.31 - Curva $N_{c r} v s . L$ para cantoneira $L 70 \times 1,50 \mathrm{~mm}$ com rótulas cilíndricas, e comprimentos $\left(L_{c}\right)$ selecionados.

Os resultados obtidos são exibidos na Fig. 2.32, onde se vêem as trajetórias de equilíbrio (somente trecho inferior para algumas curvas) para cada uma das seis barras em ambas as situações de imperfeição de flexão (CD e TD), definidas em função da força axial normalizada $\left(N / N_{c r}\right)$ e do deslocamento $d_{m}$ na metade do comprimento da barra (as trajetórias de equilíbrio em função do giro $(\beta)$ na metade do comprimento não exibiram valores significativos). 


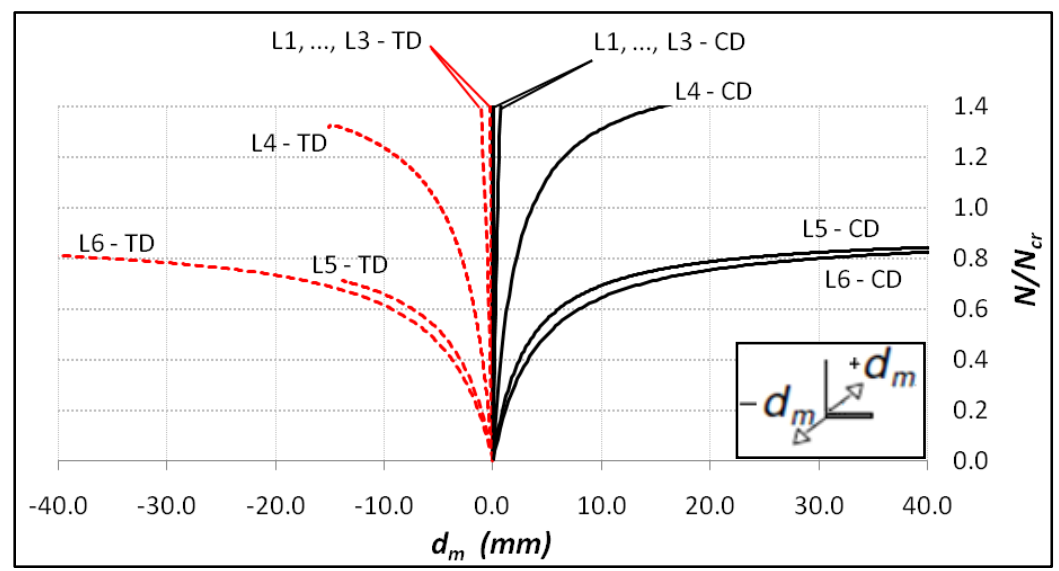

Figura 2.32 - Trajetórias de equilíbrio elástico não linear - Força axial de compressão normalizada $\left(N / N_{c r}\right) v s$. Deslocamento $d_{m}$ - para barras de diversos comprimentos $\left(L_{c}\right)$ e sentido da imperfeição global de flexão alternado.

Com relação às trajetórias de equilíbrio elástico não linear para as barras utilizando somente imperfeições de flexão, repara-se que:

i. Primeiramente, nenhuma barra apresentou rotações de torção, i.e., somente foram verificados deslocamentos típicos do modo global de flexão (no caso de barras longas) e estes associados a deslocamentos de modos locais simétricos (para o caso de barras curtas a intermediárias). Pode-se dizer então, em outras palavras, que a distribuição de tensões permanece simétrica entre as duas abas, não provocando o surgimento de torção por conta do equilíbrio entre as mesmas (hipótese esta que na prática é infactível, tanto geometricamente como fisicamente);

ii. A reserva de resistência das barras nestas condições é consideravelmente maior que no caso de haver imperfeições de torção. Além disso, sem a consideração da não linearidade do material, o comportamento das barras praticamente não se altera com a mudança no sentido da imperfeição (exceto por uma maior dificuldade de convergência numérica no caso de tração na região da dobra, como se vê nas curvas das barras L5-TD e L4-TD);

iii. Por fim, para ambos os casos de imperfeição nota-se também que, a partir do comprimento $L_{4}$, que já se situa próximo da região final do platô da curva $N_{c r} x L$, a reserva de resistência característica de cada barra diminui bruscamente, até estabilizar com um comportamento mais bem definido na região do modo crítico de flexão $\left(L_{5}\right.$ e $\left.L_{6}\right)$. 


\subsubsection{Comportamento Elasto-plástico de Cantoneiras sob Diferentes Condições de} Imperfeição Global de Flexão

Conforme apresentado na análise anterior, fica claro que a imperfeição global por torção deve ser inserida nas análises para que se obtenha uma condição mais realista de comportamento. Portanto, já buscando amplitudes de imperfeições compatíveis com aquelas encontradas experimentalmente (e.g., Popovic et al. (1999), Young (2004), e Chodraui et al. (2006)), adotou-se, além das imperfeições globais de flexão de $L / 1000$, uma imperfeição global por torção com amplitude ${ }^{1}$ de $(0,64 \cdot t)$, onde $t$ é a espessura da aba da cantoneira.

Ademais, com a intenção de se verificar a resposta da cantoneira aos diferentes panoramas de tensões provocados pela mudança no sentido da imperfeição de flexão, também a não linearidade material passa a ser contabilizada nas análises por meio de um diagrama multilinear de Tensão x Deformação (Fig. 2.33), o qual representa aqui o mesmo material (com valores corrigidos pelo efeito da estricção dos corpos de prova) utilizado no programa experimental deste trabalho, descrito no item 3.

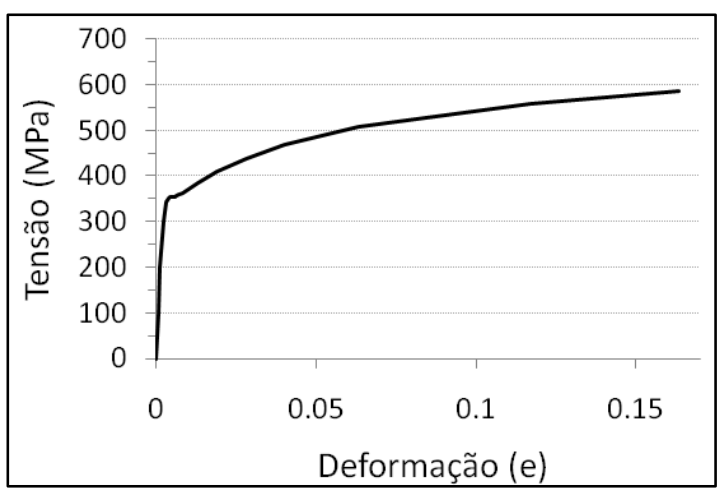

Figura 2.33 - Diagrama Tensão vs. Deformação utilizado (mesmo material da etapa experimental deste trabalho).

Entretanto, vale comentar que, com exceção da barra de comprimento L1, todas as demais apresentaram exatamente a mesma resposta entre as análises elásticas e as análises com não linearidade física. Ou seja, o mecanismo de falha da cantoneira foi puramente devido a efeitos geométricos. Os resultados utilizados nas análises para a barra de comprimento L1, apresentados a seguir, levam em consideração a plasticidade do material.

\footnotetext{
1 A amplitude da imperfeição global de torção de $(0,64 \cdot t)$ é baseada nos trabalhos de Chodraui et al. (2006) e Maia et al. (2008), que, por sua vez, baseados em um trabalho de Schafer e Peköz (1998), afirmam ser uma boa medida na obtenção de resultados numéricos em comparação com experimentais diversos.
} 
Por conseguinte, para facilitar a visualização dos resultados obtidos, as trajetórias de equilíbrio não linear são separadas por comprimento de barra $\left(L_{c}\right)$, sendo exibidas nas figuras 2.34 a 2.39 as curvas de deslocamento $\left(d_{m}\right)$ e também de giro $(\beta)$ em função da força axial de compressão normalizada $\left(N / N_{c r}\right)$, onde $N_{c r}$ é a força axial de flambagem elástica para a barra sem imperfeição.

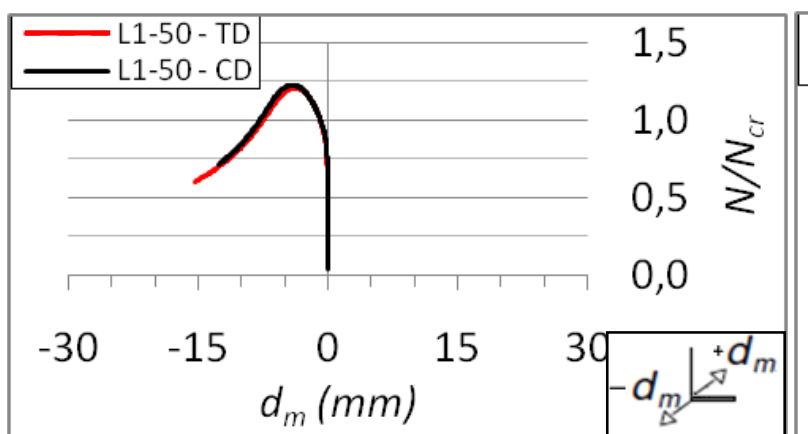

(a)

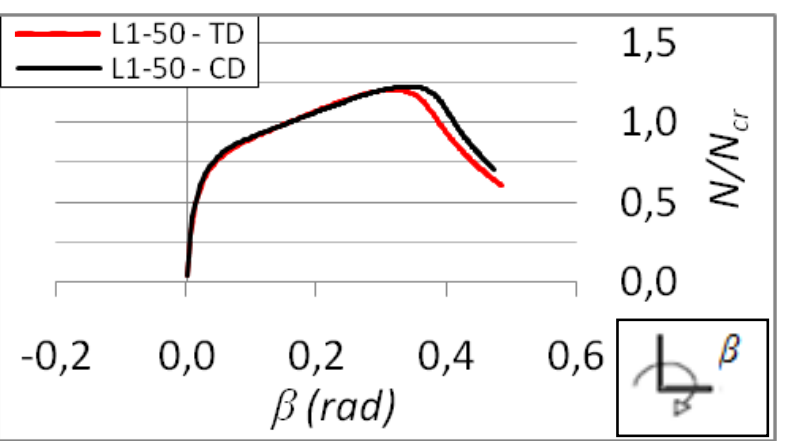

(b)

Figura 2.34 - Trajetórias normalizadas $\left(N / N_{c r}\right)$ em função do deslocamento $d_{m}$ (a), e do giro $\beta$ (b), para as duas condições de imperfeição de flexão, TD (Tração na dobra) e CD (Compressão na dobra), na barra $L_{1}\left(L_{c}=50 \mathrm{~cm}\right)$.

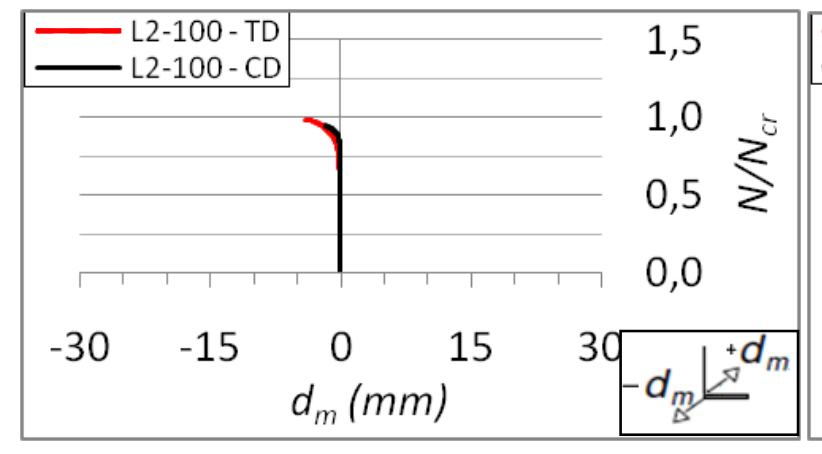

(a)

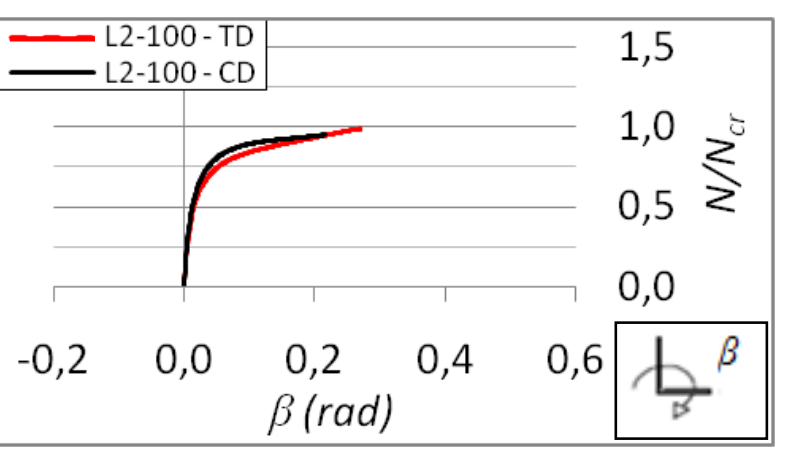

(b)

Figura 2.35 - Trajetórias normalizadas $\left(N / N_{c r}\right)$ em função do deslocamento $d_{m}(\mathrm{a})$, e do giro $\beta(\mathrm{b})$, para as duas condições de imperfeição de flexão, TD (Tração na dobra) e CD (Compressão na dobra), na barra $L_{2}\left(L_{c}=100 \mathrm{~cm}\right)$.

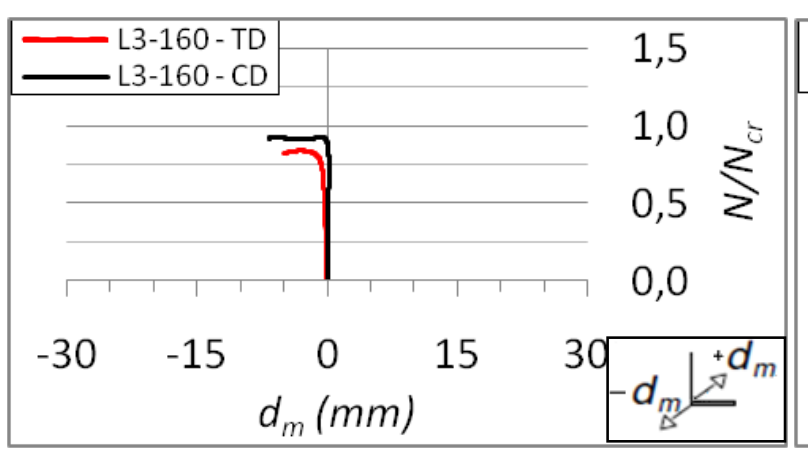

(a)

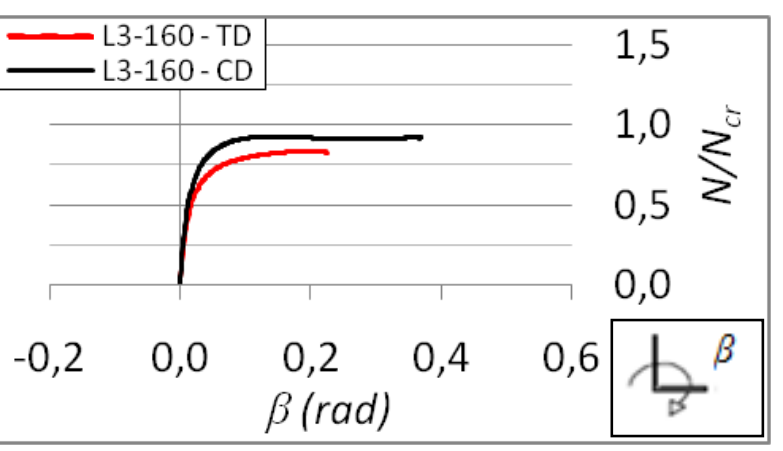

(b)

Figura 2.36 - Trajetórias normalizadas $\left(N / N_{c r}\right)$ em função do deslocamento $d_{m}(\mathrm{a})$, e do giro $\beta$ (b), para as duas condições de imperfeição de flexão, TD (Tração na dobra) e CD (Compressão na dobra), na barra $L_{3}\left(L_{c}=160 \mathrm{~cm}\right)$. 


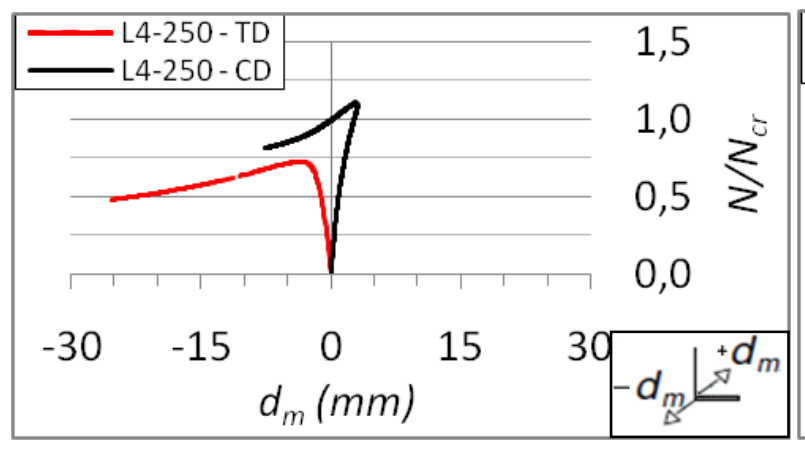

(a)

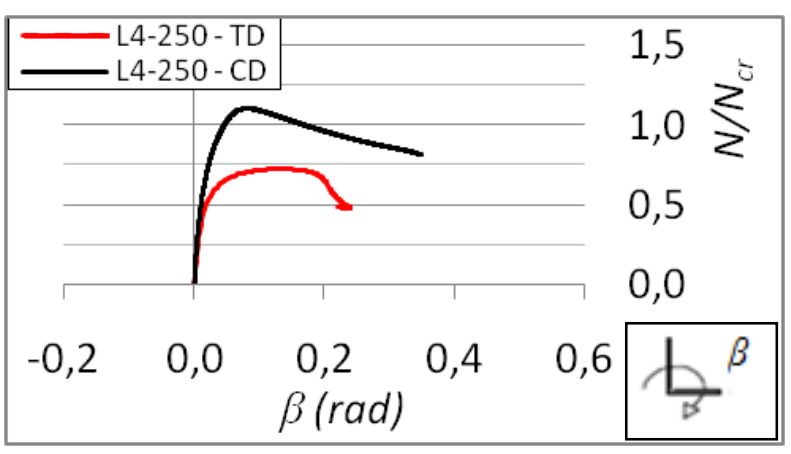

(b)

Figura 2.37 - Trajetórias normalizadas ( $N / N_{c r}$ ) em função do deslocamento $d_{m}(\mathrm{a})$, e do giro $\beta$ (b), para as duas condições de imperfeição de flexão, TD (Tração na dobra) e CD (Compressão na dobra), na barra $L_{4}\left(L_{c}=250 \mathrm{~cm}\right)$.

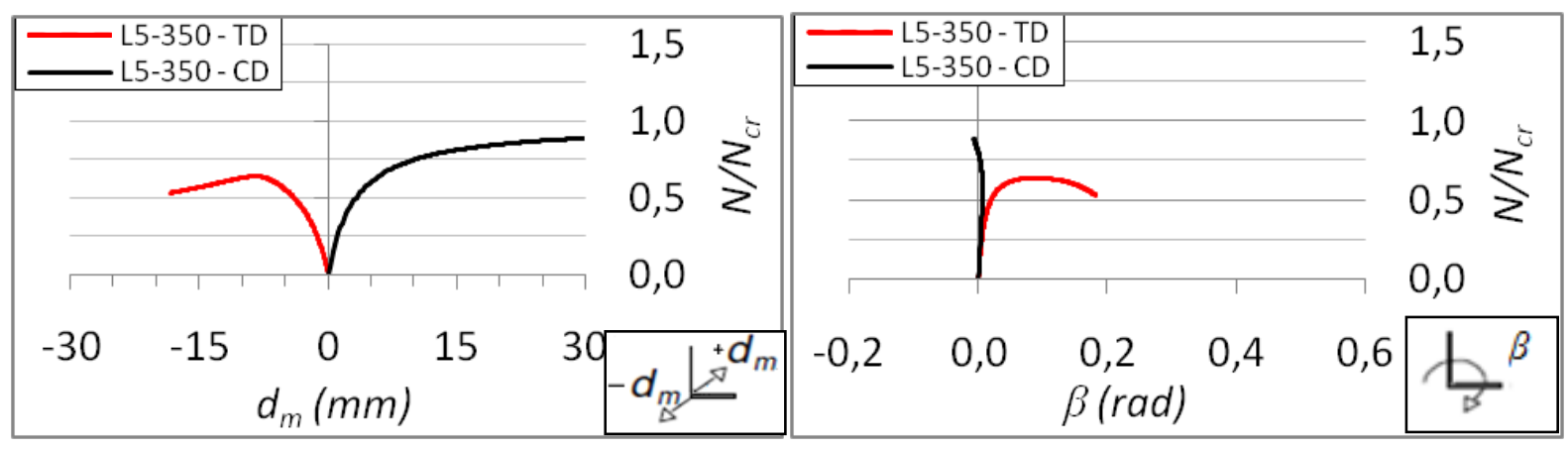

(a)

(b)

Figura 2.38 - Trajetórias normalizadas $\left(N / N_{c r}\right)$ em função do deslocamento $d_{m}(\mathrm{a})$, e do giro $\beta$ (b), para as duas condições de imperfeição de flexão, TD (Tração na dobra) e CD (Compressão na dobra), na barra $L_{5}\left(L_{c}=350 \mathrm{~cm}\right)$.

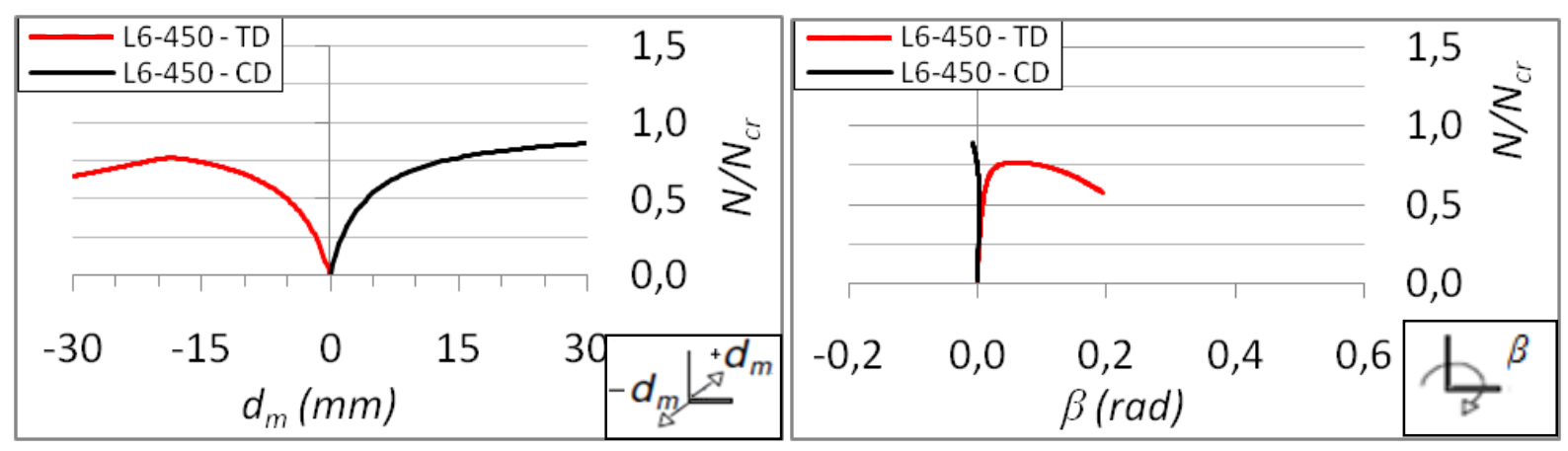

(a)

(b)

Figura 2.39 - Trajetórias normalizadas ( $N / N_{c r}$ ) em função do deslocamento $d_{m}(\mathrm{a})$, e do giro $\beta$ (b), para as duas condições de imperfeição de flexão, TD (Tração na dobra) e CD (Compressão na dobra), na barra $L_{6}\left(L_{c}=450 \mathrm{~cm}\right)$.

Com os resultados obtidos, permite-se fazer as seguintes considerações:

i. Primeiramente, todas as barras cuja imperfeição de flexão provoca compressão na região da dobra apresentaram força axial de compressão resistente igual ou superior a da barra cuja imperfeição provoca tração na mesma região. Em outras palavras, pode-se entender que a imperfeição de flexão CD conduz a uma condição mais estável; 
ii. Boa parte deste comportamento se deve à redução da excentricidade entre a linha de ação da força aplicada e a posição do centróide efetivo da seção transversal, o qual, conforme apresentado no Cap. 2 desta dissertação, se desloca no sentido "das bordas livres para a região da dobra" por conta dos efeitos causados pela torção (Stowell, 1951). Além disso, é importante mencionar que as trajetórias mostradas anteriormente não contabilizam os deslocamentos das imperfeições geométricas inseridas, ou seja, são a partir da barra com imperfeições;

iii. No caso das três barras menores $\left(L_{1}\right.$ a $\left.L_{3}\right)$, ambas as condições de imperfeição apresentam um comportamento muito semelhante, conforme ilustram as Figuras 2.40 a 2.42 nas configurações deformadas para o ponto de força máxima de compressão. Os gráficos das Figuras 2.34 a 2.36 também deixam claro os deslocamentos característicos do modo de flexo-torção, dada uma determinada rotação $\beta$ na metade do comprimento (cuja magnitude pouco varia), juntamente com deslocamentos $d_{m}$ muito pequenos;

iv. Uma pequena diferença de comportamento em função da condição de imperfeição se nota a partir do comprimento $L_{3}$, onde, apesar de apresentar as mesmas características gerais para $d_{m}$ e $\beta$ das barras menores, conforme ilustram os gráficos (a) e (b) da Fig. 2.36, respectivamente, e também as Figuras 2.42 (a) e (b), o caso de imperfeição CD conduz a uma força axial de compressão resistente superior, demonstrando que já nesta faixa de comprimentos (região central do platô característico de flexo-torção - vide Fig. 2.31) a imperfeição de flexão (no caso, com a amplitude de $L / 1000=1,6 \mathrm{~mm}$ ) contribui com uma condição estável até um nível superior de tensões (cerca de 10\%);

v. No caso da barra de comprimento $L_{4}$ já se apresenta um comportamento mais interessante. Pelo seu comprimento se posicionar em uma região relativamente ${ }^{1}$ próxima do final do platô de flexo-torção, é possível identificar mais claramente a ocorrência dos dois modos globais (flexo-torção e flexão em torno do eixo de

\footnotetext{
1 Apesar da Figura 2.27 mostrar graficamente uma proximidade entre o comprimento $L_{4}$ e o comprimento relativo à mudança no modo crítico de flambagem de flexo-torção para flexão, este último modo apresenta, no ponto $L_{4}$, uma força axial de flambagem elástica cerca de $75 \%$ superior à força do primeiro modo (flexo-torção). É interessante lembrar também que é comentado no início do item 2.2 sobre a ocorrência, em um ensaio experimental de Maia et al. (2008), de um modo de falha exibindo deslocamentos de flexão, estando o comprimento da barra em um trecho de flexo-torção, e sendo a diferença entre as forças axiais de flambagem, neste caso, de $60 \%$.
} 
menor inércia). O gráfico da Figura 2.37 (a) ilustra, para o caso de imperfeição provocando tração na dobra (TD), um deslocamento $d_{m}$ crescente (no sentido "negativo", i.e. comprimindo as bordas livres) até a força máxima ("peak load"), que é continuamente acompanhado pelo giro $\beta$ na metade da barra, conforme ilustra o gráfico da Figura 2.37 (b), desta forma, culminando em uma deformada com deslocamentos típicos de flexo-torção e flexão em torno do eixo de menor inércia (Fig.2.43.b);

vi. Ainda para a mesma barra $L_{4}$, no caso de imperfeição de flexão do tipo $C D$, repara-se que, antes de atingir a força máxima, o deslocamento $d_{m}$ (Fig. 2.38 (a)) apresenta pequenas amplitudes (no máximo $d_{m}=3 \mathrm{~mm}$, para este caso), assim como a trajetória do giro $\beta$ (Fig. 2.38 (b)). Contudo, o pico de aplicação da força axial de compressão é marcado por uma mudança brusca no sentido do deslocamento $d_{m}$, passando o giro $\beta$, neste ponto, a crescer em uma taxa mais elevada, entretanto, sem mais reservas de resistência, caracterizando um trecho descendente na trajetória de equilíbrio (desta forma a barra apresenta uma deformada no ponto de força máxima de compressão (Fig. 2.43.a), e outra para pontos da trajetória descendente "pós-pico");

vii. Por outro lado, mas não menos interessante, tem-se o caso das barras $L_{5}$ e $L_{6}$, que apresentam modo crítico do flambagem elástica por flexão em torno do eixo de menor inércia. Para estas, nota-se um comportamento que, em função da imperfeição de flexão, é muito parecido com o caso das barras de comprimentos menores. ( $\mathrm{vi}_{1}$ ) Como se vê em ambos os gráficos das Figuras 2.38 e 2.39, as condições de imperfeição $C D$ e TD determinam claramente o modo de instabilidade da barra, neste caso, bem característico desde o início da aplicação da força. $\left(v_{2}\right)$ As barras com imperfeição de flexão TD apresentam deslocamentos bem característicos de flexo-torção, com baixos valores de $d_{m}$, e giro na metade do comprimento $\beta$ considerável. ( $\left(\mathrm{vi}_{3}\right)$ Já as barras com imperfeição $\mathrm{CD}$ apresentam somente deslocamentos de flexão no mesmo sentido da imperfeição, enquanto o giro $\beta$ não apresenta amplitudes maiores do que a própria imperfeição de torção inserida inicialmente. As figuras 2.44 e 2.45 ilustram a configuração deformada das referidas barras para a força máxima de compressão resistente. 


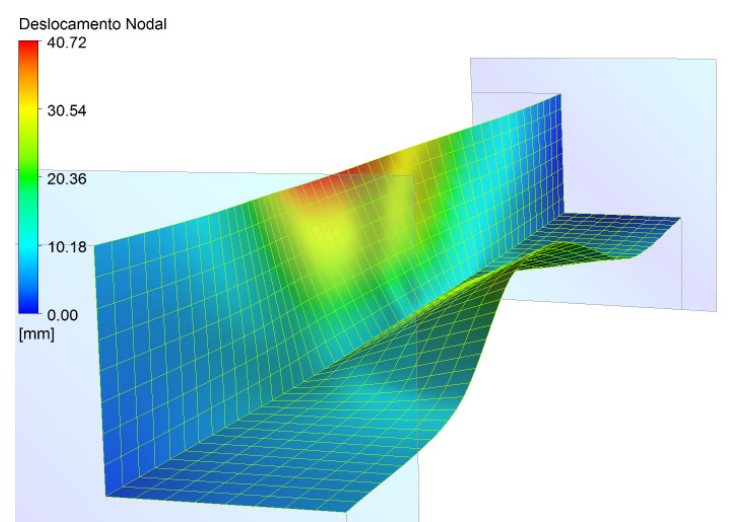

(a)

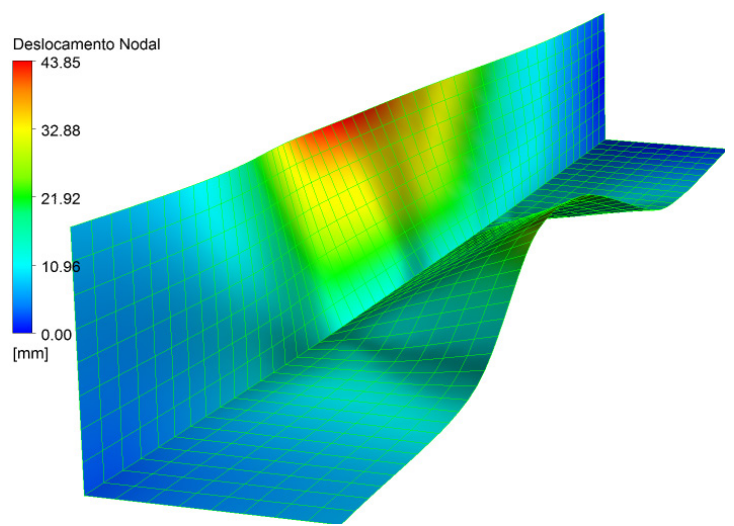

(b)

Figura 2.40 - Deformada no ponto limite para barra $L_{1}-($ a) $C D$ - Compressão na dobra; (b) TD - Tração na dobra.

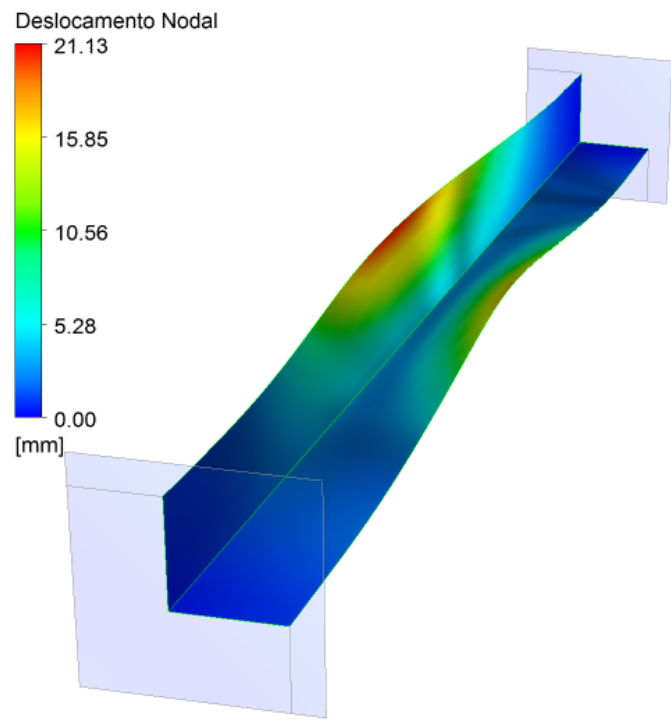

(a)

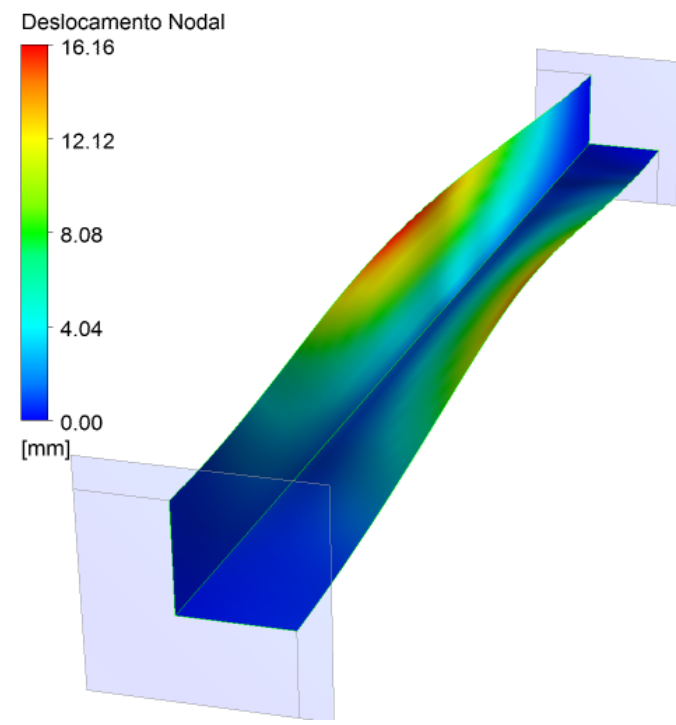

(b)

Figura 2.41 - Deformada no ponto limite para barra $L_{2}$ - (a) CD - Compressão na dobra; (b) TD - Tração na dobra.

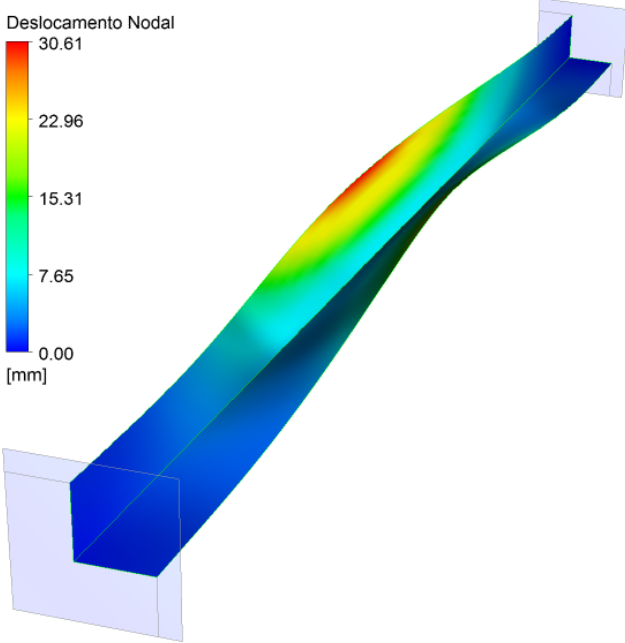

(a)

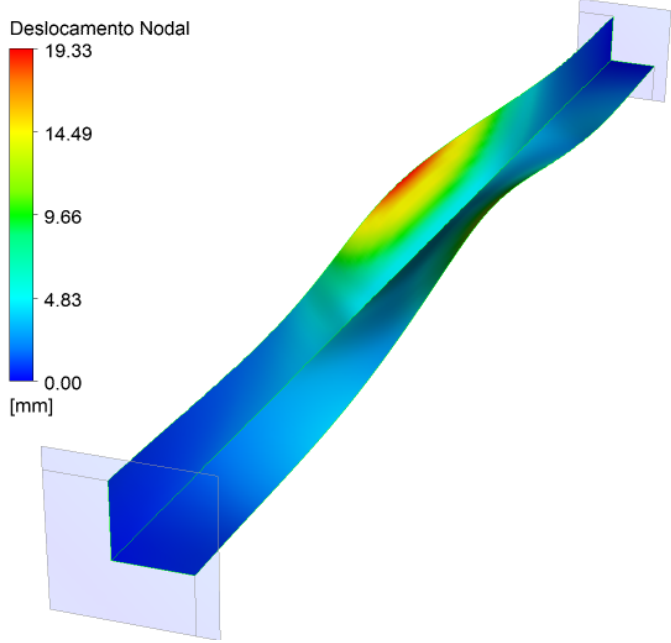

(b)

Figura 2.42 - Deformada no ponto limite para barra $L_{3}-$ (a) CD - Compressão na dobra; (b) TD - Tração na dobra. 


\section{3}

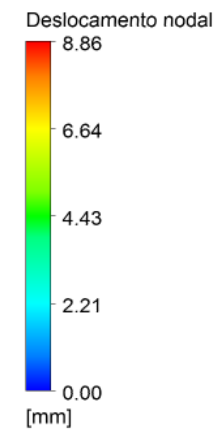

(a)

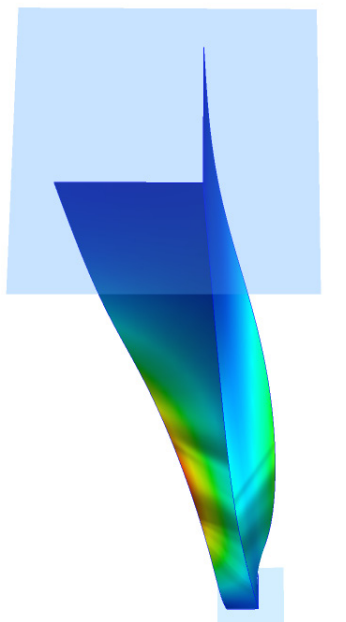

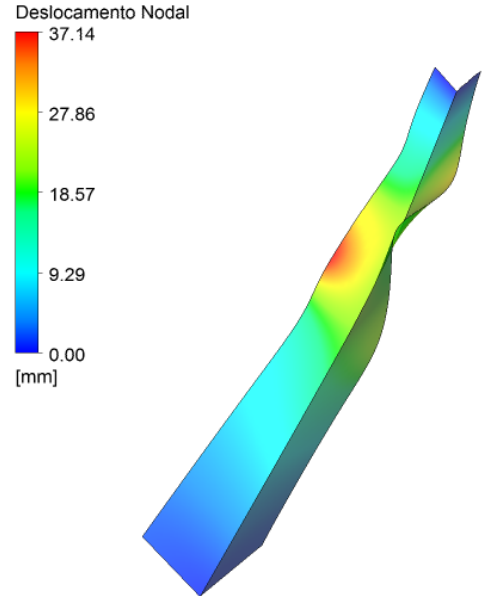

(b)

Figura 2.43 - Deformada no ponto limite para barra $L_{4}-(a) C D$ - Compressão na dobra; (b) TD - Tração na dobra.

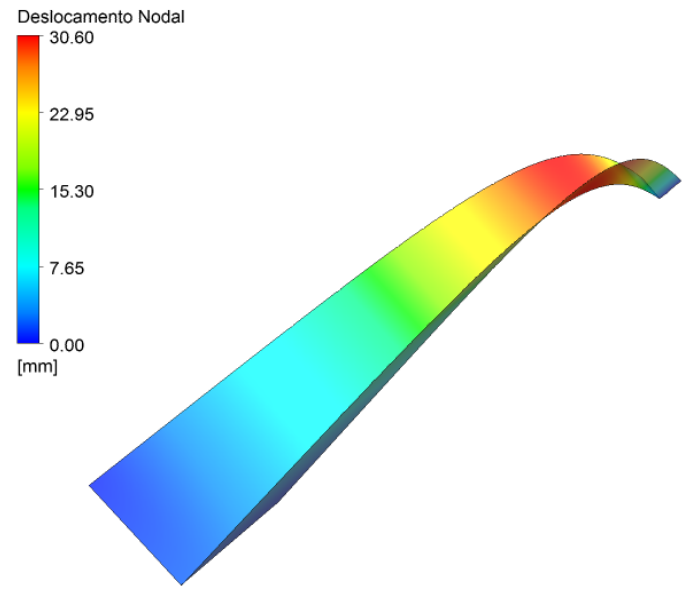

(a)

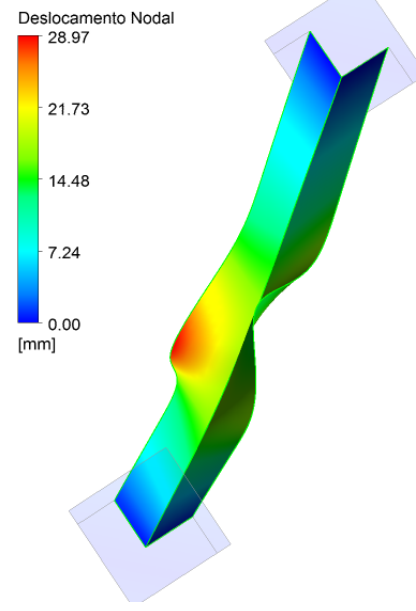

(b)

Figura 2.44 - Deformada no ponto limite para barra $L_{5}-$ (a) CD - Compressão na dobra; (b) TD - Tração na dobra.

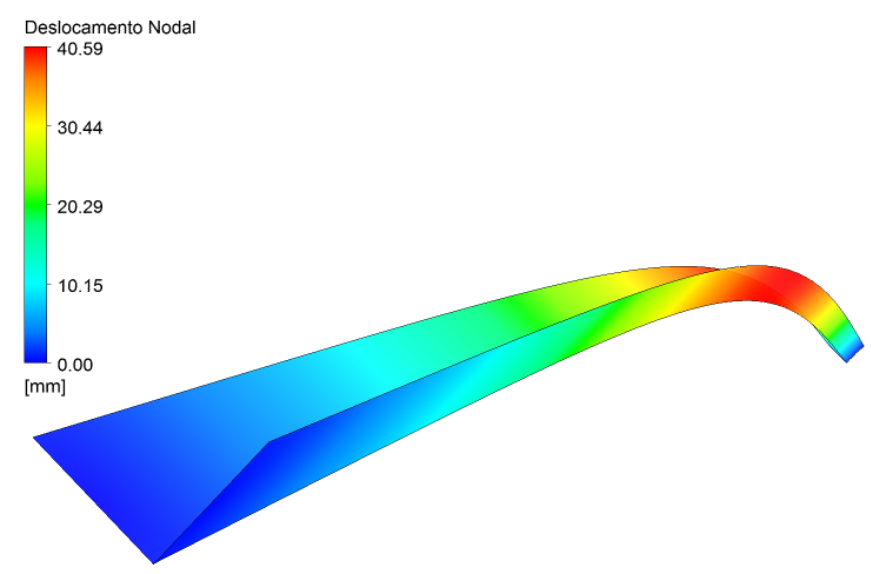

(a)

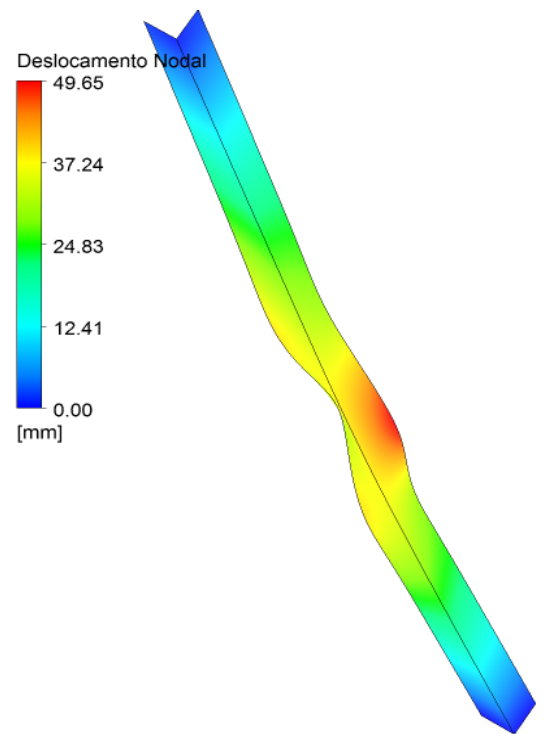

(b)

Figura 2.45 - Deformada no ponto limite para barra $L_{6}-$ (a) CD - Compressão na dobra; (b) TD - Tração na dobra. 
Como se pôde perceber até aqui, existe uma forte influência da imperfeição de flexão sobre o comportamento das cantoneiras, podendo esta imperfeição ser responsável direta pelo modo de instabilidade da barra, desde que o seu comprimento esteja, para a curva típica $N_{c r}$ vs. $L_{c}$, entre a região intermediária do platô de flexo-torção e o trecho inicial do ramo descendente de flexão. Contudo, é claro que tais limites não podem ser assim generalizados, em função do diferente comportamento entre cantoneiras de abas com diferentes esbeltezes.

Logo, para se ter uma idéia do efeito das imperfeições de flexão sobre cantoneiras com abas mais compactas, uma nova série de estudos numéricos foi elaborada, tal como a anterior, mas com a seção transversal $450 \times 3,00 \mathrm{~mm}$. Comparativamente à seção $L 70 \times 1,50 \mathrm{~mm}$ analisada anteriormente, cuja relação $b / t$ das abas é de aproximadamente 45 , tem-se uma seção transversal muito mais compacta, com uma relação $b / t$ de aproximadamente 15 , entretanto, em termos de momento de inércia, tem-se para a nova seção uma redução de aproximadamente $30 \%$.

Sendo assim, em termos de força axial resistente de compressão $\left(N_{c, R}\right)$ das barras analisadas, são apresentados os resultados juntamente ${ }^{1}$ com a curva $N_{c r} v s$. $L_{c}$ resultante da análise elástica de estabilidade (barra sem imperfeições). A Figura 2.46 apresenta estes resultados para o caso da seção $L 70 \times 1,50 \mathrm{~mm}$ estudada anteriormente, com algumas análises adicionais de barras com comprimentos pequenos a intermediários (a saber: 35; 60; 120; 200; e $300 \mathrm{~cm}$, além daquelas marcadas pela Fig. 2.31), enquanto a Figura 2.47 apresenta os resultados para o caso da seção $L 50 \times 3,00 \mathrm{~mm}$, cujos comprimentos $L_{c}$ analisados foram: $25 ; 50$; 70; 80; 90; e $130 \mathrm{~cm}$. As imperfeições geométricas iniciais consideradas são as mesmas das análises anteriores: imperfeição de flexão de $L / 1000$ nos sentidos TD (tração na dobra) e CD (compressão na dobra), e imperfeição global por torção de 0,64·t.

Apenas a título de ilustração, e para mostrar um pouco da interação modal ocorrida no caso da cantoneira $550 \times 3,00 \mathrm{~mm}$, as Figuras 2.48 e 2.49 apresentam, para as diferentes condições de imperfeição analisadas, a configuração deformada da barra de comprimento $L_{c}=80 \mathrm{~cm}$ no ponto de força máxima de compressão ("peak load").

\footnotetext{
${ }^{1}$ A sobreposição dos resultados de força máxima resistente $\left(N_{c, R}\right)$ com a curva $N_{c r} x L_{c}$, apenas é feita para ilustrar a posição dos comprimentos das barras analisadas em relação à curva.
} 


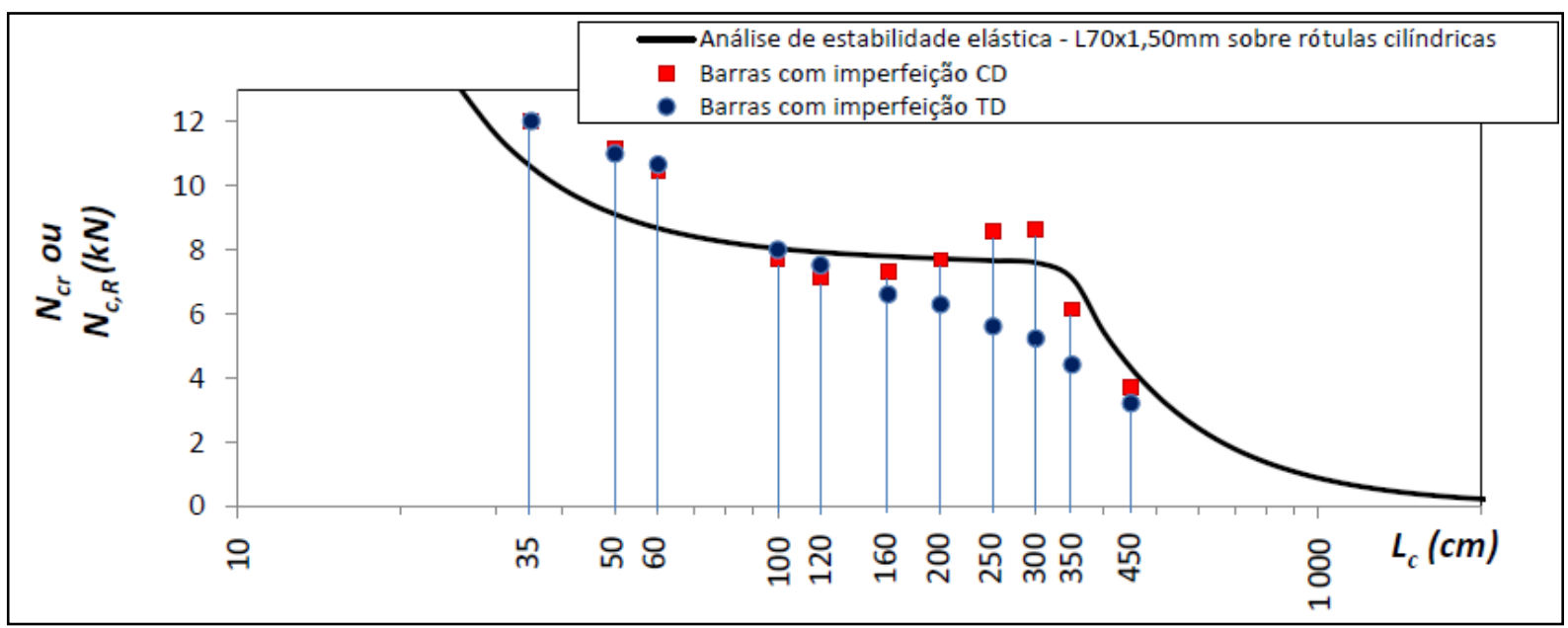

Figura 2.46-Curva $N_{c r}$ vs. L para cantoneira $L 70 \times 1,50 \mathrm{~mm}$ com rótulas cilíndricas, e resultados de força axial de compressão resistente obtidos em análise não linear física e geométrica sob diferentes condições de imperfeição.

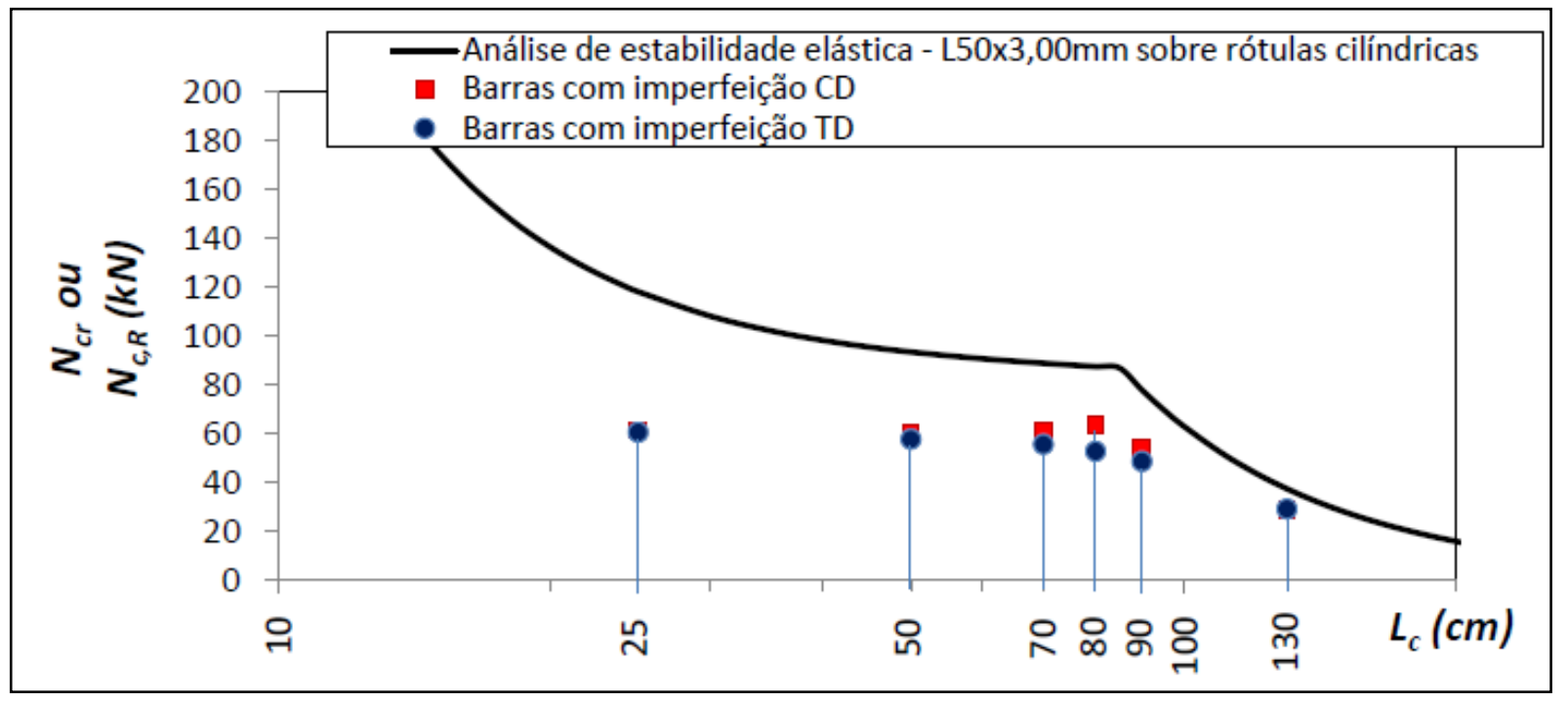

Figura 2.47-Curva $N_{c r}$ vs. L para cantoneira $L 50 \times 3,00 \mathrm{~mm}$ com rótulas cilíndricas, e resultados de força axial de compressão resistente obtidos em análise não linear física e geométrica sob diferentes condições de imperfeição.

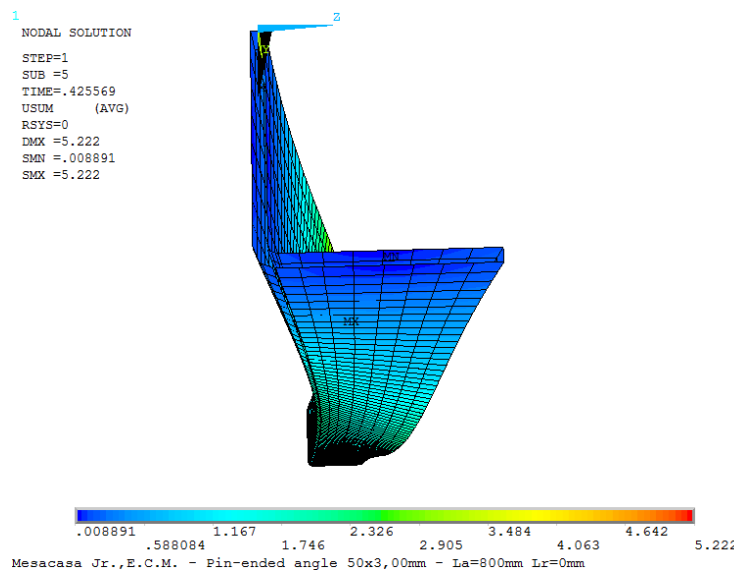

(a)

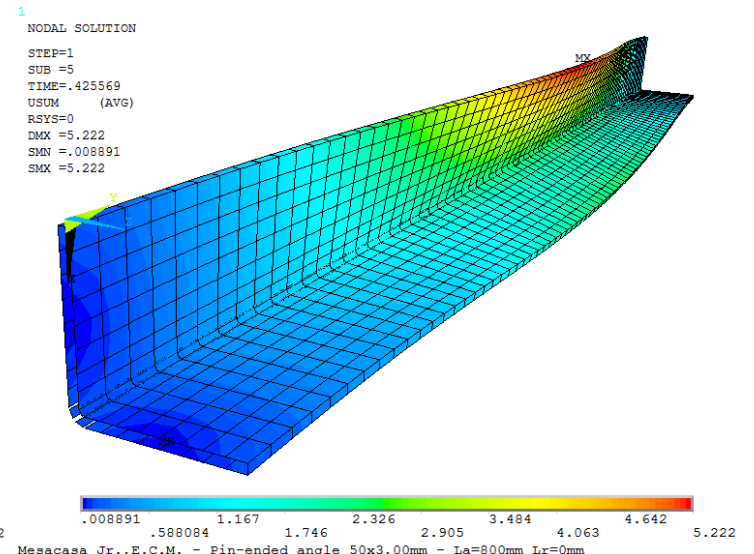

(b)

Figura 2.48 - Configuração deformada para carregamento máximo no perfil $450 \times 3,00 \mathrm{~mm}$, comprimento $L_{c}=80 \mathrm{~cm}$, e imperfeição de flexão tipo $C D$ (compressão na dobra). 


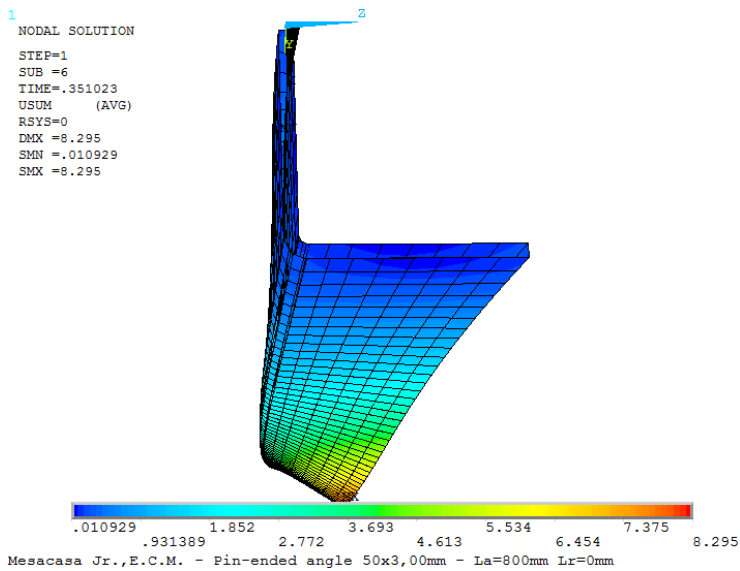

(a)

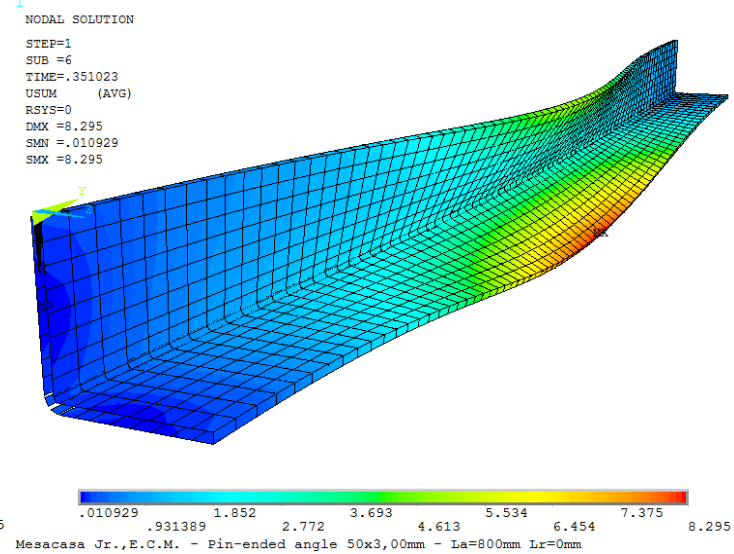

(b)

Figura 2.49 - Configuração deformada para carregamento máximo no perfil $L 50 \times 3,00 \mathrm{~mm}$, comprimento $L_{c}=80 \mathrm{~cm}$, e imperfeição de flexão tipo TD (tração na dobra).

Com base nos resultados apresentados pelos gráficos das Figuras 2.46 e 2.47 é possível listar as seguintes constatações:

i. Em termos de força axial de compressão resistente $\left(N_{c, R}\right)$, somente verifica-se diferença significativa entre barras de mesmo comprimento $L_{c}$ e diferentes sentidos da imperfeição global de flexão, no caso de comprimentos próximos da transição entre o modo crítico de flexo-torção e o modo crítico de flexão. No caso da seção transversal $L 70 \times 1,50 \mathrm{~mm}$, esta "região de transição" está compreendida aproximadamente entre os comprimentos 160 e $450 \mathrm{~cm}$, enquanto no caso da seção transversal $L 50 \times 3,00 \mathrm{~mm}$ esta região se dá somente entre 70 e $90 \mathrm{~cm}$;

ii. Para o caso da cantoneira $L 70 \times 1,50 \mathrm{~mm}$, a diferença na força axial de compressão resistente entre um caso e outro de sentido da imperfeição chega a ser de $65 \%$ para $L_{c}=300 \mathrm{~cm}$. Para esta barra, dois modos globais são claramente identificados na configuração deformada, sendo que o caso de maior força resistente apresenta flexão em torno do eixo de menor inércia no sentido da imperfeição aplicada (CD), e o de menor força resistente apresenta flexo-torção com flexão em torno do eixo de menor inércia tendendo a comprimir as bordas livres;

iii. Os resultados obtidos para a cantoneira $550 \times 3,00 \mathrm{~mm}$ deixam claro a existência de uma interação modal semelhante a da seção mais esbelta (vide Figuras 2.48 e 2.49), embora neste caso não haja, no ponto de máxima diferença da força axial de compressão resistente, o surgimento de dois modos globais completamente 
distintos (verifica-se apenas os deslocamentos característicos de flexão em sentidos opostos, conforme sentido da imperfeição aplicada, mas os deslocamentos devidos à torção se fazem sempre presentes). Assim, os efeitos decorrentes do sentido da imperfeição de flexão são menos notáveis quanto mais compacta for a seção transversal da cantoneira;

iv. Por fim, conforme se nota nos resultados para ambas as seções transversais, o comprimento que demarca aproximadamente a transição entre os modos críticos de flambagem global por flexo-torção e por flexão, apresenta também a máxima sensibilidade ao sentido da imperfeição global de flexão, no entanto, uma faixa de comprimentos maior é afetada sobre o platô de flexo-torção do que sobre o trecho descendente de flexão (a rigor, em termos de força axial de compressão resistente, todos os comprimentos menores que aquele da transição entre os modos críticos de flambagem são afetados pela imperfeição de flexão).

\subsubsection{Efeito da Amplitude da Imperfeição Global de Torção com Diferentes} Imperfeições de Flexão

Complementarmente, foi verificado também o efeito da amplitude da imperfeição global de torção, a qual, conforme visto no final do item 2.2.1, é fundamental para que as análises numéricas possam caracterizar os fenômenos ocorridos na prática, até porque seria ilusório admitir uma distribuição de tensões perfeitamente simétrica entre as abas da cantoneira devido à total ausência de imperfeições de torção.

Assim, foram realizados alguns testes, variando a amplitude da imperfeição de torção de 0,64·t (amplitude utilizada nas análises do item 2.2.2 deste trabalho) até 0,05·t.

Os resultados obtidos, em geral, não apresentaram diferenças significativas em termos de força axial de compressão resistente, deslocamentos ou trajetórias de equilíbrio.

Apenas para ilustrar tal verificação, os gráficos das Figuras 2.50 e 2.51 apresentam as trajetórias de equilíbrio em função do deslocamento $d_{m}$ e do giro $\beta$ para a força axial de compressão normalizada $\left(N / N_{c r}\right)$ em dois casos de imperfeição local aplicada a barra $L_{5}$ estudada no item 2.2.2. A primeira imperfeição verificada é de 0,20·t (Fig. 2.50 (a) e (b)), enquanto a segunda é de $0,05 \cdot t$ (Fig. 2.51 (a) e (b)). 


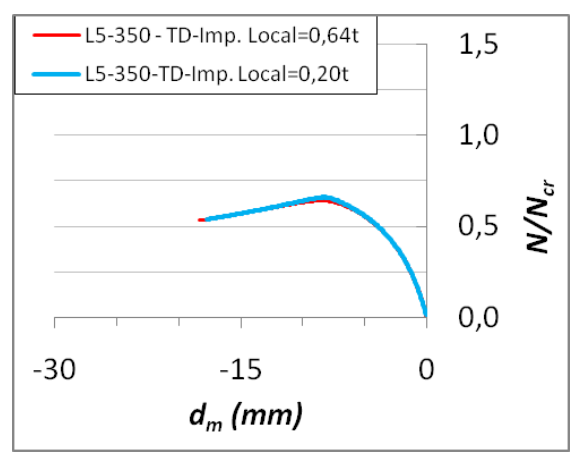

(a)

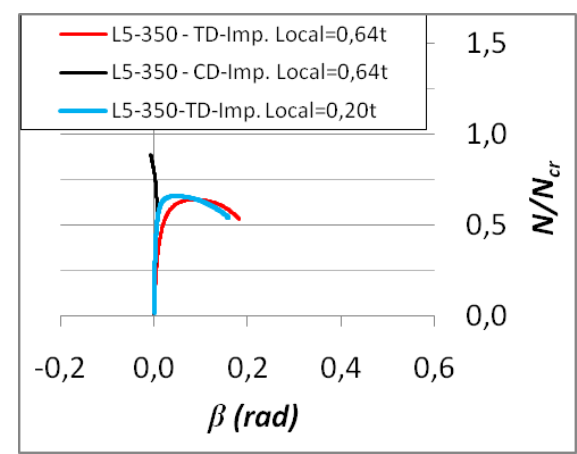

(b)

Figura 2.50 - Trajetórias normalizadas $\left(N / N_{c r}\right)$ em função do deslocamento $d_{m}(\mathrm{a})$, e do giro $\beta(\mathrm{b})$, para duas condições de imperfeição de torção, $0,64 \cdot t$ e $0,20 \cdot t$, na barra $L_{5}\left(L_{c}=350 \mathrm{~cm}\right)$.

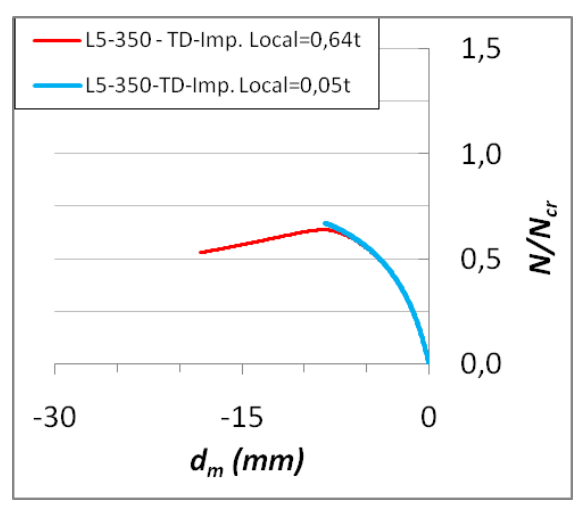

(a)

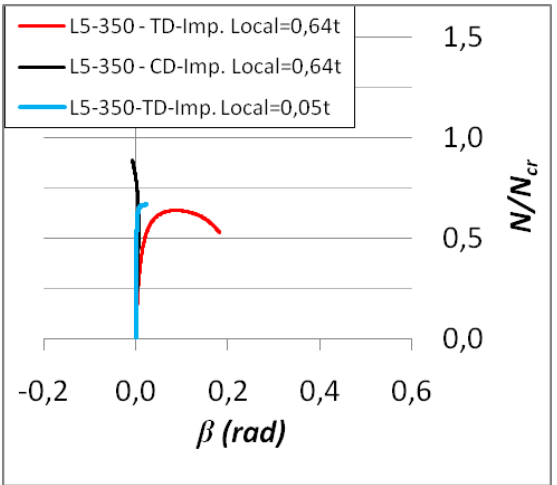

(b)

Figura 2.51 - Trajetórias normalizadas $\left(N / N_{c r}\right)$ em função do deslocamento $d_{m}(\mathrm{a})$, e do giro $\beta(\mathrm{b})$, para duas condições de imperfeição de torção, $0,64 \cdot t$ e $0,05 \cdot t$, na barra $L_{5}\left(L_{c}=350 \mathrm{~cm}\right)$.

Como se pode ver nos gráficos apresentados, não se obtém praticamente nenhuma diferença entre as amplitudes $0,64 \cdot t$ e $0,20 \cdot t$, sendo que apenas ocorre alguma mudança sobre a trajetória de equilíbrio não linear para imperfeição com amplitude de $0,05 \cdot t$, e assim mesmo não afetando a força máxima resistente de compressão, a qual ficou limitada por problemas numéricos que dificultaram a convergência a partir deste ponto, mas deixam evidente a ocorrência de algum tipo de instabilidade neste ponto.

Ademais, diga-se que a amplitude de $0,05 \cdot t$, em termos práticos, também não tem qualquer sentido por ser um valor muitíssimo baixo.

Em caráter complementar, e de modo a demonstrar a influência de diferentes configurações de imperfeição para barras com comprimentos situados junto ao início e ao final do platô de flexo-torção obtido por análise de estabilidade elástica, foi realizada uma nova série de análises, para a qual foi utilizada a seção transversal $L 70 \times 1,50 \mathrm{~mm}$, com dois 
comprimentos (50 e $250 \mathrm{~cm}$ ), e cinco tensões de escoamento $(20,30,50$, 80 e $120 \mathrm{MPa}$ ), de modo a obter resultados para esbeltez reduzida $\left(\lambda_{0}=\left(A \cdot f_{y} / N_{e}\right)^{0,5}\right)$ distribuídos entre 0,68 e 1,82 .

Para avaliar de forma mais precisa a influência das imperfeições geométricas, foram analisadas três amplitudes para imperfeição de torção $(0,1 \cdot t, 0,2 \cdot t$ e $0,5 \cdot t)$, e três amplitudes para imperfeição de flexão (L/500, L/1000 e L/1500), sendo esta última avaliada em ambos os sentidos (CD e TD). A Tabela 2.1 apresenta os resultados de $N / N_{c r}$ para todas as condições supracitadas.

Tabela 2.1 - Resultados de força axial resistente $N / N_{c r}$ para diferentes condições de imperfeição

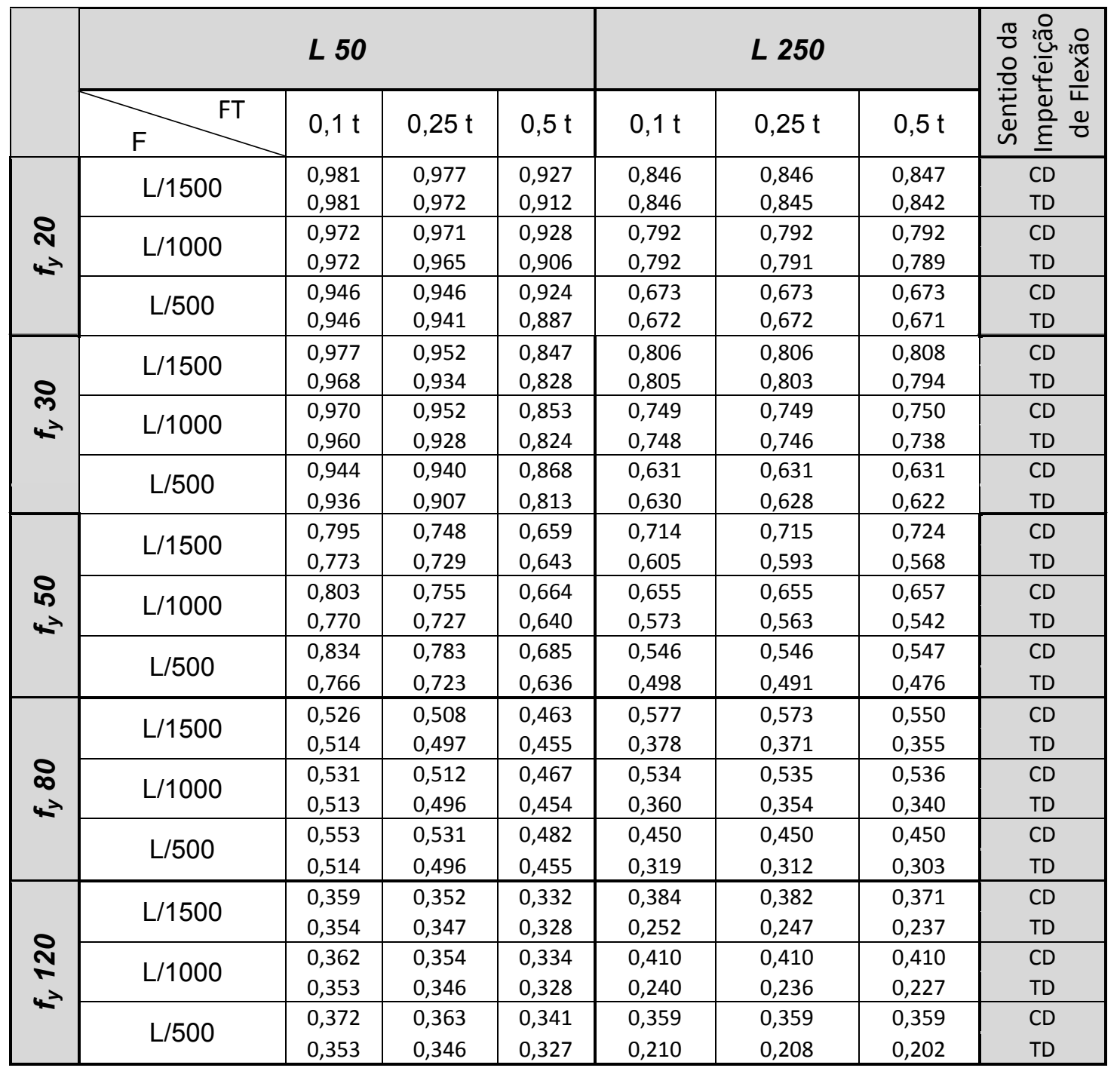

Corroborando com o que foi exposto até então, repara-se que a influência das imperfeições de torção é pequena, mesmo para barras curtas, enquanto a amplitude da imperfeição de flexão pode exercer uma influência maior, especialmente no caso de barras de comprimento elevado. Contudo, de forma mais relevante, tem-se na mudança do sentido da 
imperfeição de flexão a maior variação nos resultados de força resistente de compressão das barras, conforme ilustram complementarmente os gráficos das Figuras 2.52 a 2.55 para três valores de tensão de escoamento (30, 50 e $120 \mathrm{MPa})$.

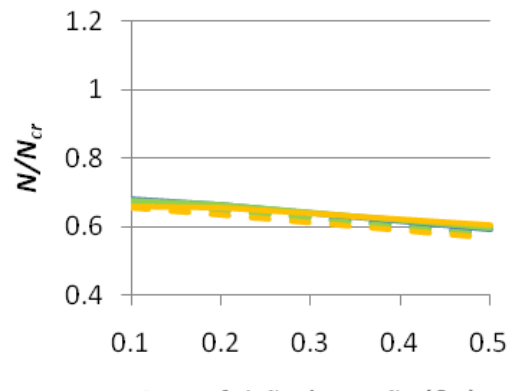

Imperfeição de torção $(\beta \cdot t)$

(a)

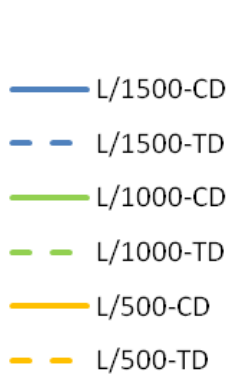

(N)

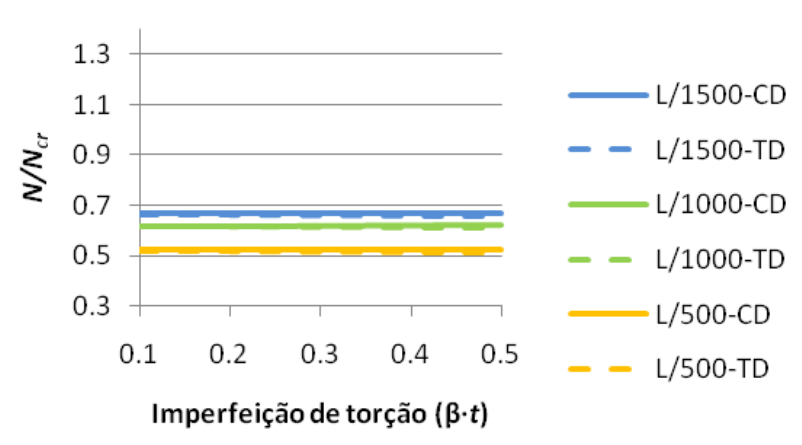

(b)

Figura 2.52 - Força axial resistente $N / N_{c r}$ segundo amplitude de imperfeições de torção, para diferentes imperfeições de flexão, para barra de comprimento (a) $50 \mathrm{~cm}$, e (b) $250 \mathrm{~cm}$, e $f_{y}=30 \mathrm{MPa}$.
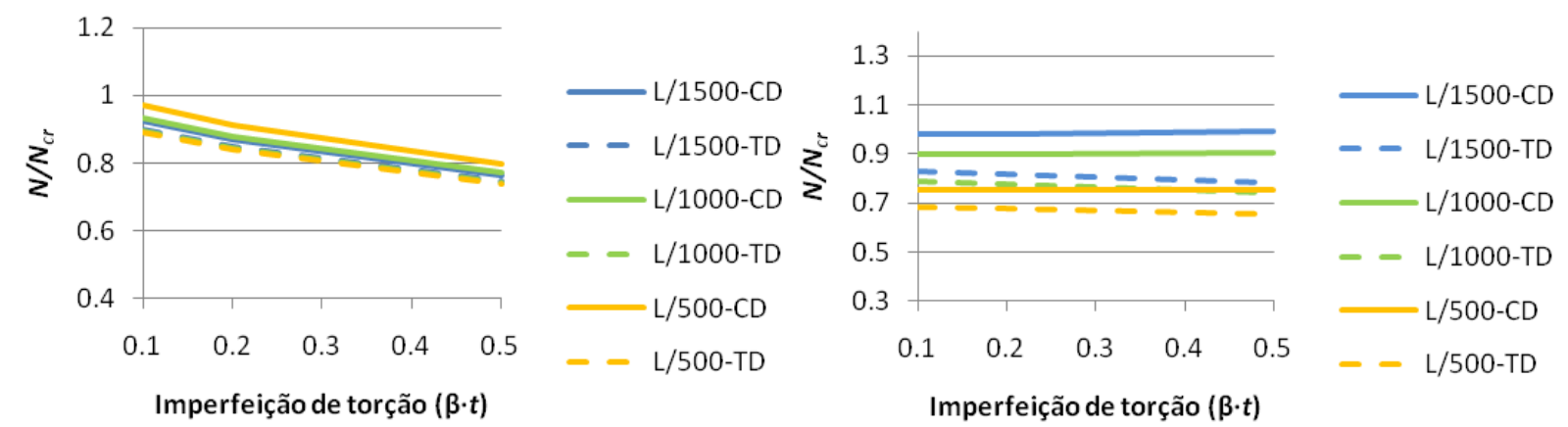

Figura 2.53 - Força axial resistente $N / N_{c r}$ segundo amplitude de imperfeições de torção, para diferentes imperfeições de flexão, para barra de comprimento (a) $50 \mathrm{~cm}$, e (b) $250 \mathrm{~cm}$, e $f_{y}=50 \mathrm{MPa}$.

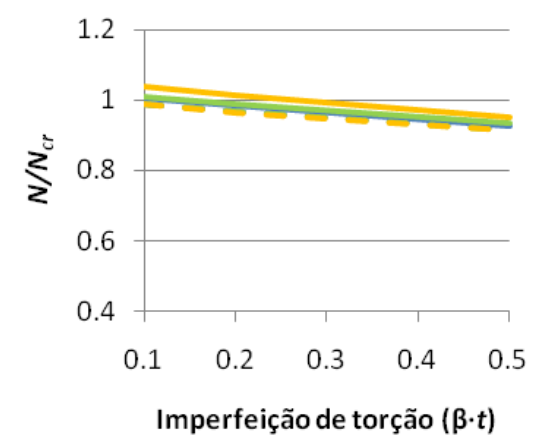

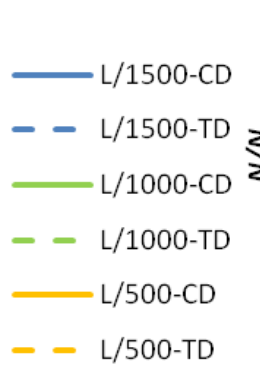

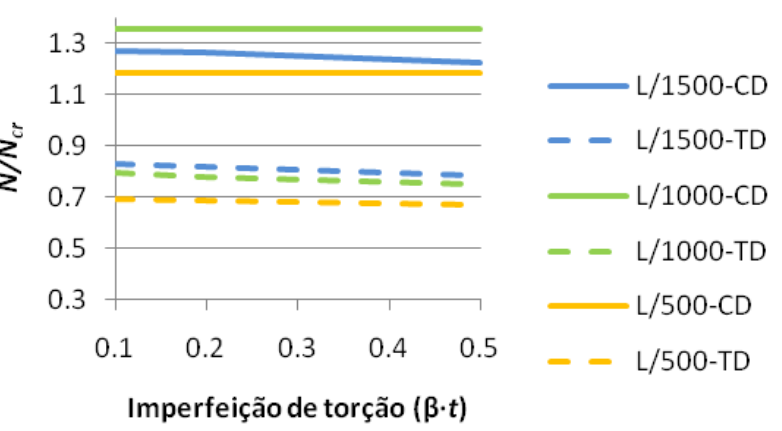

Figura 2.54-Força axial resistente $N / N_{c r}$ segundo amplitude de imperfeições de torção, para diferentes imperfeições de flexão, para barra de comprimento (a) $50 \mathrm{~cm}$, e (b) $250 \mathrm{~cm}$, e $f_{y}=120 \mathrm{MPa}$. 


\subsubsection{Interpretação de Resultados Experimentais Considerando os Efeitos da} Imperfeição Geométrica Inicial de Flexão

A aplicação do que foi exposto nos itens 2.2.1 a 2.2.3 é bastante vasta, e não se restringe somente aos resultados cujo modo de falha relatado pelo autor seja "incompatível" com a análise de estabilidade elástica, ou cuja força axial de compressão resistente obtida é muito diferente do esperado, apesar disso, para bem ilustrar um exemplo, apresenta-se aqui o caso experimental de um ocorrido inicialmente "paradoxal", tanto em termos de modo de falha como de força axial resistente de compressão.

Tomando-se como base os ensaios de Popovic et al. (1999) para a seção transversal $L 50 \times 2,50 \mathrm{~mm}$, cujos resultados observados de algumas barras seguem um nítido padrão de influência da excentricidade na aplicação da força (recorde que Popovic et al. (1999) utilizaram excentricidades de L/1000 na aplicação da força de compressão, conforme já comentado no item 2.1.5 deste trabalho), foram escolhidas duas barras de igual comprimento $\left(L_{c}=675 \mathrm{~mm}\right.$ e $\left.L_{r}=100 \mathrm{~mm}\right)$ mas com modos de falha (flexo-torção, que aqui denominar-se-á "Caso 1", e flexão em torno do eixo de menor inércia, que por sua vez será “Caso 2") e força axial de compressão resistente muito diferentes (30,9 kN para o caso 1 e $47,5 k N$ para o caso 2$)$.

As análises numéricas foram elaboradas tendo em consideração todas as variáveis possíveis, como afastamento longitudinal entre o perfil e as rótulas, tensões residuais (que já demonstraram não afetar em nada os resultados, mas foram mantidas no modelo por terem sido programadas automaticamente com a ajuda de scripts elaborados durante as fases deste trabalho) e imperfeições geométricas iniciais de torção $(0,20 \cdot t)$ e flexão $(L / 1000)$, cujos valores são compatíveis com aqueles medidos experimentalmente por Popovic et al. (1999).

Assim sendo, o gráfico da Fig. 2.53 ilustra a curva de flambagem $\left(N_{c r} v s L_{c}\right)$ obtida por meio de análise de estabilidade elástica, juntamente com os resultados experimentais obtidos por Popovic et al. (1999) em toda série de ensaios para a seção transversal L50X2,50 mm e extremidades com rótulas cilíndricas, e também os resultados numéricos obtidos com os parâmetros citados no parágrafo anterior para as barras de comprimento $L_{c}=675 \mathrm{~mm}$.

Adicionalmente, as Figuras 2.56 (a) e (b) apresentam a configuração deformada das barras com imperfeição de flexão TD (a) - e que se refere à barra que se aproxima melhor do caso (1), e CD (b) - que se refere à barra que se aproxima melhor ao caso (2). 


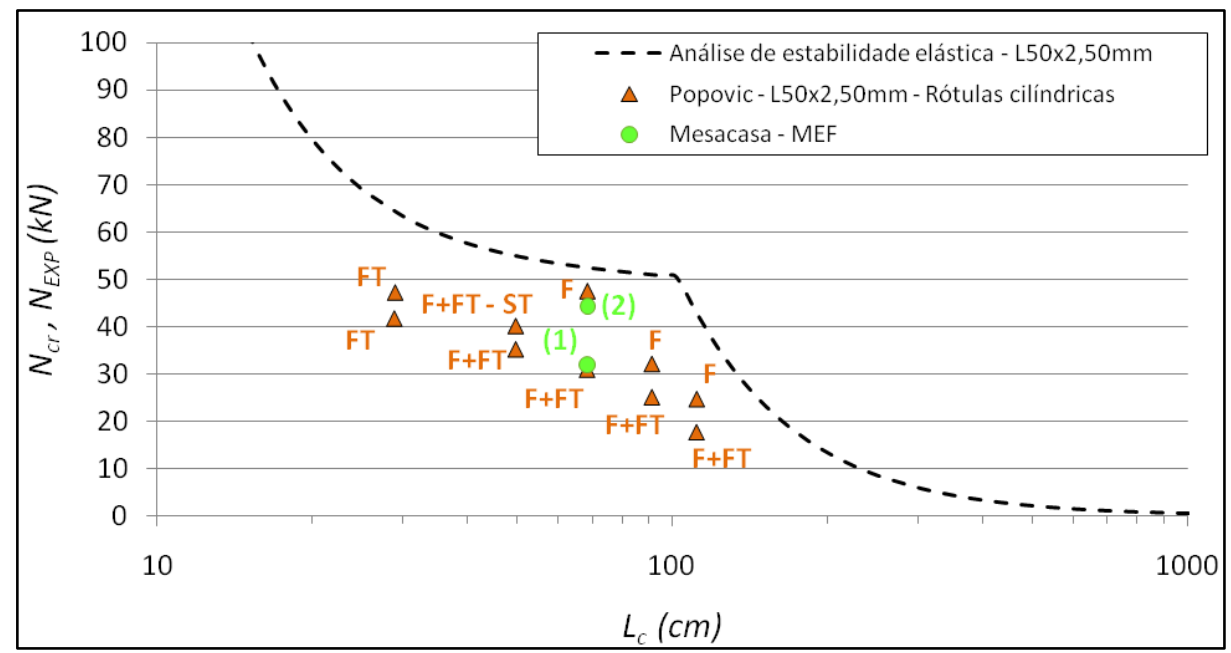

Figura 2.55 - Curva $N_{c r} v s . L_{c}$ para cantoneira $L 50 \times 2,50 \mathrm{~mm}$, juntamente com resultados experimentais de

Popovic et al (1999), e resultados numéricos deste trabalho para barra de comprimento $L_{c}=675 \mathrm{~mm}$.

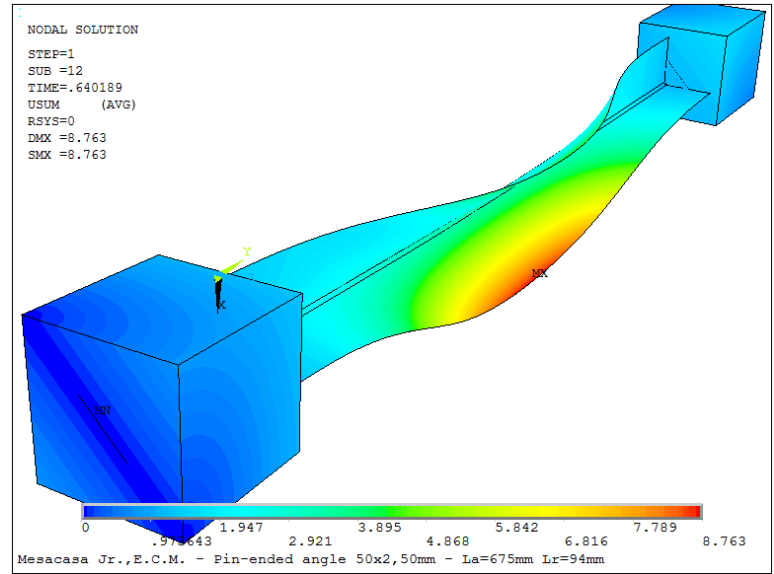

(a)

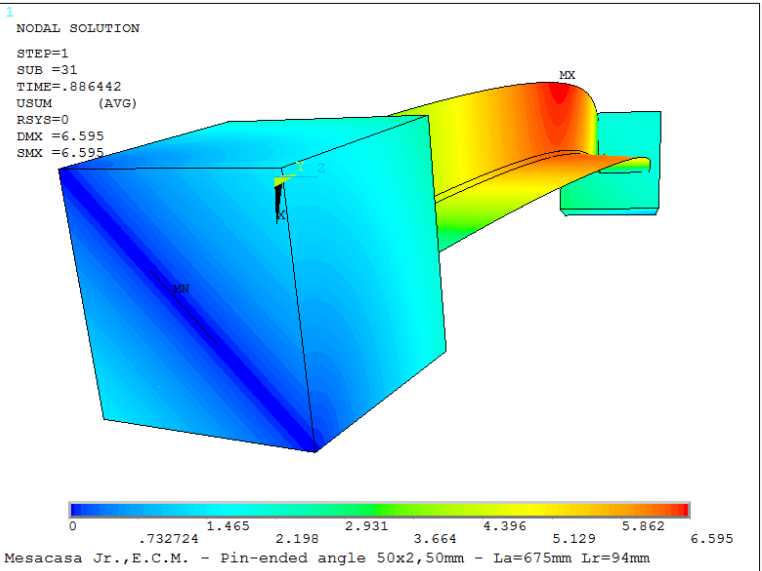

(b)

Figura 2.56 - Configuração deformada para cantoneira $L 50 \times 2,50 \mathrm{~mm}, L_{c}=675 \mathrm{~mm}$, e $L_{r}=100 \mathrm{~mm}$, no ponto de força máxima de compressão. Caso de imperfeição de flexão TD (a) e CD (b).

Portanto, como se pode notar no gráfico da Fig. 2.55 , em termos de força axial de compressão resistente, os resultados obtidos numericamente se aproximam bastante dos resultados experimentais para ambos os casos de imperfeição (Numérico do Caso 1=32,01 kN e numérico do Caso 2=44,3 kN). De igual forma, segundo ilustrado pelas Figuras 2.56 (a) e (b), em termos de configuração deformada também são obtidos resultados numéricos perfeitamente compatíveis com o estudo experimental, tendo em vista a ocorrência de deslocamentos típicos claros e distintos para ambos os casos. 


\section{TRABALHOS EXPERIMENTAIS}

Para compor este trabalho foram selecionados estudos experimentais variados sobre cantoneiras de aço formadas a frio submetidas à compressão centrada, dentre os quais, eventualmente, foram analisadas também cantoneiras conectadas pela aba e cantoneiras enrijecidas, porém, por uma questão de foco estes casos não são tratados aqui.

Assim, são relacionados aqui os trabalhos de Prabhu (1982), Wilhoite (1984) apud Rasmussen (2003), Popovic et al. (1999), Young (2004), Chodraui et al. (2006), Maia et al. (2008), Bonatto (2009), e ainda ensaios realizados para este trabalho, descritos no item 3.1.

A Tabela 3.1, apresentada abaixo, descreve as propriedades geométricas e materiais dos perfis utilizados por cada autor, enquanto a Tabela 3.2 apresenta os resultados dos ensaios em termos de força máxima resistente $\left(N_{\text {exp }}\right)$, modo de falha observado (que pode ser: local $(L)$; por flexão em torno do eixo de menor inércia (F); por flexo-torção $(F T)$; Snap-through (ST); ou ainda não ter sido relatado $(N D))$, condições de vínculos de extremidade na execução dos mesmos (denominadas "Rot" para rotuladas, e "Eng" para engastadas) e os comprimentos de cada barra $\left(L_{c}\right)$, bem como a distância entre a extremidade da barra e o centro da rótula $\left(L_{r}\right)$ nos casos de barras com extremidades rotuladas.

Tabela 3.1 - Propriedades geométricas e mecânicas dos perfis

\begin{tabular}{|c|c|c|c|c|c|c|c|c|}
\hline Autor & $\begin{array}{l}\text { Seção } \\
\text { Nominal }\end{array}$ & $b_{f}(m m)$ & $t(\mathrm{~mm})$ & $r d_{i}(m m)$ & $A\left(\mathrm{~mm}^{2}\right)$ & $r_{\min }(\mathrm{mm})$ & $f_{y}(M P a)$ & $E(M P a)$ \\
\hline \multirow{2}{*}{ Prabhu (1982) } & $45 \times 3,00$ & 44,25 & 2,93 & 8,00 & 246,69 & 8,56 & 330 & 200.000 \\
\hline & $65 \times 4,00$ & 64,40 & 3,86 & 13,00 & 475,28 & 12,53 & 377 & 200.000 \\
\hline Wilhoite (1984) & $70 \times 3,00$ & 69,3 & 3,00 & 3,00 & 402,58 & 13,67 & 465 & 203.000 \\
\hline \multirow{3}{*}{$\begin{array}{l}\text { Popovic et al. } \\
\text { (1999) }\end{array}$} & $50 \times 2,50$ & 50,00 & 2,31 & 2,31 & 225,9 & 9,84 & 396 & 207.100 \\
\hline & $50 \times 4,00$ & 50,37 & 3,79 & 3,79 & 360,7 & 9,67 & 388 & 209.800 \\
\hline & $50 \times 5,00$ & 50,47 & 4,70 & 4,70 & 442,0 & 9,53 & 388 & 207.400 \\
\hline \multirow{3}{*}{ Young (2004) } & $70 \times 1,20$ & 71,7 & 1,171 & 2,60 & 165,91 & 14,46 & 550 & 208.000 \\
\hline & $70 \times 1,50$ & 71,5 & 1,496 & 2,60 & 210,64 & 14,37 & 530 & 207.000 \\
\hline & $70 \times 1,90$ & 72,0 & 1,883 & 2,60 & 265,94 & 14,41 & 500 & 208.000 \\
\hline $\begin{array}{c}\text { Chodraui et al. } \\
\text { (2006) }\end{array}$ & $60 \times 2,25$ & 60,0 & 2,38 & 2,38 & 277,28 & 11,88 & 371 & 205.000 \\
\hline Maia et al. (2008) & $60 \times 2,25$ & 60,0 & 2,38 & 2,38 & 276,00 & 11,88 & 357 & 205.000 \\
\hline Bonatto (2009) & $27 \times 1,06$ & 27,0 & 1,06 & 1,00 & 55,59 & 5,35 & 226 & 205.000 \\
\hline Mesacasa & $60 \times 2,00$ & 60,0 & 2,00 & 2,00 & 234,12 & 11,94 & 350 & 200.000 \\
\hline
\end{tabular}


Sendo que na tabela 3.1: $b_{f}$ é a largura da aba; $t$ a espessura; $r d_{i}$ o raio interno de dobramento; $A$ é a área bruta da seção; $r_{\min }$ o raio de giração em relação ao eixo de menor inércia; $f_{y}$ a resistência ao escoamento; e $E$ o módulo de elasticidade longitudinal do aço.

Tabela 3.2 - Resultados dos ensaios experimentais

\begin{tabular}{|c|c|c|c|c|c|c|c|c|}
\hline Autor & Seção & Ensaio* & $L_{c}(\mathrm{~mm})$ & $L_{r}(m m)$ & $\begin{array}{l}\text { Condições } \\
\text { de vinculo }\end{array}$ & $\lambda_{\text {máx }}$ & $N_{\text {exp }}(k N)$ & $\begin{array}{l}\text { Modo de } \\
\text { Falha }\end{array}$ \\
\hline \multirow{16}{*}{$\begin{array}{l}\text { న్ } \\
\frac{0}{2} \\
\frac{2}{2} \\
\frac{5}{0} \\
\frac{0}{2}\end{array}$} & \multirow{8}{*}{ 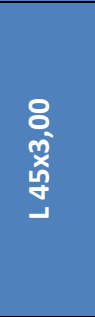 } & 1 & 1.171 & N.D. & Rot & 136,8 & 24,0 & $F$ \\
\hline & & 2 & 1.171 & N.D. & Rot & 136,8 & 24,0 & $F$ \\
\hline & & 3 & 1.511 & N.D. & Rot & 176,5 & 14,6 & $F$ \\
\hline & & 4 & 1.511 & N.D. & Rot & 176,5 & 15,4 & $F$ \\
\hline & & 5 & 1.856 & N.D. & Rot & 216,8 & 10,8 & $F$ \\
\hline & & 6 & 1.856 & N.D. & Rot & 216,8 & 9,7 & $F$ \\
\hline & & 7 & 2.181 & N.D. & Rot & 254,8 & 7,6 & $F$ \\
\hline & & 8 & 2.181 & N.D. & Rot & 254,8 & 8,1 & $F$ \\
\hline & \multirow{8}{*}{$\begin{array}{l}8 \\
\text { ष } \\
0 \\
0 \\
0\end{array}$} & 1 & 1.148 & N.D. & Rot & 91,6 & 88,0 & $F$ \\
\hline & & 2 & 1.148 & N.D. & Rot & 91,6 & 88,5 & $F$ \\
\hline & & 3 & 1.651 & N.D. & Rot & 131,8 & 51,4 & $F$ \\
\hline & & 4 & 1.651 & N.D. & Rot & 131,8 & 48,7 & $F$ \\
\hline & & 5 & 2.126 & N.D. & Rot & 169,7 & 29,7 & $F$ \\
\hline & & 6 & 2.126 & N.D. & Rot & 169,7 & 32,0 & $F$ \\
\hline & & 7 & 2.626 & N.D. & Rot & 209,6 & 19,7 & $F$ \\
\hline & & 8 & 2.626 & N.D. & Rot & 209,6 & 18,5 & $F$ \\
\hline \multirow{7}{*}{ 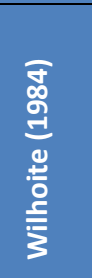 } & \multirow{7}{*}{ 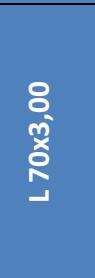 } & 1 & 823 & N.D. & Rot & 60,5 & 72,5 & $N D$ \\
\hline & & 2 & 1.277 & N.D. & Rot & 90,2 & 58,3 & $N D$ \\
\hline & & 3 & 1.227 & N.D. & Rot & 90,2 & 60,1 & $N D$ \\
\hline & & 4 & 1.227 & N.D. & Rot & 90,2 & 65,0 & $N D$ \\
\hline & & 5 & 1.636 & N.D. & Rot & 120,2 & 48,4 & $N D$ \\
\hline & & 6 & 1.636 & N.D. & Rot & 120,2 & 52,1 & $N D$ \\
\hline & & 7 & 1.636 & N.D. & Rot & 120,2 & 59,2 & $N D$ \\
\hline \multirow{30}{*}{ 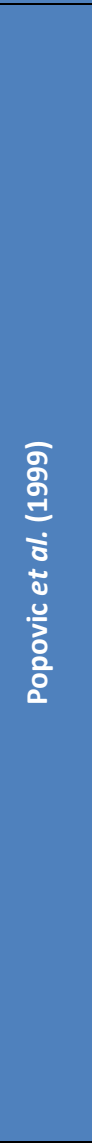 } & \multirow{16}{*}{ 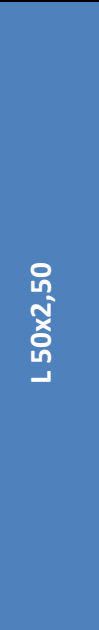 } & 1 & 550 & - & Eng & 27,9 & 54,0 & $F T$ \\
\hline & & 2 & 970 & - & Eng & 49,3 & 41,5 & $F T$ \\
\hline & & 3 & 1.379 & - & Eng & 70,1 & 37,0 & $F+F T$ \\
\hline & & 4 & 1.747 & - & Eng & 88,8 & 31,3 & $F+F T$ \\
\hline & & 5 & 2.199 & - & Eng & 111,8 & 26,4 & $F+F T$ \\
\hline & & 6 & 2.598 & - & Eng & 132 & 22,3 & $F$ \\
\hline & & 1 (TD) & 286 & 100 & Rot & 46,6 & 41,7 & $F T$ \\
\hline & & $2(C D)$ & 285 & 100 & Rot & 46,5 & 47,2 & $F T$ \\
\hline & & $3(T D)$ & 490 & 100 & Rot & 68,7 & 35,2 & $F+F T$ \\
\hline & & $4(C D)$ & 490 & 100 & Rot & 68,7 & 40,1 & $F+F T-S T$ \\
\hline & & $5(T D)$ & 674 & 100 & Rot & 87,6 & 30,9 & $F+F T$ \\
\hline & & $6(C D)$ & 675 & 100 & Rot & 87,7 & 47,5 & $F$ \\
\hline & & $7(T D)$ & 900 & 100 & Rot & 110,6 & 25,1 & $F+F T$ \\
\hline & & $8(C D)$ & 900 & 100 & Rot & 110,6 & 32,1 & $F$ \\
\hline & & $9(T D)$ & 1.099 & 100 & Rot & 130,6 & 17,7 & $F+F T$ \\
\hline & & $10(C D)$ & 1.100 & 100 & Rot & 130,7 & 24,7 & $F$ \\
\hline & \multirow{6}{*}{$\begin{array}{l}8 \\
\text { ष्र } \\
\text { ष्रे }\end{array}$} & 1 & 970 & - & Eng & 55,0 & 119,5 & $F+F T$ \\
\hline & & 2 & 1.381 & - & Eng & 78,3 & 94,9 & $F+F T$ \\
\hline & & 3 & 1.743 & - & Eng & 98,9 & 67,6 & $F$ \\
\hline & & $1(T D)$ & 285 & 100 & Rot & 51,9 & 130,7 & $F+F T$ \\
\hline & & $2(T D)$ & 490 & 100 & Rot & 76,6 & 105,0 & $F$ \\
\hline & & 3 (TD) & 675 & 100 & Rot & 97,8 & 73,1 & $F+F T$ \\
\hline & \multirow{8}{*}{ 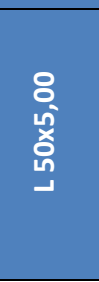 } & 1 & 970 & - & Eng & 57,5 & 144,2 & $F+F T$ \\
\hline & & 2 & 1.378 & - & Eng & 81,7 & 101,7 & $F$ \\
\hline & & 3 & 1.749 & - & Eng & 103,8 & 84,6 & $F$ \\
\hline & & 1 (TD) & 285 & 100 & Rot & 54,3 & 154,8 & $F$ \\
\hline & & $2(T D)$ & 490 & 100 & Rot & 80,2 & 119,1 & $F+F T$ \\
\hline & & $3(C D)$ & 490 & 100 & Rot & 80,2 & 117,3 & $F$ \\
\hline & & $4(T D)$ & 675 & 100 & Rot & 102,4 & 91,9 & $F$ \\
\hline & & 5 (CD) & 675 & 100 & Rot & 102.4 & 84.1 & $F$ \\
\hline
\end{tabular}


... continuação - Tabela 3.2

\begin{tabular}{|c|c|c|c|c|c|c|c|c|}
\hline Autor & Seção & Ensaio & $L_{b}(\mathrm{~mm})$ & $L_{r}(\mathrm{~mm})$ & $\begin{array}{l}\text { Condições } \\
\text { de vínculo }\end{array}$ & $\lambda_{\operatorname{máx}}$ & $N_{\text {exp }}(k N)$ & $\begin{array}{l}\text { Modo de } \\
\text { Falha* }\end{array}$ \\
\hline \multirow{24}{*}{ 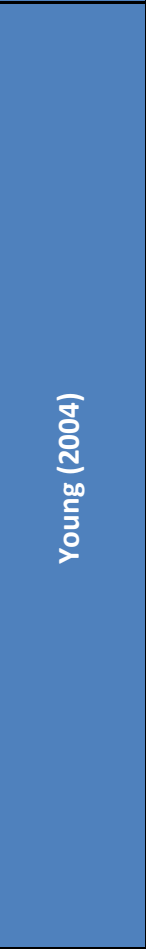 } & \multirow{9}{*}{ ํㅗㄹ } & 1 & 250 & - & Eng & 8,7 & 23,8 & $L$ \\
\hline & & 2 & 250 & - & Eng & 8,7 & 23,6 & $L$ \\
\hline & & 3 & 1.000 & - & Eng & 34,8 & 18,7 & $F+F T$ \\
\hline & & 4 & 1.501 & - & Eng & 52,2 & 15,2 & $F+F T$ \\
\hline & & 5 & 2.001 & - & Eng & 69,6 & 12,6 & $F+F T$ \\
\hline & & 6 & 2.500 & - & Eng & 87,0 & 11,6 & $F+F T$ \\
\hline & & 7 & 2.500 & - & Eng & 87,0 & 11,9 & $F+F T$ \\
\hline & & 8 & 3.000 & - & Eng & 104,4 & 8,0 & $F+F T$ \\
\hline & & 9 & 3.500 & - & Eng & 121,9 & 5,8 & $F+F T$ \\
\hline & \multirow{7}{*}{ 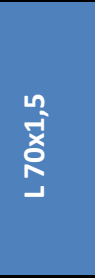 } & 1 & 249 & - & Eng & 8,7 & 39,6 & $L$ \\
\hline & & 2 & 999 & - & Eng & 35,0 & 31,0 & $F+F T$ \\
\hline & & 3 & 1.499 & - & Eng & 52,2 & 25,2 & $F+F T$ \\
\hline & & 4 & 2.000 & - & Eng & 70,0 & 17,5 & $F+F T$ \\
\hline & & 5 & 2.500 & - & Eng & 87,5 & 15,7 & $F+F T$ \\
\hline & & 6 & 3.000 & - & Eng & 105,4 & 13,1 & $F+F T$ \\
\hline & & 7 & 3.500 & - & Eng & 122,5 & 11,5 & $F+F T$ \\
\hline & \multirow{8}{*}{ 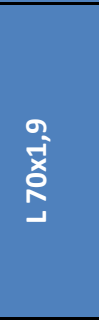 } & 1 & 251 & - & Eng & 8,7 & 56,5 & $L$ \\
\hline & & 2 & 250 & - & Eng & 8,7 & 57,7 & $L$ \\
\hline & & 3 & 1.000 & - & Eng & 34,9 & 47,8 & $F T$ \\
\hline & & 4 & 1.501 & - & Eng & 52,3 & 35,6 & $F+F T$ \\
\hline & & 5 & 2.000 & - & Eng & 69,7 & 27,1 & $F+F T$ \\
\hline & & 6 & 2.500 & - & Eng & 87,2 & 22,4 & $F+F T$ \\
\hline & & 7 & 3.000 & - & Eng & 104,6 & 14,8 & $F+F T$ \\
\hline & & 8 & 3.500 & - & Eng & 122,0 & 14,4 & $F+F T$ \\
\hline \multirow{4}{*}{ 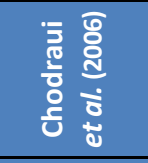 } & \multirow{4}{*}{$\begin{array}{l}\text { 20 } \\
\frac{1}{8} \\
0 \\
\end{array}$} & 1 & 480 & 67,5 & Rot & 51,7 & 31,0 & $F+F T$ \\
\hline & & 2 & 835 & 67,5 & Rot & 81,6 & 29,0 & $F+F T$ \\
\hline & & 3 & 1.195 & 67,5 & Rot & 111,9 & 23,0 & $F+F T$ \\
\hline & & 4 & 1.550 & 67,5 & Rot & 141,8 & 21,0 & $F+F T$ \\
\hline \multirow{11}{*}{ 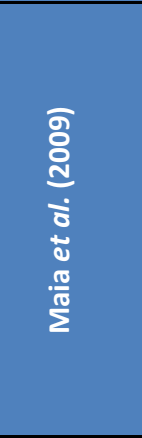 } & \multirow{11}{*}{ 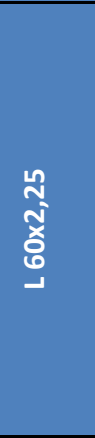 } & 1 & 480 & 67,5 & Rot & 51,8 & 31,0 & $F T$ \\
\hline & & 2 & 650 & 67,5 & Rot & 66,1 & 36,1 & $F T$ \\
\hline & & 3 & 835 & 67,5 & Rot & 81,6 & 29,0 & $F T$ \\
\hline & & 4 & 1.000 & 67,5 & Rot & 95,5 & 39,8 & $F$ \\
\hline & & 5 & 1.195 & 67,5 & Rot & 111,9 & 22,5 & $F T$ \\
\hline & & 6 & 1.350 & 67,5 & Rot & 125,0 & 28,5 & $F$ \\
\hline & & 7 & 1.550 & 67,5 & Rot & 141,8 & 21,0 & $F T$ \\
\hline & & 1 & 615 & - & Eng & 25,9 & 40,9 & $F T$ \\
\hline & & 2 & 970 & - & Eng & 40,8 & 34,5 & $F T$ \\
\hline & & 3 & 1.330 & - & Eng & 56 & 30,6 & $F T$ \\
\hline & & 4 & 1.685 & - & Eng & 70,9 & 26,7 & $F T$ \\
\hline \multirow{9}{*}{ 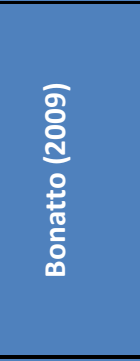 } & \multirow{9}{*}{ 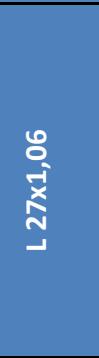 } & 1 & 350 & 52,7 & Rot & 85,1 & 4,90 & $F T$ \\
\hline & & 2 & 350 & 52,7 & Rot & 85,1 & 5,13 & $F T$ \\
\hline & & 3 & 350 & 52,7 & Rot & 85,1 & 5,20 & $F T$ \\
\hline & & 4 & 450 & 52,7 & Rot & 103,8 & 5,71 & $F T$ \\
\hline & & 5 & 450 & 52,7 & Rot & 103,8 & 4,57 & $F T$ \\
\hline & & 6 & 450 & 52,7 & Rot & 103,8 & 4,76 & $F T$ \\
\hline & & 7 & 550 & 52,7 & Rot & 122,5 & 4,42 & $F$ \\
\hline & & 8 & 550 & 52,7 & Rot & 122,5 & 5,40 & $F$ \\
\hline & & 9 & 550 & 52,7 & Rot & 122,5 & 4,36 & $F$ \\
\hline \multirow{5}{*}{ 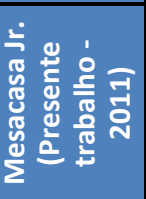 } & \multirow{5}{*}{ 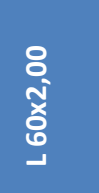 } & 1 & 400 & - & Eng & 16,8 & 41,43 & $F T$ \\
\hline & & 2 & 600 & - & Eng & 25,1 & 38,84 & $F T$ \\
\hline & & 3 & 900 & - & Eng & 37,7 & 32,05 & $F T$ \\
\hline & & 4 & 1.200 & - & Eng & 50,3 & 29,99 & $F T$ \\
\hline & & 5 & 1.800 & - & Eng & 75,4 & 20,60 & $F T$ \\
\hline
\end{tabular}

* No caso dos ensaios de Popovic et al. (1999), a força axial de compressão foi aplicada com uma excentricidade de $L / 1000$, ora de modo a provocar tração na região da dobra (TD), ora compressão (CD). 


\subsection{Ensaios Experimentais Realizados}

Os ensaios experimentais realizados na primeira etapa deste trabalho foram planejados para abranger uma faixa de valores de esbeltez reduzida $\left(\lambda_{0}=\left(A \cdot f_{y} / N_{e}\right)^{0,5}\right.$, sendo $N_{e}$ a força axial de flambagem elástica por flexão) pouco explorada nos ensaios até então realizados no Departamento de Engenharia de Estruturas da Escola de Engenharia de São Carlos.

Os ensaios realizados por Chodraui et al. (2006) e Maia et al. (2008) envolveram barras com $\lambda_{0}$ variando de 0,70 a 1,30. Buscou-se, portanto, valores menores, na faixa de 0,20 a 1,00. Desta forma, foram calculados outros comprimentos para as barras, trabalhando-se unicamente em condições de extremidade engastada (flexão e empenamento completamente restringidos).

O objetivo de se obter apenas resultados somente para barras com extremidades engastadas vai além da maior simplicidade e controle das variáveis que podem afetar o ensaio. Os resultados obtidos por Young (2004), demasiadamente conservadores segundo o próprio autor, mostram-se distintos daqueles já obtidos por outros autores, apesar das significativas diferenças nas condições de ensaio e seção transversal utilizada. Logo, as condições de extremidades engastadas nos ensaios deste trabalho também tiveram a intenção de verificar resultados que confirmem o conservadorismo neste tipo de condição de extremidade.

Os comprimentos utilizados podem ser vistos na Tabela 3.2, bem como os resultados obtidos nos ensaios. As propriedades geométricas e materiais são apresentados na Tabela 3.1, enquanto a Tabela 3.3 apresenta os valores medidos nos ensaios de caracterização do material, os quais foram realizados segundo a norma ASTM A370:1992.

As Figuras 3.1.a-b mostram dois dos ensaios, que foram realizados em uma máquina servo-controlada INSTRON 8506, com capacidade nominal de $2.500 \mathrm{kN}$, onde foi aplicada condição de carregamento monotônico com controle de deslocamento (permitindo que o ensaio continue mesmo após atingir a força máxima resistente da barra) a uma taxa de $0,01 \mathrm{~mm} / \mathrm{segundo}$.

O Apêndice B apresenta os resultados obtidos para cada uma das barras ensaiadas, bem como parte do registro fotográfico que permite a identificação do modo de falha de cada uma delas. 
Tabela 3.3 - Resultados dos ensaios de caracterização do material - cantoneira simples L60x2,00 e cantoneira enrijecida $L 50 \times 13 \times 2,00$

\begin{tabular}{|c|c|c|c|c|c|c|c|c|}
\hline \multirow{2}{*}{ Perfil } & \multirow{2}{*}{$\begin{array}{c}\text { Área do } \\
\text { corpo de } \\
\text { prova } \\
\left(\mathrm{cm}^{2}\right)\end{array}$} & \multicolumn{3}{|c|}{ Escoamento } & \multicolumn{3}{|c|}{ Ruptura } & \multirow{2}{*}{$\begin{array}{c}\text { Alongamento } \\
(\%) \\
(L=50 \mathrm{~mm})\end{array}$} \\
\hline & & Força $(k N)$ & $\begin{array}{l}\text { Tensão } \\
\text { (MPa) }\end{array}$ & $\begin{array}{l}\text { Tensão } \\
\text { média } \\
\text { (MPa) }\end{array}$ & Força $(k N)$ & $\begin{array}{l}\text { Tensão } \\
\text { (MPa) }\end{array}$ & $\begin{array}{l}\text { Tensão } \\
\text { média } \\
\text { (MPa) }\end{array}$ & \\
\hline \multirow{4}{*}{ 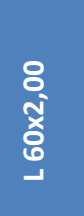 } & 0,248 & 9,00 & 363,0 & \multirow{4}{*}{350,8} & 12,68 & 511,3 & \multirow{4}{*}{500,3} & 29,0 \\
\hline & 0,248 & 8,94 & 360,5 & & 12,59 & 507,7 & & 29,6 \\
\hline & 0,248 & 8,39 & 338,3 & & 12,16 & 490,3 & & 30,6 \\
\hline & 0,248 & 8,47 & 341,5 & & 12,20 & 492,0 & & 27,4 \\
\hline
\end{tabular}

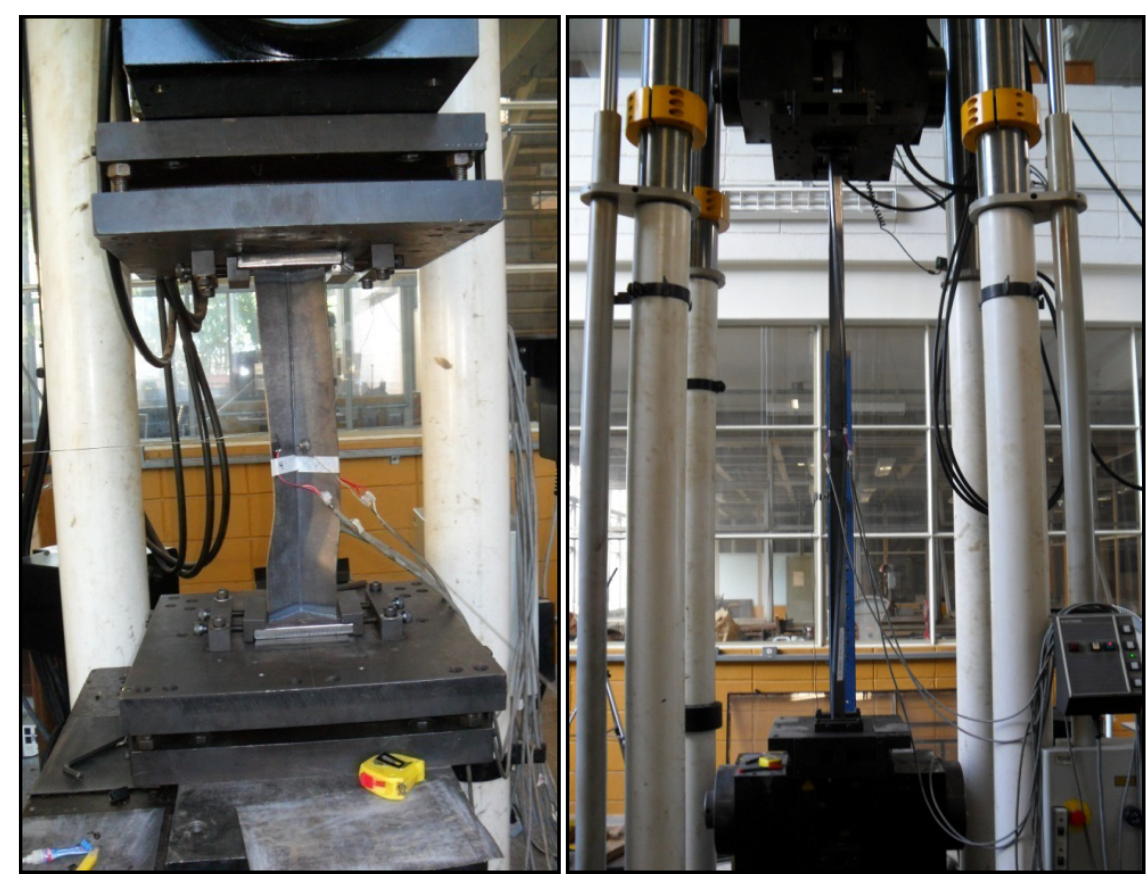

(a)

(b)

Figura 3.1 - Imagens de ensaios de cantoneiras sob compressão centrada.

Quanto à instrumentação das barras, foram utilizados extensômetros com base de medida de $5 \mathrm{~mm}$ para leitura das deformações apenas na barra mais curta (400 $\mathrm{mm}$ ). Todas as demais tiveram medidos apenas o deslocamento na direção dos eixos principais de inércia, na metade do comprimento de cada barra, bem como deslocamento axial e força aplicada.

A Figura 3.2 mostra esquematicamente a posição dos transdutores de deslocamento (utilizados transdutores com curso de $100 \mathrm{~mm}$ ) e a posição de fixação dos mesmos ao perfil ensaiado, bem como a posição dos extensômetros, que foram instalados na metade do comprimento da barra. 


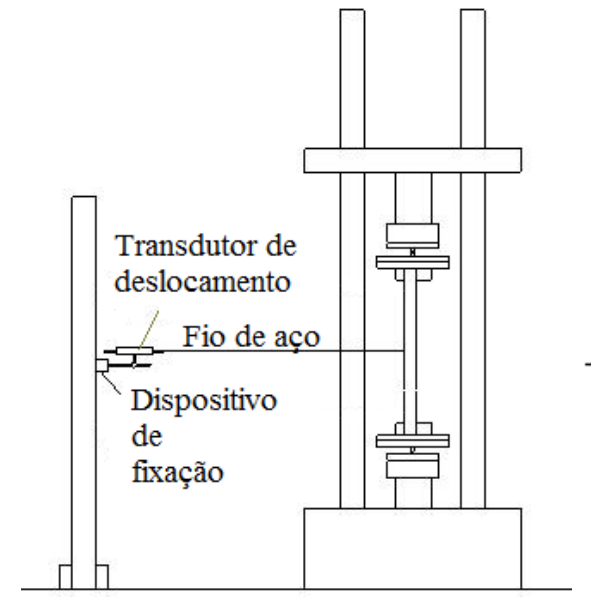

(a)

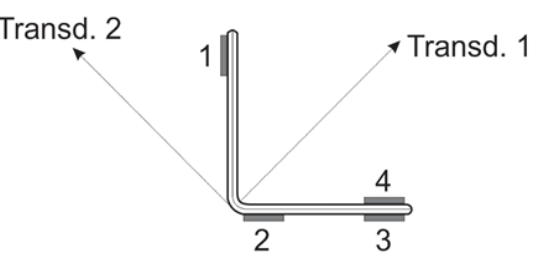

(b)

Figura 3.2 - Esquema de montagem para ensaios de compressão de cantoneiras simples - Instrumentação dos perfis

Deste modo, para exemplificar o processo de interpretação dos resultados que foi conferido a todas as barras ensaiadas, é apresentada na Fig. 3.3 a curva de deslocamento axial $\left(U_{y}\right)$ vs Carregamento aplicado $\left(N_{\text {exp }}\right)$, e na Fig. 3.4 são mostradas as curvas de Deslocamento vs $N_{\text {exp }}$ para cada um dos transdutores de deslocamento, conforme legenda na própria figura, ambas representando o ensaio de uma cantoneira sob compressão centrada $460 \times 2,00 \mathrm{~mm}$ de comprimento $L_{c}=600 \mathrm{~mm}$.

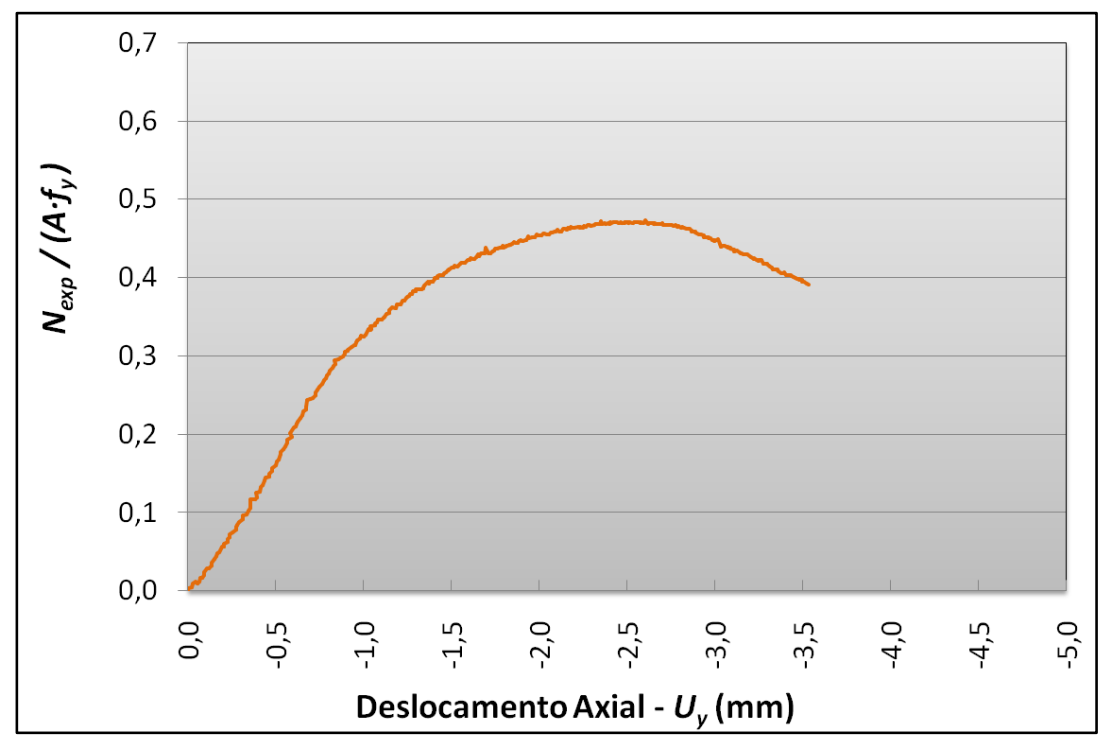

Figura 3.3 - Curva Força vs Deslocamento axial para ensaio do perfil L60x2,00 de comprimento $L_{c}=600 \mathrm{~mm}$ 


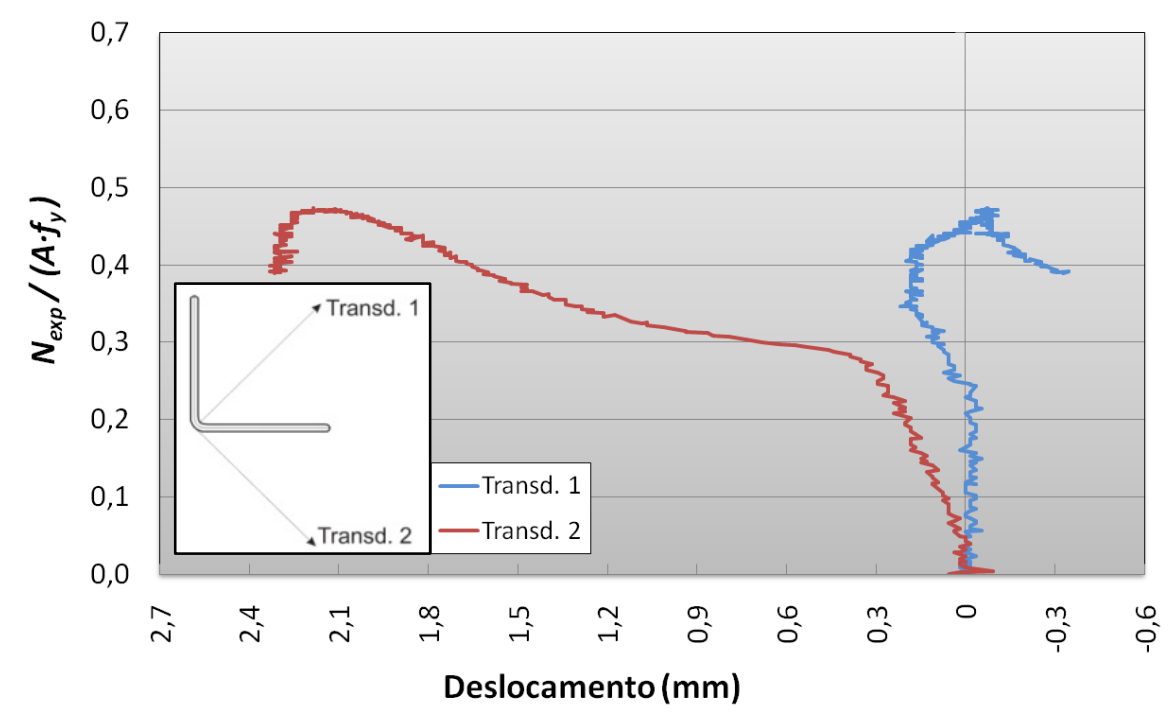

Figura 3.4 - Curva Força vs Deslocamento dos transdutores para ensaio do perfil L60x2,00 de comprimento $L_{c}=600 \mathrm{~mm}$

A análise dos gráficos resultantes do referido ensaio permitem as seguintes considerações:

i. Com base na curva $N_{\exp }$ vs $U_{y}$ nota-se a aplicação monotônica da força axial de compressão até o limite máximo de $38,838 \mathrm{kN}$. Em geral, como o procedimento é conduzido com controle de deslocamentos, a aplicação da força (a rigor, deslocamento) é mantida até que fique bem caracterizada a obtenção do pico máximo de força resistente a compressão ("peak load"). No caso da ocorrência de fenômenos como "snap-through", manter a aplicação do carregamento pode ser importante na obtenção de um segundo pico de força resistente, o que não foi o caso para nenhuma das cantoneiras simples sob compressão centrada analisadas;

ii. Os deslocamentos dos transdutores (Fig. 3.4) permitem, mesmo sem a análise do registro fotográfico (no caso deste trabalho, todos os ensaios também foram filmados em alta definição), que se deduza a ocorrência de um modo de instabilidade por flexo-torção, tal como se deu o deslocamento na direção do eixo de menor inércia (transdutor 2), da ordem de $2 \mathrm{~cm}$ para a força máxima, enquanto o transdutor de deslocamento 1 não registrou deslocamentos significativos na direção do eixo de maior inércia.

É importante lembrar que os transdutores de deslocamento não foram efetivos nos deslocamentos de todos os ensaios, visto que na maioria deles, a torção ocasionada na 
metade do comprimento do perfil fazia com que a aba da cantoneira tocasse o fio de aço, induzindo deslocamentos irreais, especialmente no caso das cantoneiras enrijecidas, onde o fato foi recorrente.

Contudo, seguem ainda duas imagens (Fig. 3.5) do ensaio da barra anteriormente analisada, ilustrando o modo de falha, conforme comentado, claramente característico de flexo-torção.
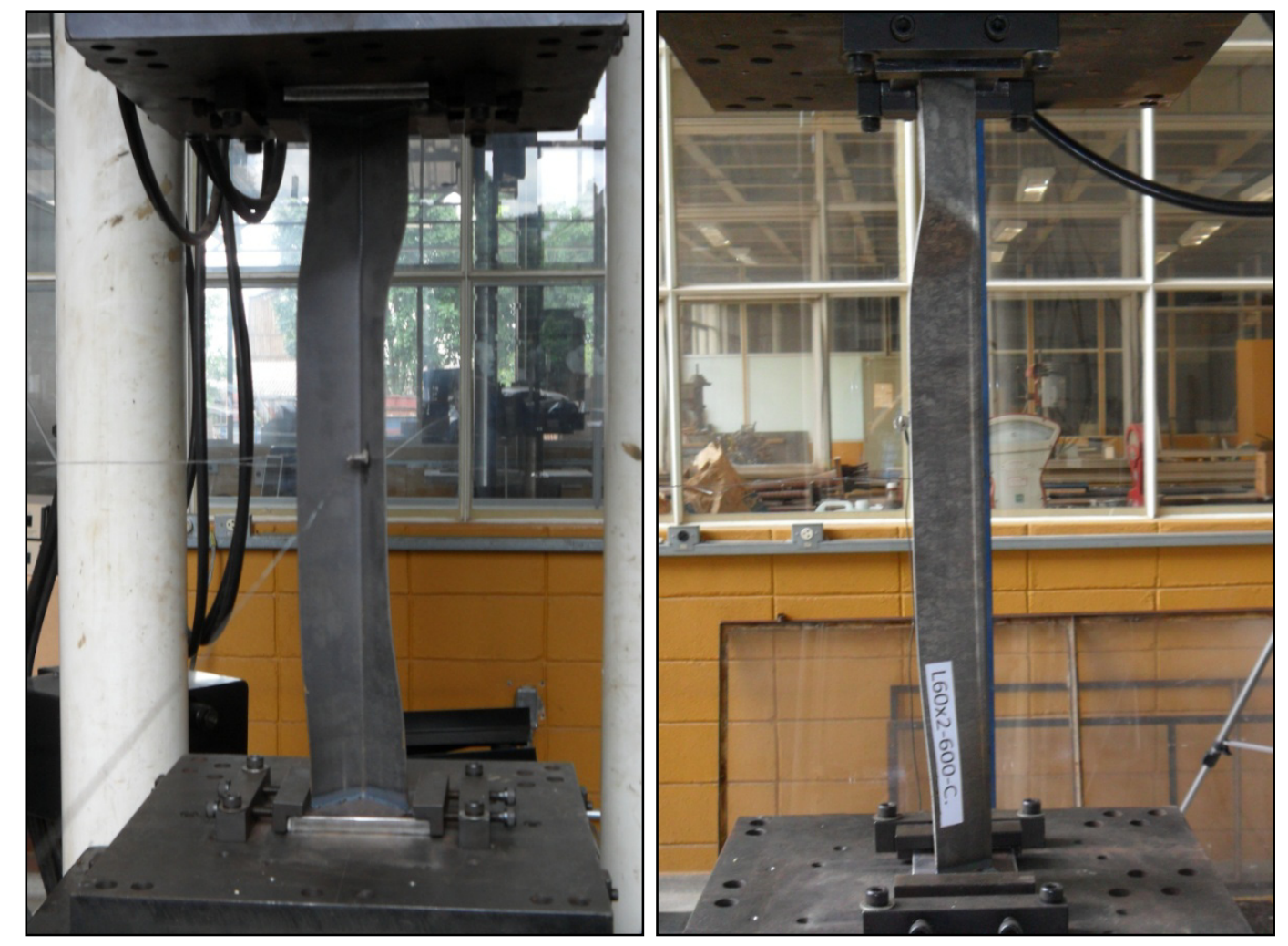

Figura 3.5 - Configuração deformada após pico de força de compressão ("peak load”) para perfil $L 60 \times 2,00-L_{c}=600 \mathrm{~mm}$ - Deslocamentos característicos do modo de flexo-torção 


\section{PROCEDIMENTOS DE DIMENSIONAMENTO}

Segundo as normas Norte-Americana (ANSI AISI S100-2007), Australiana (AS/NZS 4600:2005) e Brasileira (ABNT NBR 14762:2010), o valor característico (nominal) da força axial de compressão resistente $\left(N_{c, R k}\right)$, com base no clássico Método das Larguras Efetivas (MLE), é dado por:

$$
N_{c, R k}=\chi \cdot A_{e f} \cdot f_{y}
$$

Onde $A_{e f}$ é a área efetiva da seção, $f_{y}$ é a resistência ao escoamento do aço, e $\chi$ é o fator de redução da força resistente dado por:

$$
\begin{aligned}
& \lambda_{0} \leq 1,5 \Rightarrow \chi=0,658^{\lambda_{0}^{2}} \\
& \lambda_{0}>1,5 \Rightarrow \chi=\frac{0,877}{\lambda_{0}^{2}}
\end{aligned}
$$

Sendo o índice de esbeltez reduzido $\left(\lambda_{0}\right)$ obtido por:

$$
\lambda_{0}=\sqrt{\frac{A \cdot f_{y}}{N_{e}}}
$$

Onde, $N_{e}$ é a menor das forças axiais de flambagem elástica.

Para o caso de cantoneiras, não há um procedimento específico a ser adotado, sendo estas, portanto, classificadas junto ao grupo de perfis monossimétricos, de modo que a força axial de flambagem elástica seja determinada como o menor valor obtido com base nos modos de flexão em torno do eixo de menor inércia e flexo-torção.

As normas ANSI AISI S100-2007 e AS/NZS 4600:2005 recomendam, somente para cantoneiras esbeltas, a consideração de uma excentricidade adicional de $L / 1000$ na aplicação da força, o que, fatalmente, conduz a um procedimento analítico para flexocompressão. Entretanto, esta excentricidade adicional será desconsiderada neste trabalho, 
pois os resultados experimentais deixam claro que com esta excentricidade, e em alguns casos até mesmo para compressão centrada (e.g., Young, 2004), a previsão de força axial resistente de compressão das cantoneiras pode ser demasiadamente conservadora.

Não obstante, paralelamente ao MLE, o recente Método da Resistência Direta (MRD) tem sido progressivamente desenvolvido e utilizado, desde a sua inclusão na norma NorteAmericana em 2004 (NAS, 2004) como um método alternativo.

No Brasil, o MRD integra a ABNT NBR 14762:2010, onde define a força axial de compressão resistente de barras sob compressão centrada como sendo o menor valor calculado para flambagem global $\left(N_{c, R e}\right)$, local $\left(N_{c, R \ell}\right)$ e distorcional $\left(N_{c, R d i s t}\right)$, sendo que no caso da barra analisada não apresentar um dos três modos de flambagem, basta que o cálculo do esforço resistente respectivo não seja levado em consideração.

Assim, para se determinar o valor característico da força axial de compressão resistente associado à flambagem global por flexão, torção ou flexo-torção $\left(N_{c, R e}\right)$, são aplicadas as Eq. 4.1, 4.2 e 4.3, sendo $N_{e}$ obtido por meio de uma análise de estabilidade elástica, e tomando $A_{e f}=A$.

Para a força axial de compressão resistente associada à flambagem local $\left(N_{c, R \ell}\right)$, temse as Equações 4.4, considerando a interação local/global:

$$
\begin{array}{cc}
N_{c, R \ell}=N_{c, R e} & \text { para } \lambda_{\ell} \leq 0,776 \\
N_{c, R \ell}=\left(1-\frac{0,15}{\lambda_{\ell}^{0,8}}\right) \frac{N_{c, \mathrm{Re}}}{\lambda_{\ell}^{0,8}} & \text { para } \lambda_{\ell}>0,776
\end{array}
$$

sendo $\lambda_{e}$ definido por:

$$
\lambda_{\ell}=\left(\frac{N_{c, \mathrm{Re}}}{N_{\ell}}\right)^{0,5}
$$

onde $N_{\ell}$ é a força axial de flambagem local elástica.

E por fim, para a força axial de compressão resistente associada à flambagem distorcional $\left(N_{c, \text { Rdist }}\right)$, tem-se que:

$$
\begin{array}{ll}
N_{c, \text { Rdist }}=A f_{y} & \text { para } \lambda_{\text {dist }} \leq 0,561 \\
N_{c, \text { Rdist }}=\left(1-\frac{0,25}{N_{\text {dist }}^{1,2}}\right) \frac{A f_{y}}{N_{\text {dist }}^{1,2}} & \text { para } \lambda_{\text {dist }}>0,561
\end{array}
$$


onde $\lambda_{\text {dist }}=\left(\frac{A f_{y}}{N_{\text {dist }}}\right)^{0,5}$, e $N_{\text {dist }}$ é a força axial de flambagem distorcional elástica.

Adicionalmente, a norma Norte-Americana ANSI AISI S100-2007 apresenta uma lista de seções transversais "pré-qualificadas" para uso com o MRD, para as quais foram calibradas as curvas definidas pelas expressões 4.4 e 4.6, permitindo o uso de coeficientes de ponderação diferenciados. Como se sabe, as cantoneiras ainda permanecem em estudo, e não fazem parte da mesma.

Desta forma, diversos autores têm dirigido esforços no sentido de propor um procedimento adequado para previsão da força axial resistente de compressão para cantoneiras, alguns ainda com base no MLE, outros mais recentes totalmente direcionados ao MRD.

Dentre estas propostas, são abordadas neste trabalho a de (i) Young (2004) e a de (ii) Rasmussen (2003), ambas baseadas no MLE, e descritas nos itens 4.1 e 4.2, respectivamente, e também a de (iii) Chodraui et al. (2006) e a de (iv) Silvestre et al. (2012), baseadas no MRD, e descritas nos itens 4.3 e 4.4. Além disso, são analisados três diferentes procedimentos baseados em norma para o MLE, e também dois procedimentos para o MRD, os quais são explicados nos itens 4.5 e 4.6 deste trabalho.

É importante realçar, no entanto, que nem todos esses procedimentos são "coerentes" com a teoria apresentada, em grande parte, devido a grande variação verificada nos resultados experimentais, que sofrem a influência de fatores como os que foram detalhados nos itens 2.1 e 2.2 deste trabalho.

\subsection{Procedimento Proposto por Young (2004)}

Segundo Young (2004), ao comparar os resultados obtidos experimentalmente (referindo-se aos ensaios do próprio autor) com a curva baseada no procedimento normativo (definida pelas equações 4.2), considerando a força axial de flambagem elástica como sendo a mínima entre os modos de flexão e flexo-torção, resultados demasiadamente conservadores são obtidos, enquanto se considerar somente a força axial de flambagem elástica por flexão em torno do eixo de menor inércia (F) (i.e., ignorando o modo de flexo- 
torção - FT), nota-se que, para barras de pequeno comprimento $L_{c}$ a curva é conservadora, enquanto para barras intermediárias a longas a curva é contra a segurança.

A Figura 4.1 ilustra uma das séries experimentais ensaiadas por Young (2004) comparativamente as curvas citadas (considerando modos F e FT, ou somente F). Os demais resultados experimentais obtidos pelo autor, inclusive os de Popovic et al. (1999) com extremidades engastadas, citados no referido trabalho, apresentam comportamento bastante parecido.

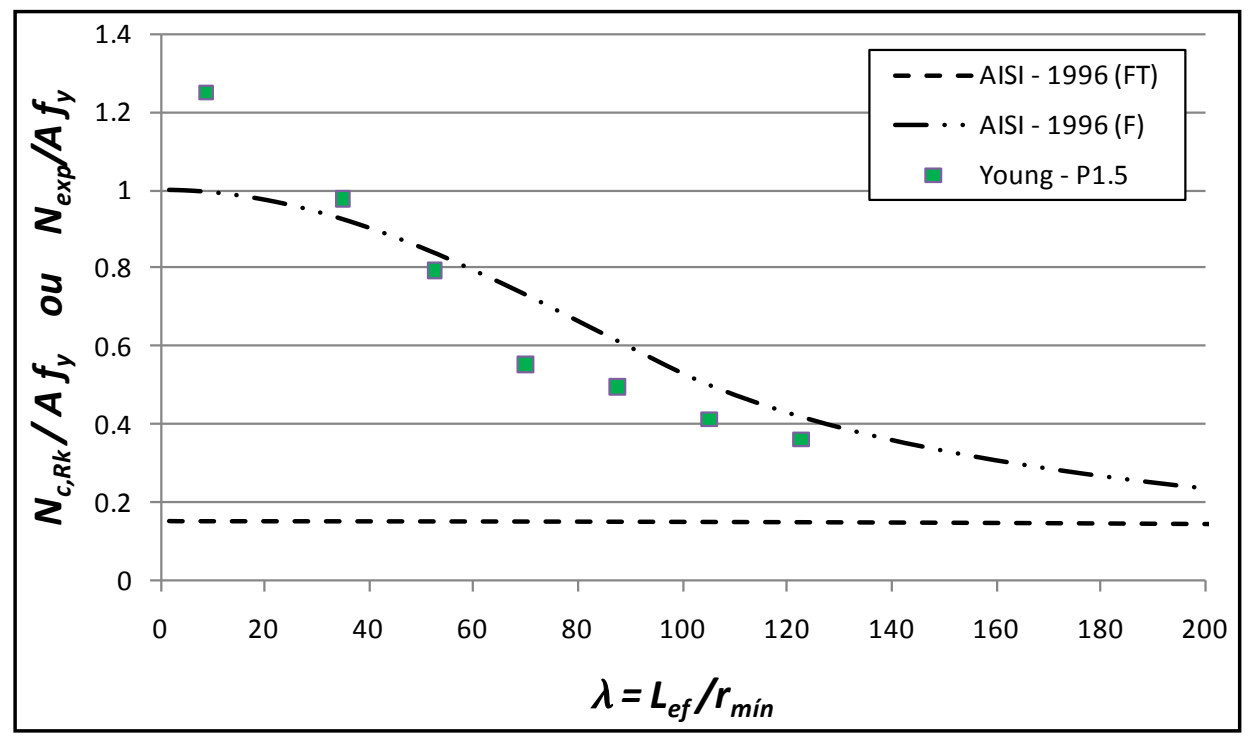

Figura 4.1 - Comparação de uma série $(L 70 \times 1,50)$ de resultados experimentais de Young (2004) com curvas de dimensionamento baseadas somente no modo de flexão ou flexo-torção. Adaptado de Young (2004).

Tendo em vista a ocorrência de tais resultados, o autor propôs um ajuste na curva definida nas Eq. 4.2, resultando em uma nova curva dada por:

$$
\begin{aligned}
& \lambda_{0} \leq 1,4 \Rightarrow \chi=0,5^{\lambda_{0}^{2}} \\
& \lambda_{0}>1,4 \Rightarrow \chi=\frac{0,5}{\lambda_{0}^{2}}
\end{aligned}
$$

Onde o parâmetro de esbeltez reduzida $\left(\lambda_{0}\right)$ é obtido por meio da Eq. 4.3, e a força axial de flambagem elástica é determinada com base somente no modo de flexão em torno do eixo de menor inércia $(F)$. 
A proposta de Young (2004), portanto, consiste em desconsiderar completamente o modo de flexo-torção, e utilizar a nova curva baseada nas Equações 4.7 para obter o fator de redução da força axial de compressão resistente $(\chi)$. A Figura 4.2 apresenta outra série de ensaios de Young (2004), desta vez mostrando também a curva de dimensionamento proposta.

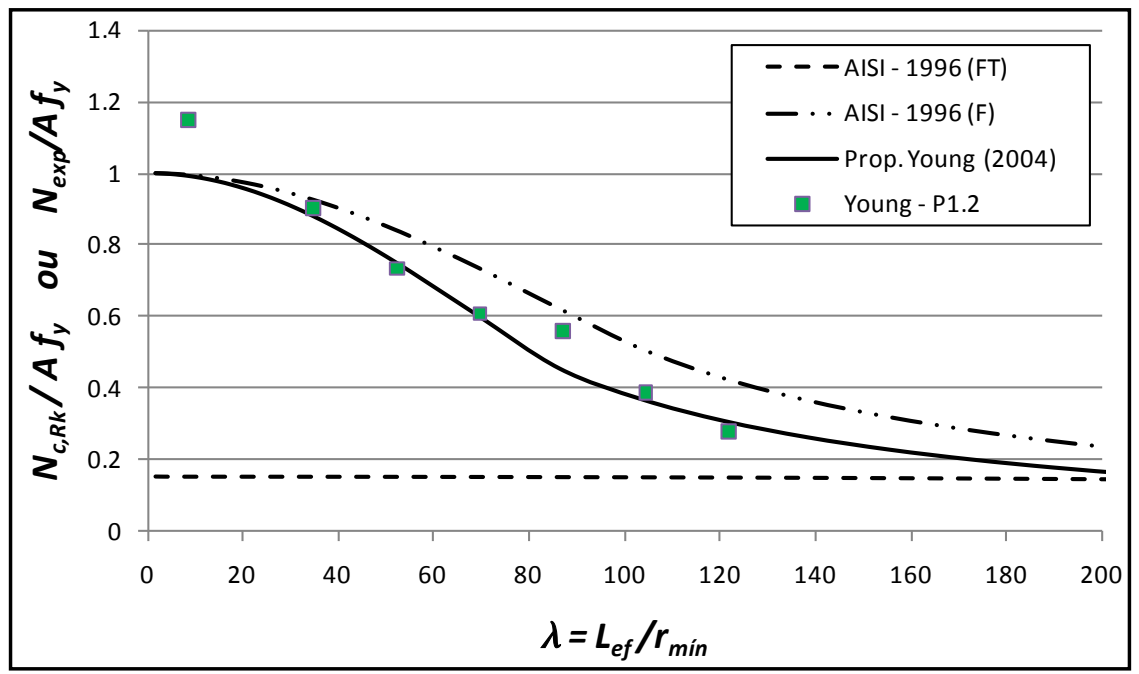

Figura 4.2 - Série de resultados experimentais $L 70 \times 1,20$ de Young (2004) com curvas de dimensionamento baseadas somente no modo de flexão (F) ou flexo-torção (FT) e curva proposta pelo autor. Adaptado de Young (2004).

É importante salientar, contudo, que a proposta de Young (2004) é destinada somente a casos de cantoneiras com extremidades engastadas, sendo a utilização deste procedimento para casos com extremidades rotuladas uma extrapolação da proposta do autor.

\subsection{Procedimento Proposto por Rasmussen (2003)}

No trabalho elaborado por Rasmussen (2003) são avaliados diversos modelos teóricos em comparação com resultados experimentais selecionados de outros autores (Wilhoite 1984, e Popovic et al. - 1999). Dentre tais modelos, apenas aquele que demonstrou o melhor desempenho é detalhado aqui.

A proposta, chamada em seu trabalho de "P9", consiste em desconsiderar o modo global de flexo-torção, e fazer o dimensionamento para flexo-compressão devido a uma excentricidade $\left(e_{0}\right)$ na aplicação da força, medida do centróide da seção transversal bruta ao 
centróide da seção efetiva, o qual tem sua posição obtida por meio da solução de Stowell (Stowell, 1949), sem utilizar o método das larguras efetivas para tal.

Assim, segundo Rasmussen (2003), a força axial de compressão resistente característica $\left(N_{R k}\right)$ para cantoneiras de abas iguais deve ser determinada com base na expressão de interação:

$$
\frac{N_{S k}}{N_{c, R k}}+\frac{C_{m} M_{S k}}{M_{R k}\left(1-\frac{N_{S k}}{N_{e y}}\right)} \leq 1
$$

Sendo $C_{m}=1$ para momento constante, e $N_{e y}$ a força axial elástica de flexão em torno do eixo de menor inércia.

A força axial de compressão resistente $\left(N_{c, R k}\right)$ é dada pelo procedimento normativo descrito no início do Capítulo 4 deste trabalho, mas desconsiderando-se o modo de flexo-torção no cálculo de $N_{e}$.

O momento fletor resistente $\left(M_{R k}\right)$, deve ser calculado com base no início do escoamento da seção efetiva, assim:

$$
M_{R k}=W_{e f} \cdot f_{y}
$$

Sendo $W_{\text {ef }}$ o módulo elástico da seção efetiva em relação à fibra extrema que atinge o escoamento.

O momento fletor solicitante $M_{s k}$ é dado pelo produto da força axial solicitante $N_{S k}$ pela excentricidade sugerida por Rasmussen (2003):

$$
M_{S k}=N_{S k} \cdot e_{0}
$$

Sendo $e_{0}$ dado por:

$$
e_{0}=\left\{\begin{array}{ccc}
0 & \text { para } \lambda_{p} \leq 1,22 \\
\frac{5}{16 \sqrt{2}} \frac{\lambda_{p}-1,22}{\lambda_{p}-0,22} \cdot b & \text { para } \lambda_{p}>1,22
\end{array}\right.
$$

Onde $b$ é a largura plana da aba da cantoneira e $\lambda_{p}$ é o índice de esbeltez reduzido associado à flambagem local calculado para a tensão de escoamento, 


$$
\lambda_{p}=\sqrt{\frac{f_{y}}{\sigma_{c r}}}
$$

o qual, por sua vez, é função da tensão convencional de flambagem elástica de chapa $\left(\sigma_{c r}\right)$, dada por $\left(N_{c r} / A\right)$, com $N_{c r}$ definido pela Eq. 2.11, $\operatorname{com} k=0,43$.

A força axial resistente característica $\left(N_{R k}\right)$ é obtida com base na condição limite da expressão 4.8 , tal qual mostrado na expressão 4.13 , considerando $N_{S k}=N_{R k}$.

$$
\frac{N_{R k}}{N_{c, R k}}+\frac{N_{R k} \cdot e_{0}}{M_{R k}\left(1-\frac{N_{R k}}{N_{e y}}\right)}=1
$$

\subsection{Procedimento Proposto por Chodraui et al. (2006)}

O presente procedimento, idealizado no trabalho de Chodraui et al. (2006), e mais tarde com a corroboração de Maia et al. (2008), apresenta, segundo estes autores, um bom desempenho frente a diversos ensaios experimentais, com resultados ligeiramente a favor da segurança, e tem ainda a seu favor uma considerável simplicidade para aplicação.

Sendo baseado no MRD, este procedimento tem como premissa básica a consideração de ambos os modos de flambagem, global por flexão (F) e global por flexo-torção (FT), como modos globais, sendo, portanto, a força axial de flambagem global elástica $\left(N_{e}\right)$ o mínimo valor entre os dois modos.

Além disso, é tomado para o modo local sempre um único valor de força axial de flambagem local elástica $\left(N_{\ell}\right)$, obtido no ponto de mínimo valor do modo "global" de flexotorção, que para as cantoneiras é sempre obtido na intersecção entre o modo de flexotorção e o modo de flexão, tal como ilustra a Figura 4.3, no ponto "FT*", sendo que na mesma figura o fator de carga ("load factor") é dado por $\left(\sigma_{c r} / f_{y}\right)$, e o comprimento de semionda ("half-wavelength") expresso em milímetros.

Segundo Chodraui et al. (2006), tal procedimento é baseado na "coincidência" entre o modo global por torção e o modo local, no primeiro ramo da curva de flambagem. 


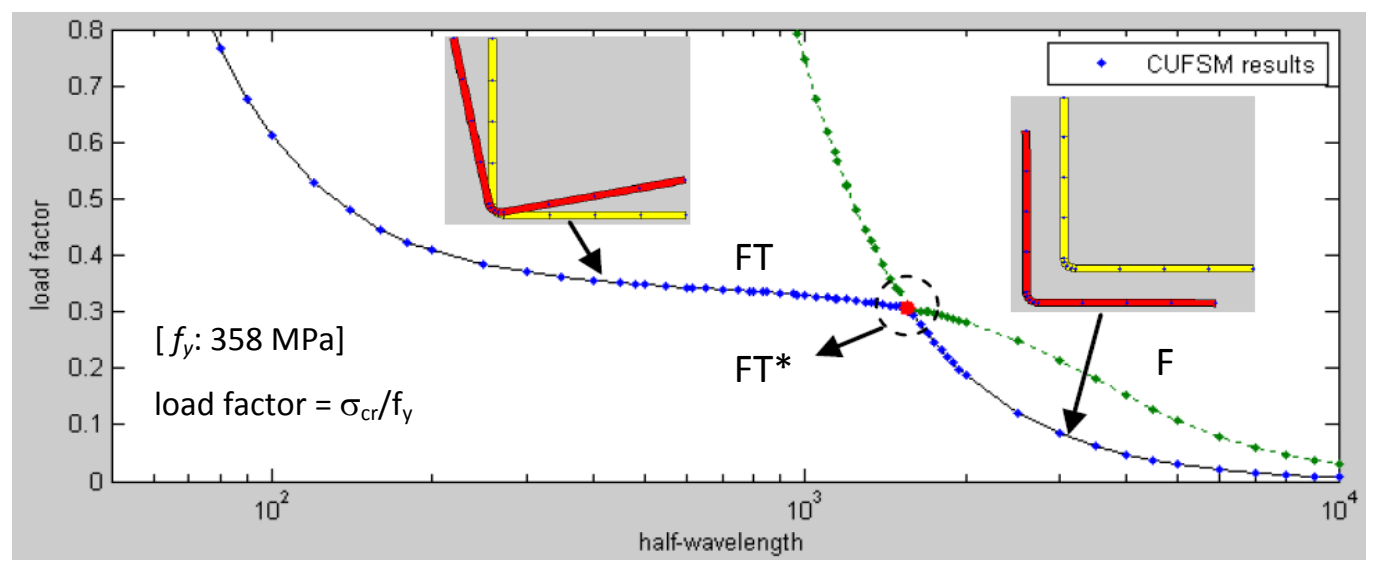

Figura 4.3 - Curva "Fator de carga vs. Comprimento de semi-onda" (em mm) para cantoneira L60x2,38mm, mostrando o ponto de intersecção FT*. Adaptado de: Maia et al. (2008)

Portanto, apenas para deixar claro o procedimento, o valor característico da força axial resistente de compressão $\left(N_{c, R k}\right)$ para cantoneiras, segundo Chodraui et al. (2006), seria definido tal como ilustra o fluxograma da Fig. 4.4.

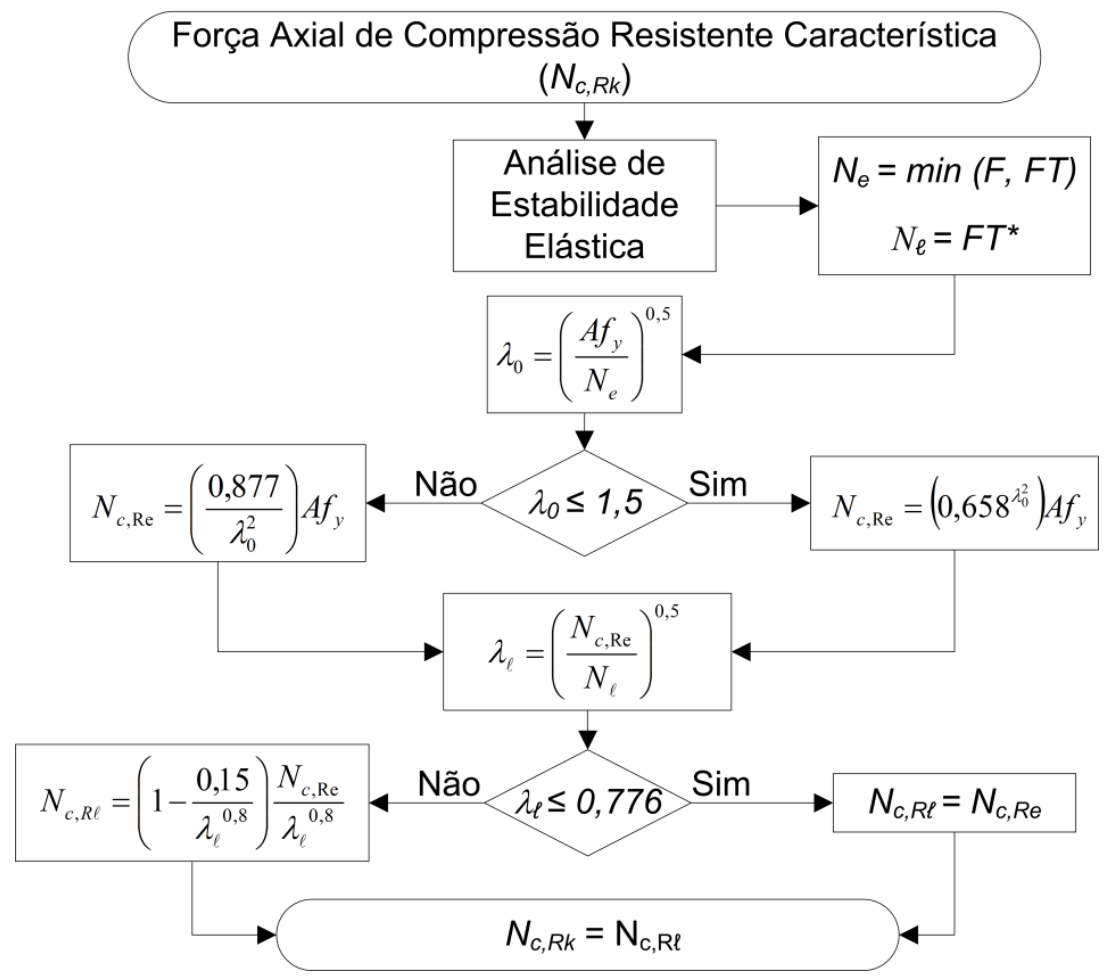

Figura 4.4 - Fluxograma para obtenção de força axial de compressão resistente para cantoneiras segundo Chodraui et al. (2006) 


\subsection{Procedimento Proposto por Silvestre et al. (2012)}

A mais recente proposta para previsão da força axial resistente de cantoneiras é de Silvestre et al. (2012), que já tendo analisado o desempenho de procedimentos como os citados nos itens anteriores, bem como boa parte do estudo teórico descrito no Cap. 2 deste trabalho, sugerem que o procedimento para cantoneiras engastadas seja diferente do procedimento para cantoneiras rotuladas, resultando assim em dois processos distintos.

O primeiro, composto de forma a melhor se ajustar aos resultados experimentais (Silvestre et al. (2012) trabalharam com uma compilação de resultados experimentais quase tão vasta quanto a deste trabalho, incluindo os próprios ensaios experimentais aqui realizados) e numéricos de cantoneiras com extremidades engastadas, combina a curva de dimensionamento proposta por Young (2004), definida pelas Equações 4.7, com a curva de dimensionamento do MRD para interação local/global, dada pelas Eqs. 4.4.

O segundo procedimento, exclusivo para cantoneiras rotuladas (rótulas cilíndricas), combina a utilização da curva de dimensionamento proposta por Young (2004) (Eq. 4.7) com uma nova curva de dimensionamento considerando a interação local/global, ajustada a partir daquela definida pelas Equações 4.4. A nova curva proposta é dada por:

$$
\begin{array}{cc}
N_{c, R \ell}=N_{c, R e} & \text { para } \lambda_{\ell} \leq 0,71 \\
N_{c, R \ell}=\left(1-0,25 \frac{N_{\ell}}{N_{e}}\right) N_{\ell} & \text { para } \lambda_{\ell}>0,71
\end{array}
$$

sendo $\lambda_{e}$ o mesmo da Eq. 4.5.

Ademais, ambos os procedimentos sugerem a desconsideração do modo de flexotorção na determinação de $N_{e}$, tal como no procedimento proposto por Young (2004).

Desta forma, os dois procedimentos resultam claramente distintos em função de uma curva ajustada para o caso de cantoneiras com extremidades rotuladas.

O fluxograma apresentado na Fig. 4.5 ilustra mais claramente o processo sugerido por Silvestre et al. (2012). 


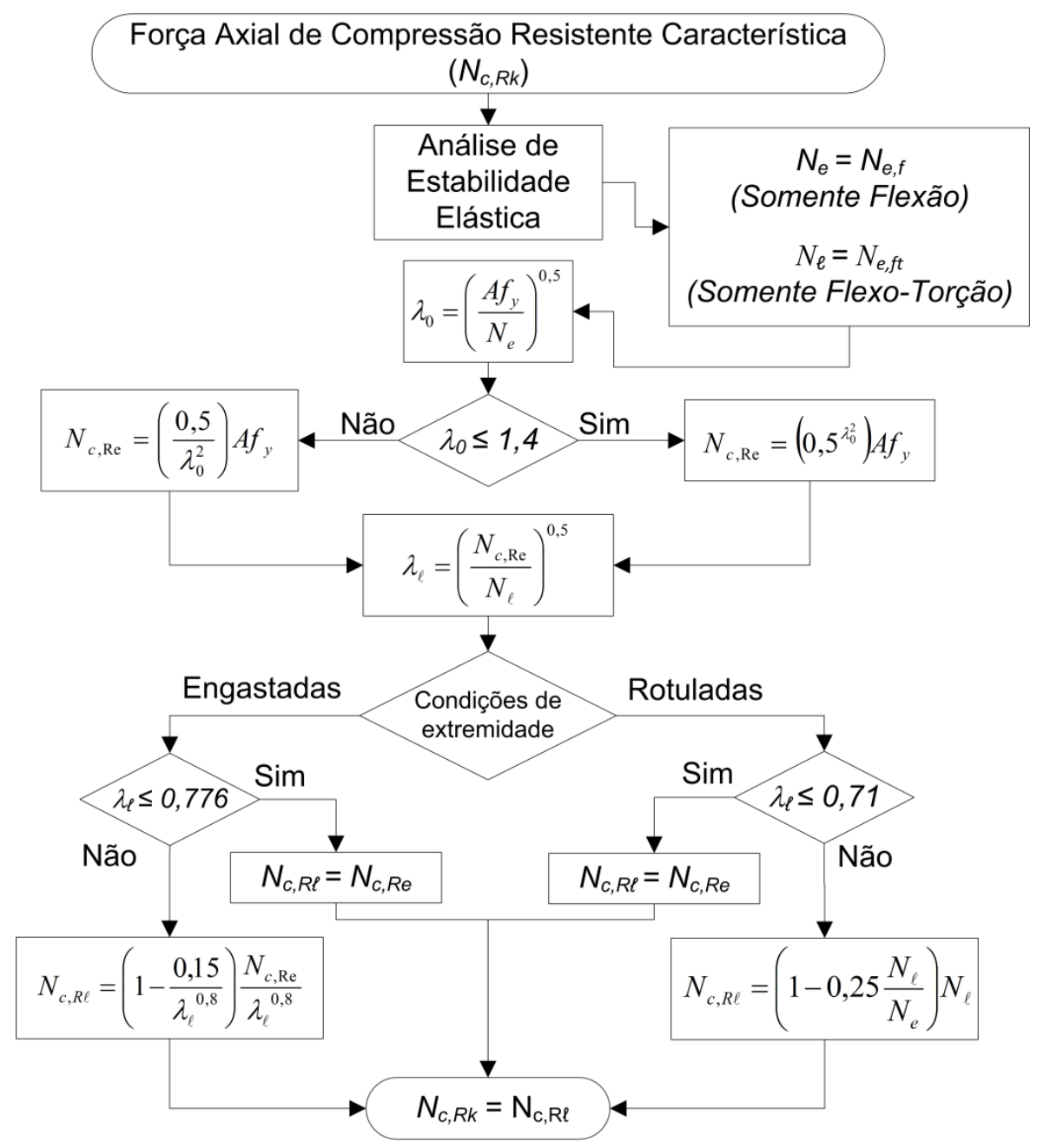

Figura 4.5 - Fluxograma para obtenção de força axial de compressão resistente para cantoneiras segundo Silvestre et al. (2012)

\subsection{Procedimentos Baseados no MLE}

Para análise comparativa junto aos demais procedimentos neste trabalho, três outros baseados na ABNT NBR 14762:2010 são abordados.

O primeiro (que será referido neste trabalho pela sigla "MLE $\left(\mathrm{FT}_{\mathrm{Aef}}\right)$ "), pode-se entender como sendo o atual procedimento normativo, apresentado no início do presente Capítulo pelas expressões 4.1 a 4.3 , e considerando $N_{e}$ como sendo a menor das forças axiais de flambagem elástica considerando o modo global de flexão $\left(N_{e, f}\right)$ e o modo global por flexo-torção $\left(N_{e, f t}\right)$. Naturalmente, este procedimento envolve também a consideração do modo local, por meio da área efetiva $\left(A_{e f}\right)$ da seção transversal. 
Entretanto, conforme já comentado (e foi o que deu início a tantas pesquisas sobre cantoneiras), este procedimento apresenta alguns resultados demasiadamente conservadores, especialmente aqueles apresentados por Young (2004), conforme ilustram as Figuras 4.1 e 4.2 .

Deste modo, é analisado um segundo procedimento (referido pela sigla "MLE $\left(\mathrm{FT}_{\mathrm{A}}\right)$ "), modificado apenas no sentido de não mais considerar o modo local por meio do cálculo da área efetiva da seção. Assim, se considera $N_{e}$ ainda como a menor das forças axiais de flambagem elástica obtida para o modo global de flexão $\left(N_{e, f}\right)$ e para o modo global por flexo-torção $\left(N_{e, f t}\right)$.

Além disso, um terceiro procedimento (referido mais adiante pela sigla "MLE (F)"), semelhante àquele apresentado por Young (2004), pode ser avaliado. Neste, leva-se em consideração para $N_{e}$ somente a força axial de flambagem elástica para o modo global de flexão $\left(N_{e, f}\right)$, e simplesmente desconsiderando a existência do modo global por flexo-torção $\left(N_{e, f t}\right)$

\subsection{Procedimentos Baseados no MRD}

Não obstante, o MRD também permite uma série de diferentes interpretações, sendo que algumas delas já foram verificadas por Chodraui et al. (2006) ${ }^{*}$, contudo, tendo em vista a maior abrangência deste trabalho, foram selecionados dois destes procedimentos para serem aqui revistos.

O primeiro, consiste na interpretação de ambos os modos de flambagem, global por flexão e por flexo-torção, como modos globais, de forma que a força axial de flambagem global elástica $\left(N_{e}\right)$ seja dada pelo mínimo valor entre os dois modos.

Ainda, pode-se incluir o modo global de flexo-torção "também" como um modo local, tal como o procedimento sugerido por Silvestre et al. (2012), porém fazendo uso da curva clássica do MRD para interação local/global.

Um segundo procedimento, ainda mais simples que o primeiro, pode vir da consideração de ambos os modos, de flexão e de flexo-torção, como globais, mas neste

\footnotetext{
* Estes procedimentos, embora tenham sido avaliados por Chodraui et al. (2006), são incluídos neste item do trabalho (Procedimentos Baseados em Norma para o MRD) por serem os procedimentos mais comuns, aos quais um engenheiro, ao interpretar a norma, poderia fazer uso segundo sua interpretação.
} 
caso, entendendo que não existe para cantoneiras um modo local. Sendo o cálculo de $N_{c, R e,}$ portanto, tal como para o modo distorcional, ignorado.

Os fluxogramas exibidos nas Figuras 4.6 e 4.7 ilustram os dois procedimentos anteriormente descritos, sendo o primeiro, por uma questão apenas de nomenclatura, referido pelas letras "GL" (numa alusão a "global" e "local"), e o segundo somente pela letra "G" (devido a consideração apenas do modo global).

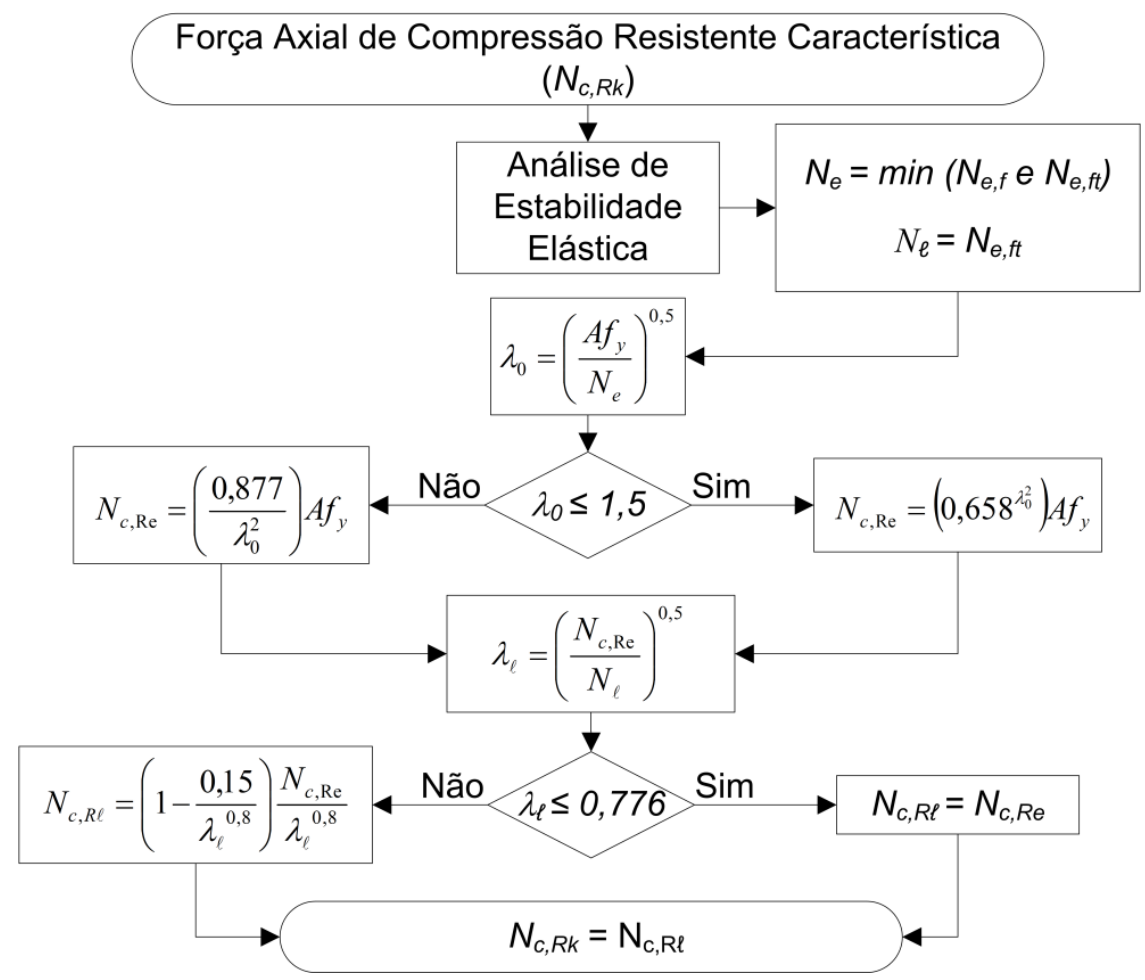

Figura 4.6 - Fluxograma para obtenção de força axial de compressão resistente para cantoneiras segundo procedimento ABNT NBR 14762:2010 (MRD-GL)

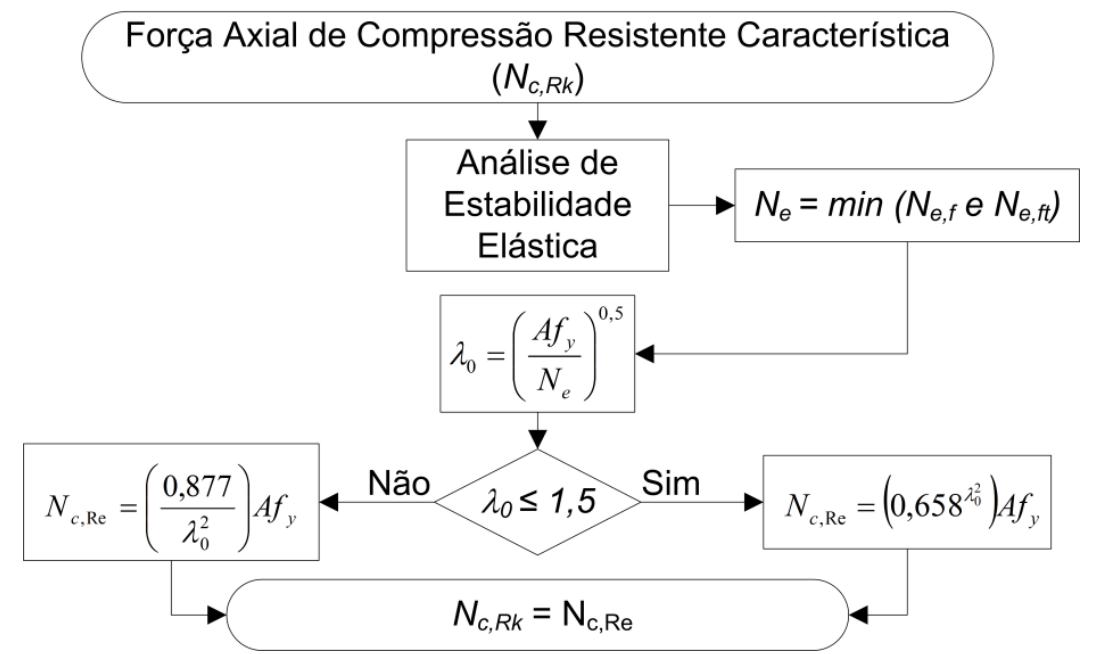

Figura 4.7 - Fluxograma para obtenção de força axial de compressão resistente para cantoneiras segundo procedimento ABNT NBR 14762:2010 (MRD-G) 


\section{AVALIAÇÃO DOS RESULTADOS TEÓRICOS E EXPERIMENTAIS}

Após os estudos teóricos apresentados neste trabalho, é possível compreender de forma mais clara os principais fatores que influenciam o comportamento de cantoneiras simples sob compressão centrada. Deste modo, já se mostra razoável a realização de uma análise completa dos resultados experimentais apresentados no Capítulo 3 à luz dos procedimentos de previsão teórica descritos no Capítulo 4.

No entanto, para a avaliação de todos estes procedimentos, é importante detalhar que:

i. Todas as análises, no caso de cantoneiras com extremidades rotuladas, podem levar em consideração o efeito do afastamento longitudinal das rótulas. Assim, de maneira mais precisa, pode ser utilizada a expressão 2.17 na determinação dos autovalores relativos ao modo de flexão em torno do eixo de menor inércia (lembrando que para o modo de flexo-torção o comprimento a ser considerado é o próprio $L_{c}$, não havendo influência devido ao afastamento das rótulas). No entanto, caso a opção seja utilizar uma análise de estabilidade elástica realizada por meio de outro recurso, sem levar em consideração o efeito do afastamento longitudinal das rótulas, é importante lembrar que se deve utilizar o comprimento efetivo da barra $\left(L_{c}+2 L_{r}\right)$, o qual não deve conduzir a erros grosseiros (neste caso, a favor da segurança) desde que a relação $L_{r} / L_{c}$ mantenha-se abaixo de 1 (valor este que é consideravelmente alto, e deve satisfazer a maioria dos casos típicos de ensaios experimentais, especialmente para barras mais curtas);

ii. Para a consideração de diferentes vínculos de extremidade nas cantoneiras, recomenda-se que se faça uso da GBT (e.g., por meio do código computacional de uso livre GbTUL (Bebiano et al. - 2008)), que permite a consideração de diferentes condições em ambas as direções principais para uma barra, de maneira direta. Contudo, caso a opção seja a análise pelo Método das Faixas Finitas, a 
utilização dos coeficientes de flambagem de barras comprimidas também não devem conduzir a erros consideráveis;

iii. Nas análises de estabilidade elástica realizadas para este estudo foi utilizado o GBTUL (Bebiano et al. - 2008), sendo que a determinação das forças axiais de flambagem elástica referentes ao modo global de flexão em torno do eixo de menor inércia $\left(N_{e, f}\right)$ foi feita por meio da consideração isolada do modo de deformação 3 (vide Fig. 2.2.c), enquanto a respectiva força para o modo de flexo-torção $\left(N_{e, f t}\right)$ foi obtida considerando-se somente os modos de deformação 2, 4 e 6;

iv. Por fim, é importante comentar que os ensaios experimentais realizados por Prabhu (1982) e Wilhoite (1984) apud Rasmussen (2003), foram desconsiderados nestas análises. Quanto ao primeiro, considera-se que as barras analisadas possuíam esbeltez muito elevada, juntamente com seções transversais relativamente compactas, o que (provavelmente) fez com que todas as barras apresentassem um modo de falha por flexão em torno do eixo de menor inércia, o que não faz parte da problemática deste estudo. Já sobre o segundo autor, não foi possível obter o trabalho original para um estudo mais apurado dos procedimentos experimentais e seus respectivos resultados (apesar das exaustivas buscas durante os primeiros meses deste trabalho), sendo faltantes algumas informações importantes, como detalhes do aparato de ensaio e até mesmo o modo de falha daquelas barras.

Desta forma, para se ter, primeiramente, uma visão mais ampla dos resultados obtidos, - gráfico da Figura 5.1 oferece a média geral (considerando todos os resultados experimentais) para a variável "Erro de Modelo" ( $N_{\text {exp }} / N_{c, R k}$, onde $N_{\text {exp }}$ é força máxima resistente verificada experimentalmente), de forma separada para barras rotuladas e engastadas, em função de cada procedimento teórico apresentado no Capítulo 4 (a nomenclatura utilizada é apresentada na Tabela 5.1).

Além disso, o mesmo gráfico fornece, ainda, os valores de Desvio Padrão resultante de cada procedimento teórico para cada série analisada (rotuladas ou engastadas), permitindo avaliar, com isso, a dispersão dos resultados em cada procedimento.

No Apêndice A é possível analisar individualmente os resultados da variável erro de modelo em função do índice de esbeltez de cada barra $\left(\lambda=L d r_{\min }\right)$ para todos os procedimentos teóricos avaliados. 
Tabela 5.1 - Siglas utilizadas para se referir aos procedimentos de previsão teórica

\begin{tabular}{|c|c|}
\hline Sigla & Referência para consulta neste trabalho \\
\hline MLE ( $\left.\mathrm{FT}_{\text {Aef }}\right)$ & Descrito no item 4.5, é o procedimento normativo atual para o MLE; \\
\hline $\operatorname{MLE}\left(\mathrm{FT}_{\mathrm{A}}\right)$ & Descrito no item 4.5, desconsidera o modo local (utiliza a área bruta da seção); \\
\hline MLE (F) & Descrito no item 4.5, varia do MLE ( $\left.\mathrm{FT}_{\text {Aef }}\right)$ pela desconsideração do modo de flexo-torção; \\
\hline MLE (Young) & Procedimento descrito no item 4.1, proposto por Young (2004); \\
\hline MLE (Ras) & Procedimento descrito no item 4.2, proposto por Rasmussen (2003); \\
\hline MRD (GL) & Procedimento descrito no item 4.5 - Fig. 4.6; \\
\hline $\mathrm{MRD}(\mathrm{G})$ & Procedimento descrito no item 4.5 - Fig. 4.7; \\
\hline MRD (Chod) & Descrito no item 4.3 - Fig. 4.4, proposto por Chodraui et al. (2006); \\
\hline MRD (Sil) & Descrito no item 4.4 - Fig. 4.5, proposto por Silvestre et al. (2012). \\
\hline
\end{tabular}

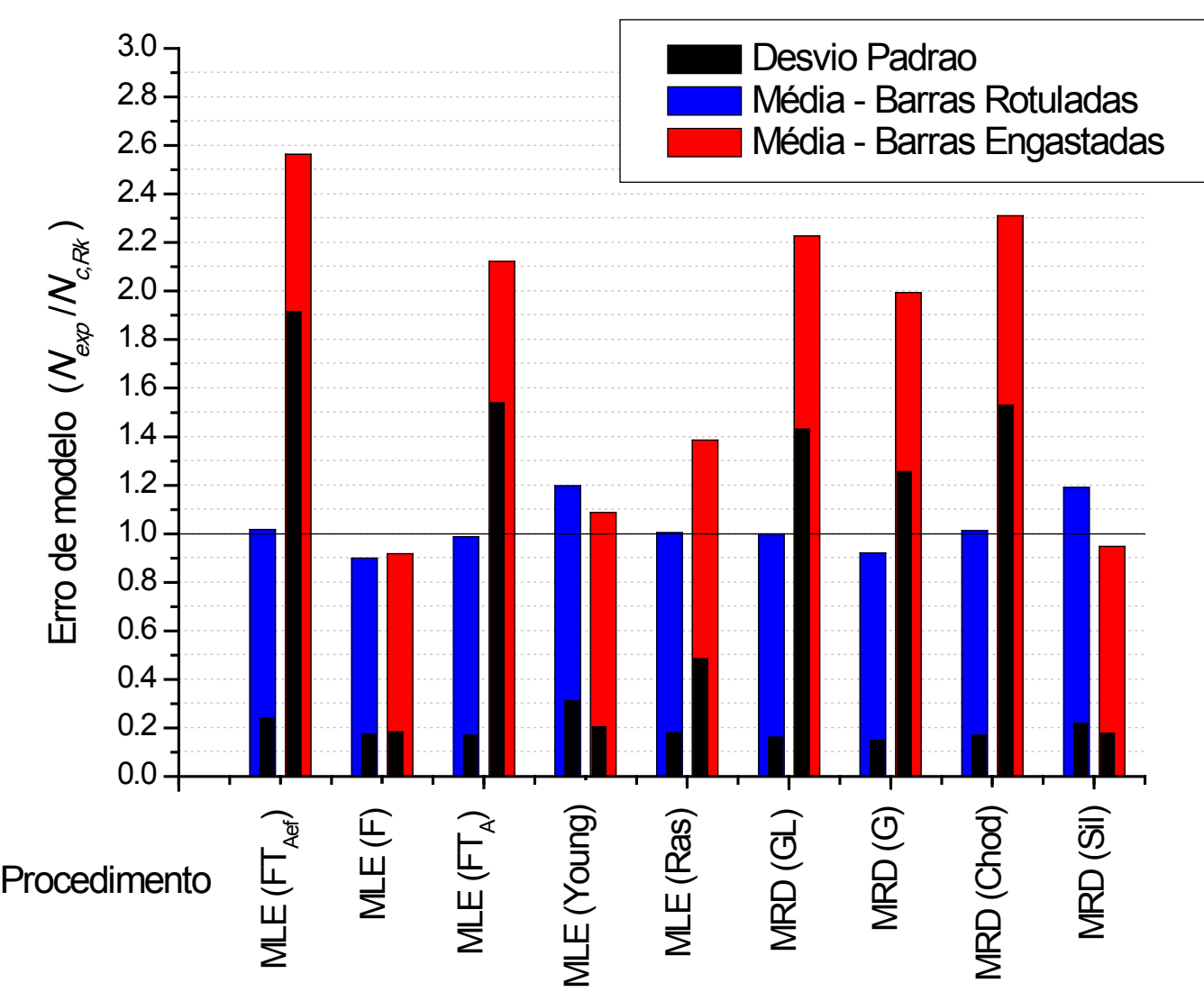

Figura 5.1 - Média e Desvio Padrão para variável "Erro de Modelo" em função dos diferentes procedimentos de previsão teórica aplicados a barras rotuladas e engastadas.

A avaliação da Figura 5.1 permite elucidar as seguintes questões:

i. Primeiramente, confirmam-se alguns resultados apontados por outros autores (e.g., Young (2004) e Rasmussen (2003)), sobre previsões teóricas demasiadamente conservadoras (mas repara-se também que nenhum procedimento apresentou a condição "oposta", com resultados demasiadamente contra a segurança). 
Contudo, a maior dispersão dos resultados ocorre para o caso de barras com extremidades engastadas;

ii. Entre os procedimentos que subestimam a capacidade resistente das cantoneiras com extremidades engastadas, estão todos aqueles que consideram o modo de flexo-torção como um modo global. No entanto, esta discrepância nos resultados não é função da "ocorrência" do modo de flexo-torção (que acontece, de fato, nos resultados experimentais), mas sim da diferente reserva de resistência "pós crítica"* para cantoneiras engastadas e cantoneiras rotuladas, a qual também varia de baixa (para barras mais longas) a consideravelmente elevada (no caso de barras mais curtas), conforme apresentado no capítulo 2 deste trabalho;

\section{Barras com extremidades rotuladas}

i. Conforme já ilustrado no capítulo 2, as barras com extremidades rotuladas, em geral, apresentam menor reserva de resistência pós crítica (para os comprimentos considerados) que aquelas com extremidades engastadas, isto faz com que a dispersão nos resultados de várias barras com mesmo valor de esbeltez reduzida $\left(\lambda_{0}\right)$ seja menor, o que pode conduzir a resultados mais "assertivos". Neste caso, apenas o procedimento MLE (Young) e MRD (Sil) apresentaram resultados conservadores (lembrando que ambos utilizam a mesma curva de dimensionamento, proposta por Young (2004)), enquanto, por outro lado, somente os procedimentos MLE (F) e MRD (G) foram contra a segurança, embora nenhum deles com erros demasiadamente grandes;

ii. $\quad$ Para ilustrar melhor o caso das barras com extremidades rotuladas, a Figura 5.2 dispõe, para a proposta MLE (Young) (cujos resultados se assemelham a MRD (Sil)), os resultados da variável erro de modelo em função do índice de esbeltez da barra $\left(\lambda=L_{c} / r_{\min }\right)$, na qual se pode notar que existe uma clara tendência de resultados a favor da segurança para barras com esbeltez $(\lambda)$ acima de 75 , e

\footnotetext{
* O termo "pós crítico" refere-se à trajetória de equilíbrio não linear de uma barra com imperfeições geométricas iniciais,
} com ou sem a consideração da não linearidade material (equilíbrio não linear elastoplástico, ou elástico, respectivamente). 
contra a segurança para barras $\operatorname{com} \lambda$ abaixo de 75 , além de um desvio padrão relativamente alto;

iii. Da mesma maneira, é interessante mostrar a dispersão dos resultados de erro de modelo para o procedimento MLE (F), apresentado na Fig. 5.3 , onde se nota a disposição de resultados em torno da média 0,9. Estes resultados demonstram que a curva de dimensionamento normativa (lembrando que neste procedimento apenas o modo de flexão em torno do eixo de menor inércia é levado em consideração) não é apropriada para nenhuma faixa de esbeltezes, mas apresenta um erro aproximadamente constante em função da esbeltez;

iv. É possível se ter uma visão melhor da tendência de comportamento das cantoneiras com extremidades rotuladas tomando, por exemplo, os resultados de Chodraui et al. (2006), assim, a Figura 5.5 mostra os resultados de força máxima resistente obtidos experimentalmente pelo autor (conforme Tab. 3.2), juntamente com as curvas de dimensionamento baseadas nos procedimentos $\operatorname{MLE}(F), M L E\left(F_{\text {Aef }}\right.$ ), MLE (Young) e MLE (Ras). Em geral (referindo-se aos resultados de outros autores, aqui omitidos graficamente), existe uma tendência, sobre o platô característico de flexo-torção, de que os resultados se dispersem entre a curva MLE ( $\left.\mathrm{FT}_{\text {Aef }}\right)$ e a curva $\mathrm{MLE}(\mathrm{F})$, sendo que em termos de média, o procedimento proposto por Rasmussen (2003) é o de melhor desempenho, conforme ilustrado pela Figura 5.4;

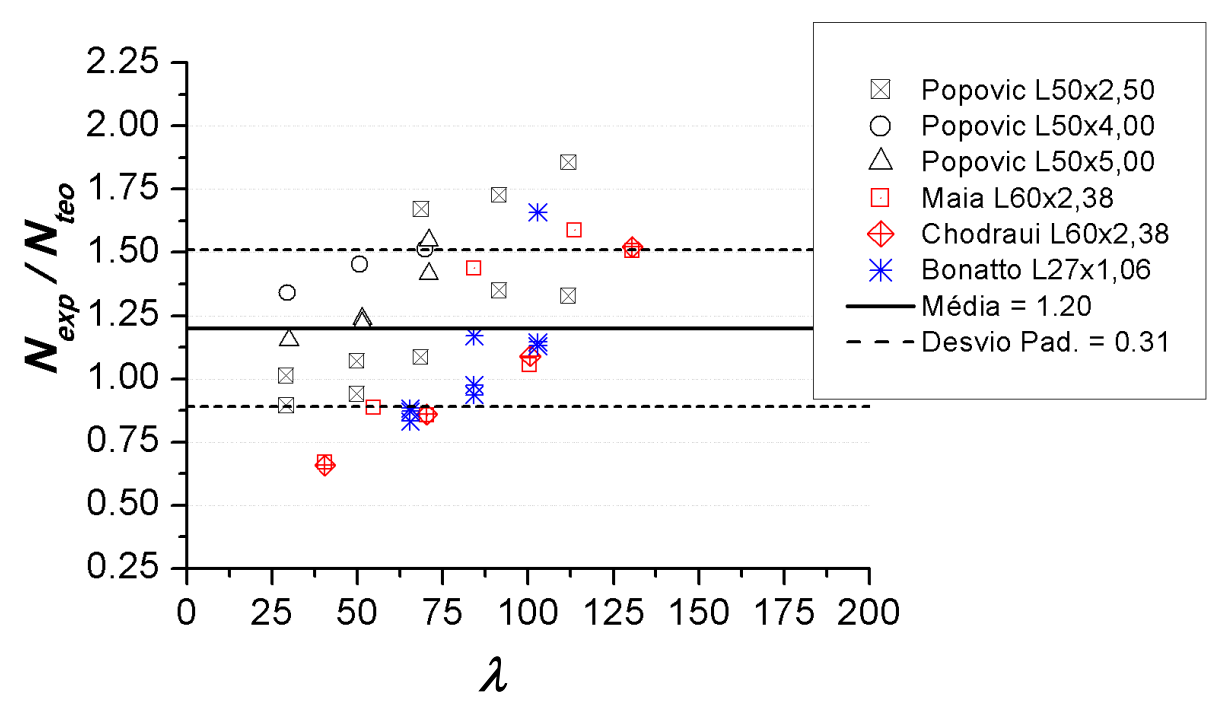

Figura 5.2 - Erro de Modelo para procedimento MLE (Young) em função da esbeltez ( $\lambda$ ) - Barras Rotuladas 


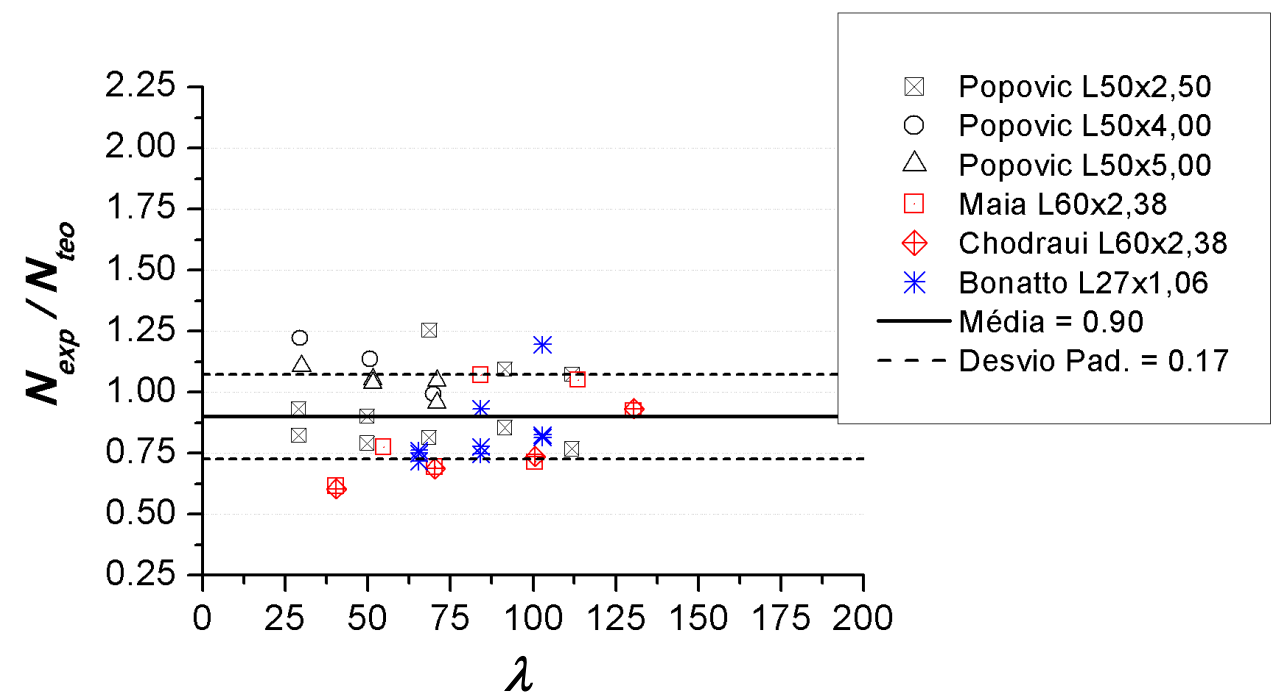

Figura 5.3 - Erro de Modelo para procedimento MLE (F) em função da esbeltez $(\lambda)$ - Barras Rotuladas

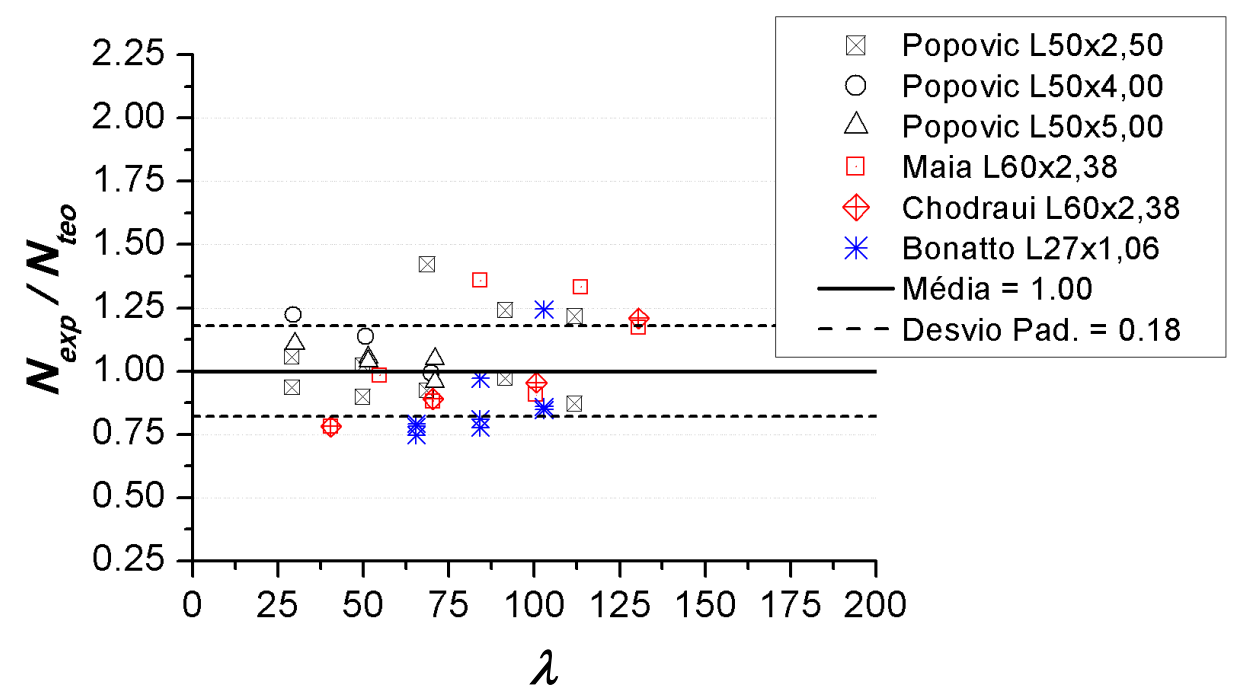

Figura 5.4 - Erro de Modelo para procedimento MLE (Ras) em função da esbeltez ( $\lambda$ ) - Barras Rotuladas

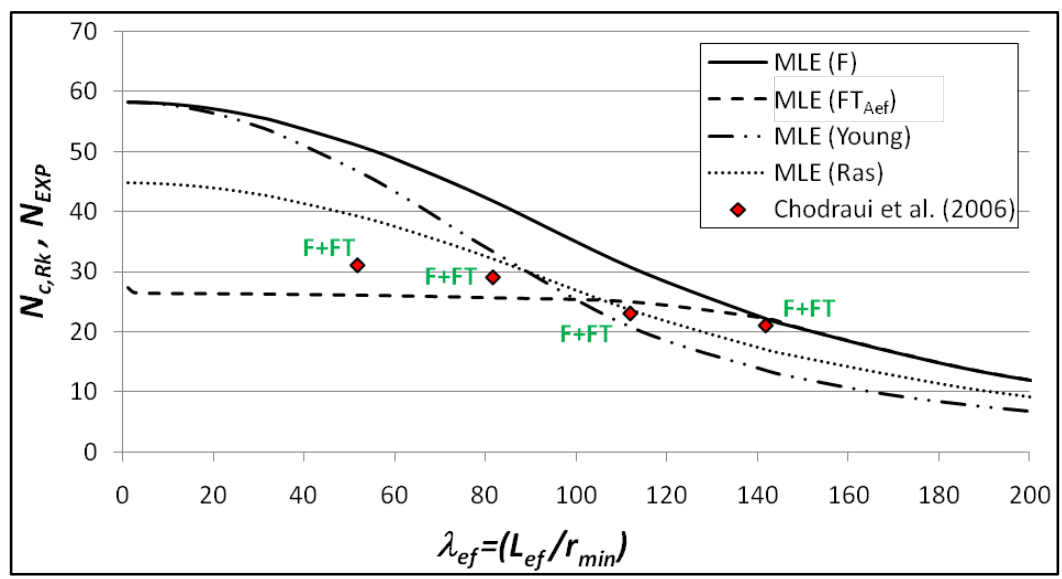

Figura 5.5 - Curvas de dimensionamento baseadas nos procedimentos MLE (F), MLE (FT), MLE (Young) e MLE

(Ras), juntamente com resultados experimentais obtidos por Chodraui et al. (2006) - Barras Rotuladas 
- Barras com extremidades engastadas

i. Para barras com extremidades engastadas, como se vê na Fig. 5.1, quatro procedimentos tiveram médias de erro de modelo próximas de 1: MLE (F), MLE (Young), MLE (Ras) e MRD (Sil). Como se vê, no caso dos procedimentos baseados no MRD, apenas o proposto por Silvestre et al. (2012) apresentou bons resultados, sendo também o único que, assim como os outros três citados baseados no MLE, ignora o modo de flexo-torção como modo global (item 4.4);

ii. O procedimento MLE (F), como pode ser visto na Figura 5.6, apresentou um resultado semelhante ao mesmo método para barras com extremidades rotuladas, porém, com uma tendência para resultados levemente conservadores no caso de barras mais curtas $(\lambda<50)$. Este panorama sugere que um ajuste na curva de dimensionamento poderia conduzir a bons resultados, e no caso das barras engastadas, é exatamente o que ocorre para o procedimento MLE (Young), cujos resultados são expostos na Figura 5.7. Lembrando, porém, como comentado anteriormente, no caso das barras rotuladas o procedimento MLE (Young) não se enquadrou bem à variação dos resultados em função da esbeltez das barras, apresentando um desvio padrão razoavelmente elevado;

iii. O procedimento MLE (Ras), ora muito interessante no caso das cantoneiras com extremidades rotuladas, mostrou-se conservador no caso das barras engastadas, com média e desvio padrão demasiadamente elevados (vide Figura 5.8), especialmente para o caso de seções transversais mais esbeltas, como as de Young (2004);

iv. Por fim, tem-se a recente proposta MRD (Sil), com resultados ilustrados na Figura 5.9, e cujo desempenho no caso das barras rotuladas foi muito semelhante ao do MLE (Young). Para barras com extremidades engastadas, no entanto, MRD (sil) apresenta resultados razoáveis, apesar dos ensaios de Maia et al. (2008), que se dispõem um pouco dispersos do conjunto de resultados ${ }^{*}$, influenciando a média abaixo de 1 na variável erro de modelo, e também apesar da tendência levemente conservadora para barras com $\lambda>150$, devido à curva proposta por Young (2004), que claramente não aproxima bem os resultados de barras longas.

\footnotetext{
* Em um estudo semelhante, Silvestre et al. (2012) não consideram os resultados obtidos por Maia et al. (2008) para barras engastadas, justamente por se apresentarem relativamente dispersos dos demais resultados. Neste trabalho, optou-se por manter os resultados no conjunto analisado, mas de fato, são resultados consideravelmente distintos dos demais.
} 


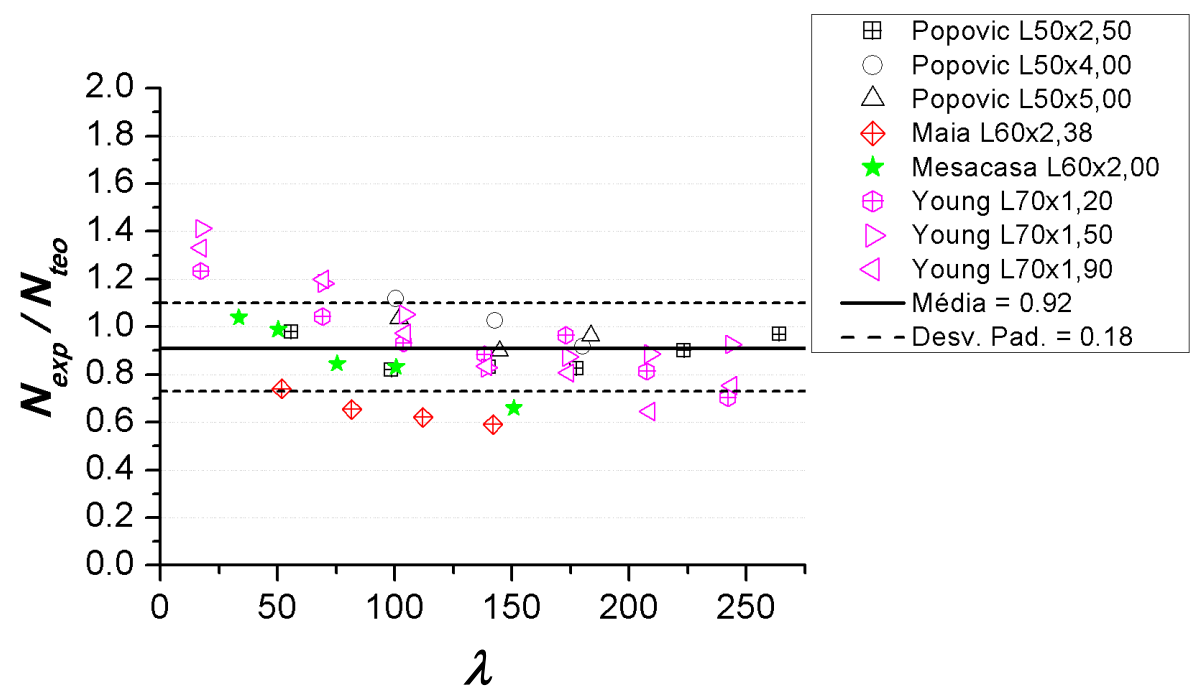

Figura 5.6 - Erro de Modelo para procedimento MLE (F) em função da esbeltez $(\lambda)$ - Barras Engastadas

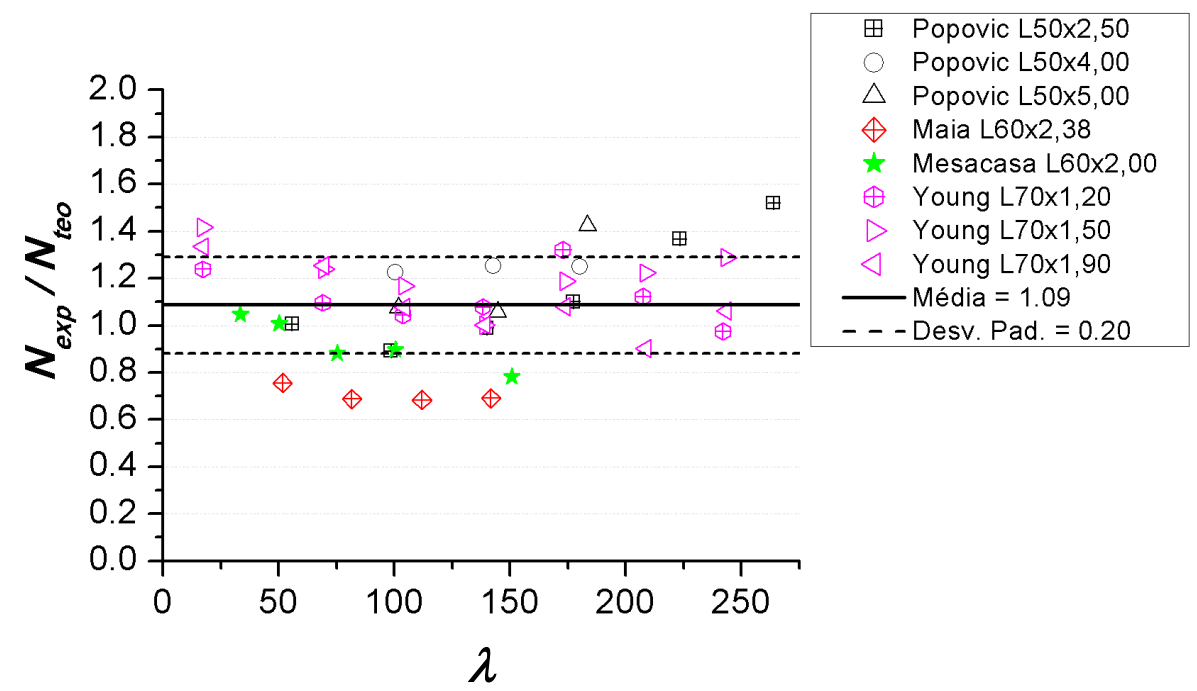

Figura 5.7 - Erro de Modelo para procedimento MLE (Young) em função da esbeltez ( $\lambda$ ) - Barras Engastadas

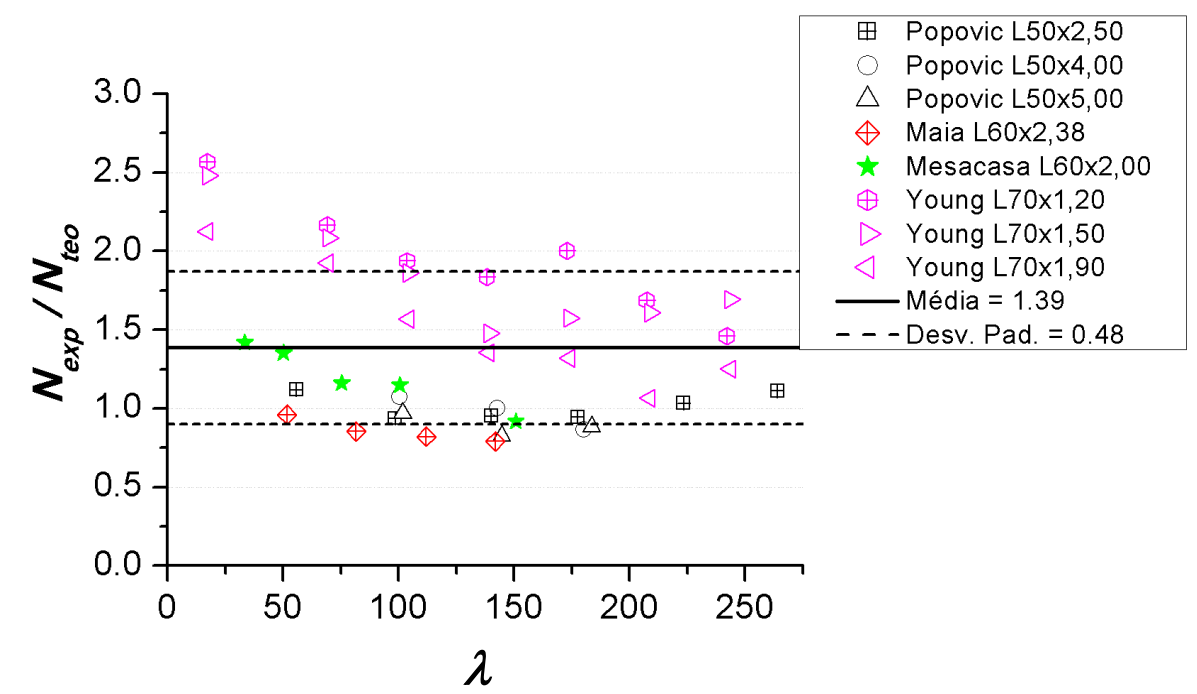

Figura 5.8 - Erro de Modelo para procedimento MLE (Ras) em função da esbeltez $(\lambda)$ - Barras Engastadas 


\section{CONCLUSÕES}

Foram abordadas neste trabalho diferentes questões com relação ao comportamento e ao dimensionamento de cantoneiras esbeltas de abas iguais a serem comentadas.

Primeiramente, com relação a "coincidência" entre os modos de instabilidade global por torção e local de chapa no primeiro ramo da curva $N_{c r} v s$. $L_{c}$, ficou claro, conforme apresentado nos trabalhos de Dinis et al. (2010-b), Silvestre et al. (2012), e comentado no capítulo 2 desta dissertação, que o típico comportamento observado nesta faixa de comprimentos para as cantoneiras, deve ser visto como de um modo global por torção, que juntamente com os deslocamentos típicos de flexão, os quais possuem uma grande influência sobre o comportamento não linear das barras, determinam o típico modo de flexo-torção.

O modo de flexo-torção, que está associado ao típico platô horizontal da curva $N_{c r} v s . L_{c}$, acaba por provocar uma "aglomeração" nos valores de índice de esbeltez reduzido associado à flambagem global $\left(\lambda_{0}\right)$ para séries de barras com diferentes comprimentos mas mesmo material e seção transversal. Isto se deve ao fato de que os valores de força axial de flambagem elástica sobre este platô são muito próximos (pouco variam em função do comprimento). Por outro lado, para estas mesmas barras com diferentes comprimentos ao longo do platô horizontal de flexo-torção, repara-se que há uma considerável variação na força axial de compressão resistente obtida experimentalmente.

Conforme comentado no capítulo 2, Dinis et al. (2010-a, 2012) e Silvestre et al. (2012), demonstram que este comportamento está associado à diferente reserva de resistência póscrítica para barras com diferentes comprimentos ao longo do platô de flexo-torção, o que, de fato, conduz a diferentes resultados de força axial resistente.

No caso das barras com extremidades rotuladas, esta dispersão característica dos resultados de força axial resistente em função do índice de esbeltez reduzido associado à flambagem global é muito menor, de modo que, para as faixas de comprimentos analisadas, os resultados apresentam-se mais agrupados, o que conduz a melhores previsões teóricas de força máxima resistente. 
Além disso, foram apresentados estudos de variáveis com relação direta a alguns comportamentos tidos como "paradoxais", como, por exemplo, os diferentes modos de instabilidade (flexo-torção e flexão em torno do eixo de menor inércia) que podem ser vistos para barras com comprimentos sobre o platô característico do modo de flexo-torção, ou mesmo para barras com comprimentos sobre a curva do modo de flexão em torno do eixo de menor inércia.

Dentre estas variáveis, no caso de barras com extremidades rotuladas, mostrou-se como uma potencial causa da "antecipação" do modo de flexão em torno do eixo de menor inércia para barras cujo comprimento se situa sobre o platô característico de flexo-torção, o afastamento entre as extremidades da barra e o eixo da rótula. Conforme explanado no item 2.1, tais afastamentos exercem uma influência semelhante a de "elementos contraventados" ("leaning columns"), sendo, assim, um fator desestabilizante ao conjunto analisado.

Esta influência dos afastamentos longitudinais pode ser consideravelmente grande, dependendo unicamente da relação entre os comprimentos da barra flexível $\left(L_{c}\right)$ e do referido afastamento longitudinal (visto como elemento rígido $-L_{r}$ ). 0 item 2.1.4 mostra esta influência com exemplos experimentais selecionados em trabalhos de outros autores, a qual pode conduzir, especialmente para a faixa de comprimentos próximos da transição entre os modos de flexo-torção e flexão, a previsões e interpretações equivocadas com relação aos modos de instabilidade e força axial de flambagem global elástica.

Por outro lado, foi apresentada também a influência das imperfeições geométricas iniciais, em especial as de flexão em torno do eixo de menor inércia, que se mostraram determinantes sobre o comportamento não linear das cantoneiras.

Este estudo mostra, conforme apresentado no item 2.2, que é possível obter diferentes possibilidades de interação entre os modos de instabilidade por flexão em torno do eixo de menor inércia e flexo-torção, apenas em função do sentido da imperfeição de flexão em torno do eixo de menor inércia e do comprimento da barra.

Excepcionalmente, sobre uma faixa de comprimentos que se estende em função da esbeltez da seção transversal, mas sempre com centro no ponto de intersecção entre os modos críticos de instabilidade (neste trabalho esta faixa de comprimentos é chamada de "região de transição"), é possível verificar consideráveis diferenças de força axial de compressão resistente, sendo sempre a menor delas obtida quando a imperfeição de flexão tende a provocar compressão nas bordas livres da cantoneira. 
Além disso, ainda com base somente no sentido da imperfeição de flexão, diferentes níveis de interação entre os modos de instabilidade podem conduzir a uma interpretação no mínimo atípica, pois a imperfeição de flexão, quando tendendo a provocar compressão na região da dobra, também conduz a deslocamentos típicos de flexão em torno do eixo de menor inércia (no mesmo sentido da imperfeição), podendo culminar na manifestação de um modo de flexão puro, mesmo para um comprimento de barra sobre o patamar do modo de flexo-torção. Por outro lado, quando a imperfeição se dá no sentido oposto, a tendência é de se ter sempre deslocamentos típicos de flexo-torção, podendo, inclusive, haver instabilidade por flexo-torção em uma barra cujo comprimento esteja já sobre a curva característica do modo crítico de flexão em torno do eixo de menor inércia.

Assim, explicam-se comportamentos inesperados, como barras com instabilidade por flexão com força axial resistente superior a outra de mesmo comprimento e instabilidade por flexo-torção, ou mesmo a manifestação de modos de instabilidade não previstos em função do comprimento das barras.

Não obstante, foi desenvolvida também uma etapa de ensaios experimentais, que compreendeu a análise de cantoneiras simples com extremidades engastadas, e adicionalmente, mas não inclusas na pauta desta dissertação, cantoneiras enrijecidas, também com extremidades engastadas, além de uma série de cantoneiras simples e outra de cantoneiras enrijecidas conectadas pelas abas, e dois ensaios de referência com cantoneiras laminadas, sendo todos estes testes conduzidos com as extremidades das barras engastadas.

Assim, os ensaios experimentais realizados neste trabalho (referindo-se novamente somente a cantoneiras simples sob compressão centrada) se unem com outros realizados por diversos autores, perfazendo um total de 42 ensaios para barras com extremidades engastadas, e 38 ensaios para barras com extremidades rotuladas, todos eles utilizados para a avaliação de diferentes procedimentos de cálculo, com origem nos procedimentos normativos, ou sugeridos por outros autores.

Em um panorama geral, dentre os nove procedimentos de previsão teórica avaliados (cinco baseados no MLE, e quatro no MRD), apenas dois baseados no MLE e um no MRD resultam consideravelmente seguros e efetivos na previsão da força máxima resistente de cantoneiras.

É interessante mencionar que, do ponto de vista do comportamento mecânico das cantoneiras, nenhum destes procedimentos se mostra completamente adequado, tendo em vista fatores não considerados, como, por exemplo, a ocorrência de instabilidade por flexo-torção. 
No caso do MLE, um dos procedimentos com bons resultados foi o MLE (Young), o qual não se mostrou muito atrativo no caso de barras com extremidades rotuladas. Contudo, acredita-se que, na hipótese de se manter a linha de pensamento do autor da proposta, é possível um melhor ajuste na curva de dimensionamento sugerida, de forma a se otimizar os valores de erro de modelo para as diferentes faixas de comprimentos, reduzindo o desvio padrão, e mantendo um procedimento para dimensionamento seguro e simples.

O segundo procedimento foi o MLE (Ras), o qual não se mostrou muito eficiente para o caso de barras engastadas. Neste procedimento, apesar de haver uma consideração mais completa dos fenômenos envolvidos, tem-se também uma maior complexidade de cálculo devido à análise de flexo-compressão (apesar de haver um procedimento análogo simplificado, também formulado por Rasmussen (2003), mas não incluído nesta dissertação), e também a necessidade de ajuste considerando o caso de seções transversais mais esbeltas para barras com extremidades engastadas (e.g., seções ensaiadas por Young (2004), para as quais o procedimento MLE (Ras) apresentou resultados conservadores).

Por outro lado, o único procedimento verificado com bons resultados no MRD foi aquele proposto por Silvestre et al. (2012), que apesar de ser de fácil utilização, apresenta como principal desvantagem o fato de se ter, na verdade, dois procedimentos, um aplicável somente às barras engastadas e outro somente às barras rotuladas, deixando em aberto todas as condições de extremidade que diferem destas duas condições ideais.

Além disso, com relação aos procedimentos de previsão teórica, é importante comentar que no caso de se ter um procedimento baseado somente nos resultados de força axial de flambagem por flexão, pode acontecer, tanto para barras engastadas quanto rotuladas, de se verificar eventuais resultados demasiadamente contra a segurança unicamente em função do sentido da imperfeição de flexão, sendo estes resultados, em geral, muito próximos daqueles obtidos ao considerar o modo de flexo-torção como um modo global (e.g., $\operatorname{MLE}\left(\mathrm{FT}_{\text {Aef }}\right), \operatorname{MLE}\left(\mathrm{FT}_{\mathrm{A}}\right), \operatorname{MRD}(\mathrm{GL}), \operatorname{MRD}(\mathrm{G})$ e $\operatorname{MRD}$ (Chod)).

Entretanto, é notável que, estatisticamente, atender tal hipótese pode ser muito conservador, sendo esta questão, portanto, passível de um estudo mais cuidadoso, envolvendo também as cantoneiras com extremidades engastadas, para que se confirmem as hipóteses de comportamento, e se possa conduzir, então, a um estudo de confiabilidade aplicado a um procedimento que desconsidere o modo de flexo-torção como modo global. 


\section{REFERÊNCIAS BIBLIOGRÁFICAS}

AMERICAN IRON AND STEEL INSTITUTE (AISI), 1996, - Cold-Formed Steel Design Manual, Washington, DC.

AMERICAN IRON AND STEEL INSTITUTE (AISI), 2001. North American specification for the design of cold-formed steel structural members. Washington, DC.

AMERICAN IRON AND STEEL INSTITUTE (AISI), 2004. Appendix 1 - Design of cold-formed steel structural members using the direct strength method. North American specification for the design of cold-formed steel structural members. Washington, DC.

ASSOCIAÇÃO BRASILEIRA DE NORMAS TÉCNICAS (ABNT), 2001, NBR 14762 Dimensionamento de Estruturas de Aço Constituídas por Perfis Formados a Frio (Procedimento). Rio de Janeiro, RJ. Brasil.

ASSOCIAÇÃO BRASILEIRA DE NORMAS TÉCNICAS (ABNT), 2010, NBR 14762 — Dimensionamento de Estruturas de Aço Constituídas por Perfis Formados a Frio (Procedimento). Rio de Janeiro, RJ. Brasil.

ASSOCIAÇÃO BRASILEIRA DE NORMAS TÉCNICAS (ABNT), 2008, NBR 8800 - Projetos de estruturas de aço e de estruturas mistas de aço e concreto de edifícios. Rio de Janeiro, RJ. Brasil.

BEBIANO, R.; PINA, P.; SILVESTRE, N.; e CAMOTIM D. (2008). GBTUL - Buckling and Vibration Analysis of Thin-Walled Members, DECivil/IST, Technical University of Lisbon (http://www.civil.ist.utl.pt/gbt). 
BONATTO, R. (2009) Estudo do comportamento estrutural e otimização de cantoneiras de aço formadas a frio. 106 p., Dissertação (Mestrado) - Universidade Federal do Rio Grande do Sul, Porto Alegre - RS, 2009.

BULSON, P. S. (1969) The Stability of Flat Plates. American Elsevier Pub. Co., 1969, 470 p., New York. ISBN: 0444196544.

CAMOTIM, D.; SILVESTRE, N.; e DINIS, P. B., (2006) Análise numérica de elementos estruturais de aço enformados a frio: desenvolvimentos recentes e perspectivas futuras. Revista SulAmericana de Engenharia Estrutural, V.3 n.1, pp.55-100. Passo Fundo-RS, Brasil.

CHODRAUI, G. M. B. (2006) Análise teórica e experimental de perfis de aço formados a frio submetidos à compressão. 294 p., Tese (Doutorado) - Escola de Engenharia de São Carlos, Universidade de São Paulo, São Carlos - SP, 2006.

CHODRAUI, G. M. B.; SHIFFERAW, Y.; MALITE, M.; e SCHAFER, B. W. (2006). Cold-formed steel angles under axial compression. In: 18. International Specialty Conference on coldFormed Steel Structures, LaBOUBE, R.A.; YU, W.W. (Eds.), pp. 285-300. Orlando, FL, United states: University of Missouri-Rolla.

DINIS, P. B., CAMOTIM, D.; e SILVESTRE, N. (2010-a). Post-Buckling Behaviour and Strength of Angle Columns. In: SDSS'Rio 2010 Stability and Ductility of Steel Structures, BATISTA, E.; VELLASCO, P.; e LIMA, L. de. (Eds.) Rio de Janeiro - RJ. Brasil.

DINIS, P. B.; CAMOTIM, D.; e SILVESTRE, N. (2010-b). On the local and global buckling behaviour of angle, T-section and cruciform thin-walled columns and beams. Thin Walled Structures, V. 48, pp. 786-797, DOI: 10.1016/j.tws.2010.04.012.

DINIS, P. B.; CAMOTIM, D.; e SILVESTRE, N. (2011-a). On the Mechanics of Thin-Walled Angle Column Instability. Thin Walled Structures, V. 52, pp. 80-89, (C) Elsevier Science Ltd., DOI: 10.1016/j.tws.2011.12.007. 
DINIS, P. B.; CAMOTIM, D.; e SILVESTRE, N. (2011-b). On the Design of Cold-Formed Steel Angle Columns. In: 6. International Conference on Thin-Walled Structures (ICTWS 2011). DUBINA, D.; e UNGUREANU, V. (Eds.) Timisoara - Romênia.

ELLOBODY, E.; e YOUNG, B., (2005) Behavior of Cold-Formed Steel Plain Angle Columns. Journal of Structural Engineering, V.131, n.3., pp. 457-466. CASCE, ISSN 0733-9445.

GALAMBOS, T.V.; e SUROVEK, A.E., (2008) Structural Stability of Steel: Concepts and Applications for Structural Engineers. New Jersey: John Wiley \& Sons, Inc. ISBN 978-0-47003778-2.

GONÇALVES, R., (2000). Imperfeições locais em estruturas de aço conceitos, resultados e reflexões, Dissertação (Mestrado) - Instituto Superior Tecnico, Universidade Técnica de Lisboa, Lisboa - PT, 2000.

HANCOCK, G. J.; MURRAY, T. M.; ELLIFRITT, D. S., (2001) Cold-Formed Steel Structures to the AISI Specification. New York: Marcel Dekker, ISBN: 0-8247-9294-7.

MAIA, W. F., (2008) Sobre a estabilidade de cantoneiras de aço formadas a frio submetidas à compressão. 182 p. Dissertação (Mestrado) - Escola de Engenharia de São Carlos, Universidade de São Paulo, São Carlos, 2008.

MAIA, W.F.; MUNAIAR NETO, J.; e MALITE, M., (2008) Stability of Cold-Formed Steel Simple And Lipped Angles Under Compression. In 19. International Specialty Conference on ColdFormed Steel Structures, LaBOUBE, R.A.; YU, W.W. (Eds.), pp. 111-125. St. Louis, Missouri.

MESACASA JR., E.C.; e MALITE, M., (2011). Sobre o Comportamento Estrutural e o Dimensionamento de Cantoneiras de Aço Formadas a Frio Submetidas à Compressão. In Congresso de Métodos Numéricos em Engenharia. Coimbra: (c) APMTAC, Portugal, 2011.

PEKOZ, T. (1986). Development of a Unified Approach to the Design of Cold-Formed Steel Members. In: 8. International Speciality Conference on Cold-Formed Steel Structures: Recent Research and Developments in Cold-Formed Steel Design. YU, W.W., e SENNE, J.H. (Eds.) pp. 77-87. St. Louis, Missouri. 
POPOVIC, D.; HANCOCK, G. J.; e RASMUSSEN, K. J. R., (1999) Axial compression tests of coldformed angles. Journal of Structural Engineering, V.125 n.5, pp.515-523. CASCE, ISSN 07339445. New York, N.Y.

POPOVIC, D.; HANCOCK, G. J.; RASMUSSEN, K. J. R. (2001) Compression tests on coldformed angles loaded parallel with a leg. Journal of Structural Engineering, V. 127, n. 6, pp. 600-607, CASCE, ISSN 0733-9445. New York, N.Y.

PRABHU, T. S., (1982) Ultimate Strength of cold-formed equal-leg single angles. $161 \mathrm{p}$. Dissertação (Mestrado) - University of Windsor, Windsor, Ontario, Canada, 1982.

QUACH, W. M.; TENG, J. G.; e CHUNG, K. F. (2006). Finite element predictions of residual stresses in press-braked thin-walled steel sections. Engineering Structures, V. 28 n.11, pp. 1609-1619. DOI: 10.1016/j.engstruct.2006.02.013

RASMUSSEN, K. J. R. (2003) Design of angle columns with locally unstable legs. Research Report n. R830. Australia: Department of Civil Engineering, University of Sydney, June, 2003.

SCHAFER, B. W.; e ADANY, S. (2006). Buckling analysis of cold-formed steel members using CUFSM: Conventional and constrained finite strip methods In: 18. International Specialty Conference on cold-Formed Steel Structures, LaBOUBE, R.A.; YU, W.W. (Eds.), pp. 39-54. Orlando, FL, United states: University of Missouri-Rolla.

SCHAFER, B. W.; e PEKÖZ, T. (1998). Computational modeling of cold-formed steel: characterizing geometric imperfections and residual stresses. Journal of Constructional Steel Research, V.47 n.3, pp. 193-210. DOI: 10.1016/S0143-974X(98)00007-8

SHIFFERAW, Y.; e SCHAFER, B. W. (2011). Behavior and design of cold-formed steel lipped and plain angles. In: Annual Stability Research Conference - Structural Stability Research Council. Pittsburgh, Pennsylvania, May 10-14, 2011. 
SHI, G.; LIU, Z.; e CHUNG, K.F., (2009). Numerical Study On the Local Buckling of 420MPa Steel Equal Angle Coloums Under Axial Compression. In: Proceedings of Sixth International Conference on Advances in Steel Structures. CHAN, S. L. (ed.) Hong Kong Institute of Steel Construction. Hong Kong - China.

SILVESTRE, N.; DINIS, P. B.; e CAMOTIM, D., (2011). Design of Cold-Formed Steel Angles: A Novel Approach. Journal of Structural Engineering, V.--, n.--, pp.--, (A ser publicado).

YOUNG, B., (2004) Tests and design of fixed-ended cold-formed steel plain angle columns. Journal of Structural Engineering, v.130, n.12, pp. 1931-1940, December, 2004. CASCE, ISSN 0733-9445

YOUNG, B.; e RASMUSSEN, K. J. L,. (1999). Behaviour of cold-formed singly symmetric columns. Thin-Walled Structures, V.33, pp.83-102. (C) Elsevier Science Ltd., ISSN 0263-8231. 


\section{APÊNDICE A - ERROS DE MODELO}

São apresentados a seguir, individualmente, as distribuições de erro de modelo para os diferentes procedimentos teóricos estudados em função da esbeltez da barra $\left(\lambda=L_{c} / r_{\min }\right)$. As Figuras A.1 a A.9 apresentam os resultados para barras com extremidades rotuladas, e as Figuras A.10 a A.18 para barras com extremidades engastadas.

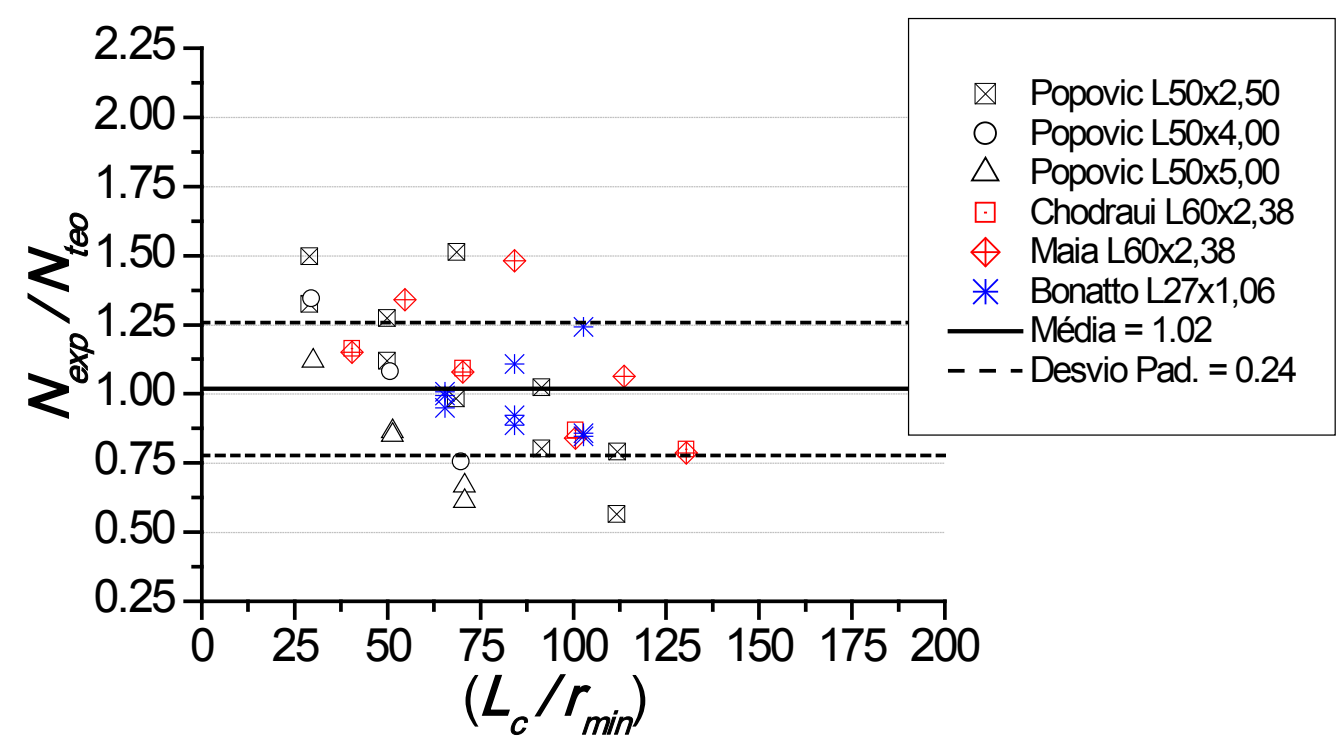

Figura A.1 - Erro de Modelo para procedimento MLE ( $\left.\mathrm{FT}_{\text {Aef }}\right)$ em função da esbeltez $(\lambda)$ - Barras Rotuladas

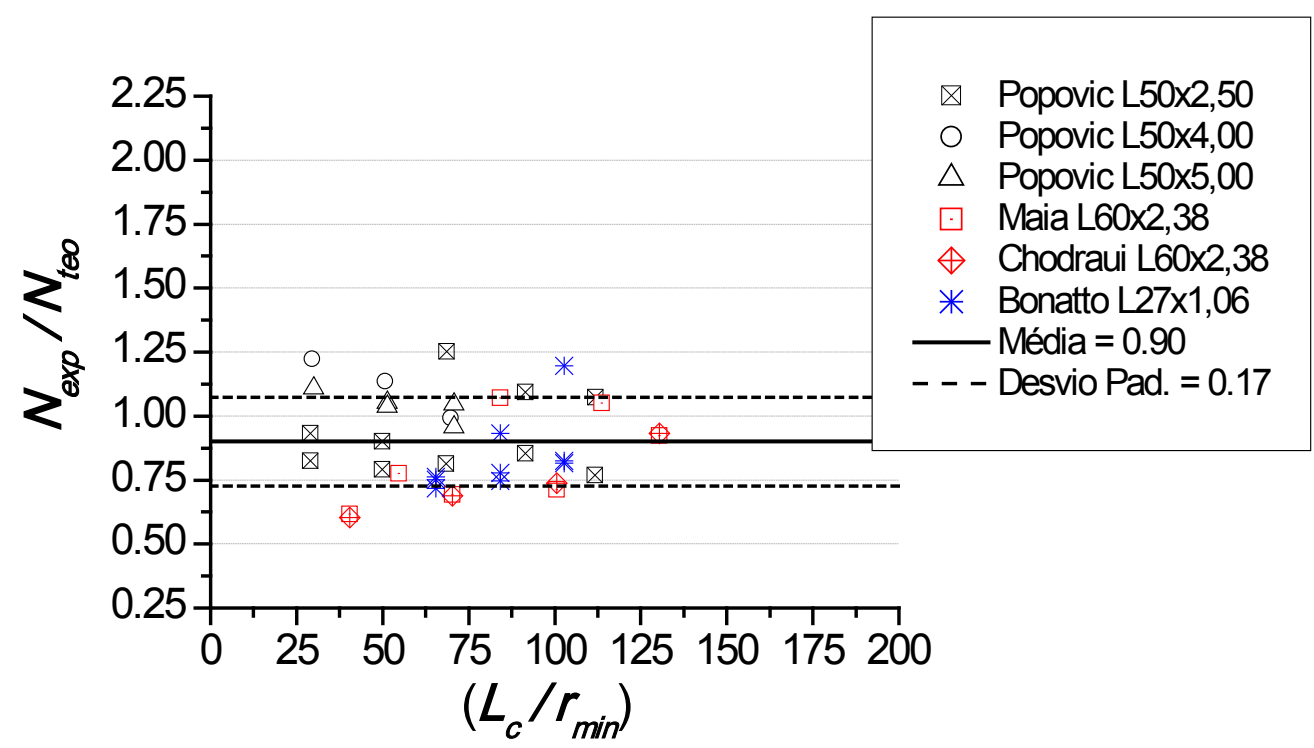

Figura A.2 - Erro de Modelo para procedimento MLE (F) em função da esbeltez $(\lambda)$ - Barras Rotuladas 


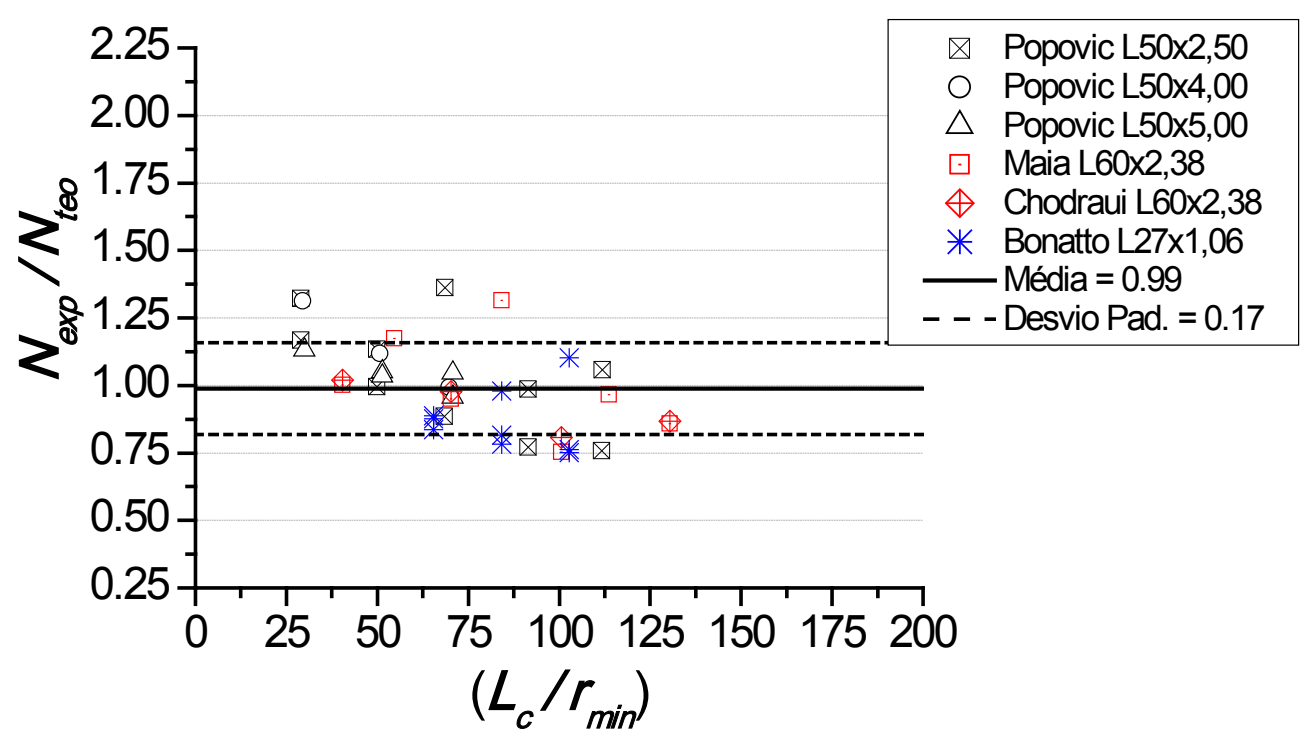

Figura A.3 - Erro de Modelo para procedimento $M L E\left(F_{A}\right)$ em função da esbeltez $(\lambda)$ - Barras Rotuladas

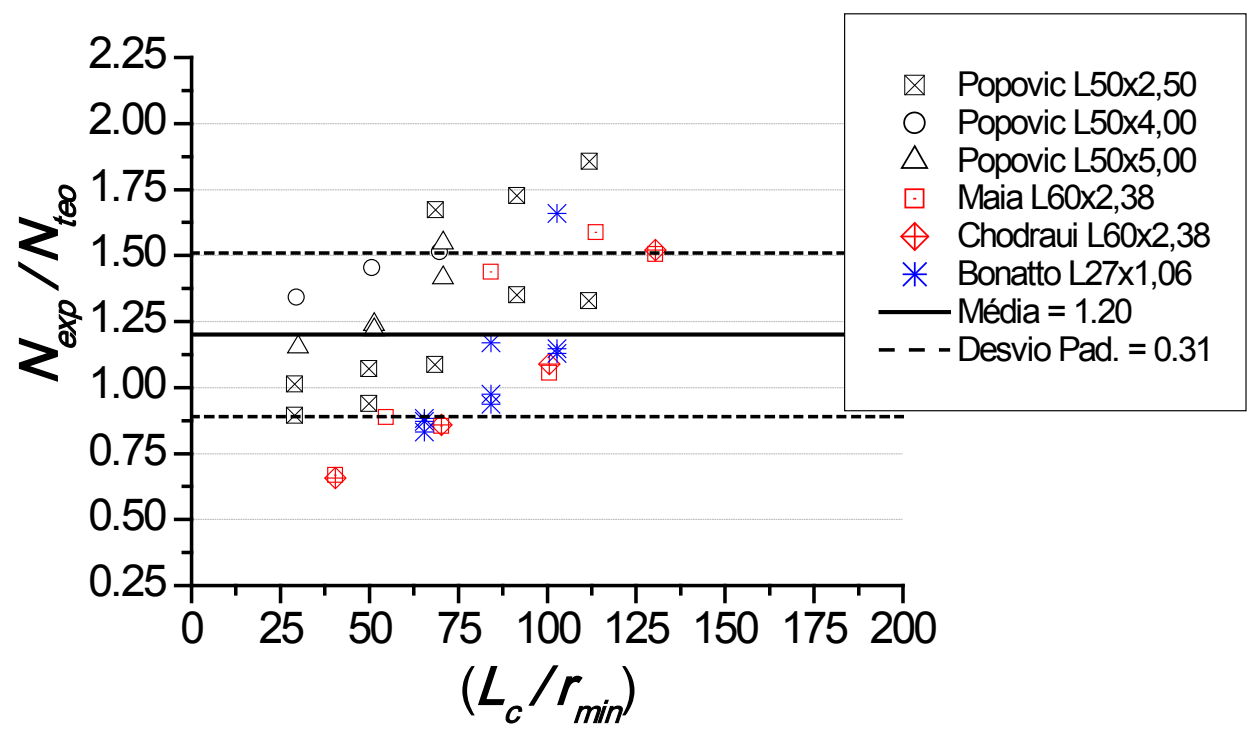

Figura A.4 - Erro de Modelo para procedimento MLE (Young) em função da esbeltez $(\lambda)$ - Barras Rotuladas

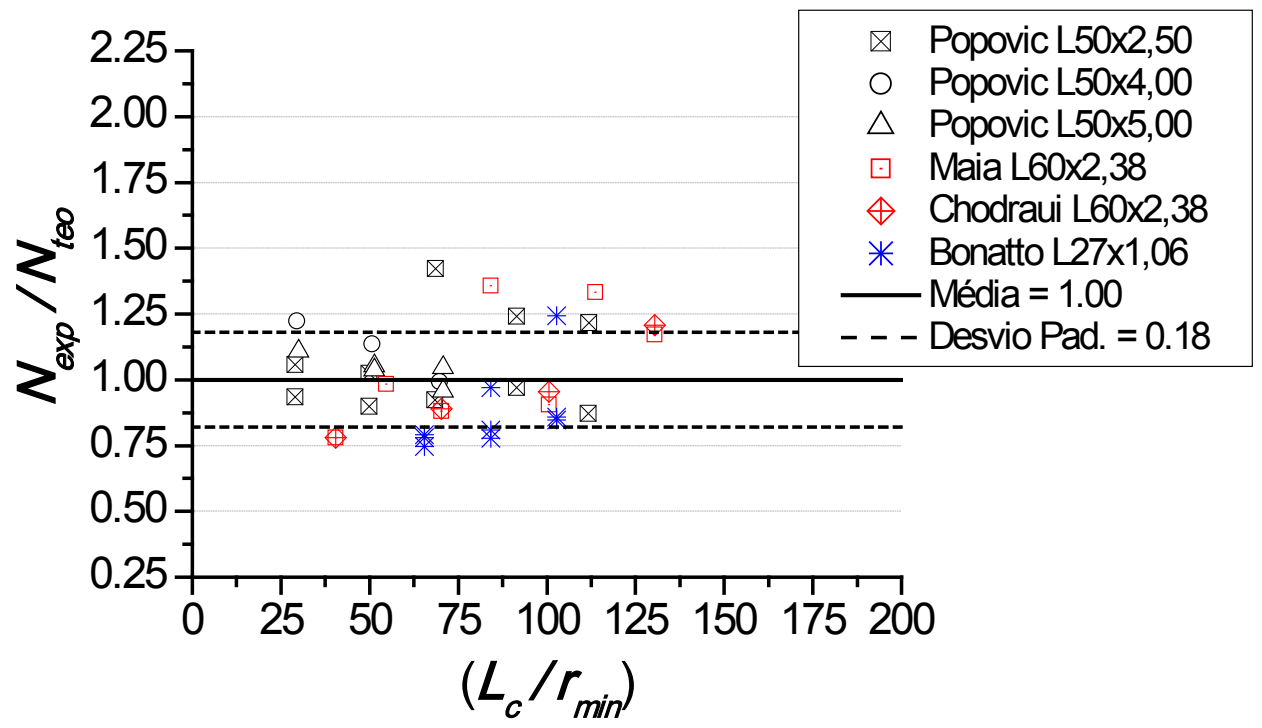

Figura A.5 - Erro de Modelo para procedimento MLE (Ras) em função da esbeltez ( $\lambda$ ) - Barras Rotuladas 


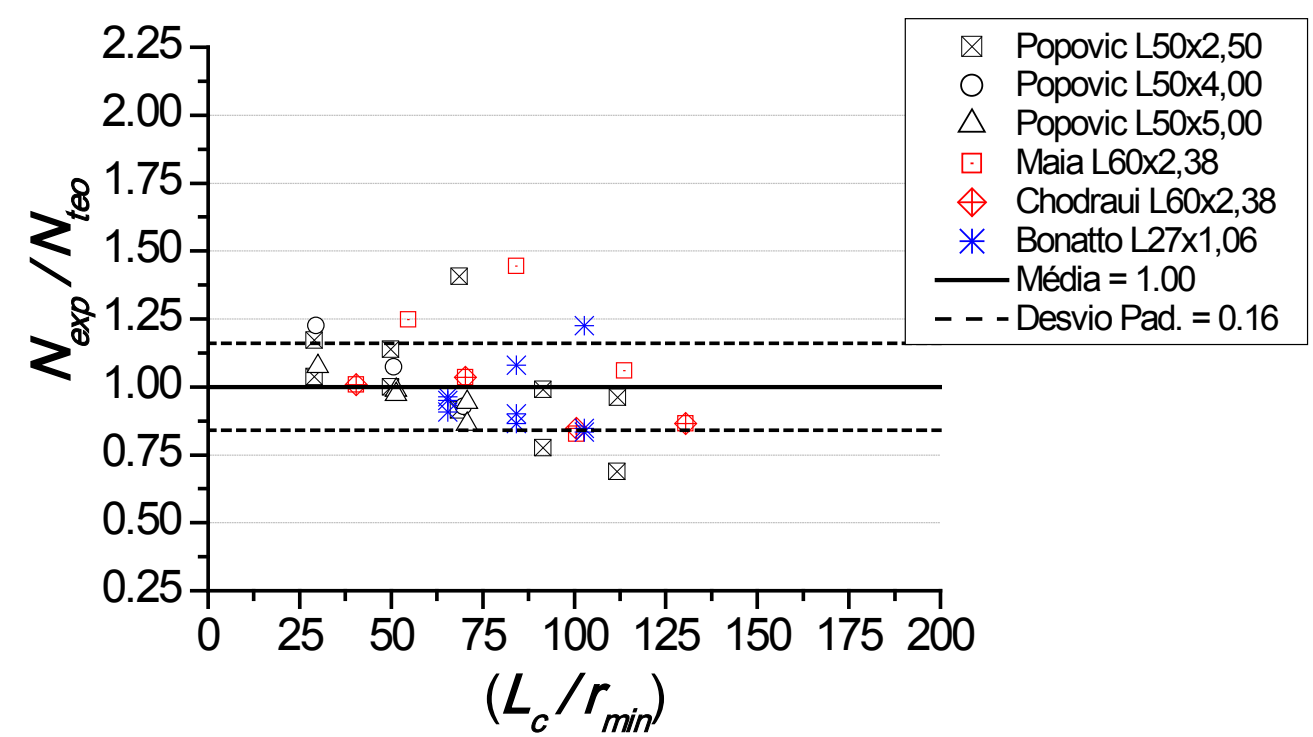

Figura A.6 - Erro de Modelo para procedimento MRD (GL) em função da esbeltez $(\lambda)$ - Barras Rotuladas

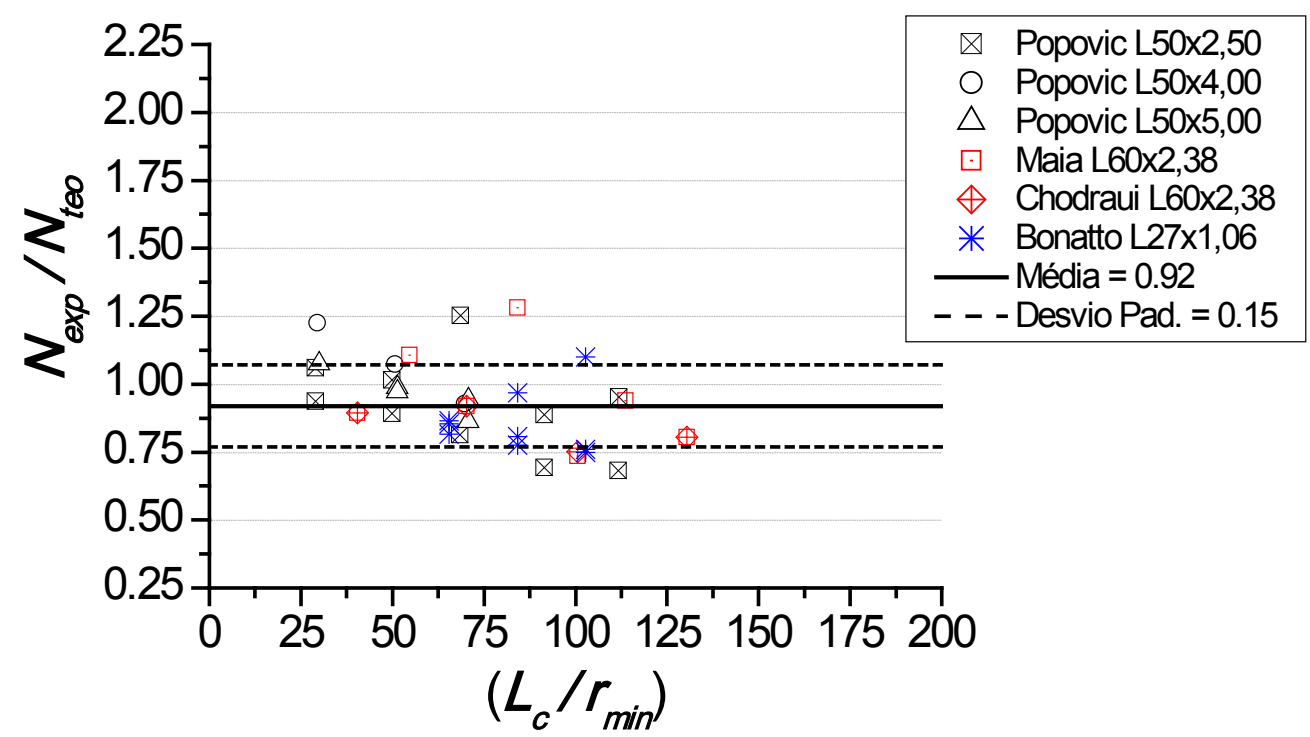

Figura A.7 - Erro de Modelo para procedimento MRD (G) em função da esbeltez $(\lambda)$ - Barras Rotuladas

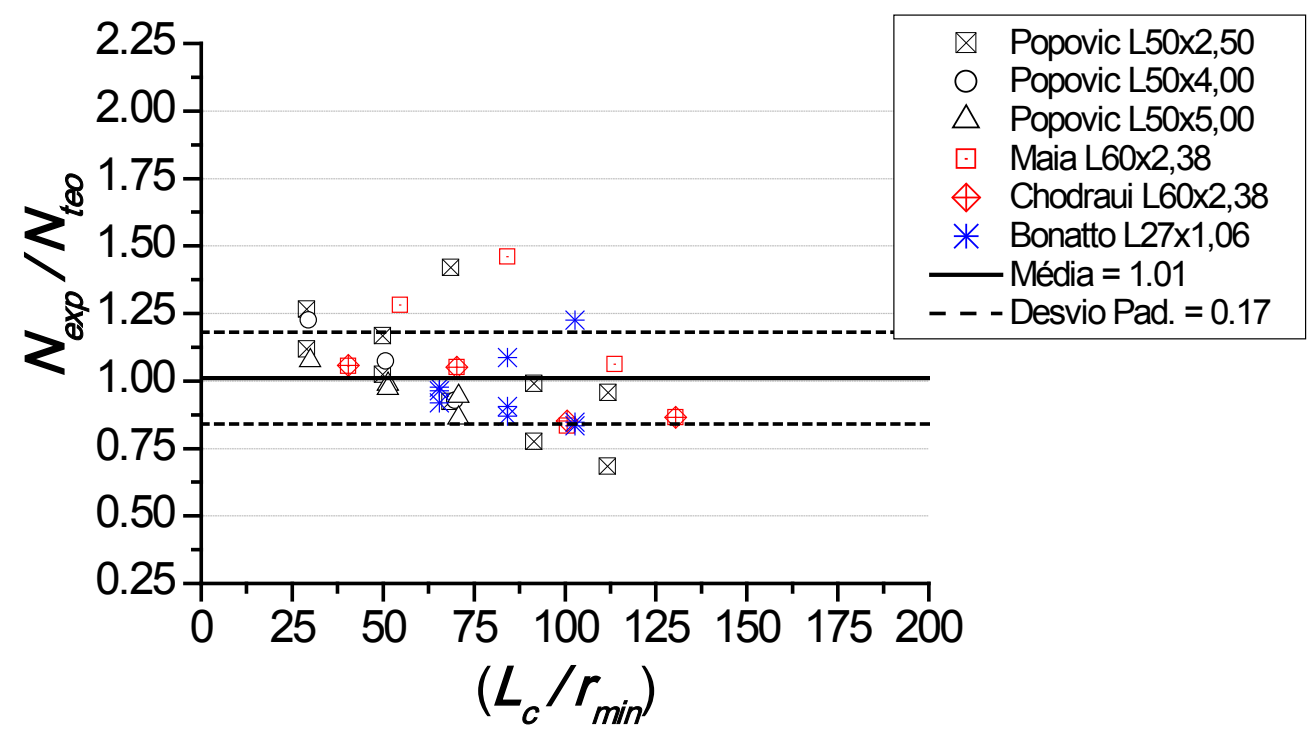

Figura A.8 - Erro de Modelo para procedimento MRD (Chod) em função da esbeltez $(\lambda)$ - Barras Rotuladas 


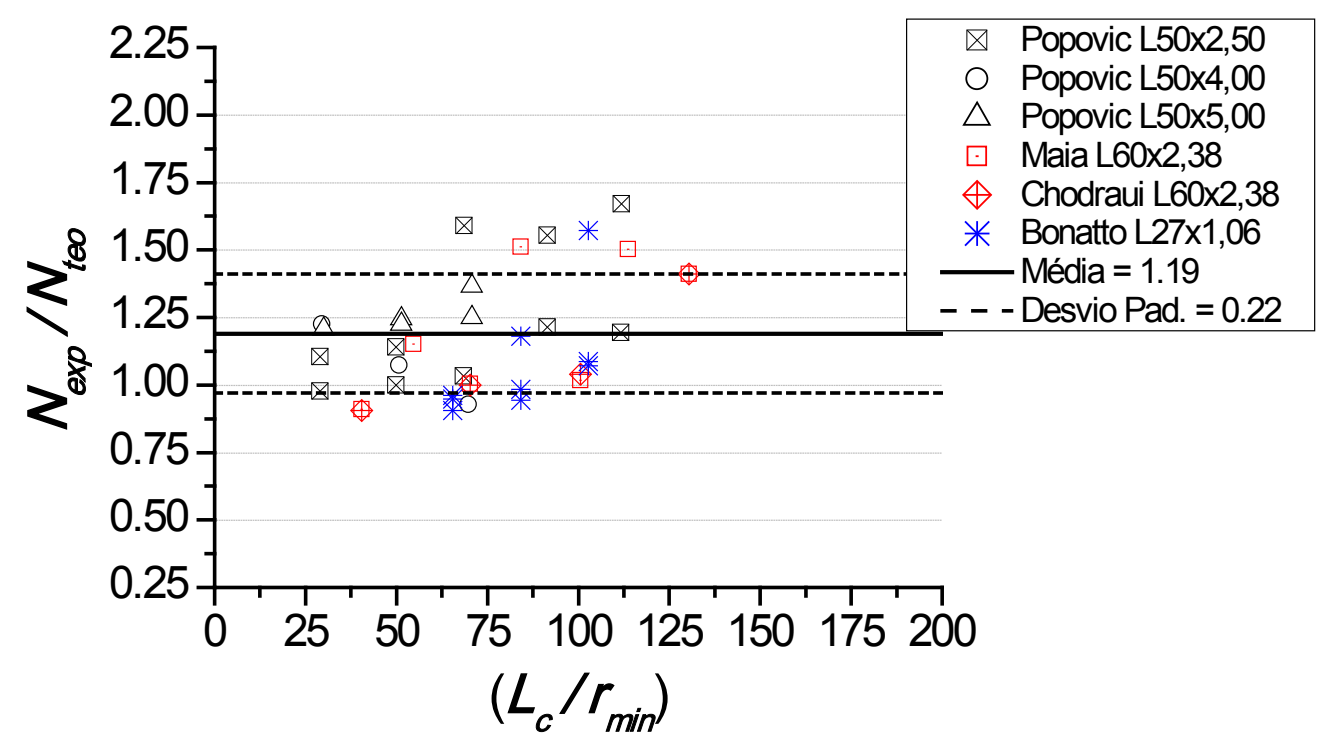

Figura A.9 - Erro de Modelo para procedimento MRD (Sil) em função da esbeltez $(\lambda)$ - Barras Rotuladas

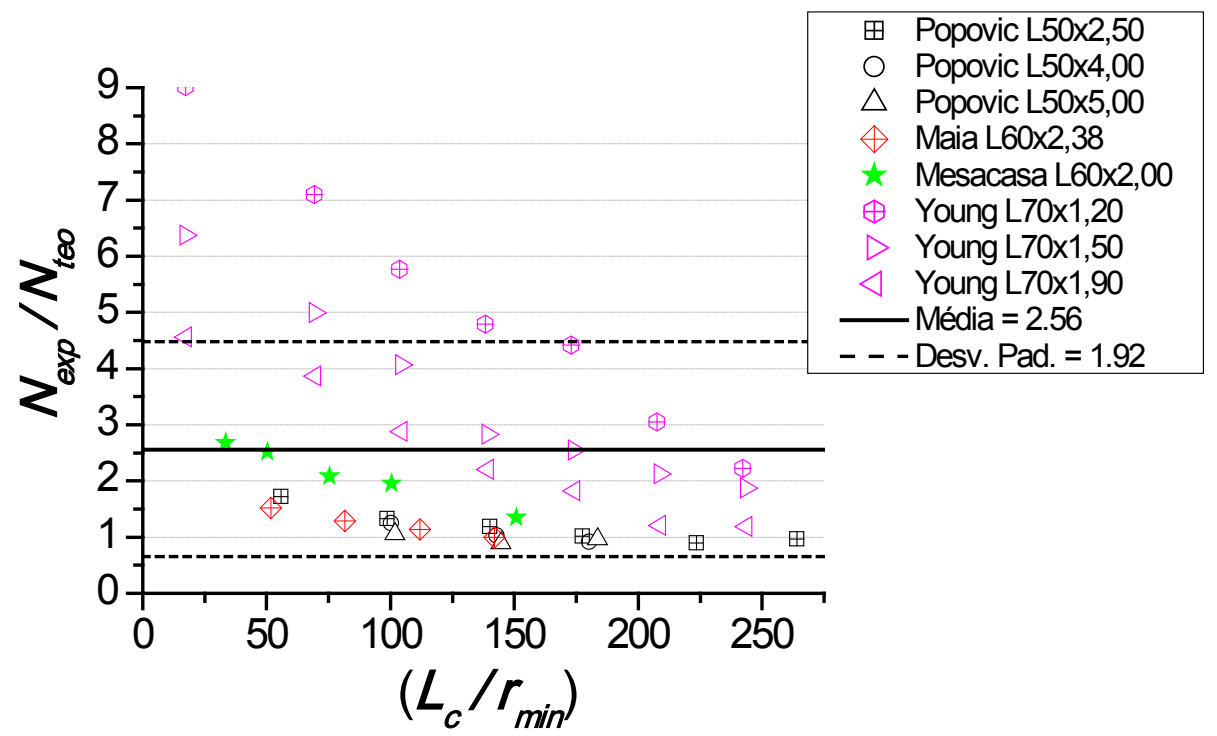

Figura A.10 - Erro de Modelo para procedimento $\operatorname{MLE}\left(\mathrm{FT}_{\text {Aef }}\right)$ em função da esbeltez $(\lambda)$ - Barras Rotuladas

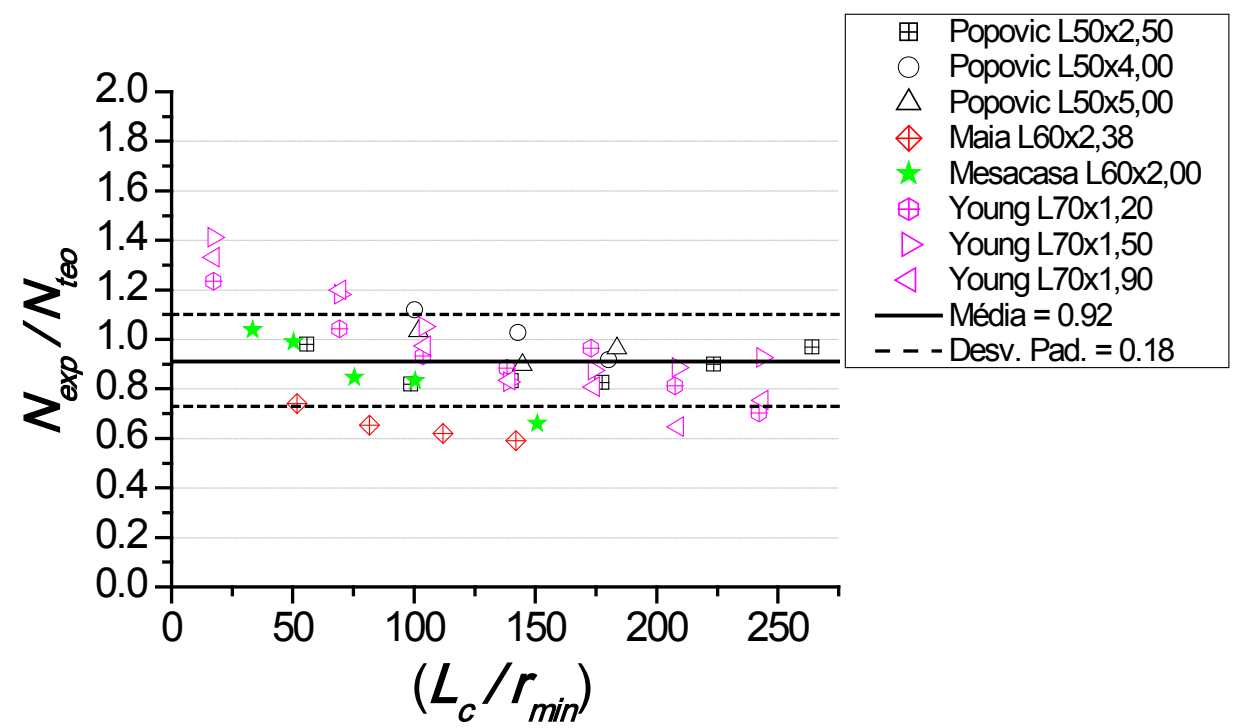

Figura A.11 - Erro de Modelo para procedimento MLE (F) em função da esbeltez $(\lambda)$ - Barras Rotuladas 


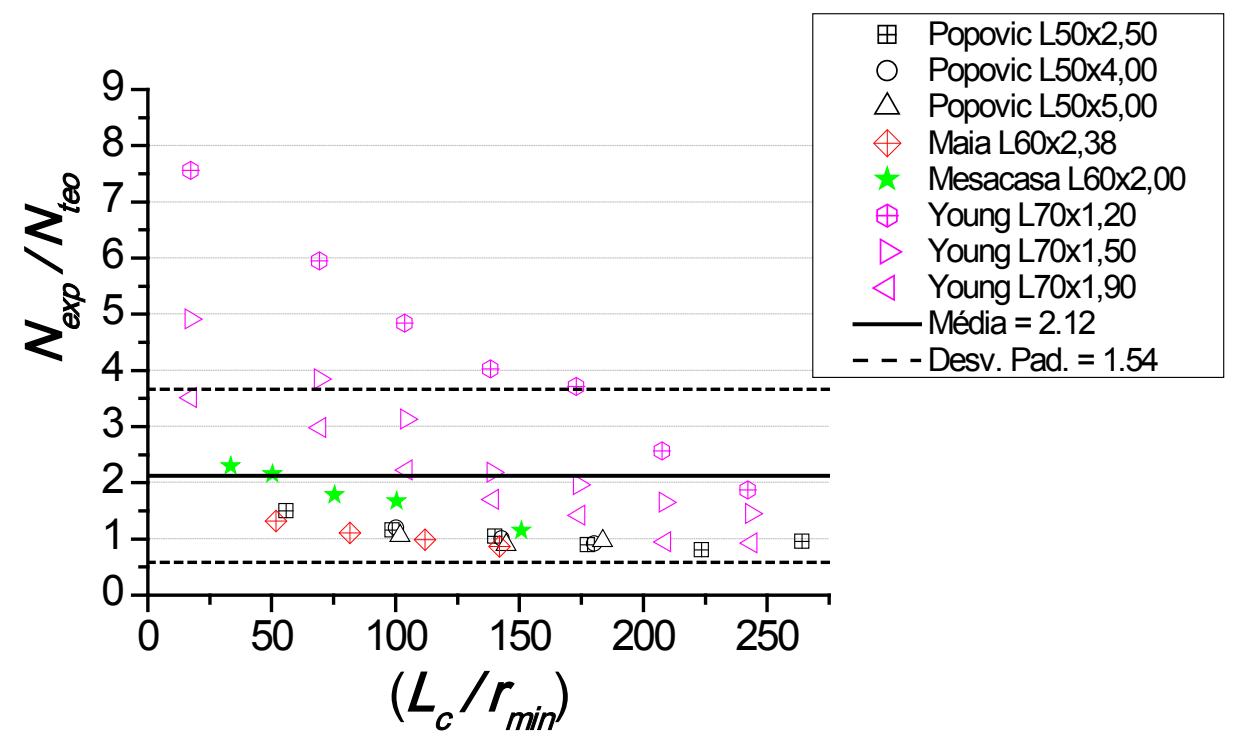

Figura A.12 - Erro de Modelo para procedimento $\operatorname{MLE}\left(\mathrm{FT}_{\mathrm{A}}\right)$ em função da esbeltez $(\lambda)$ - Barras Rotuladas

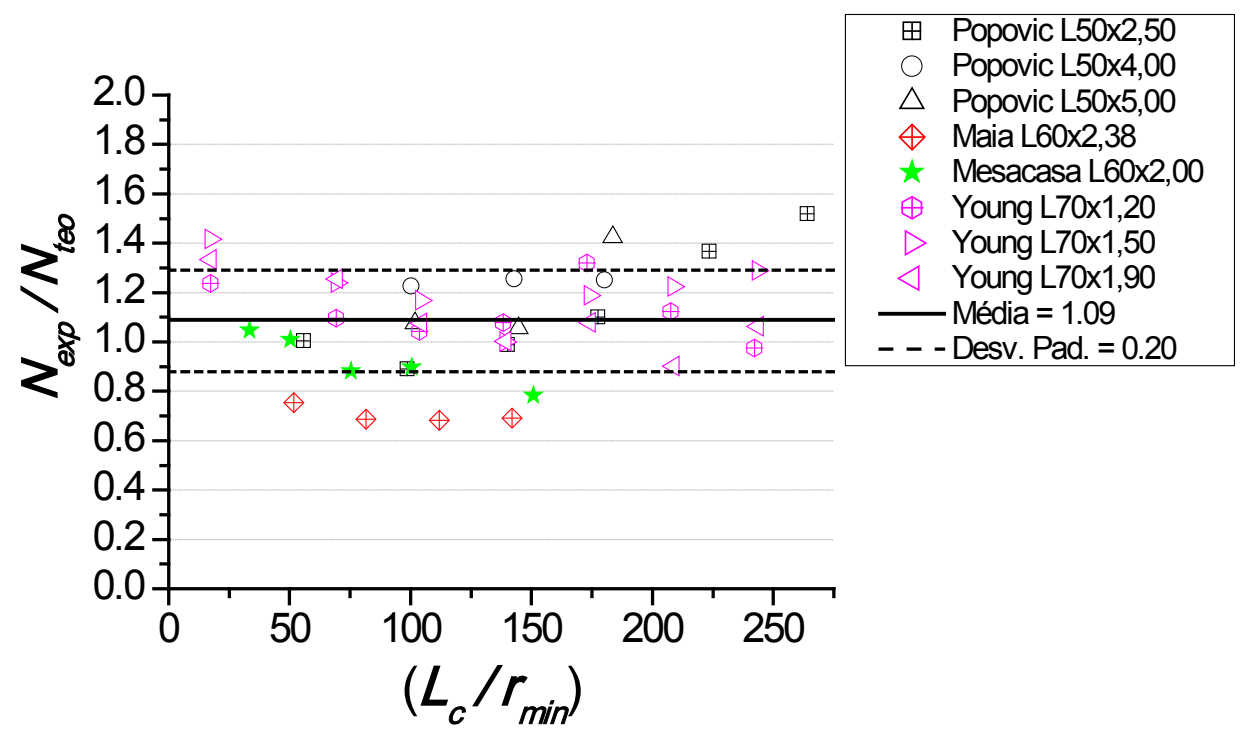

Figura A.13 - Erro de Modelo para procedimento MLE (Young) em função da esbeltez $(\lambda)$ - Barras Rotuladas

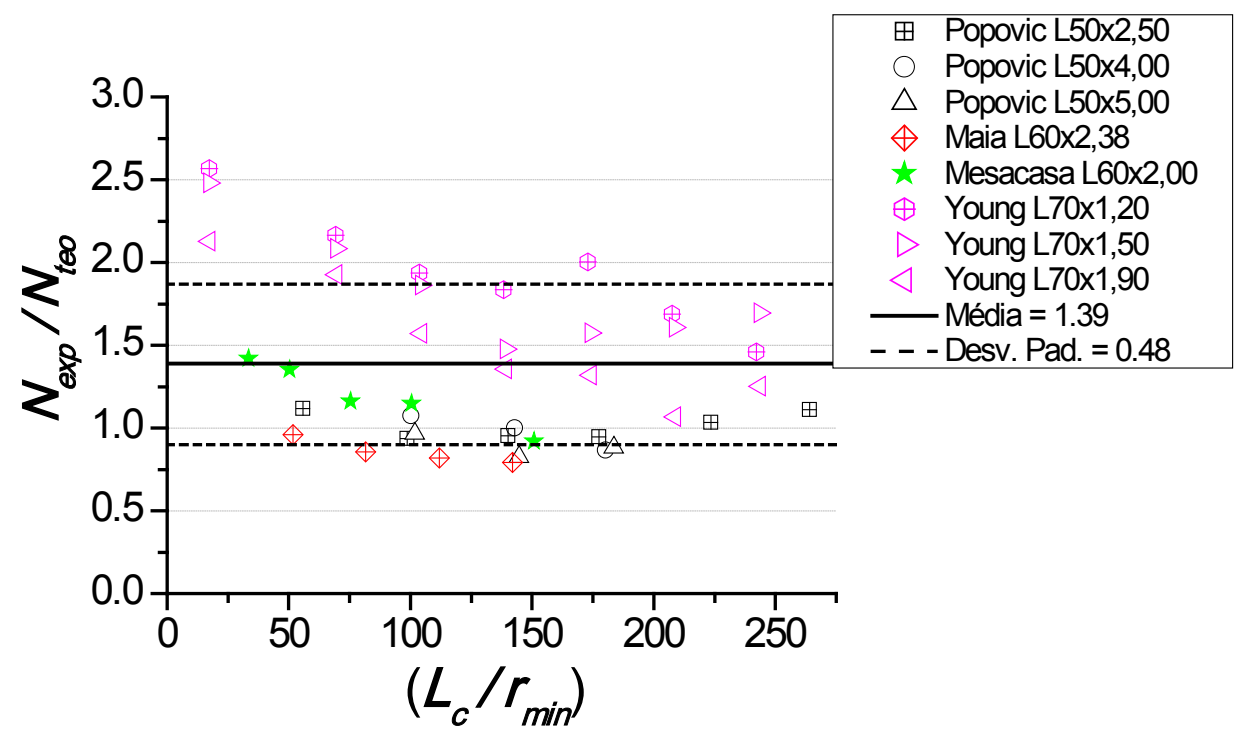

Figura A.14 - Erro de Modelo para procedimento MLE (Ras) em função da esbeltez $(\lambda)$ - Barras Rotuladas 


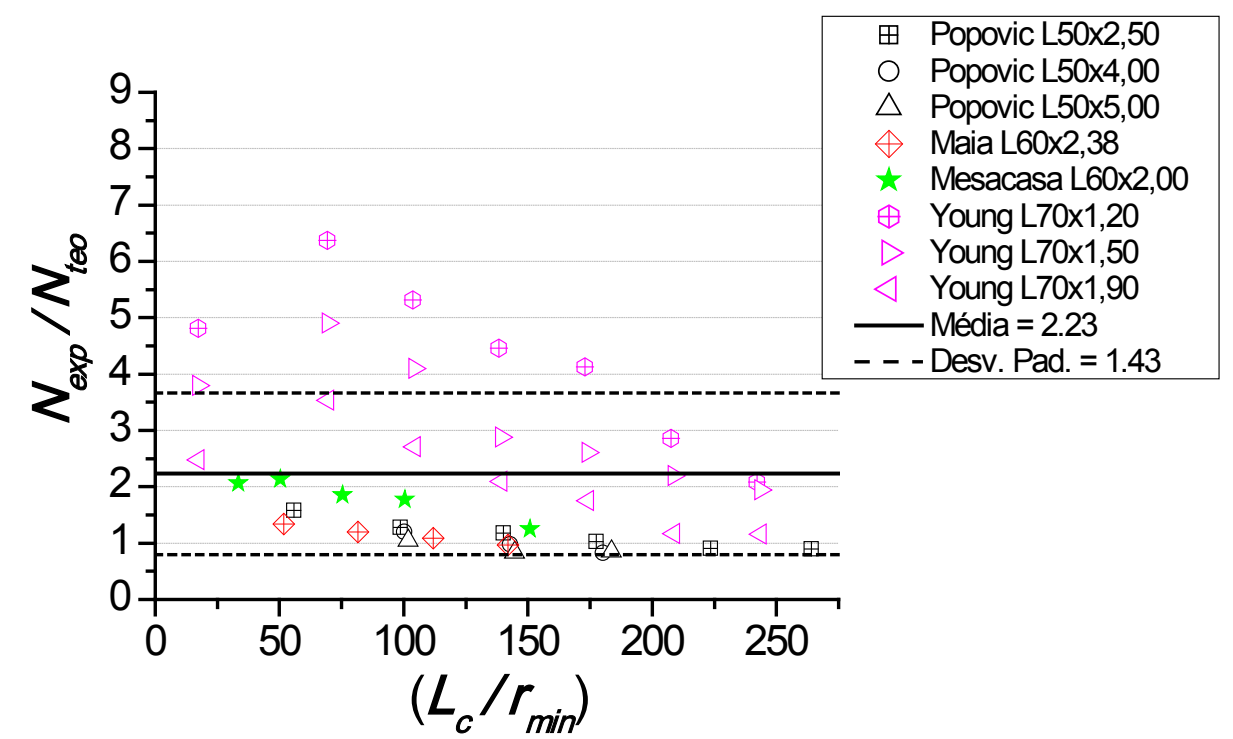

Figura A.15 - Erro de Modelo para procedimento MRD (GL) em função da esbeltez $(\lambda)$ - Barras Rotuladas

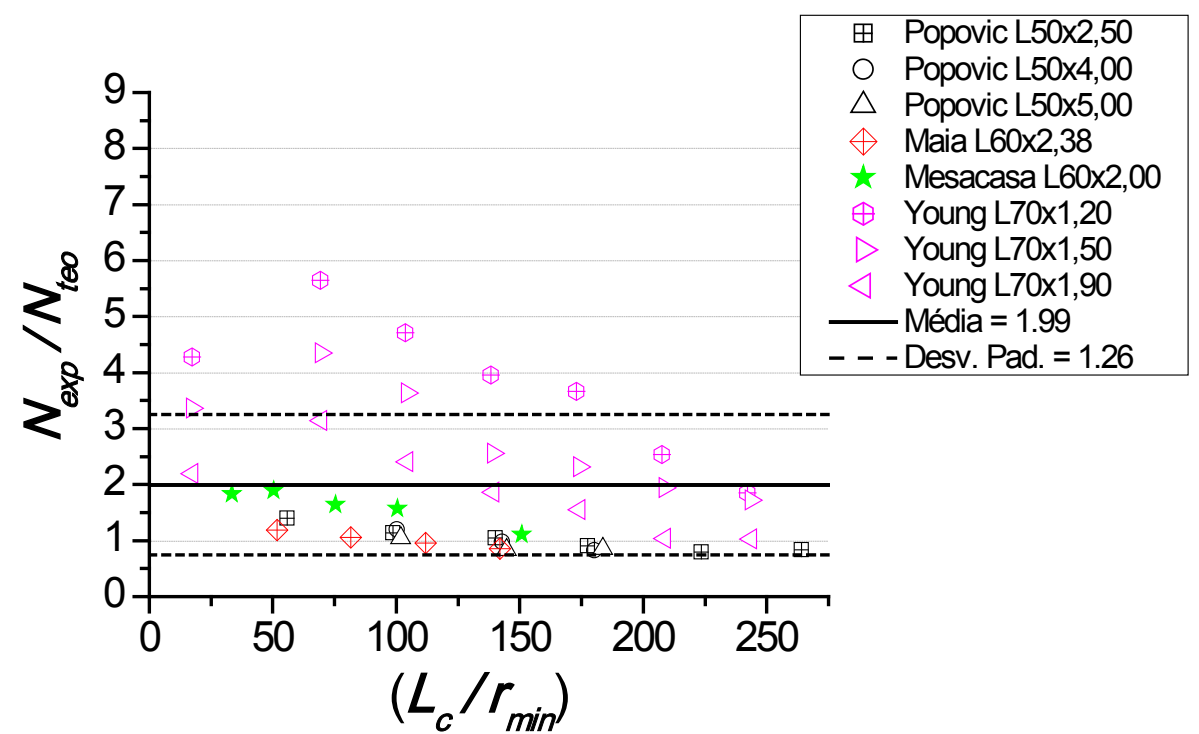

Figura A.16 - Erro de Modelo para procedimento MRD (G) em função da esbeltez $(\lambda)$ - Barras Rotuladas

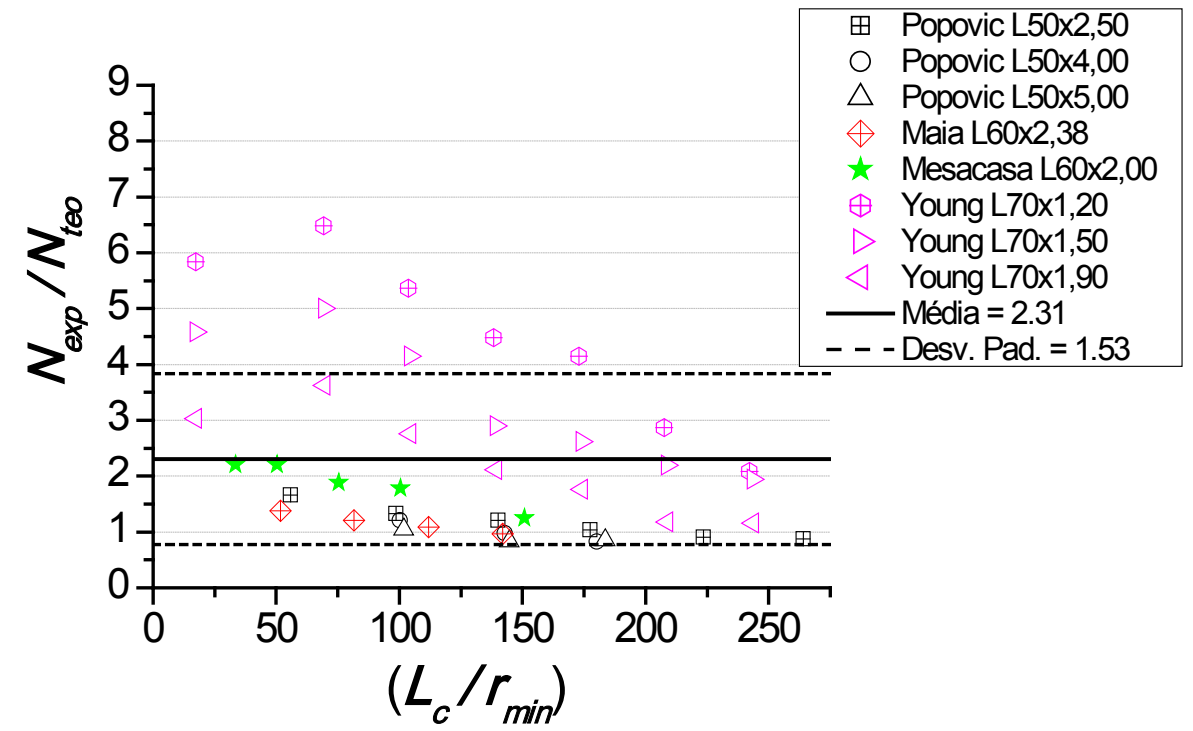

Figura A.17 - Erro de Modelo para procedimento MRD (Chod) em função da esbeltez $(\lambda)$ - Barras Rotuladas 


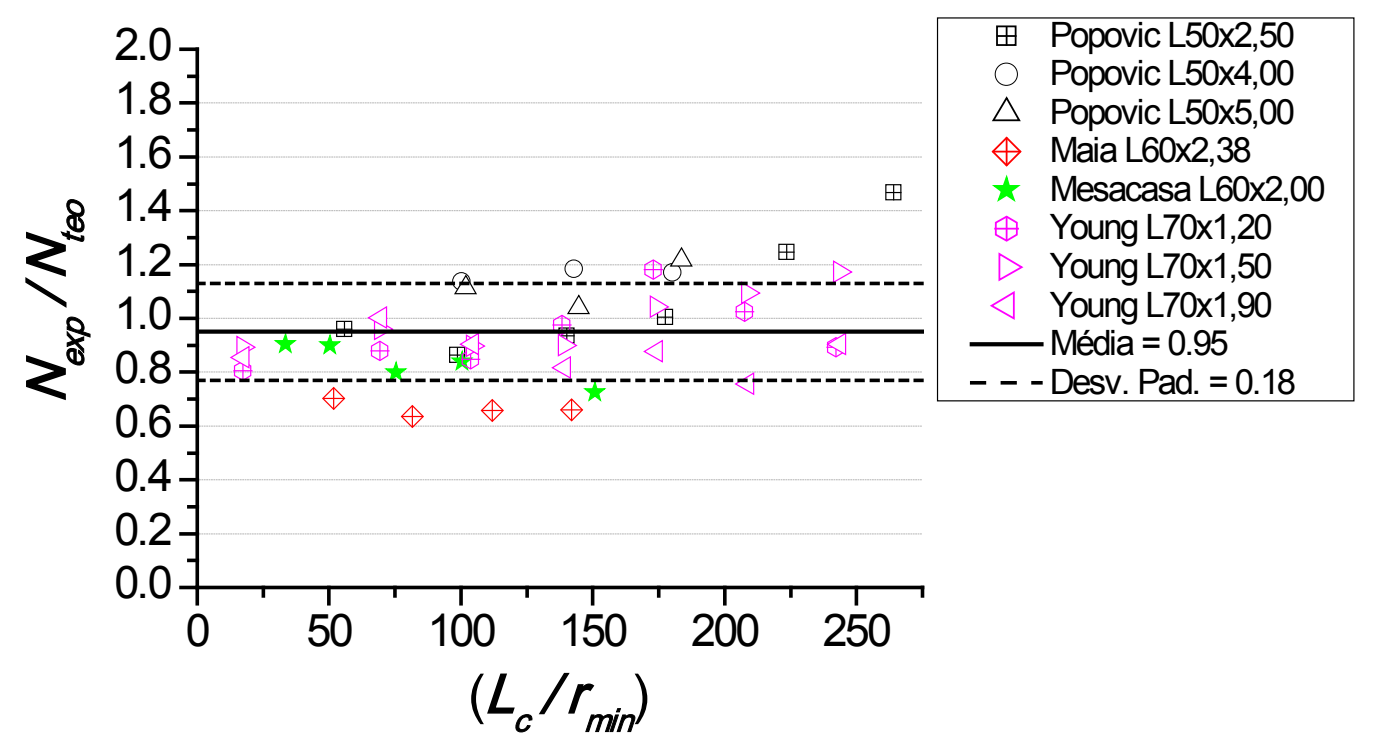

Figura A.18 - Erro de Modelo para procedimento MRD (Sil) em função da esbeltez ( $\lambda$ ) - Barras Rotuladas 


\section{APÊNDICE B - ENSAIOS EXPERIMENTAIS}

\section{Cantoneira Simples L60x2,00 - Compressão centrada}

- $\angle 400 \mathrm{~mm} ; N_{\text {exp }}=41,432 \mathrm{kN}$
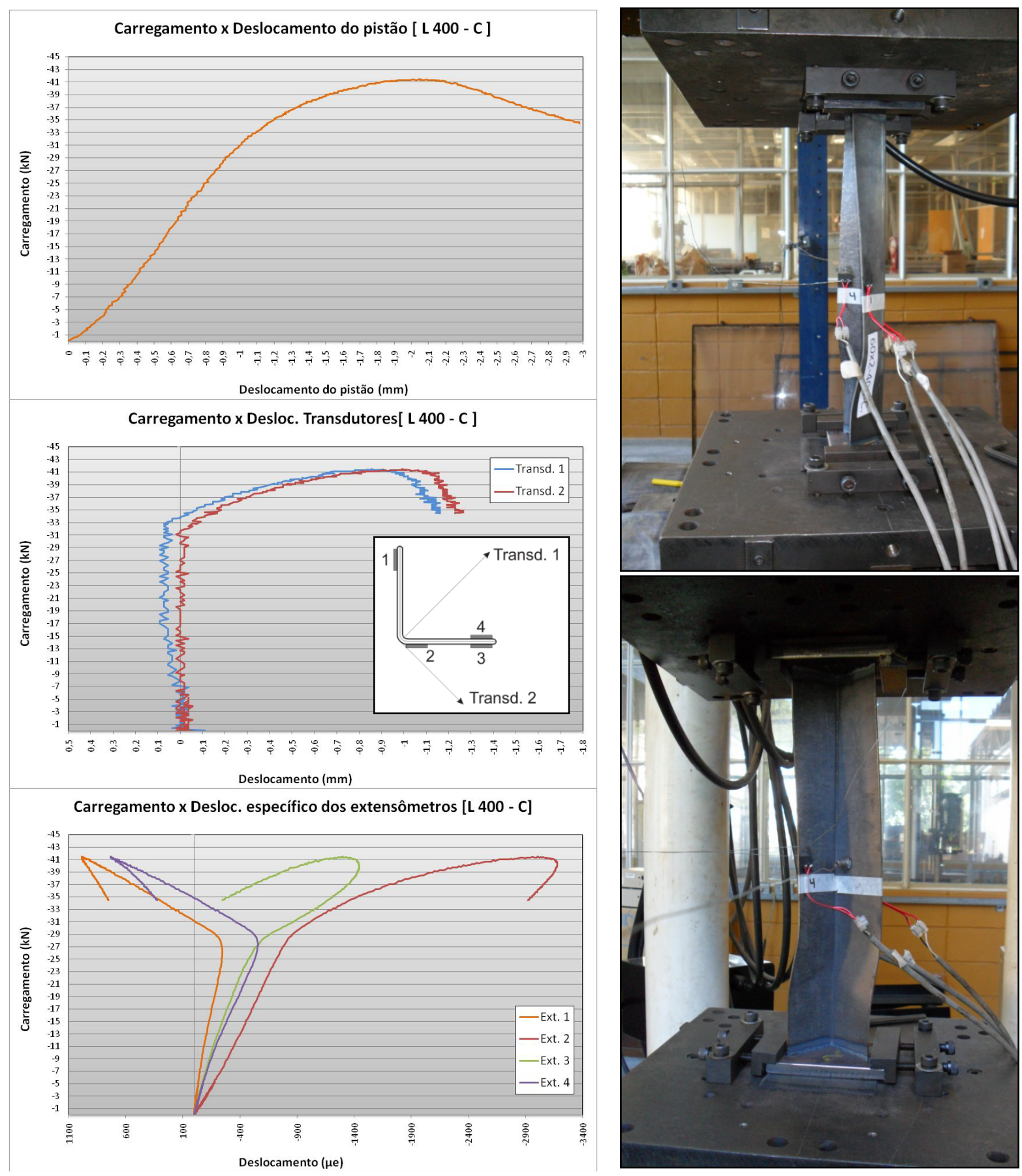
- L $600 \mathrm{~mm} ; N_{\text {exp }}=38,838 \mathrm{kN}$

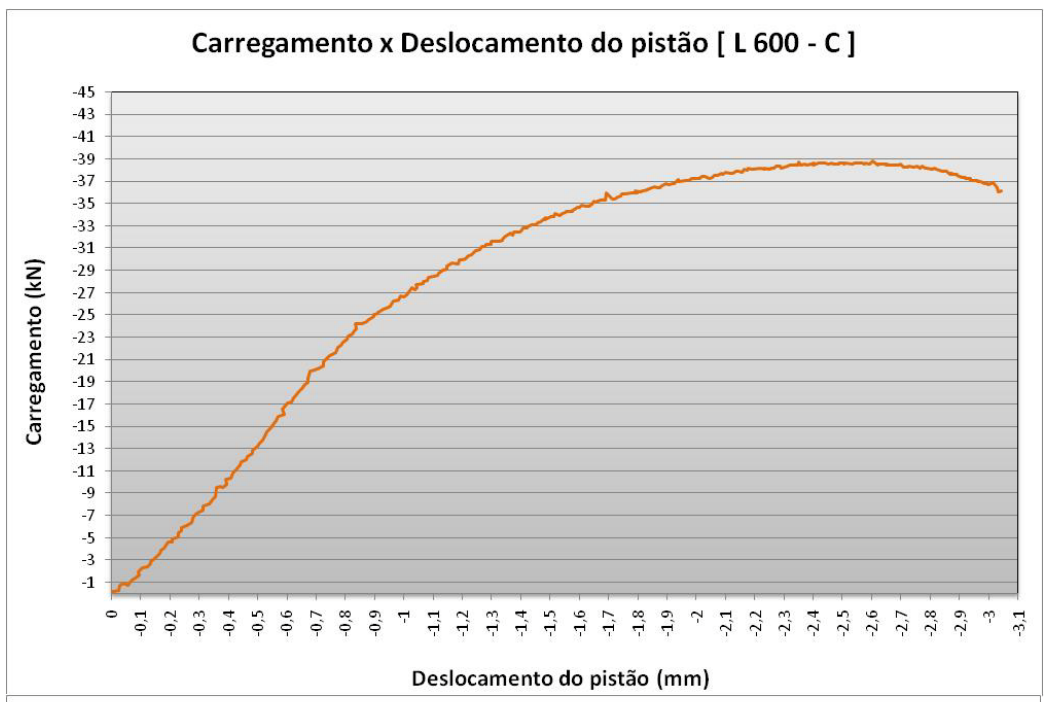

Carregamento x Desloc. Transdutores [ L 600 - C ]
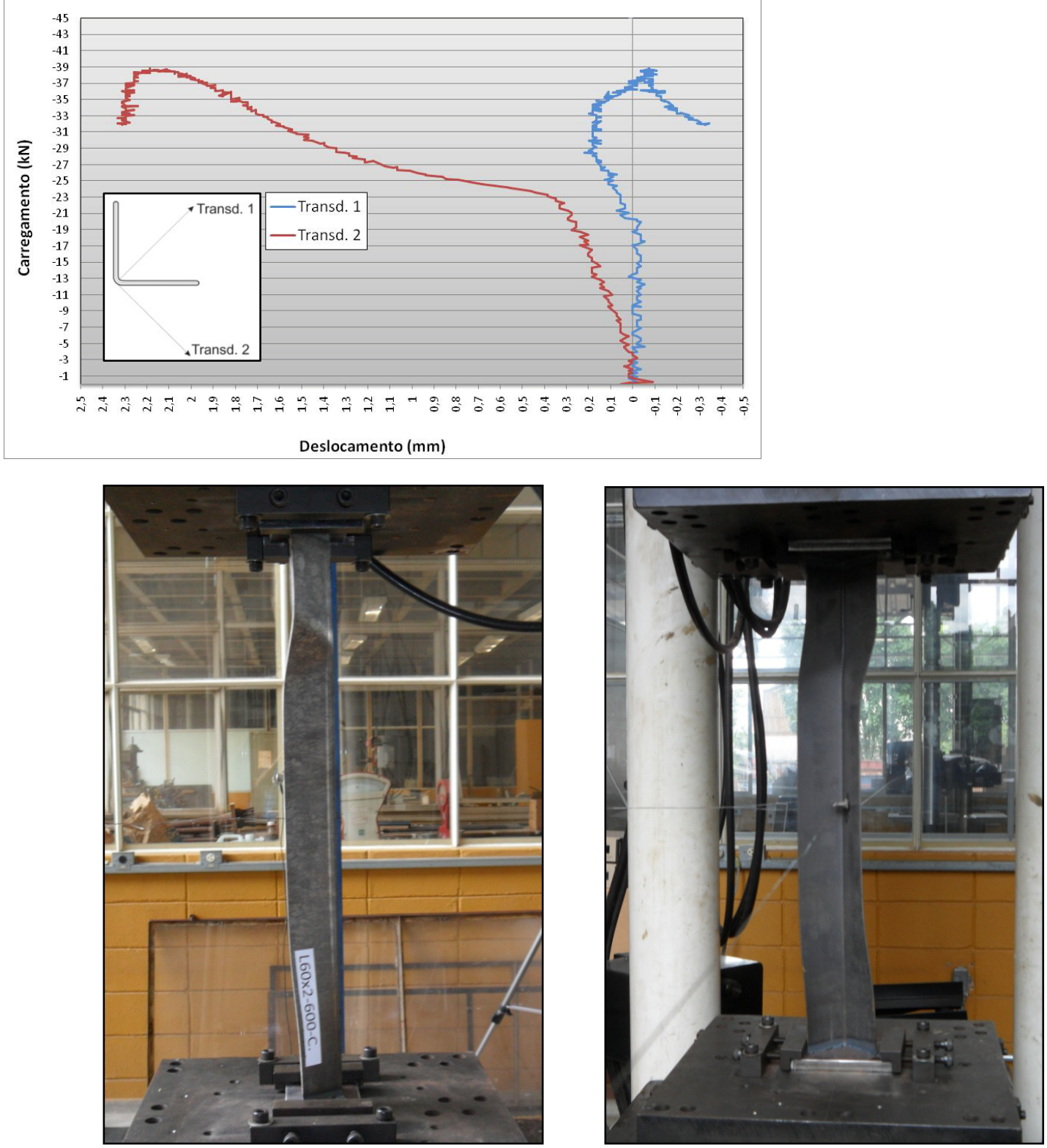
- $\quad L 900 \mathrm{~mm} ; N_{\text {exp }}=32,047 \mathrm{kN}$
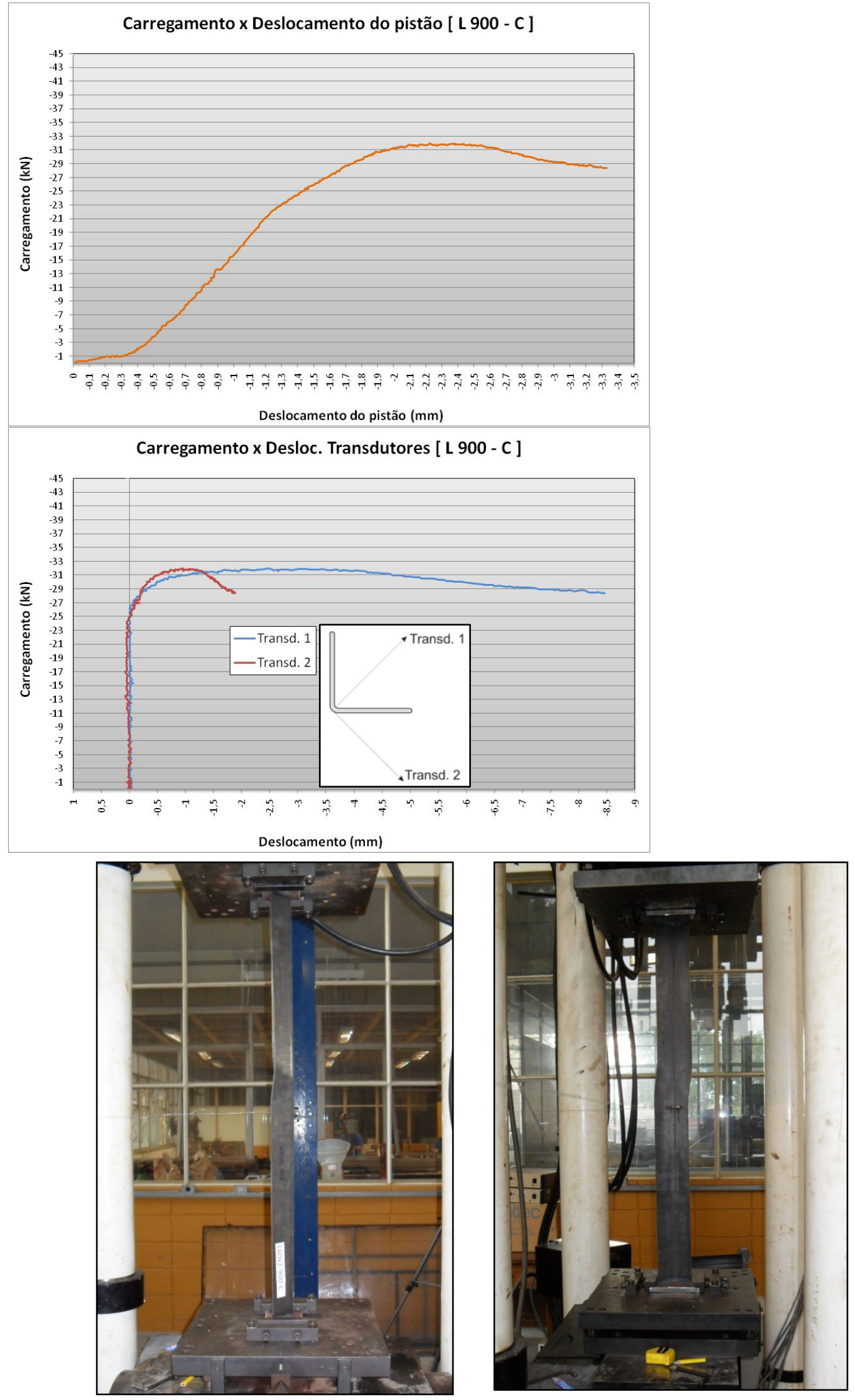
- L $1200 \mathrm{~mm} ; \boldsymbol{N}_{\text {exp }}=29,987 \mathrm{kN}$
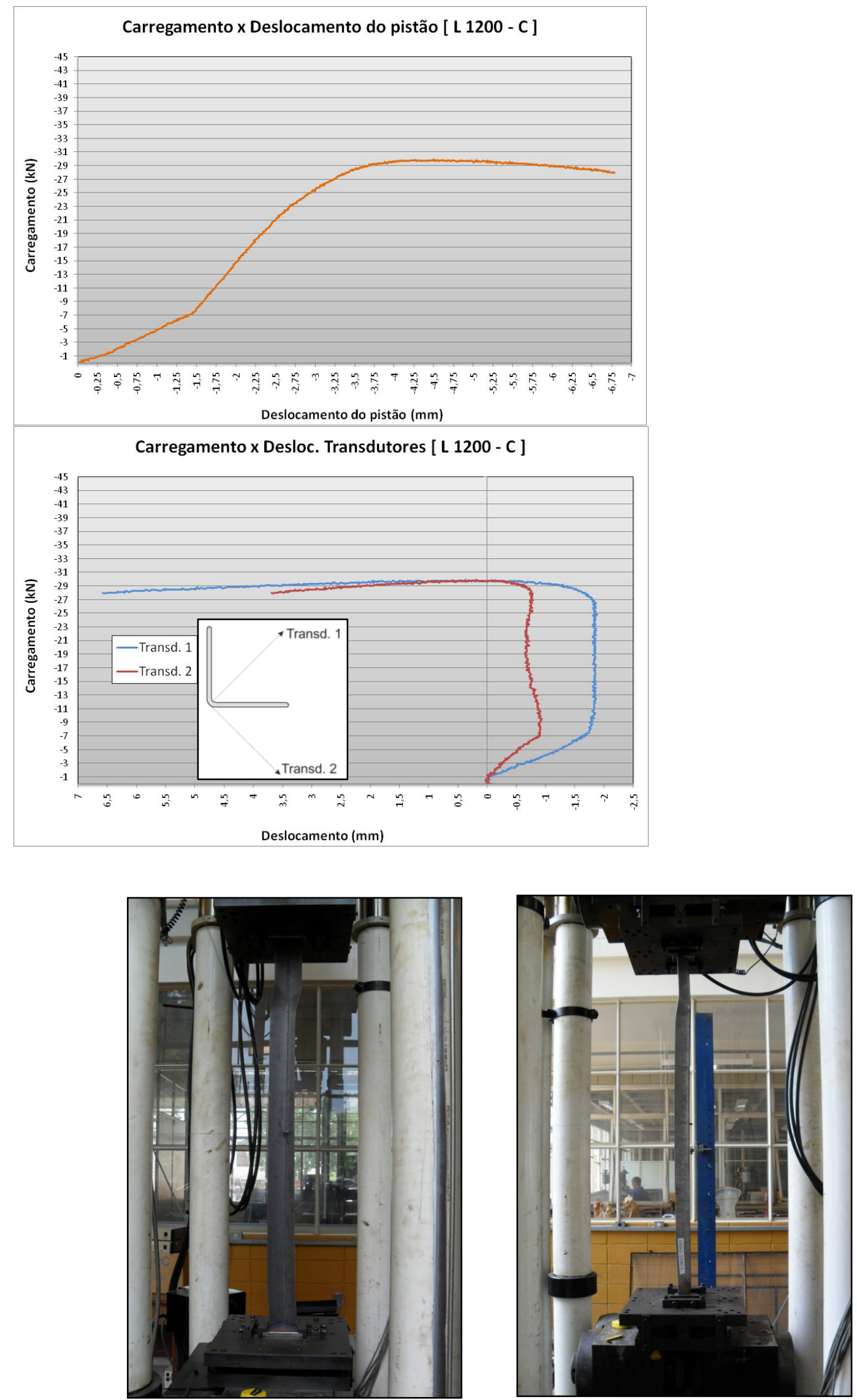
- $\quad L 1800 \mathrm{~mm} ; N_{\text {exp }}=20,601 \mathrm{kN}$
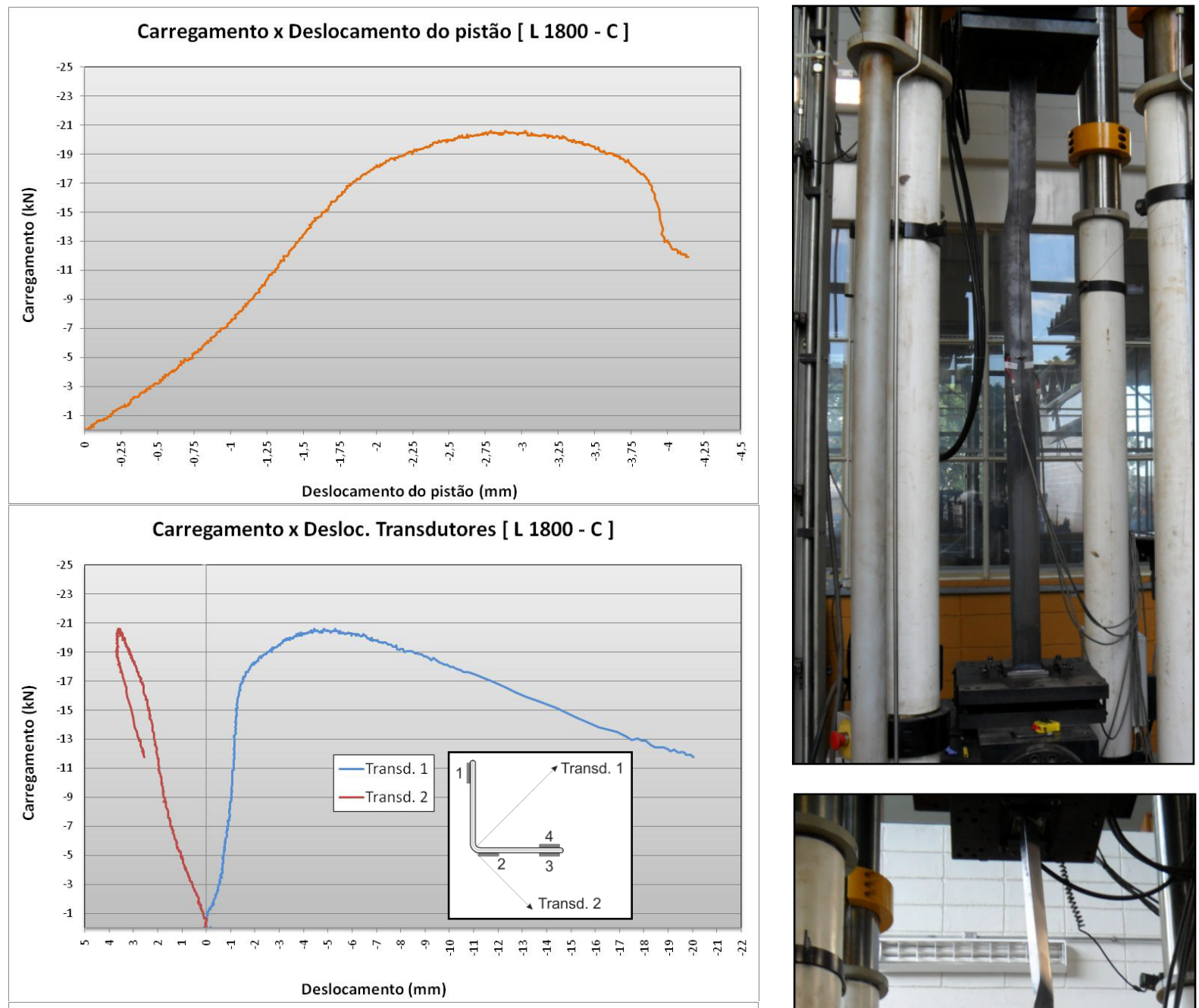

Carregamento x Desloc. específico dos extensômetros [L 1800 - C]
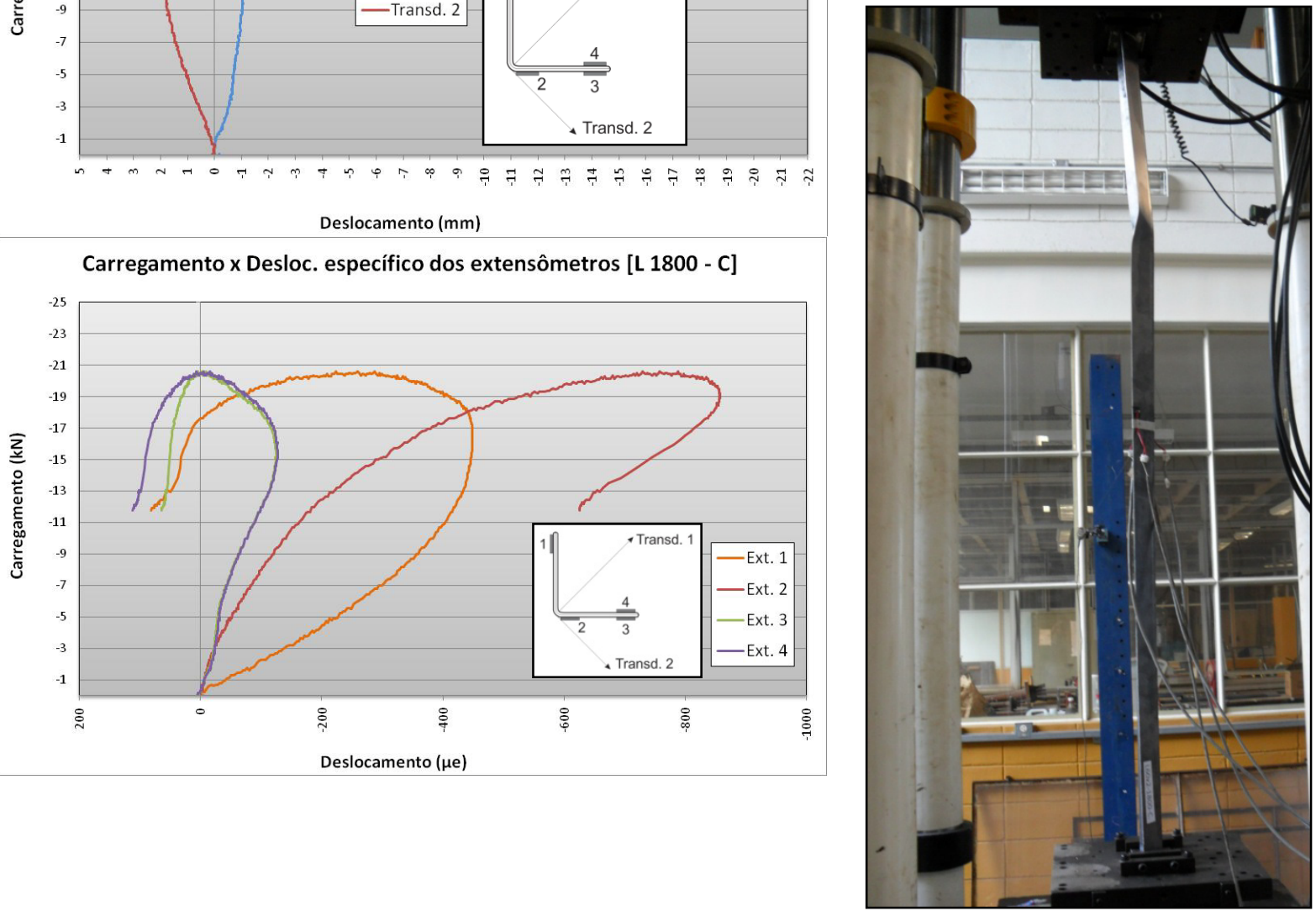